\title{
atmosphere
}

Air Quality

and Source

Apportionment

Edited by

Rebecca J. Sheesley

Printed Edition of the Special Issue Published in Atmosphere 
Rebecca J. Sheesley (Ed.)

\section{Air Quality and Source Apportionment}

MDPI 
This book is a reprint of the Special Issue that appeared in the online, open access journal, Atmosphere (ISSN 2073-4433) from 2015-2016, available at:

http://www.mdpi.com/journal/atmosphere/special_issues/air_quality

Guest Editor

Rebecca J. Sheesley

Department of Environmental Science, Baylor University

USA

Editorial Office

MDPI AG

St. Alban-Anlage 66

Basel, Switzerland

Publisher

Shu-Kun Lin

Managing Editor

Lucy Lu

\section{Edition 2016}

MDPI • Basel • Beijing • Wuhan • Barcelona • Belgrade

ISBN 978-3-03842-298-3 (Hbk)

ISBN 978-3-03842-299-0 (electronic)

Articles in this volume are Open Access and distributed under the Creative Commons Attribution license (CC BY), which allows users to download, copy and build upon published articles even for commercial purposes, as long as the author and publisher are properly credited, which ensures maximum dissemination and a wider impact of our publications. The book taken as a whole is ( 2016 MDPI, Basel, Switzerland, distributed under the terms and conditions of the Creative Commons by Attribution (CC BY-NC-ND) license (http://creativecommons.org/licenses/by-nc-nd/4.0/). 


\section{Table of Contents}

List of Contributors .................................................................................................. VII

About the Guest Editor.............................................................................................. XII

Preface to "Air Quality and Source Apportionment" .............................................. XIII

\section{Section 1: Source Apportionment and Air Quality for PM Mass and Inorganic Components}

Pavla Dagsson-Waldhauserova, Agnes Ösp Magnusdottir, Haraldur Olafsson and Olafur Arnalds

The Spatial Variation of Dust Particulate Matter Concentrations during Two

Icelandic Dust Storms in 2015

Reprinted from: Atmosphere 2016, 7(6), 77

http://www.mdpi.com/2073-4433/7/6/77.

Nitika Dewan, Yu-Qin Wang, Yuan-Xun Zhang, Yang Zhang, Ling-Yan He, Xiao-Feng Huang and Brian J. Majestic

Effect of Pollution Controls on Atmospheric PM2.5 Composition during Universiade in Shenzhen, China

Reprinted from: Atmosphere 2016, 7(4), 57

http://www.mdpi.com/2073-4433/7/4/57. 19

Frauke Hennig, Dorothea Sugiri, Lilian Tzivian, Kateryna Fuks,

Susanne Moebus, Karl-Heinz Jöckel, Danielle Vienneau,

Thomas A. J. Kuhlbusch, Kees de Hoogh, Michael Memmesheimer,

Hermann Jakobs, Ulrich Quass and Barbara Hoffmann

Comparison of Land-Use Regression Modeling with Dispersion and Chemistry

Transport Modeling to Assign Air Pollution Concentrations within the Ruhr Area

Reprinted from: Atmosphere 2016, 7(3), 48

http://www.mdpi.com/2073-4433/7/3/48. 
Yonghong Liu, Qianru Zhu, Dawen Yao and Weijia Xu

Forecasting Urban Air Quality via a Back-Propagation Neural Network and a

Selection Sample Rule

Reprinted from: Atmosphere 2015, 6(7), 891-907

http://www.mdpi.com/2073-4433/6/7/891

\section{Xingcheng Lu and Jimmy C. H. Fung}

Source Apportionment of Sulfate and Nitrate over the Pearl River Delta Region in China

Reprinted from: Atmosphere 2016, 7(8), 98

http://www.mdpi.com/2073-4433/7/8/98

Mario Alfonso Murillo-Tovar, Hugo Saldarriaga-Noreña,

Leonel Hernández-Mena, Arturo Campos-Ramos, Beatriz Cárdenas-González, Jesús Efren Ospina-Noreña, Ricardo Cosío-Ramírez, José de Jesús Díaz-Torres and Winston Smith

Potential Sources of Trace Metals and Ionic Species in PM2.5 in Guadalajara, Mexico: A Case Study during Dry Season

Reprinted from: Atmosphere 2015, 6(12), 1858-1870

http://www.mdpi.com/2073-4433/6/12/1834

Hongmei Zhao, Daniel Q. Tong, Pius Lee, Hyuncheol Kim and Hang Lei

Reconstructing Fire Records from Ground-Based Routine Aerosol Monitoring Reprinted from: Atmosphere 2016, 7(3), 43

http://www.mdpi.com/2073-4433/7/3/43.

\section{Section 2: Detailed Organic Aerosol Composition and Source Apportionment}

Jeffrey K. Bean, Cameron B. Faxon, Yu Jun Leong, Henry William Wallace, Basak Karakurt Cevik, Stephanie Ortiz, Manjula R. Canagaratna, Sascha Usenko, Rebecca J. Sheesley, Robert J. Griffin and Lea Hildebrandt Ruiz Composition and Sources of Particulate Matter Measured near Houston, TX:

Anthropogenic-Biogenic Interactions

Reprinted from: Atmosphere 2016, 7(5), 73

http://www.mdpi.com/2073-4433/7/5/73. 137 
Steven G. Brown, Taehyoung Lee, Paul T. Roberts and Jeffrey L. Collett

Wintertime Residential Biomass Burning in Las Vegas, Nevada; Marker

Components and Apportionment Methods

Reprinted from: Atmosphere 2016, 7(4), 58

http://www.mdpi.com/2073-4433/7/4/58

Amanda S. Willoughby, Andrew S. Wozniak and Patrick G. Hatcher

Detailed Source-Specific Molecular Composition of Ambient Aerosol Organic

Matter Using Ultrahigh Resolution Mass Spectrometry and ${ }^{1} \mathrm{H}$ NMR

Reprinted from: Atmosphere 2016, 7(6), 79

http://www.mdpi.com/2073-4433/7/6/79 



\section{List of Contributors}

Olafur Arnalds Faculty of Environmental Sciences, Agricultural University of Iceland, Keldnaholt, Reykjavik 112, Iceland.

Jeffrey K. Bean McKetta Department of Chemical Engineering, The University of Texas at Austin, Austin, TX 78712, USA.

Steven G. Brown Sonoma Technology Inc., 1455 N. McDowell Blvd., Suite D, Petaluma, CA 94954, USA; Department of Atmospheric Science, Colorado State University, Fort Collins, CO 80523, USA.

Arturo Campos-Ramos Universidad de Guanajuato, Carretera Irapuato-Silao, Ex Hacienda El Copal Km 9, C.P. 36500, Irapuato, Guanajuato, Mexico.

Manjula R. Canagaratna Aerodyne Research Inc., Billerica, MA 01821, USA.

Beatriz Cárdenas-González Comisión Ambiental de la Megalópolis, Calle el Oro 17, Colonia Roma Norte, Del. Cuauhtemoc, C.P. 06700, Ciudad de Mexico, D.F., Mexico.

Basak Karakurt Cevik Department of Civil and Environmental Engineering, Rice University, Houston, TX 77005, USA.

Jeffrey L. Collett Department of Atmospheric Science, Colorado State University, Fort Collins, CO 80523, USA.

Ricardo Cosío-Ramírez Centro de Investigación y Asistencia en Tecnología y Diseño del Estado de Jalisco, Av. Normalistas 800, Colonia Colinas de la Normal, C.P. 44270, Guadalajara, Jalisco, Mexico.

Pavla Dagsson-Waldhauserova Faculty of Environmental Sciences, Czech University of Life Sciences, Prague 165 21, Czech Republic; Faculty of Environmental Sciences, Agricultural University of Iceland, Keldnaholt, Reykjavik 112, Iceland; Faculties of Physical and Earth Sciences, University of Iceland, Reykjavik 101, Iceland.

Kees de Hoogh University of Basel, Basel 4003, Switzerland; Department of Epidemiology and Public Health, Swiss Tropical and Public Health Institute, Socinstr. 57, Basel 4051, Switzerland.

Nitika Dewan Department of Chemistry and Biochemistry, University of Denver, Denver, CO 80208, USA.

José de Jesús Díaz-Torres Centro de Investigación y Asistencia en Tecnología y Diseño del Estado de Jalisco, Av. Normalistas 800, Colonia Colinas de la Normal, C.P. 44270, Guadalajara, Jalisco, Mexico. 
Cameron B. Faxon McKetta Department of Chemical Engineering, The University of Texas at Austin, Austin, TX 78712, USA.

Kateryna Fuks Working group of Environmental Epidemiology of Cardiovascular Aging and Allergies, IUF-Leibniz Research Institute for Environmental Medicine, Auf'm Hennekamp 50, Düsseldorf 40225, Germany.

Jimmy C. H. Fung Division of Environment, Hong Kong University of Science \& Technology, Clear Water Bay, Hong Kong, China; Department of Mathematics, Hong Kong University of Science \& Technology, Clear Water Bay, Hong Kong, China.

Robert J. Griffin Department of Civil and Environmental Engineering, Rice University, Houston, TX 77005, USA.

Patrick G. Hatcher Department of Chemistry and Biochemistry, Old Dominion University, Norfolk, VA 23529, USA.

Ling-Yan He Key Laboratory for Urban Habitat Environmental Science and Technology, School of Environment and Energy, Peking University Shenzhen Graduate School, Shenzhen 518055, China.

Frauke Hennig Working group of Environmental Epidemiology of Cardiovascular Aging and Allergies, IUF-Leibniz Research Institute for Environmental Medicine, Auf'm Hennekamp 50, Düsseldorf 40225, Germany.

Leonel Hernández-Mena Centro de Investigación y Asistencia en Tecnología y Diseño del Estado de Jalisco, Av. Normalistas 800, Colonia Colinas de la Normal, C.P. 44270, Guadalajara, Jalisco, Mexico.

Lea Hildebrandt Ruiz McKetta Department of Chemical Engineering, The University of Texas at Austin, Austin, TX 78712, USA.

Barbara Hoffmann Working group of Environmental Epidemiology of Cardiovascular Aging and Allergies, IUF-Leibniz Research Institute for Environmental Medicine, Auf'm Hennekamp 50, Düsseldorf 40225, Germany; Heinrich Heine University of Düsseldorf, Medical Faculty, Deanery of Medicine, Moorenstraße 5, Düsseldorf 40225, Germany.

Xiao-Feng Huang Key Laboratory for Urban Habitat Environmental Science and Technology, School of Environment and Energy, Peking University Shenzhen Graduate School, Shenzhen 518055, China.

Hermann Jakobs Rhenish Institute for Environmental Research (RIU), Aachenerstr. 209, 50931 Köln, Germany.

Karl-Heinz Jöckel Institute for Medical Informatics, Biometry and Epidemiology, University Hospital, University Duisburg-Essen, Essen 45141, Germany. 
Hyuncheol Kim UMD/Cooperative Institute for Climate and Satellites, College Park, MD 20740, USA; U.S. NOAA Air Resources Laboratory, College Park, MD 20740, USA.

Thomas A. J. Kuhlbusch IUTA e.V., Air Quality \& Sustainable Nanotechnology Unit, Duisburg, Germany.

Pius Lee U.S. NOAA Air Resources Laboratory, College Park, MD 20740, USA.

Taehyoung Lee Department of Environmental Science, Hankuk University of Foreign Studies, Yongin 427-010, Korea.

Hang Lei U.S. NOAA Air Resources Laboratory, College Park, MD 20740, USA.

Yu Jun Leong Department of Civil and Environmental Engineering, Rice University, Houston, TX 77005, USA.

Yonghong Liu School of Engineering, Sun Yat-Sen University, Guangzhou 510275, China.

Xingcheng Lu Division of Environment, Hong Kong University of Science \& Technology, Clear Water Bay, Hong Kong, China.

Agnes Ösp Magnusdottir Faculty of Environmental Sciences, Agricultural University of Iceland, Keldnaholt, Reykjavik 112, Iceland.

Brian J. Majestic Department of Chemistry and Biochemistry, University of Denver, Denver, CO 80208, USA.

Michael Memmesheimer Rhenish Institute for Environmental Research (RIU), Aachenerstr. 209, 50931 Köln, Germany.

Susanne Moebus Institute for Medical Informatics, Biometry and Epidemiology, University Hospital, University Duisburg-Essen, Essen 45141, Germany.

Mario Alfonso Murillo-Tovar Centro de Investigaciones Químicas, Instituto de Investigación en Ciencias Básicas y Aplicadas, Universidad Autónoma del Estado de Morelos, Av. Universidad 1001, Colonia Chamilpa, C.P. 62209, Cuernavaca, Morelos, Mexico; Cátedras, Consejo Nacional de Ciencia y Tecnología, Av. Insurgentes Sur 1582, Colonia Crédito Constructor, Del. Benito Juárez, C.P. 03940, Ciudad de México, D.F., Mexico.

Haraldur Olafsson Icelandic Meteorological Office, Reykjavik 108, Iceland;

Faculties of Physical and Earth Sciences, University of Iceland, Reykjavik 101, Iceland.

Stephanie Ortiz Department of Environmental Science, Baylor University, Waco, TX 76798, USA. 
Jesús Efren Ospina-Noreña Facultad de Ciencias Agrarias, Departamento de Agronomía, Universidad Nacional de Colombia, Sede Bogotá, C.P. 111321, Colombia.

Ulrich Quass IUTA e.V., Air Quality \& Sustainable Nanotechnology Unit, Duisburg, Germany.

Paul T. Roberts Sonoma Technology Inc., 1455 N. McDowell Blvd., Suite D, Petaluma, CA 94954, USA.

Hugo Saldarriaga-Noreña Centro de Investigaciones Químicas, Instituto de Investigación en Ciencias Básicas y Aplicadas, Universidad Autónoma del Estado de Morelos, Av. Universidad 1001, Colonia Chamilpa, C.P. 62209, Cuernavaca, Morelos, Mexico.

Rebecca J. Sheesley Department of Environmental Science, Baylor University, Waco, TX 76798, USA.

Winston Smith Peace Corps, 1111 20th Street, NW Washington, DC 20526, USA.

Dorothea Sugiri Working group of Environmental Epidemiology of Cardiovascular Aging and Allergies, IUF-Leibniz Research Institute for Environmental Medicine, Auf'm Hennekamp 50, Düsseldorf 40225, Germany.

Daniel Q. Tong U.S. NOAA Air Resources Laboratory, College Park, MD 20740, USA; UMD/Cooperative Institute for Climate and Satellites, College Park, MD 20740, USA.

Lilian Tzivian Working group of Environmental Epidemiology of Cardiovascular Aging and Allergies, IUF-Leibniz Research Institute for Environmental Medicine, Auf'm Hennekamp 50, Düsseldorf 40225, Germany.

Sascha Usenko Department of Environmental Science, Baylor University, Waco, TX 76798, USA.

Danielle Vienneau Department of Epidemiology and Public Health, Swiss Tropical and Public Health Institute, Socinstr. 57, Basel 4051, Switzerland; University of Basel, Basel 4003, Switzerland.

Henry William Wallace Department of Civil and Environmental Engineering, Rice University, Houston, TX 77005, USA.

Yu-Qin Wang College of Resources and Environment, University of Chinese Academy of Sciences, Beijing 100049, China. 
Amanda S. Willoughby Current address: Department of Physical and Environmental Sciences, Texas A \& M University-Corpus Christi, Corpus Christi, TX 78412, USA; Department of Chemistry and Biochemistry, Old Dominion University, Norfolk, VA 23529, USA.

Andrew S. Wozniak Department of Chemistry and Biochemistry, Old Dominion University, Norfolk, VA 23529, USA.

Weijia Xu Institute of Advanced Technology, Sun Yat-Sen University, Guangzhou 510275, China.

Dawen Yao School of Engineering, Sun Yat-Sen University, Guangzhou 510275, China.

Yang Zhang College of Resources and Environment, University of Chinese Academy of Sciences, Beijing 100049, China.

Yuan-Xun Zhang College of Resources and Environment, University of Chinese Academy of Sciences, Beijing 100049, China; Huairou Eco-Environmental Observatory, Chinese Academy of Sciences, Beijing 101408, China.

Hongmei Zhao Key Laboratory of Wetland Ecology and Environment, Northeast Institute of Geography and Agroecology, Chinese Academy of Sciences, Changchun 130102, China.

Qianru Zhu Guangdong Provincial Academy of Environmental Science, Guangzhou 510045, China. 


\section{About the Guest Editor}

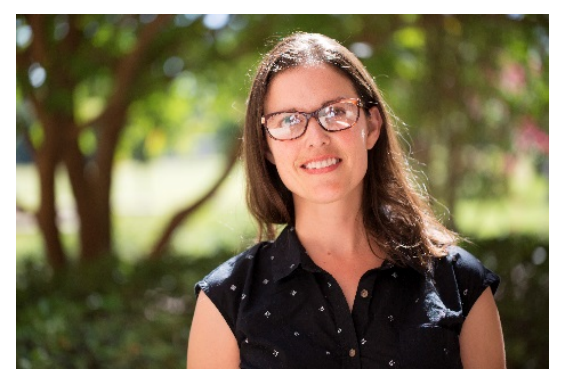

Rebecca J. Sheesley is an associate professor in the Department of Environmental Science at Baylor University. Sheesley received her Ph.D. in Environmental Chemistry and Technology from the University of Wisconsin-Madison. She has 42 publications in the areas of source characterization, source apportionment, analytical method development and detailed organic carbon characterization as it relates to air quality. Her work on air quality spans the globe, with studies in the continental United States (the Upper Midwest, New York, North Carolina California, and Texas), the North American Arctic, Mexico, Sweden, the Maldives, and India. 


\section{Preface to "Air Quality and Source Apportionment"}

In designing this Special Issue, I had requested novel analytical and numerical (i.e., modeling) techniques for air quality applications of source apportionment of atmospheric particulate matter (PM) in under-studied areas. By incorporating both numerical and chemical source apportionment techniques, I was hoping to encourage a cross pollination of ideas. Novel techniques will be vital to tackle air quality issues that are emerging around the globe. Quantifying the impact of emission sources on atmospheric PM is key to development of effective mitigation strategies and to deconvoluting atmospheric chemistry during transport. Since I was interested in novel techniques and locations, I kept the call for papers very broad. In response we received and chose a very diverse set of manuscripts.

The manuscripts in this Special Issue can be split into two sections: (1) Source apportionment and air quality for PM mass and inorganic components; and (2) Detailed organic aerosol and source apportionment. These two sections include manuscripts utilizing both numerical and chemical methodology. Section 1 has seven manuscripts. Dagsson-Waldhauserova et al. presented a study of the physical characterization of volcanic dust events for use with source apportionment and quantification of air quality impacts in Iceland. Dewan et al. presented a combination of novel chemical (trace element and stable lead isotopes) and water-soluble ions which were paired with principal component analyses for source apportionment in Shenzhen, China. Hennig et al. conducted a study to assess two different air quality models (Land Use Regression and Dispersion and Chemistry Transport Models) and their treatment of emission sources in the Ruhr area of Germany for use to estimate air pollution exposure in epidemiology studies. Liu et al. used meteorological factors to forecast $\mathrm{SO}_{2}, \mathrm{NO}_{2}$ and $\mathrm{PM}_{10}$ using a back propagation neural network model in Guangzhou, China. Lu et al. utilized a Weather Research Forecast (WRF)-Sparse Matrix Operator Kernel Emission (SMOKE)-Comprehensive Air Quality Model with Extensions (CAMx) modeling and particulate source apportionment technology to understand source contributions (i.e. power plant, industrial, mobile, and biogenic emissions) to particulate sulfate and nitrate in the Pearl River Delta region in China. Murillo-Tovar et al. determined enrichment of anthropogenic sources for fine particulate trace metals and ionic species in Guadalajara, Mexico. Finally, Zhao et al. conducted data mining of routine IMPROVE (Interagency Monitoring of Protected Visual Environments) network data combined with satellite fire detection to identify/apportion fire episodes in the USA from 2001-2011. 
Section 2 included three manuscripts which focused on detailed organic aerosol composition. Bean et al. presents source apportionment using chemical characterization (Aerosol Chemical Speciation Monitor), temporal trends and positive matrix factorization for aerosol in a forested area near Houston, TX, USA. Brown et al. presents a comparison of chemical tracers for biomass burning (levoglucosan, water soluble $\mathrm{K}^{+}$, the molecular fragment $\mathrm{C}_{2} \mathrm{H}_{4} \mathrm{O}_{2}{ }^{+}$from the Aerodyne High Resolution Aerosol Mass Spectrometer, and UV-Black Carbon from an aethalometer) in Las Vegas, NV, USA. Finally, Willoughby et al. utilized advanced instrumentation (ultrahigh resolution mass spectrometry and proton nuclear magnetic resonance spectroscopy) for apportionment of organic aerosol among biomass burning, urban and marine sources in Virginia and Philadelphia, PA, USA.

Rebecca J. Sheesley

Guest Editor 


Section 1:

Source Apportionment and Air Quality for PM Mass and

Inorganic Components 



\title{
The Spatial Variation of Dust Particulate Matter Concentrations during Two Icelandic Dust Storms in 2015
}

\author{
Pavla Dagsson-Waldhauserova, Agnes Ösp Magnusdottir, Haraldur Olafsson \\ and Olafur Arnalds
}

\begin{abstract}
Particulate matter mass concentrations and size fractions of $\mathrm{PM}_{1}, \mathrm{PM}_{2.5}$, $\mathrm{PM}_{4}, \mathrm{PM}_{10}$, and $\mathrm{PM}_{15}$ measured in transversal horizontal profile of two dust storms in southwestern Iceland are presented. Images from a camera network were used to estimate the visibility and spatial extent of measured dust events. Numerical simulations were used to calculate the total dust flux from the sources as 180,000 and 280,000 tons for each storm. The mean $\mathrm{PM}_{15}$ concentrations inside of the dust plumes varied from 10 to $1600 \mu \mathrm{g} \cdot \mathrm{m}^{-3}\left(\mathrm{PM}_{10}=7\right.$ to $\left.583 \mu \mathrm{g} \cdot \mathrm{m}^{-3}\right)$. The mean $\mathrm{PM}_{1}$ concentrations were $97-241 \mu \mathrm{g} \cdot \mathrm{m}^{-3}$ with a maximum of $261 \mu \mathrm{g} \cdot \mathrm{m}^{-3}$ for the first storm. The $\mathrm{PM}_{1} / \mathrm{PM}_{2.5}$ ratios of $>0.9$ and $\mathrm{PM}_{1} / \mathrm{PM}_{10}$ ratios of $0.34-0.63$ show that suspension of volcanic materials in Iceland causes air pollution with extremely high $\mathrm{PM}_{1}$ concentrations, similar to polluted urban areas in Europe or Asia. Icelandic volcanic dust consists of a higher proportion of submicron particles compared to crustal dust. Both dust storms occurred in relatively densely inhabited areas of Iceland. First results on size partitioning of Icelandic dust presented here should challenge health authorities to enhance research in relation to dust and shows the need for public dust warning systems.
\end{abstract}

Reprinted from Atmosphere. Cite as: Dagsson-Waldhauserova, P.; Magnusdottir, A.Ö.; Olafsson, H.; Arnalds, O. The Spatial Variation of Dust Particulate Matter Concentrations during Two Icelandic Dust Storms in 2015. Atmosphere 2016, 7, 77.

\section{Introduction}

Air pollution from natural sources accounts for a significant part of the total particulate matter pollution on Earth. Deserts, stratovolcanoes, and arable land areas contribute to global air pollution in addition to emissions from industrialized and densely inhibited regions. Desert dust has a remarkable influence on Earth's ecosystems as well as human health. Several studies have shown that suspended desert dust can increase mortality hundreds of kilometers downwind from dust sources [1-6]. Mortality was found to increase by $2 \%-12 \%$ with every $10 \mu \mathrm{g} \cdot \mathrm{m}^{-3}$ increase in particulate matter $\left(\mathrm{PM}_{10}\right)$ concentration. Some of these studies reported increased mortality for the $\mathrm{PM}_{2.5}$ dust particulate matter. A decrease of mixing layer height was associated with an increase of daily mortality while the effect of mixing 
layer thinning on particle toxicity was exacerbated when Saharan dust outbreaks occurred [7]. Positive associations between mass concentrations of larger sizes of particles, such as $\mathrm{PM}_{15}$, were observed for cardiopulmonary and ischemic heart disease causes of death during the long-term studies on air pollution and mortality of the American Cancer Society [8]. The studies on levels and speciation of $\mathrm{PM}_{1}$ in Europe are, however, scarce [9-11]. The $\mathrm{PM}_{1}$ fraction has considerable importance in relation to health because of high potential for entering the lungs [12]. Moreover, submicron particles are more likely to travel further distances during the long range transport than larger particles [13].

In spite of a cold and moist climate, Iceland has been identified as the most active and largest Arctic and European desert [14]. Other cold climate and high latitudes regions with considerable dust inputs are Alaska, Greenland, Svalbard, Antarctica, and South America [15-20]. One of the most extreme wind erosion events on Earth was measured in Iceland in 2010 [21]. Annual dust day frequency in Iceland is comparable to the major desert areas of the world [22,23]. Emissions from local dust sources, enhanced by strong winds, affect regional air quality in Iceland, such as in the capital Reykjavik [24]. Particulate Matter $\left(\mathrm{PM}_{10}\right)$ concentrations during dust events in Reykjavik often exceed the health limit of $50 \mu \mathrm{g} \cdot \mathrm{m}^{-3}$ over $24 \mathrm{~h}[25,26]$, while $\mathrm{PM}_{10}$ concentrations measured during dust events in the vicinity of dust sources $(<30 \mathrm{~km})$ exceed the health limit in order of 10-100 times [26-28]. This shows that atmospheric aerosols, mainly dust, can markedly impair air quality in non-polluted Arctic/sub-Arctic regions.

Icelandic dust differs from dust originating from most continental deserts. It is volcanogenic in origin, of basaltic composition, with lower $\mathrm{SiO}_{2}$ proportions $(<50 \%)$ and higher $\mathrm{Al}_{2} \mathrm{O}_{3}, \mathrm{Fe}_{2} \mathrm{O}_{3}$, and $\mathrm{CaO}$ contents than crustal dust [23,27-29]. This volcanic dust contains about $80 \%$ volcanic glass with numerous large gas bubbles and massive shards. It is extremely angular with sharp-tipped shards and often with curved and concave shard-faces. Fine pipe-vesicular structures of glass, as known from asbestos, can be also found. All these factors suggest that volcanic dust can be easily suspended and have highly negative effects on human health as concluded by Carlsen et al. [30].

Studies that provide PM mass concentration measurements during dust storms in Iceland are few and limited in scope, excluding research related to volcanic eruptions $[23,24,27,28,31]$. None of these studies dealt with the size partitioning of the PM components. Here we presented a study on PM source characteristics of volcanic dust during two dust events from different dust sources in Iceland. The emphasis was given to the fine dust fraction of $\mathrm{PM}_{1}$. An effort has been made to measure the transverse horizontal profile of dust storms and estimate the spatial extent of such storms in the terms of PM concentrations, dust load computation, and visibility information obtained from cameras. 


\section{Experiments}

\subsection{Instrumentation and Measurement Setup}

Two dust storms were measured in southwestern Iceland in the summer of 2015. Measurements of both storms began after the dust plume was visible from Reykjavík with transverse horizontal profile measurements through the dust plumes. The source area of the first dust event on 15 June 2015 was Landeyjasandur (Storm 1, Figure 1A), about $100 \mathrm{~km}$ from Reykjavík, while the second dust storm on 4 August 2015 originated from the Hagavatn dust source (Storm 2, Figure 1B), about 85 km distance from Reykjavik.

A mobile instrument, aerosol monitor DustTrak DRX 8533EP, was used to measure particulate matter (PM) mass concentrations at several places within the dust plume. The DustTrak instrument provides measurements of mass concentration from 0.001 to $150 \mathrm{mg} \cdot \mathrm{m}^{-3}$ with the mass fraction concentrations corresponding to $\mathrm{PM}_{1}, \mathrm{PM}_{2.5}, \mathrm{PM}_{4}, \mathrm{PM}_{10}$, and the total $\mathrm{PM}_{15}$. Five minute measurements were made at each stop in the dust plume, consisting of 60 five-second sampling periods. The measurement time was short to allow for travel through the dust storm with measurements at as many places as possible. All measurements were calculated as 5-min averages. The TSI DustTraks have given similar results in parallel measurements of PM mass concentration as Beta attenuation instruments (Thermo ESM Andersen FH 62 I-R) [32]. This instrument has been used in Iceland by the Environmental Agency of Iceland (EAI) since 1996 and we have found good relation between $\mathrm{PM}_{10}$ concentrations obtained by DustTrak DRX and the Thermo ESM. The error range for absolute values for other PM size ranges could be $\pm 10 \%$ [33]. We emphasize that the DustTrak measurements in both storms are complemented by an independent measurement by the Thermo ESM instrument at the EAI in Reykjavik $\left(\mathrm{PM}_{10}\right.$ 30-min maxima of about $300 \mu \mathrm{g} \cdot \mathrm{m}^{-3}$ for Storm 1 and about $200 \mu \mathrm{g} \cdot \mathrm{m}^{-3}$ for Storm 2). Measurements for Storm 1 with DustTrak at Keldnaholt (Reykjavik) and Thermo ESM at Grensásvegur (Reykjavik), approx. $5 \mathrm{~km}$ apart are very similar $\left(\mathrm{PM}_{10}\right.$ 30-min maxima of about $224 \mu \mathrm{g} \cdot \mathrm{m}^{-3}$ vs. $280 \mu \mathrm{g} \cdot \mathrm{m}^{-3}$ at the same time, with the latter being closer to the center of the plume). Similar agreement was found for Storm 2 . These numbers indicate that large scale errors sometimes reported for measurements with the TSI DustTraks do not apply here [32,33].

In this study, we used a unique dataset from a network of active cameras operated by the Icelandic Road and Coastal Administration to find the exact extent and area of the dust plume [34]. A total of 25 cameras were used to estimate the visibility changes during these dust storms. Figure 2 presents the time laps images from the web cameras with corresponding visibility estimations. The houses on the photos are situated at about $1 \mathrm{~km}$ from the camera. The mountains in the background 
are about $3.5 \mathrm{~km}$ from the camera. Subsequently, maps of the dust storms were made in ArcMap 10.1.
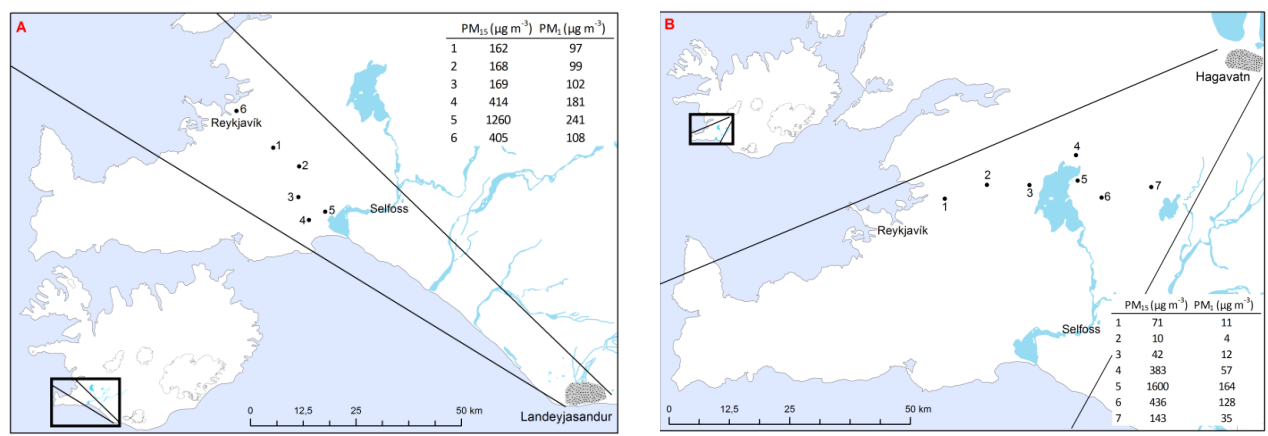

Figure 1. Spatial location of the dust storms. Left figure (A, Storm 1) shows the dust storm from Landeyjasandur on 15 June 2015. The measurement locations are marked on the map with the numbers corresponding to the information on the $\mathrm{PM}_{15}$ and $\mathrm{PM}_{1}$ concentrations in the table. Right figure (B, Storm 2$)$ shows the dust storm from the Hagavatn on 4 August 2015. The lines on the figures depict the dispersal area of the dust plumes estimated from the images of the Icelandic Road and Coastal Administration web camera network [34].

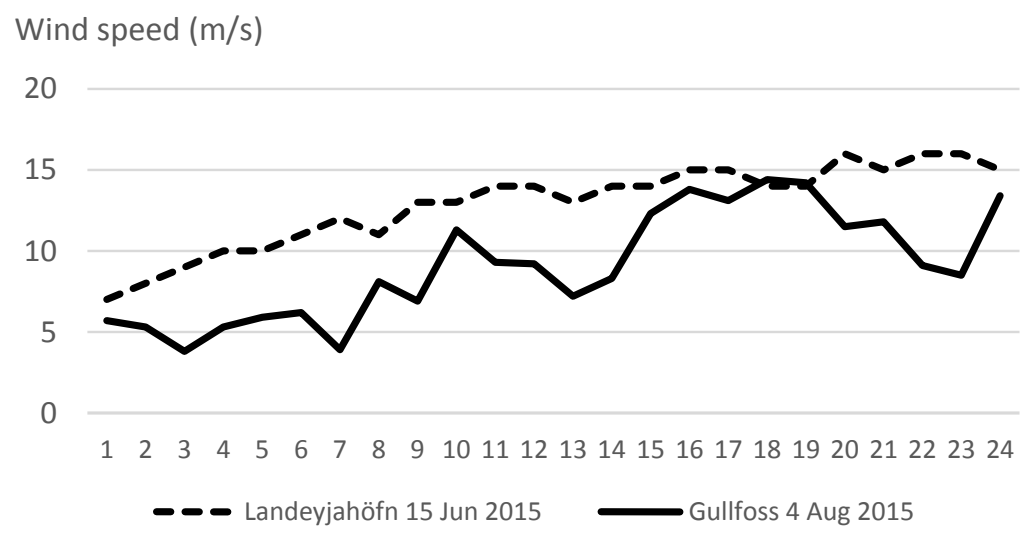

Figure 2. Observations of mean 10 min wind speed from 01-24 UTC at Landeyjahöfn (at the dust source for Storm 1) on 15 June 2015 and at Gullfoss (about $15 \mathrm{~km} \mathrm{SE}$ of the dust source for Storm 2) on 4 August 2015. 


\subsection{Meteorological Conditions and Transport of Dust}

Figure 2 shows the observed 10 min average wind speed at the weather stations Landeyjahöfn (Storm 1), which is close to the dust source, and Gullfoss (Storm 2) which is at a $15 \mathrm{~km}$ distance from the source, but does not capture the catabatic wind effects at the source. The wind speed was gradually increasing from about 6 to $16 \mathrm{~m} \cdot \mathrm{s}^{-1}$ during the Landaeyjasandur dust event (Storm 1). The Hagavatn dust event (Storm 2) occurred with wind speeds from about 4 to $14 \mathrm{~m} \cdot \mathrm{s}^{-1}$ measured at Gullfoss. A numerical simulation of surface winds during the two events is shown in Figure 3. The simulation was carried out with the numerical model HIRLAM with a horizontal resolution of $5 \mathrm{~km}$. The simulation was initialized at 00UTC the same day, using initial and boundary conditions from the operational suite at the European Centre for Medium range Weather Forecasts. The true winds in the dust source area on 4 August were probably a few $\mathrm{m} \cdot \mathrm{s}^{-1}$ stronger than observed at Gullfoss. There are substantial horizontal gradients in the wind field close to the dust sources in both cases. In Storm 1 on 15 June, the mountains in S-Iceland generated a corner wind of $6-8 \mathrm{~m} \cdot \mathrm{s}^{-1}$ greater speed than in the incoming flow. This corner wind extended over a large area over the sea and the SW-coast of Iceland. The dust was lifted where this windstorm blew over the coastal areas. Once in suspension, some of the dust entered a wake area over land with weaker winds. In Storm 2 on 4 August, dust was also generated by locally enhanced winds. There was local acceleration in flow which ran along a major mountain range and had a downslope component. The local acceleration and the winds in general were underestimated by a few $\mathrm{m} \cdot \mathrm{s}^{-1}$ in the simulation (Figure 3 ), but the flow pattern and the wind directions are realistic. The orographic flow perturbation is of a smaller scale in Storm 2 on 4 August than in Storm 1 on 15 June, and consequently is harder to reproduce in a numerical simulation.

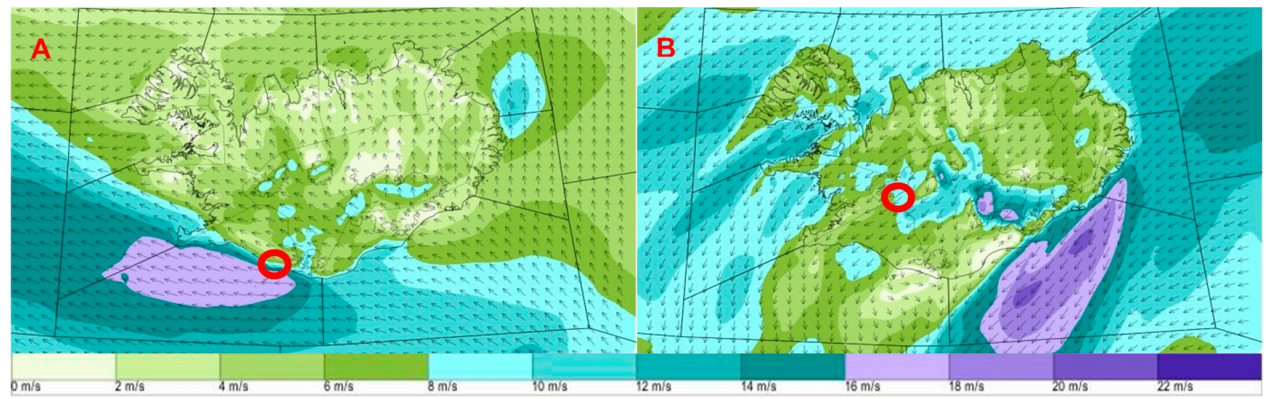

Figure 3. Numerical simulations of $10 \mathrm{~m}$ winds $\left(\mathrm{m} \cdot \mathrm{s}^{-1}\right)$ over Iceland at 15 UTC on (A) Storm 1 on 15 June 2015 and (B) Storm 2 on 4 August 2015. The locations of the dust sources are indicated with a circle. 


\section{Results and Discussion}

\subsection{Dust Concentrations and Visibility}

The spatial extent and PM concentrations measured during the two dust storms are shown in Figure 1 and Table 1 . The mean $\mathrm{PM}_{15}$ concentrations inside the dust plume 1 varied from $162 \mu \mathrm{g} \cdot \mathrm{m}^{-3}$ to $1260 \mu \mathrm{g} \cdot \mathrm{m}^{-3}\left(\mathrm{PM}_{10}=158-583 \mu \mathrm{g} \cdot \mathrm{m}^{-3}\right)$, and from $10 \mu \mathrm{g} \cdot \mathrm{m}^{-3}$ to $1600 \mu \mathrm{g} \cdot \mathrm{m}^{-3}\left(\mathrm{PM}_{10}=7-486 \mu \mathrm{g} \cdot \mathrm{m}^{-3}\right)$ inside dust plume 2 , respectively. These numbers represent rather low concentrations for an ongoing dust storm compared to the long term PM measurements provided by the Environmental Agency of Iceland (EAI) [23,26-28]. This was partly caused by moderate winds not exceeding $16 \mathrm{~m} \cdot \mathrm{s}^{-1}$ (Figures 2 and 3 ). The mean $\mathrm{PM}_{1}$ concentrations were, however, 97-241 $\mu \mathrm{g} \cdot \mathrm{m}^{-3}$ during Storm 1 and reached up to $164 \mu \mathrm{g} \cdot \mathrm{m}^{-3}$ during Storm 2 . Such high fine dust concentrations have been reported during massive dust storms from lacustrine sediment areas in Iran and during African dust episodes in Barcelona (hourly means 60-70 $\mu \mathrm{g} \cdot \mathrm{m}^{-3}$ ) [10,35]. The $\mathrm{PM}_{1}$ maximum of $261 \mu \mathrm{g} \cdot \mathrm{m}^{-3}$ measured during moderate Icelandic dust storms is comparable to the maximum of $495 \mu \mathrm{g} \cdot \mathrm{m}^{-3}$ reported from Iran during a massive dust storm when $\mathrm{PM}_{10}$ concentrations exceeded $5000 \mu \mathrm{g} \cdot \mathrm{m}^{-3}$. Relatively high $\mathrm{PM}_{1}$ annual means are regularly measured over Greece during African dust outbreaks [36].

The distance of the measurements from the dust sources was $<100 \mathrm{~km}$. The source material contains extremely fine particles. Storm 1 originated from the Landeyjarsandur dust hot spot which mostly consists of fine volcanic material from active volcanic systems such as Eyjafjallajökull and the Katla systems [14]. Figure 1B shows the values for Storm 2 which originated from the Hagavatn glacial floodplain. The Hagavatn dust materials are more crystalline in nature compared to most other Icelandic dust sources [29]. The higher $\mathrm{PM}_{1}$ concentrations during the Storm 1 than Storm 2 can be related to this difference in crystallinity and also to the early suspension in June rather than in August when submicron particles had been already removed. 


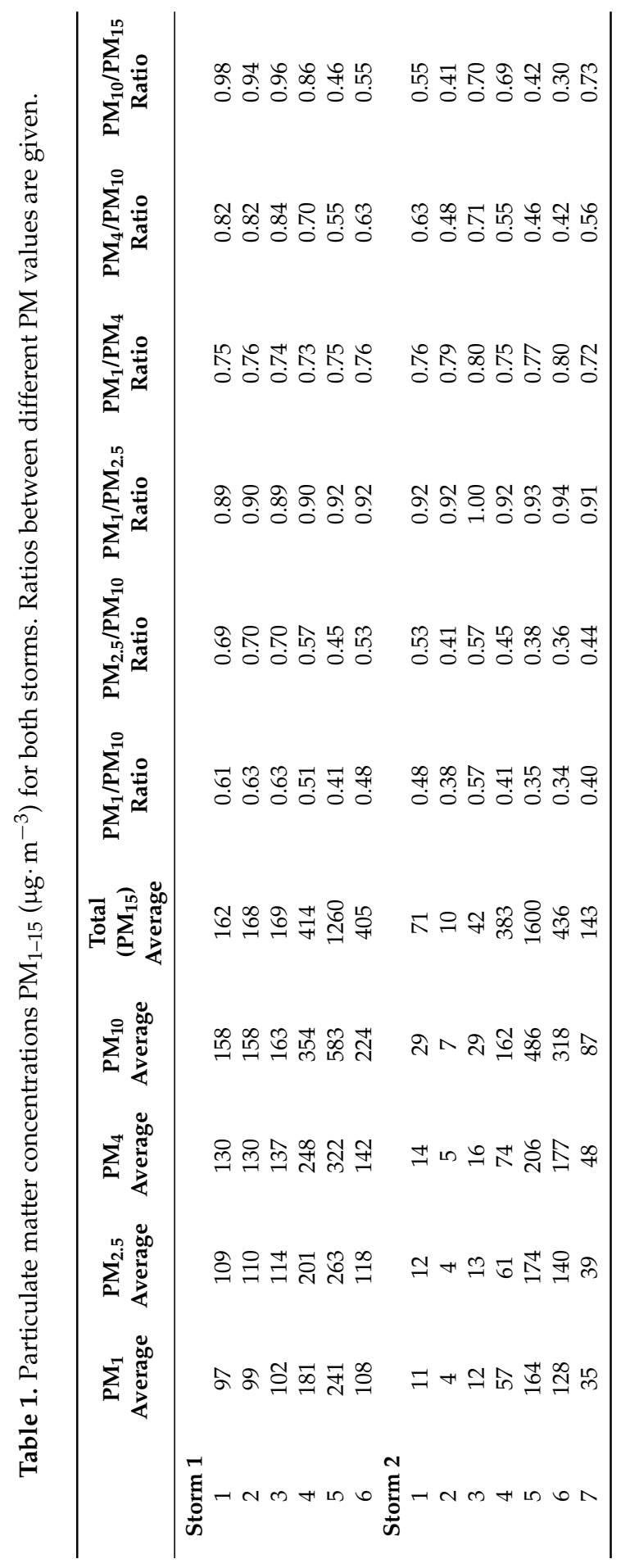


The camera network from the Icelandic Road and Coastal Administration (IRCA) was used to determine the dispersal area of these two dust storms. Figure 4 depicts a time lapse series of photos from one of these web cameras which is located in Sandskeið near Reykjavík (Point 1 at the Figures $1 \mathrm{~B}$ and 5B). The visibility was reduced down to $1 \mathrm{~km}$ during Storm 2 . The camera is located about $3.5 \mathrm{~km}$ from the mountain and about $1 \mathrm{~km}$ from the house shown in the middle of the photos. The corresponding $\mathrm{PM}_{10}$ concentrations to these visibility reductions can be obtained from DustTrak measurements close to this location for the left image only. The closest instrument (EAI) is located about $20 \mathrm{~km}$ downwind from this camera. The left picture shows the visibility was $>3.5 \mathrm{~km}$ corresponding to the $\mathrm{PM}_{10}$ of $50 \mu \mathrm{g} \cdot \mathrm{m}^{-3}$ by the EAI and $71 \mu \mathrm{g} \cdot \mathrm{m}^{-3}$ measured using the DustTrak instrument at the site. The middle photo shows the visibility was about $3.5 \mathrm{~km}$, corresponding to the $\mathrm{PM}_{10}$ of $70 \mu \mathrm{g} \cdot \mathrm{m}^{-3}$, while the photo on the right shows visibility was about $1 \mathrm{~km}$, corresponding to $\mathrm{PM}_{10}$ of $100 \mu \mathrm{g} \cdot \mathrm{m}^{-3}$. The $\mathrm{PM}_{10}$ concentrations for the middle and right picture at the location of the camera can, therefore, only be retrieved using the visibility-dust formula given by Dagsson-Waldhauserova et al. [23]. This formula is based on the long-term observations of $\mathrm{PM}_{10}$ and visibility in Iceland. Applying the formula to the visibility estimations from the camera, the $\mathrm{PM}_{10}$ concentrations are calculated as $<190 \mu \mathrm{g} \cdot \mathrm{m}^{-3}$ for the left photo, $370 \mu \mathrm{g} \cdot \mathrm{m}^{-3}$ for the middle photo, and $>780 \mu \mathrm{g} \cdot \mathrm{m}^{-3}$ for the photo on the right.
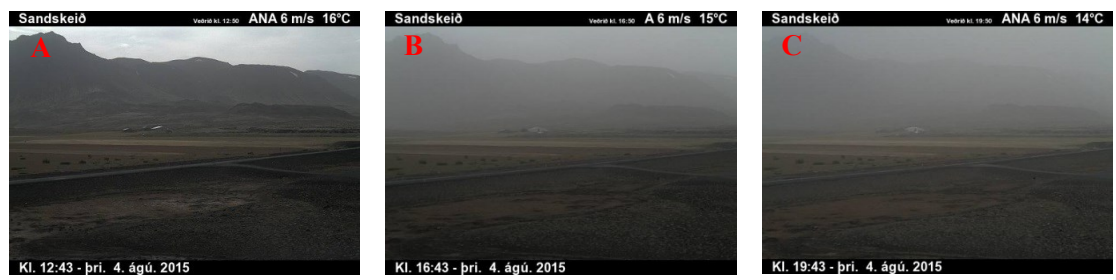

Figure 4. Changes in visibility during Storm 2 on 4 August 2015 when dust was blowing from Hagavatn. Left photo (A) shows visibility $>3.5 \mathrm{~km}$, corresponding to $\mathrm{PM}_{10}$ of $71 \mu \mathrm{g} \cdot \mathrm{m}^{-3}$, measured by a DustTrak instrument at the site. The middle photo (B) shows visibility of about $3.5 \mathrm{~km}$ corresponding to an estimated $\mathrm{PM}_{10}$ of $370 \mu \mathrm{g} \cdot \mathrm{m}^{-3}$, while the photo on the right $(\mathbf{C})$ shows about $1 \mathrm{~km}$ visibility, corresponding to an estimated $\mathrm{PM}_{10}$ of $>780 \mu \mathrm{g} \cdot \mathrm{m}^{-3}$ based on the formula from Dagsson-Waldhauserova et al. [23]. The images are from a web camera from the Icelandic Road and Coastal Administration.

Impaired visibility was observed at all spots where PM measurements were conducted (Figure 5). These images together with the IRCA camera network allowed us to estimate the spatial extent of the dust plumes as depicted in Figure 1. The total land area affected by Storm 1 was about $2450 \mathrm{~km}^{2}$ but $4220 \mathrm{~km}^{2}$ for Storm 2 . 
Numerical simulations and operational radiosoundings at Keflavik revealed the thickness of the well-mixed atmospheric boundary-layer as about $1 \mathrm{~km}$ in Strom 1 on 15 June with mean winds of about $15 \mathrm{~m} \cdot \mathrm{s}^{-1}$. The event lasted for about $8 \mathrm{~h}$, giving a total dust flux from source of about 180,000 tonnes. In Storm 2 on 4 August, the boundary-layer thickness was about $1.3 \mathrm{~km}$ and the mean winds were $12 \mathrm{~m} \cdot \mathrm{s}^{-1}$. This event lasted for about $12 \mathrm{~h}$ and the total flux from the source is estimated to be about 280,000 tonnes. Both events can thus be characterized as medium-sized (e.g., [22,37]).

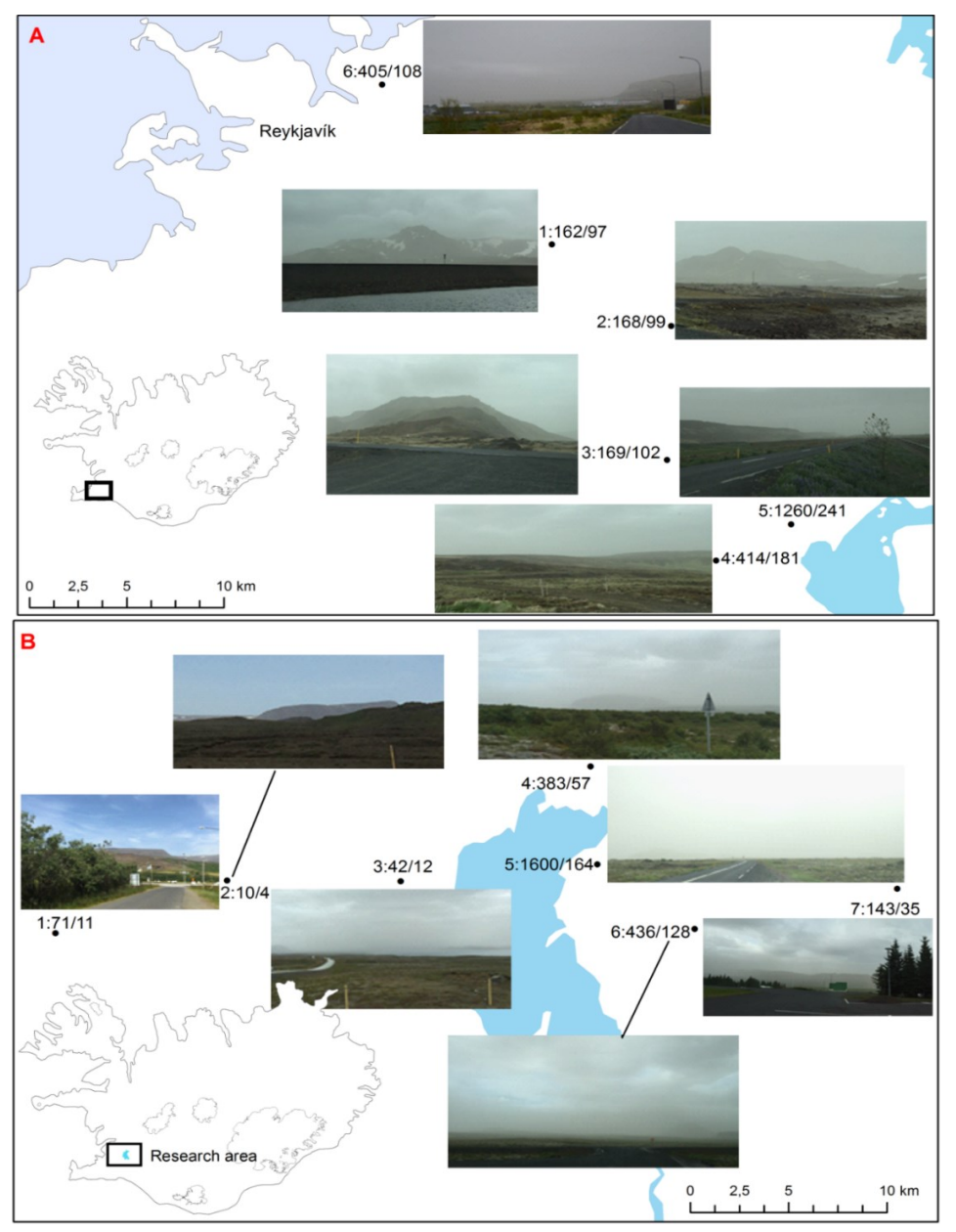

Figure 5. The measurement spots (place number: $\mathrm{PM}_{15}$ concentration/ $\mathrm{PM}_{1}$ concentration, $\mu \mathrm{g} \cdot \mathrm{m}^{-3}$ ) including a photo from every measurement spot. It can be seen that visibility was more reduced with higher dust concentrations. (A) Storm 1 from the Landeyjasandur on 15 June 2015 and (B) from Storm 2 on 4 August 2015. 
Figure 6 captured how Storm 1 passed relatively densely populated areas such as the town of Hveragerði, population of 2300, and the neighboring town of Selfoss, the eighth largest community in Iceland, with about 6500 inhabitants. The highest $\mathrm{PM}_{10}$ concentrations of $>500 \mu \mathrm{g} \cdot \mathrm{m}^{-3}$ and $\mathrm{PM}_{1}>200 \mu \mathrm{g} \cdot \mathrm{m}^{-3}$ were measured in this area. The margin of the dust plume is very visible on Figure 6A and it can clearly be seen how the visibility changed due to dust in the dust plume. Reduced visibility due to dust in Mosfellsbær (near Reykjavik) is shown on picture 6B. Here the concentrations exceeded $400 \mu \mathrm{g} \cdot \mathrm{m}^{-3}$ for $\mathrm{PM}_{10}$ and $100 \mu \mathrm{g} \cdot \mathrm{m}^{-3}$ for $\mathrm{PM}_{1}$. The long-term frequency of dust events in Iceland reports about one dust day annually for the capital of Reykjavik [23]. This number of dust storms is highly underestimated judging from our own observations as well as the measurements provided by the EAI. The meteorological stations at the towns of Hveragerði and Selfoss report 3.7 to 6.8 dust days a year.
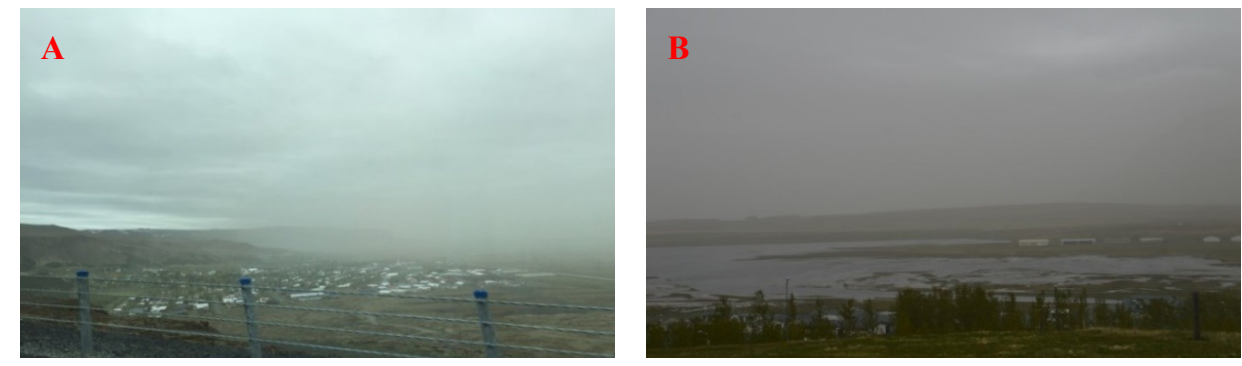

Figure 6. (A) The dust front of Storm 1 approaching to the town Hveragerði, population of 2300, which is near the town Selfoss, the eighth largest community in Iceland, with about 6500 inhabitants. The highest PM concentrations were measured in this area. The margin of the dust plume is very clear. Reduced visibility due to dust in Mosfellsbær (near Reykjavik), overlooking river Leirá, is shown on the right picture (B). Here the concentrations exceeded $400 \mu \mathrm{g} \cdot \mathrm{m}^{-3}$ for $\mathrm{PM}_{10}$ and $100 \mu \mathrm{g} \cdot \mathrm{m}^{-3}$ for $\mathrm{PM}_{1}$.

\subsection{Size Partitioning of the PM Components of Icelandic Dust}

Mineral dust outbreaks increase both fine and coarse PM concentrations [3,6, $10,13,24,38,39]$. Table 1 shows the mean $\mathrm{PM}_{1-15}$ concentrations at different locations (Figure 1) inside the dust plume. Although the $\mathrm{PM}_{10}$ concentrations are moderate $\left(<600 \mu \mathrm{g} \cdot \mathrm{m}^{-3}\right)$ for an ongoing dust storm in Iceland, the mean levels of $\mathrm{PM}_{1}$ are considerably high, such as $>97 \mu \mathrm{g} \cdot \mathrm{m}^{-3}$ for Storm 1 . The proportions of $\mathrm{PM}_{1} / \mathrm{PM}_{10}$ are significantly higher for Iceland than for any other dust events we have found in the literature. The $\mathrm{PM}_{1} / \mathrm{PM}_{10}$ ratio ranged from 0.41 to 0.63 for Storm 1 , and 0.34 to 0.57 for Storm 2, respectively (Table 1). Perez et al. [9] reported the $\mathrm{PM}_{1} / \mathrm{PM}_{10}$ ratios were relatively stable during African dust outbreaks, where the mean annual 
average decreased from 0.48 to 0.42 for dust days. Arizona dust outbreaks also had even more stable $\mathrm{PM}_{1} / \mathrm{PM}_{10}$ ratios of between 0.17 and 0.22 (0.18 on average) [38]. Claiborn et al. [39] reported no increase in $\mathrm{PM}_{1}$ during dust storms within the USA. In Iceland, the more severe the dust event was the lower $\mathrm{PM}_{1} / \mathrm{PM}_{10}$ ratio was observed. The same trend was reported from Iran where the $\mathrm{PM}_{1} / \mathrm{PM}_{10}$ ratio decreased from 0.4 to 0.05 during the dust storms with the mean ratio of 0.14 . Generally, the $\mathrm{PM}_{1} / \mathrm{PM}_{10}$ ratio $<0.4$ is attributed to the summer season with high dust suspension as summarized from 22 studies on size-segregated particulate matter ratios [40]. These comparisons showed that Icelandic volcanic dust is extremely fine compared to the crustal dust. Such high proportions $\left(>60 \%\right.$ of $\mathrm{PM}_{1}$ in $\left.\mathrm{PM}_{10}\right)$ as obtained during Storm 1 have been reported for urban air pollution, but not for natural dust. The $\mathrm{PM}_{1}$ proportion of $57 \%-60 \%$ in $\mathrm{PM}_{10}$ was found, for example, at four sites in Austria [41] while the $\mathrm{PM}_{1} / \mathrm{PM}_{10}$ ratio between 0.45 and 0.74 was found at a polluted urban site of Taipei in Taiwan [42].

Table 1 shows that the $\mathrm{PM}_{1} / \mathrm{PM}_{2.5}$ ratio ranged from 0.89 to 0.94 , thereby confirming that most of the fine dust particles were of submicron size. This is contrary to what has been reported on such ratios during dust events elsewhere. The $\mathrm{PM}_{1} / \mathrm{PM}_{2.5}$ ratio was 0.49 during dust events in the USA [39] while the $\mathrm{PM}_{1} / \mathrm{PM}_{2.5}$ was ranging from 0.05 to 0.8 , with a corresponding mean value 0.55 , during dust storms in Iran [10]. Values such as $90 \%$ of $\mathrm{PM}_{1} / \mathrm{PM}_{2.5}$ were reported from urban sites or cities such Graz in Austria [41]. High $\mathrm{PM}_{1} / \mathrm{PM}_{2.5}$ and $\mathrm{PM}_{1} / \mathrm{PM}_{10}$ ratios imply that $\mathrm{PM}_{2.5}$ or $\mathrm{PM}_{10}$ mainly consist of submicron particles that have a greater health impact than larger particles [6,10,12]. Detailed mineralogical and geochemical analyses of Icelandic dust revealed fine pipe-vesicular structures of volcanic glasses, as known from asbestos and high content of heavy metals [27,28]. Such structured submicron particles can likely have even more destructive effects on human and animal health, as reported by Carlsen et al. [30]. Figures 1 and 6 illustrate that the dust plumes with high PM concentrations are passing the most densely inhibited areas in Iceland. The frequency of such events is up to 135 dust days annually in Iceland with many crossing populated areas [23]. Currently, no warnings for the general public are issued.

About $90 \%$ of the $\mathrm{PM}_{2.5}$ particles were attributed to submicron particle fractions, and the ratios of $\mathrm{PM}_{2.5} / \mathrm{PM}_{10}$ were similar to the $\mathrm{PM}_{1} / \mathrm{PM}_{10}$ (Table 1). The mean $\mathrm{PM}_{2.5} / \mathrm{PM}_{10}$ ratio was 0.61 for Storm 1 and 0.44 for Storm 2. This is similar to what was found during dust outbreaks in Spain [9], but considerably higher than the 0.3 ratio reported from the USA [39]. The $\mathrm{PM}_{2.5} / \mathrm{PM}_{10}$ ratios in Iran ranged from 0.1 to 0.5 with the mean of 0.23 [10]. The lower values were related to the high dust season. The high proportion of fine materials in Iceland is attributed to the small grain size at the dust sources, which is a result of glacial action producing fine-grained materials. These materials are further sorted by glacio-fluvial processes at the glacial 
margins and in glacial rivers [14]. This unceasing glacial and glacio-fluvial action ensures continuous re-supply of the fine grained materials, in contrast to larger aeolian bodies on the continents.

The high ratios of $\mathrm{PM}_{10} / \mathrm{PM}_{15}$ shown in Table 1 suggest a low proportion of particles $>10 \mu \mathrm{m}$. However, $<50 \%$ proportion of $\mathrm{PM}_{10}$ on $\mathrm{PM}_{15}$ in many cases suggest the presence of larger particles. We did not find any relation between the $\mathrm{PM}_{10}$ concentration and $\mathrm{PM}_{10} / \mathrm{PM}_{15}$ ratio. There is, however, limited information on this size range of PM in the literature [8].

Our results show that Icelandic dust contains fine submicron particles, as was reported by Dagsson-Waldhauserova et al. [27]. Suspended dust measured at the Mælifellssandur glacial floodplain resulted in the high proportion of close-to-ultrafine particles, such as $0.3-0.37 \mu \mathrm{m}$. Generation of such fine particles is associated with mechanical processes of glaciers and fluvial processes [27]. However, even the finest lacustrine sediments produced from the most active dust hot spots of the world, such as the Bodele Depression in the Sahara or the Sistan Basin in Iran do not consist of such high amounts of submicron particles as observed in Icelandic dust $[3,10,13,43,44]$.

\section{Conclusions}

The study of two dust events shows the usefulness of combining photos obtained by surveillance cameras and portable dust measurement instruments for identifying the extent, magnitude, and grain size characteristics of single dust storms in Iceland. It shows that common dust storms are of several hundred thousand tons of magnitude from relatively well-defined main dust sources. The in situ measurements of two moderate Icelandic dust storms in 2015 show that aeolian dust can be very fine. The study highlights that suspended volcanic dust in Iceland can have extremely high $\mathrm{PM}_{1}$ concentrations that are comparable to urban pollution in Europe or Asia. The $\mathrm{PM}_{1} / \mathrm{PM}_{2.5}$ ratios are generally low during dust storms outside of Iceland, much lower than $>0.9$ and $\mathrm{PM}_{1} / \mathrm{PM}_{10}$ ratios of $0.34-0.63$ found in our study. The extremely high proportions of submicron particles are predicted to travel long distances. Moreover, such submicron particles pose considerable health risks because of their high potential for entering the lungs. Icelandic volcanic glass often has fine pipe-vesicular structures, known from asbestos, and has a high content of heavy metals. The two dust events with high PM concentrations reported here passed the most densely inhabited areas of Iceland and influenced an area of $2450 \mathrm{~km}^{2}$ during Storm 1 and $4220 \mathrm{~km}^{2}$ in Storm 2. The mean frequency of dust events in Iceland is about 135 dust days annually, however, health risk warnings for the general public are not being issued. The data provided stresses the need for such a warning system and is an important step towards its development. In light of the small size of the dust reported here, in addition to the high frequency of the dust events, it is 
vital to step up integrated dust and health research in Iceland. Furthermore, dust has influence on weather and climate in general, and the fine fraction of the Icelandic dust has bearings for weather forecast and climate change predictions.

Acknowledgments: This research was funded by the Icelandic Research Fund (Rannis) Grant No. 152248-051 and the Recruitment Fund of the University of Iceland. We acknowledge the Nordic Center of Excellence (NCoE) Top Research Initiative "Cryosphere-atmosphere interactions in a changing Arctic climate" (CRAICC). We acknowledge that the Icelandic Road and Costal administration allowed us to use images from their web-camera network to use in this research.

Author Contributions: A.M. and O.A. conceived and designed the experiments; A.M. performed the experiments; A.M., H.O., and P.D-W. analyzed the data and contributed reagents/materials/analysis tools; P.D-W., A.M., H.O., and O.A. wrote the paper.

Conflicts of Interest: The authors declare no conflict of interest.

\section{Abbreviations}

The following abbreviations are used in this manuscript:

PM Particulate matter

EAI Environmental Agency of Iceland

IRCA Icelandic road and coastal administration

\section{References}

1. Perez, L.; Tobias, A.; Querol, X.; Künzli, N.; Pey, J.; Alastuey, A. Coarse particles from Saharan dust and daily mortality. Epidemiology 2008, 19, 800-807.

2. Karanasiou, A.; Moreno, N.; Moreno, T.; Viana, M.; de Leeuw, F.; Querol, X. Health effects from Sahara dust episodes in Europe: Literature review and research gaps. Environ. Int. 2012, 47, 107-114.

3. Mallone, S.; Stafoggia, M.; Faustini, A.; Gobbi, G.P.; Marconi, A.; Forastiere, F. Saharan dust and associations between particulate matter and daily mortality in Rome, Italy. Environ. Health Perspect. 2011, 119, 1409-1414.

4. Stafoggia, M.; Zauli-Sajani, S.; Pey, J.; Samoli, E.; Alessandrini, E.; Basagaña, X.; Cernigliaro, A.; Chiusolo, M.; Demaria, M.; Díaz, J.; et al. Desert dust outbreaks in southern Europe: Contribution to daily $\mathrm{PM}_{10}$ concentrations and short-term associations with mortality and hospital admissions. Environ. Health Perspect. 2015, 124, 4.

5. Hyewon, L.; Ho, K.; Yasushi, H.; Youn-Hee, L.; Seungmuk, Y. Effect of Asian dust storms on daily mortality in seven metropolitan cities of Korea. Atmos. Environ. 2013, 79, 510-517.

6. The World Health Organization. Health Effects of Particulate Matter, Policy Implications for Countries in Eastern Europe, Caucasus and Central Asia; WHO Regional Publications European Series: Copenhagen, Denmark, 2013; p. 15. 
7. Pandolfi, M.; Tobias, A.; Alastuey, A.; Sunyer, J.; Schwartz, J.; Lorente, J.; Pey, J.; Querol, X. Effect of atmospheric mixing layer depth variations on urban air quality and daily mortality during Saharan dust outbreaks. Sci. Total Environ. 2014, 494-495, 283-289.

8. Krewski, D.; Jerrett, M.; Burnett, R.T.; Ma, R.; Hughes, E.; Shi, Y.; Turner, M.C.; Pope, C.A.; Thurston, G.; Calle, E.E.; et al. Extended follow-up and spatial analysis of the American Cancer Society study linking particulate air pollution and mortality. Res. Rep. Health Eff. Inst. 2009, 140, 5-114.

9. Perez, N.; Pey, J.; Querol, X.; Alastuey, A.; Lopez, J.M.; Viana, M. Partitioning of major and trace components in $\mathrm{PM}_{10}, \mathrm{PM}_{2.5}$ and $\mathrm{PM}_{1}$ at an urban site in Southern Europe. Atmos. Environ. 2008, 42, 1677-1691.

10. Shahsavani, A.; Naddafi, K.; Jafarzade Haghighifard, N.; Mesdaghinia, A.; Yunesian, M.; Nabizadeh, R.; Arahami, M.; Sowlat, M.; Yarahmadi, M.; Saki, H.; et al. The evaluation of PM10, PM2.5, and PM1 concentrations during the Middle Eastern Dust (MED) events in Ahvaz, Iran, from April through September 2010. J. Arid Environ. 2012, 77, 72-83.

11. Carbone, C.; Decesari, S.; Paglione, M.; Giulianelli, L.; Rinaldi, M.; Marinoni, A.; Cristofanelli, P.; Didiodato, A.; Bonasoni, P.; Fuzzi, S.; et al. 3-year chemical composition of free tropospheric PM1 at the Mt. Cimone GAW global station-South Europe-2165 m a.s.1. Atmos. Environ. 2014, 87, 218-227.

12. Colls, J.; Tiwary, A. Air Pollution Measurement, Modelling and Mitigation, 3rd ed.; Routledge: London, UK; New York, NY, USA, 2010.

13. Mahowald, N.M.; Albani, S.; Kok, J.F.; Engelstaeder, S.; Scanza, R.; Ward, S.; Flanner, M.G. The size distribution of desert dust aerosols and its impact on the Earth system. Aeol. Res. 2014, 15, 53-71.

14. Arnalds, O.; Dagsson-Waldhauserova, P.; Olafsson, H. The Icelandic volcanic aeolian environment: Processes and impacts-A review. Aeol. Res. 2016, 20, 176-195.

15. Nickling, W.G. Eolian sediment transport during dust storms: Slims River Valley, Yukon Territory. Can. J. Earth Sci. 1978, 15, 1069-1084.

16. Dornbrack, A.; Stachlewska, I.S.; Ritter, C.; Neuber, R. Aerosol distribution around Svalbard during intense easterly winds. Atmos. Chem. Phys. 2010, 10, 1473-1490.

17. Lancaster, N.; Nickling, W.G.; Gillies, J.A. Sand transport by wind on complex surfaces: Field studies in the McMurdo Dry Valleys, Antarctica. J. Geophys. Res. 2010, 115.

18. Crusius, J.; Schroth, A.W.; Gasso, S.; Moy, C.M.; Levy, R.C.; Gatica, M. Glacial flour dust storms in the Gulf of Alaska: Hydrologic and meteorological controls and their importance as a source of bioavailable iron. Geophys. Res. Lett. 2011, 38.

19. Bullard, J.E. Contemporary glacigenic inputs to the dust cycle. Earth Surf. Proc. Land. 2013, 38, 71-89.

20. Lamy, F.; Gersonde, R.; Winckler, G.; Esper, O.; Jaeschke, A.; Kuhn, G.; Ullermann, J.; Martinez-Garcia, A.; Lambert, F.; Kilian, R. Increased dust deposition in the Pacific Southern Ocean during glacial periods. Science 2014, 343, 403-407.

21. Arnalds, O.; Thorarinsdottir, E.F.; Thorsson, J.; Dagsson-Waldhauserova, P.; Agustsdottir, A.M. An extreme wind erosion event of the fresh Eyjafjallajokull 2010 volcanic ash. Nat. Sci. Rep. 2013, 3, 1257. 
22. Dagsson-Waldhauserova, P.; Arnalds, O.; Olafsson, H. Long-term frequency and characteristics of dust storm events in Northeastern Iceland (1949-2011). Atmos. Environ. 2013, 77, 117-127.

23. Dagsson-Waldhauserova, P.; Arnalds, O.; Olafsson, H. Long-term variability of dust events in Iceland (1949-2011). Atmos. Chem. Phys. 2014, 14, 13411-13422.

24. Thorsteinsson, T.; Gisladottir, G.; Bullard, J.; McTainsh, G. Dust storm contributions to airborne particulate matter in Reykjavík, Iceland. Atmos. Environ. 2011, 45, 5924-5933.

25. The World Health Organization. Air Quality Guidelines Global Update 2005. In Proceedings of the Report on a Working Group Meeting, Bonn, Germany, 18-20 October 2005.

26. The Environment Agency of Iceland. Air Quality in Iceland. Available online: http://ust. is/the-environment-agency-of-iceland/ (accessed on 14 February 2016).

27. Dagsson-Waldhauserova, P.; Arnalds, O.; Olafsson, H.; Skrabalova, L.; Sigurdardottir, G.; Branis, M.; Hladil, J.; Skala, R.; Navratil, T.; Chadimova, L.; et al. Physical properties of suspended dust during moist and low-wind conditions in Iceland. Icel. Agric. Sci. 2014, 27, 25-39.

28. Dagsson-Waldhauserova, P.; Arnalds, O.; Olafsson, H.; Hladil, J.; Skala, R.; Navratil, T.; Chadimova, L.; Meinander, O. Snow-dust storm: A case study from Iceland, 7 March 2013. Aeol. Res. 2015, 16, 69-74.

29. Baratoux, D.; Mangold, N.; Arnalds, O.; Bardintzeff, J.M.; Platevoet, B.; Gregorie, M.; Pinet, P. Volcanic sands of Iceland-Diverse origins of Aeolian sand deposits revealed at Dyngjusandur and Lambahraun. Earth Surf. Proc. Land 2011, 36, 1789-1808.

30. Carlsen, H.K.; Gislason, T.; Forsberg, B.; Meister, K.; Thorsteinsson, T.; Johannsson, T.; Finnbjornsdottir, R.; Oudin, A. Emergency hospital visits in association with volcanic ash, dust storms and other sources of ambient particles: A time-series study in Reykjavík, Iceland. Int. J. Environ. Res. Public Health 2015, 12, 4047-4059.

31. Blechschmidt, A.-M.; Kristjansson, J.E.; Olafsson, H.; Burkhart, J.F.; Hodnebrog, Ø. Aircraft-based observations and high-resolution simulations of an Icelandic dust storm. Atmos. Chem. Phys. 2012, 12, 7949-7984.

32. Branis, M.; Hovorka, J. Performance of a photometer DustTrak in various indoor and outdoor environments. In Proceedings of the Abstracts of the 2005 Evaluations and Assessment Conference (EAC 2005), Ghent, Belgium, 28 September-10 October 2005; p. 535.

33. Wallace, L.A.; Wheeler, A.J.; Kearney, J.; Van Ryswyk, K.; You, H.; Kulka, R.H.; Rasmussen, P.E.; Brook, J.R.; Xu, X. Validation of continuous particle monitors for personal, indoor, and outdoor exposures. J. Expo. Sci. Environ. Epidemiol. 2011, 21, 49-64.

34. The Icelandic Road and Coastal Administration. Road, Web Cameras. Available online: http:/ / www.road.is/travel-info/web-cams/ (accessed on 4 August 2015).

35. Pey, J.; Rodríguez, S.; Querol, X.; Alastuey, A.; Moreno, T.; Putaud, J.P.; Van Dingenen, R. Variations of urban aerosols in the western Mediterranean. Atmos. Environ. 2008, 42, 9052-9062.

36. Theodosi, C.; Grivas, G.; Zarmpas, P.; Chaloulakou, A.; Mihalopoulos, N. Mass and chemical composition of size-segregated aerosols $\left(\mathrm{PM}_{1}, \mathrm{PM}_{2.5}, \mathrm{PM}_{10}\right)$ over Athens, Greece: Local versus regional sources. Atmos. Chem. Phys. 2011, 11, 11895-11911. 
37. Arnalds, O.; Olafsson, H.; Dagsson-Waldhauserova, P. Quantification of iron rich volcanogenic dust emissions and deposition over ocean from Icelandic dust sources. Biogeosciences 2014, 11, 6623-6632.

38. Lundgren, D.A.; Hlaing, D.N.; Rich, T.A.; Marple, V.A. PM10/PM2.5/PM1.0 data from a trichotomous sampler. Aerosol Sci. Tech. 1996, 25, 353-357.

39. Claiborn, C.S.; Finn, D.; Larson, T.; Koenig, J. Windblown dust contributes to high $\mathrm{PM}_{2.5}$ concentrations. J. Air Waste Manag. Assoc. 2000, 50, 1440-1445.

40. Speranza, A.; Caggiano, R.; Margiotta, S.; Summa, V.; Trippett, S. A clustering approach based on triangular diagram to study the seasonal variability of simultaneous measurements of PM10, PM2.5 and PM1 mass concentration ratios. Arab. J. Geosci. 2016, 9, 132.

41. Gomišček, B.; Hauck, H.; Stopper, S.; Preining, O. Spatial and temporal variation of PM1, PM2.5, PM10 and particle number concentration during the AUPHEP-project. Atmos. Environ. 2004, 38, 3917-3934.

42. Li, C.-S.; Lin, C.-H. $\mathrm{PM}_{1} / \mathrm{PM}_{2.5} / \mathrm{PM}_{10}$ Characteristics in the urban atmosphere of Taipei. Aerosol Sci. Technol. 2002, 36, 469-473.

43. Todd, M.C.; Washington, R.; Martins, J.V.; Dubovik, O.; Lizcano, G.; M'Bainayel, S.; Engelstaedter, S. Mineral dust emission from the Bodélé Depression, northern Chad, during BoDEx 2005. J. Geophys. Res. 2007, 112.

44. Kaskaoutis, D.G.; Rashki, A.; Houssos, E.E.; Goto, D.; Nastos, P.T. Extremely high aerosol loading over Arabian sea during June 2008: The specific role of the atmospheric dynamics and Sistan dust storms. Atmos. Environ. 2014, 94, 374-384. 


\title{
Effect of Pollution Controls on Atmospheric $\mathbf{P M}_{2.5}$ Composition during Universiade in Shenzhen, China
}

\author{
Nitika Dewan, Yu-Qin Wang, Yuan-Xun Zhang, Yang Zhang, Ling-Yan He, \\ Xiao-Feng Huang and Brian J. Majestic
}

Abstract: The 16th Universiade, an international multi-sport event, was hosted in Shenzhen, China from 12 to 23 August 2011. During this time, officials instituted the Pearl River Delta action plan in order to enhance the air quality of Shenzhen. To determine the effect of these controls, the current study examined the trace elements, water-soluble ions, and stable lead isotopic ratios in atmospheric particulate matter (PM) collected during the controlled (when the restrictions were in place) and uncontrolled periods. Fine particles $\left(\mathrm{PM}_{2.5}\right)$ were collected at two sampling sites in Shenzhen: "LG" - a residential building in the Longgang District, with significant point sources around it and "PU"-Peking University Shenzhen Graduate School in the Nanshan District, with no significant point sources. Results from this study showed a significant increase in the concentrations of elements during the uncontrolled periods. For instance, samples at the LG site showed (controlled to uncontrolled periods) concentrations (in $\mathrm{ng} \cdot \mathrm{m}^{-3}$ ) of: Fe (152 to 290), As (3.65 to 8.38), $\mathrm{Pb}$ (9.52 to 70.8), and Zn (98.6 to 286). Similarly, samples at the PU site showed elemental concentrations (in $\mathrm{ng} \cdot \mathrm{m}^{-3}$ ) of: Fe (114 to 301), As (0.634 to 8.36), Pb (4.86 to 58.1 ), and $\mathrm{Zn}$ (29.5 to 259). Soluble Fe ranged from $7 \%-15 \%$ for the total measured $\mathrm{Fe}$, indicating an urban source of Fe. Ambient $\mathrm{PM}_{2.5}$ collected at the PU site has an average ${ }^{206} \mathrm{~Pb} /{ }^{204} \mathrm{~Pb}$ ratio of 18.257 and 18.260 during controlled and uncontrolled periods, respectively. The LG site has an average ${ }^{206} \mathrm{~Pb} /{ }^{204} \mathrm{~Pb}$ ratio of 18.183 and 18.030 during controlled and uncontrolled periods, respectively. The ${ }^{206} \mathrm{~Pb} /{ }^{204} \mathrm{~Pb}$ ratios at the PU and the LG sites during the controlled and uncontrolled periods were similar, indicating a common $\mathrm{Pb}$ source. To characterize the sources of trace elements, principal component analysis was applied to the elements and ions. Although the relative importance of each component varied, the major sources for both sites were identified as residual oil combustion, secondary inorganic aerosols, sea spray, and combustion. The $\mathrm{PM}_{2.5}$ levels were severely decreased during the controlled period, but it is unclear if this was a result of the controls or change in meteorology.

Reprinted from Atmosphere. Cite as: Dewan, N.; Wang, Y.-Q.; Zhang, Y.-X.; Zhang, Y.; He, L.-Y.; Huang, X.-F.; Majestic, B.J. Effect of Pollution Controls on Atmospheric $\mathrm{PM}_{2.5}$ Composition during Universiade in Shenzhen, China. Atmosphere 2016, 7, 57. 


\section{Introduction}

Due to an increase in urbanization and economic growth in China, air pollution has become a severe problem. $\mathrm{PM}_{2.5}$ is a key pollutant strongly impacted by the rapid development in China [1-3]. High $\mathrm{PM}_{2.5}$ levels are associated with human mortality [4-6], climate change [7], visibility degradation [8,9], and agricultural yield reduction [10]. Increased morbidity and mortality rates and the adverse health effects of particle exposure are predominantly linked to chemical composition of PM [11,12]. From a toxicological viewpoint, the trace metals play an important role in increasing the redox activity of ambient PM [13-15]. Metals are hard to eliminate and they therefore accumulate in organisms and plants and can cause severe human health related problems and environmental pollution [16,17]. The inhalation of metals is associated with disruption of the nervous system and the functioning of internal organs [18-20].

Shenzhen $\left(22^{\circ} 33^{\prime} \mathrm{N}, 114^{\circ} 06^{\prime} \mathrm{E}\right)$, home to a population of 10.62 million residents, is one of the most important industrial centers in China. It is a coastal city in the Guangdong Province located at the mouth of the Pearl River Delta (PRD), bordering Hong Kong. Previous studies measured $\mathrm{PM}_{2.5}$ mass concentrations during winter and summer months in Shenzhen and Hong Kong. The $\mathrm{PM}_{2.5}$ levels (in $\mu \mathrm{g} \cdot \mathrm{m}^{-3}$ ) were higher at Shenzhen, $47 \pm 17$ and $61 \pm 18$, relative to Hong Kong, $31 \pm 17$ and $55 \pm 23$, during summer and winter months, respectively [21,22]. Overall, Shenzhen displayed maximum $\mathrm{PM}_{2.5}$ levels in winter months relative to summer months [23], both of which exceed the 24-h mean ambient air quality standards of the World Health Organization (WHO) of $25 \mu \mathrm{g} \cdot \mathrm{m}^{-3}$ [24] and the annual ambient air quality standards of People's Republic of China (GB 3095-2012) of $35 \mu \mathrm{g} \cdot \mathrm{m}^{-3}$ [25].

The 16th Universiade, an international multi-sport and cultural event organized for university athletes by the International University Sports Federation, was hosted in Shenzhen, China from 12 to 23 August 2011. During this time, officials instituted several restrictions: (a) the PRD action plan [26], which includes the prevention and control of industrial pollution, flow source pollution, and dust and point source pollution; (b) an ozone controlling plan which includes control of emissions of volatile organic compounds (VOCs) and promotion of an oil to gas project for thermal power plants; and (c) traffic-control actions such as restricting access within the region in order to enhance the air quality of Shenzhen. In this study, airborne $\mathrm{PM}_{2.5}$ (aerodynamic diameter $<2.5 \mu \mathrm{m}$ ) was collected at two sampling sites in Shenzhen during the controlled period (when the restrictions were implied) and during the uncontrolled period (when the restrictions were released). A previous study had evaluated the impact of emission controls and traffic intervention measures during the 29th Olympic and Paralympics games in Beijing [27], where significant reductions in vehicle emissions and ambient traffic-related air pollutants were observed. 
In this study, we employed several chemical and statistical methods to determine the impact of the emission restrictions on $\mathrm{PM}_{2.5}$ and trace elements. We report trace elements as well as water-soluble major ions. For the first time in the region, $\mathrm{Pb}$ isotopic ratios, as well as soluble iron oxidation state speciation, are reported. In addition to quantification, we employ principal component analysis (PCA) to determine the source of trace elements, allowing a unique interpretation of the quantitative data.

\section{Materials and Methods}

\subsection{Sample Collection}

Airborne $\mathrm{PM}_{2.5}$ was collected at two sampling sites (LG and PU) in Shenzhen in 2011 both during the controlled period (12 August-23 August) and uncontrolled period (24 August-4 September) of Universiade. The map of the region showing the two sampling sites is shown in Figure 1 [28]. The "LG" site $\left(22.70^{\circ} \mathrm{N}, 114.21^{\circ} \mathrm{E}\right)$, about $500 \mathrm{~m}$ away from the main venue, is located on top of a 31 floor Lotus residential building in the Longgang District, with significant point sources (e.g., plastic processing plants, glass factories, papermaking and painting industries) nearby. During the controlled periods, these point sources were supposed to be closed. However, we note that there was no accountability and no way of verification. The "PU" site $\left(22.60^{\circ} \mathrm{N}, 113.97^{\circ} \mathrm{E}\right)$ is located at the top of Building E of the Peking University Shenzhen Graduate School in the Nanshan District, with no significant point sources around it and about $33 \mathrm{~km}$ away from the main venue. The LG site was located at $161 \mathrm{~m}$ and the PU site was located at $50 \mathrm{~m}$ above ground level, with no major geological features between the sites. The distance between the two sampling sites is about $45 \mathrm{~km}$. A previous study during the same time period at these sites showed that both PM mass and PM composition (EC/OC) were significantly (and similarly) altered when comparing the controlled and uncontrolled periods [26].

Co-located samples were collected on both $47 \mathrm{~mm}$ quartz and Teflon filters (Whatman, Pittsburgh, PA, USA) for 24-h from 12 August to 4 September with a flow rate of $21 \mathrm{~L} \cdot \mathrm{min}^{-1}$ using dual channel samplers (GUCAS 1.0) [29]. The quartz filters were used for EC/OC analysis following the protocol mentioned in EPA/NIOSH [30] and these results are reported elsewhere [26]. All sample preparation was performed under positive pressure HEPA filtered air. A microbalance (Mettler Toledo AX105DR, Columbus, OH, USA) was used for determination of mass (estimated total uncertainty of $\pm 6 \mu \mathrm{g}$ ). Prior to weighing, the filters were equilibrated in a constant humidity $(40 \% \pm 3 \%)$ and temperature $\left(20 \pm 1{ }^{\circ} \mathrm{C}\right)$ environment for $48 \mathrm{~h}$. 


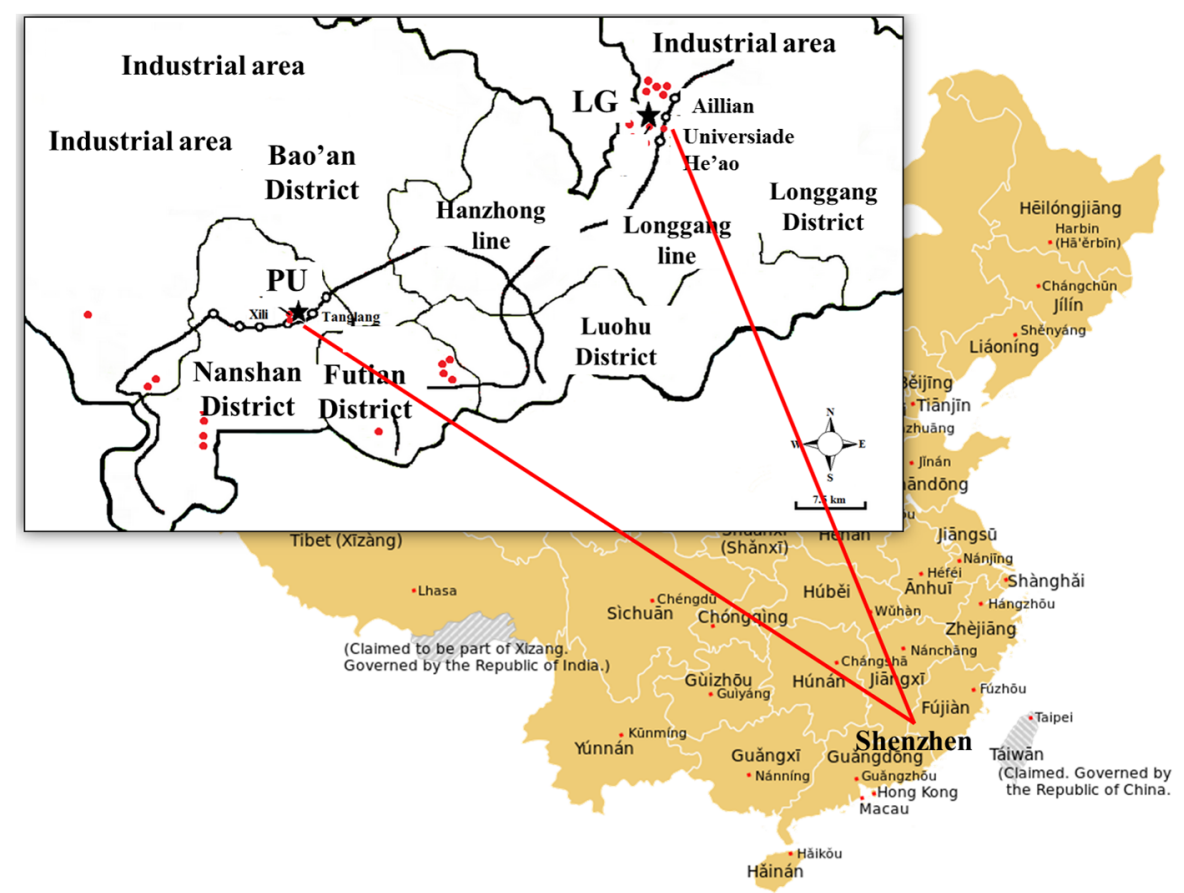

Figure 1. Map showing the geographical location of the PU and LG sampling sites (shown as stars) relative to the Universiade center in Shenzhen. The red dots in the map represent the stadiums where the events were held [28].

The temperature, pressure, wind directions, and relative humidity were constant during the controlled periods. Based on the 72-h backward HYSPLIT (Hybrid Single Particle Lagrangian Integrated Trajectory) model [31], the air mass was transported from the South Sea at both sampling sites during the controlled periods. During the uncontrolled periods, the wind directions were more variable, but northern winds were more prominent and, based on trajectory analysis, air mass was transported from an industrial zone to both sites. Additional details of the meteorology during this time can be found in a previous manuscript [26]. There were two minor rain events during the controlled and three during the uncontrolled periods, all less than $12 \mathrm{~mm}$. There were no reductions observed in the overall PM mass during those days.

\subsection{Total Elemental Analysis}

Prior to digestion, the polypropylene ring was removed from the Teflon filter using a ceramic blade. The Teflon filters were digested in sealed, pre-cleaned Teflon digestion bombs in a 30-position Microwave Rotor (Milestone Ethos, Shelton, CT, USA) with trace metal grade acid matrix (Fisher, Waltham, MA, USA) consisting of 
$1.5 \mathrm{~mL}$ of nitric acid $(16 \mathrm{M}), 750 \mu \mathrm{L}$ of hydrochloric acid $(12 \mathrm{M}), 200 \mu \mathrm{L}$ of hydrofluoric acid $(28 \mathrm{M}$ ), and $200 \mu \mathrm{L}$ of $30 \%$ hydrogen peroxide. Digestates were diluted to $30 \mathrm{~mL}$ with high purity water (>18 $\mathrm{M} \Omega \mathrm{cm}, \mathrm{MQ})$ and elemental concentrations (Al, As, Ba, Ca, Cd, Cr, Cu, Fe, K, Mg, Mn, Mo, Na, Ni, Pb, Rb, Sb, Se, Sr, Ti, V, and $\mathrm{Zn}$ ) were quantified by quadrupole inductively coupled plasma-mass spectrometry (ICP-MS, Agilent 7700, Santa Clara, CA, USA) with indium (In) as an internal standard. The accuracy of the results from the elemental analysis was verified by National Institute of Standards and Technology (NIST) Standard Reference Materials (SRM). The SRMs, San Joaquin Soil (NIST 2709) and Urban Dust (NIST 1649a), were digested and analyzed with every batch of 25 samples. The percent recovery of the reported elements from these SRMs was 85\%-120\%. Data were also blank-corrected using the average of multiple field filter blanks. Blank concentrations (in $\mu \mathrm{g} \cdot \mathrm{L}^{-1}$ ) ranged from 0.0041 ( $2.4 \%$ of the total) to 14.65 (5.3\% of the total) for the elements during the controlled and uncontrolled periods at the two sampling sites. The uncertainty associated with each element in every sample was calculated from an error propagation analysis, which included uncertainty in the field blanks and in the air flow rates.

\subsection{Soluble Ions Analysis}

For soluble ion analysis, the Teflon filters were leached in $10 \mathrm{~mL}$ high purity water for $2 \mathrm{~h}$. Water-soluble ions were analyzed from the unacidified portion using ion exchange chromatography (Dionex-ICS5000, Bannockburn, IL, USA) followed by a self-regeneration suppressor (model CSR 300 for cations and ASR 300 for anions) and coupled with conductivity detector (Thermo). Cations $\left(\mathrm{NH}_{4}{ }^{+}, \mathrm{K}^{+}, \mathrm{Na}^{+}\right.$, and $\mathrm{Mg}^{2+}$ ) were separated by Dionex IonPac CS12A column and using $20 \mathrm{mM}$ of methanesulfonic acid as a mobile phase at a flowrate of $0.5 \mathrm{~mL} \cdot \mathrm{min}^{-1}$. For anions $\left(\mathrm{Cl}^{-}, \mathrm{NO}_{3}{ }^{-}\right.$, and $\left.\mathrm{SO}_{4}{ }^{2-}\right)$, a Dionex IonPac AS22 column was used for separation along with a mixture of $4.5 \mathrm{mM}$ sodium carbonate and $1.4 \mathrm{mM}$ sodium bicarbonate as a mobile phase with a flowrate of $0.5 \mathrm{~mL} \cdot \mathrm{min}^{-1}$. A calibration curve of authentic standard (Dionex) for target ions was used to identify and quantify cations and anions in the samples. Details about calibration, method and instrument detection limits, and other measurement parameters have been previously reported [32].

\subsection{Iron Oxidation State Analysis}

Iron $(\mathrm{Fe})$ speciation analysis was also performed with the water-soluble extracts. $1.8 \mathrm{~mL}$ of the soluble extract was mixed with $0.2 \mathrm{~mL}$ of $5.88 \mu \mathrm{M}$ Ferrozine reagent ((3-(2-pyridyl)-5,6-diphenyl-1,2,4-triazine-4',4"'-disulfonic acid sodium salt), Sigma, St. Louis, MO, USA). The absorbance of the Fe(II)-Ferrozine complex was measured at $560 \mathrm{~nm}$ using a $1 \mathrm{~m}$ liquid waveguide capillary cell spectrophotometer [33,34]. The $\mathrm{pH}$ for all water extracts (each site, controlled vs. uncontrolled) ranged 
between 4.28 and 4.41. This suggests that, despite an unbuffered extract solution, $\mathrm{pH}$ effects were not important. The calibration curve generated using known Fe(II)-Ferrozine solutions provided Fe(II) concentration. Soluble Fe(III) was then determined by subtracting total soluble Fe concentration (from ICP-MS) from the soluble Fe(II) concentration.

\subsection{Stable Pb Isotope Analysis}

Stable $\mathrm{Pb}$ isotopic ratios were measured in the digested extracts with no further purification using high-resolution magnetic sector inductively coupled plasma mass spectrometer (MC)-ICP-MS (Thermo-Finnigan Neptune Plus). For the Pb isotope analysis, the digests were evaporated in Teflon vials and diluted to $2 \mathrm{~mL}$ using $2 \%$ optima grade $\mathrm{HNO}_{3}$ acid (Fisher, Waltham, MA, USA). The $\mathrm{Pb}$ content of the digests ranged from 15 to $30 \mathrm{ng}$. The uncertainties for $\mathrm{Pb}$ isotope ratios depended on the isotope system and were in the range of 0.0025 and 0.0034 for ${ }^{206} \mathrm{~Pb} /{ }^{204} \mathrm{~Pb}$ and ${ }^{207} \mathrm{~Pb} /{ }^{206} \mathrm{~Pb}$, respectively. Analysis of the common $\mathrm{Pb}$ isotopic standard (NIST 981) yielded ${ }^{206} \mathrm{~Pb} /{ }^{204} \mathrm{~Pb}=16.937 \pm 0.018(n=18)$ and ${ }^{207} \mathrm{~Pb} /{ }^{206} \mathrm{~Pb}=0.9145 \pm 0.0001$ $(n=17)$ versus the certified values of $16.944 \pm 0.015$ and $0.9146 \pm 0.0003$, respectively.

\subsection{Principal Component Analysis (PCA)}

To identify the potential origin of the elements in $\mathrm{PM}_{2.5}$, PCA was conducted using SPSS statistical software (SPSS, version 22). A varimax rotation was employed for interpretation of the principal components and factors with eigenvalues greater than unity were retained in the analysis [35]. Given that the bulk properties, $\mathrm{Pb}$ isotope ratios, and elements trends were similar at each site, it is clear that similar sources affect each site. Therefore, the sites were grouped together for the PCA analysis. Prior to conducting factor analysis, we performed a Pearson correlation matrix of 52 samples collected at two sampling sites during controlled and uncontrolled periods. Based on correlations matrix, we had a total of 26 samples with OC [26], 8 elements, and 6 ions as variables, resulting in a sample/variable ratio consistent with recommended criteria for a robust PCA analysis with KMO test of sampling adequacy $>0.5$ [36]. In addition, the significance value (0.000) for Bartlett's test of sphericity indicates that the correlations are appropriate for this data set.

\section{Results and Discussion}

\subsection{Trace Element Concentrations}

One previous study [26] has shown that during the controlled periods, the monitored $\mathrm{PM}_{2.5}$ mass concentrations were $12.9 \pm 3.7 \mu \mathrm{g} \cdot \mathrm{m}^{-3}$ at the PU site and $25.2 \pm 5.2 \mu \mathrm{g} \cdot \mathrm{m}^{-3}$ at the LG site. During uncontrolled periods, significant increases in the $\mathrm{PM}_{2.5}$ mass concentrations were observed $\left(\mathrm{PU}=48.0 \pm 8.7 \mu \mathrm{g} \cdot \mathrm{m}^{-3}\right.$ and 
$\mathrm{LG}=54.0 \pm 6.5 \mu \mathrm{g} \cdot \mathrm{m}^{-3}$ ). The fact that the wind directions were drastically different during controlled and uncontrolled periods complicate the effects of the controls and this may be another reason why such drastic differences in PM were observed between the two periods. Consistent with the increased PM mass, results from our study showed an increase in the concentrations of most abundant and trace elements in $\mathrm{PM}_{2.5}$ collected at the PU and LG sites during uncontrolled periods (Figure 2a-d). For instance, average Ca and Fe concentrations were 360 (range, 264-467) and 290 (range, 216-412) $\mathrm{ng} \cdot \mathrm{m}^{-3}$, respectively, during uncontrolled periods and 270 (range, 169-340) and 152 (range, 90-352) $\mathrm{ng} \cdot \mathrm{m}^{-3}$ during controlled periods at the LG site. Similarly, at the PU site, average Ca and Fe concentrations were 250 (range, 114-469) and $\sim 300$ (range, 201-588) $\mathrm{ng} \cdot \mathrm{m}^{-3}$, respectively, during uncontrolled periods and $\sim 100$ (range, $29-160$ ) and $\sim 115 \mathrm{ng} \cdot \mathrm{m}^{-3}$ (range, 55-169) during controlled periods. The elemental analysis showed that both $\mathrm{Al}$ and $\mathrm{K}$ were the dominant elements at both sampling sites. Also, all trace elements, except $\mathrm{Ni}$ and $\mathrm{V}$, had higher concentrations during uncontrolled periods at both sites. Both $\mathrm{Ni}$ and $\mathrm{V}$ are markers for the residual oil combustion, which suggests that oil combustion sources were essentially unaffected by the controls. The significant increase in V during the controlled periods could be attributed to emissions from ships around the Shenzhen city, however this is speculation as reliable data regarding the ship traffic are not available. There were no large scale oil power generation plants [37]. Therefore, control of oil combustion sources was likely very challenging, since all of these sources were probably small. Some striking differences include an approximate eleven-fold increase for $\mathrm{Pb}$ and an eight-fold difference for $\mathrm{Zn}$ for $\mathrm{PM}_{2.5}$ during uncontrolled periods at the PU site. Similarly, an approximate eight-fold difference was observed in the concentrations of $\mathrm{Pb}$ and a three-fold difference for $\mathrm{Zn}$ during uncontrolled periods at the LG site. Overall, the concentrations of most of the elements were higher at the LG site relative to the PU site. This may be because the LG site is close to significant point sources.

Water-soluble ions were quantified in the $\mathrm{PM}_{2.5}$ collected at the two sampling sites during controlled and uncontrolled periods and are presented in Figure 3. Elevated levels of $\mathrm{SO}_{4}{ }^{2-}$ were observed in $\mathrm{PM}_{2.5}$ during uncontrolled periods at both sites. Sources like coal power plants and industries may be playing an important role in the emissions of sulfur dioxide, which leads to sulfate. $\mathrm{NO}_{3}{ }^{-} / \mathrm{SO}_{4}{ }^{2-}$ ratio can be used as an indicator of the type of anthropogenic activity [38]. If the ratio is $>1$, it indicates greater $\mathrm{NO}_{x}$ emissions, indicating vehicular emissions are likely dominant. If the ratio is $<1$, it indicates greater $\mathrm{SO}_{2}$ emissions, and that stationary sources are dominant $[38,39]$. The average ratio at the PU site was $0.071 \pm 0.003$ and $0.12 \pm 0.02$ during controlled and uncontrolled periods respectively, whereas the average ratio at the LG site was $0.15 \pm 0.01$ and $0.13 \pm 0.01$ during controlled and uncontrolled periods, respectively. At the two sampling sites, both during controlled and uncontrolled periods, the ratio is lower than 1, indicating that stationary sources 
like industry emissions and power plants are important contributors to $\mathrm{PM}_{2.5}$ emissions in Shenzhen.
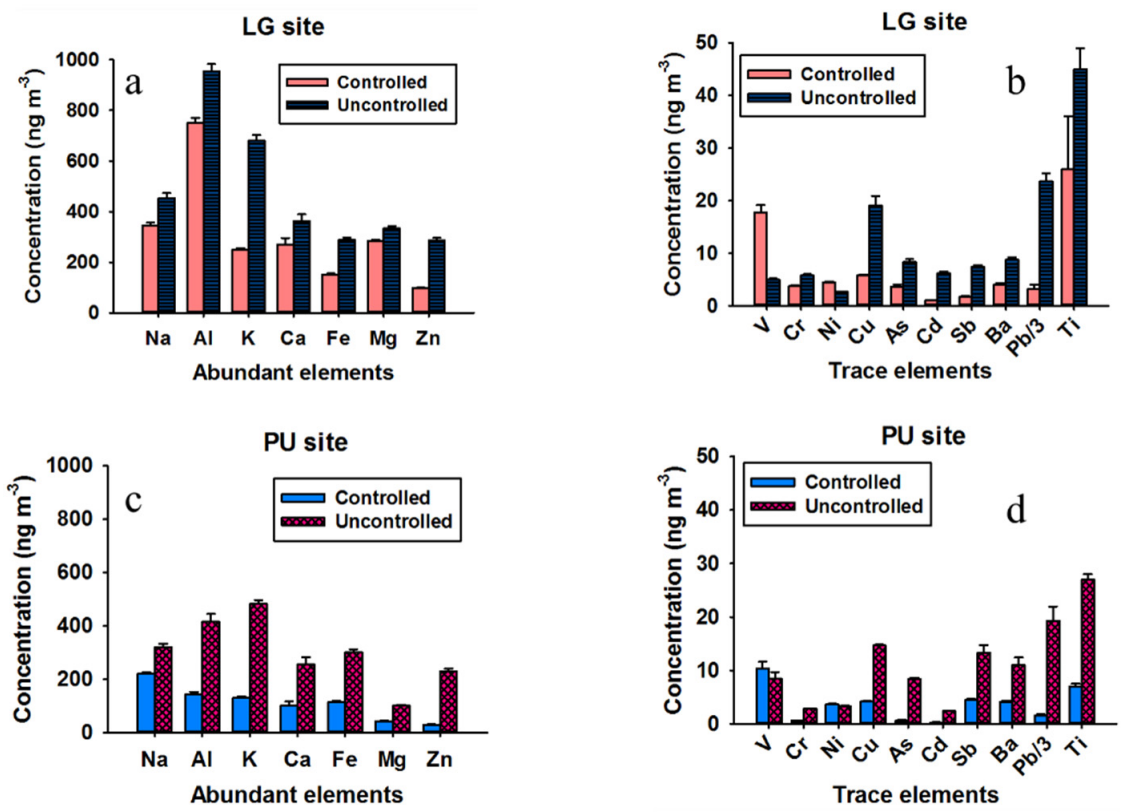

Figure 2. Average (ng. $\mathrm{m}^{-3}$ ) abundant and trace elements observed in $\mathrm{PM}_{2.5}$ at the LG site $(\mathbf{a}, \mathbf{b})$ and PU site (c,d) during controlled and uncontrolled periods.
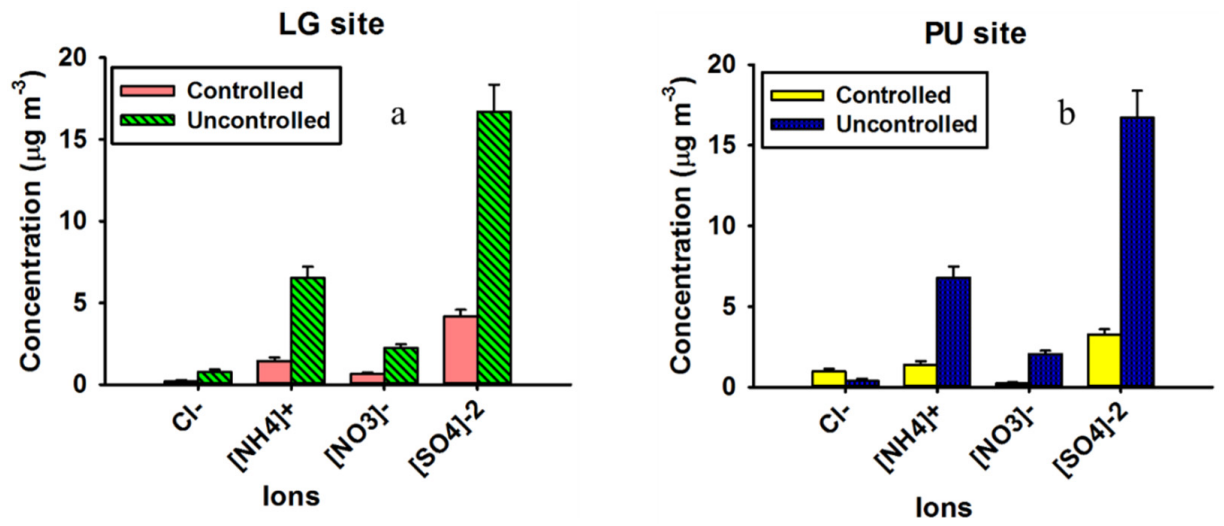

Figure 3. Average $\left(\mu \mathrm{g} \cdot \mathrm{m}^{-3}\right)$ water-soluble ions observed in $\mathrm{PM}_{2.5}$ at the LG site (a) and PU site (b) during controlled and uncontrolled periods. 


\subsection{Crustal Enrichment Factors}

Enrichment factors (EF) are used to assess whether the elements have a major crustal component [40]. EF of the elements was calculated by first normalizing the measured elemental concentrations in the sample with aluminum (Al), and then dividing by the Upper Continental Crust (UCC) ratio [41,42]. EF is calculated using the following formula:

$$
\mathrm{EF}_{\text {element }}=\frac{(\text { Concentration of element in sample/ Concentration of } \mathrm{Al} \text { in sample) }}{(\text { Concentration of element in crust / Concentration of } \mathrm{Al} \text { in crust })}
$$

$\mathrm{EF}$ is close to unity for the elements related to the reference, $\mathrm{Al}$ (marker for crustal emissions). A high EF (>>10) suggests that particular elements are enriched relative to the crust and thus are anthropogenically derived [43]. The dashed line $(E F=10)$ on the plots shown in Figure $4 a, b$ represents the level above which the element is considered to have a major anthropogenic source. The error bar represents the standard deviation of the 13 samples each during the controlled and uncontrolled periods at the two sites. The dots represent the average EF of the 13 samples for each element.
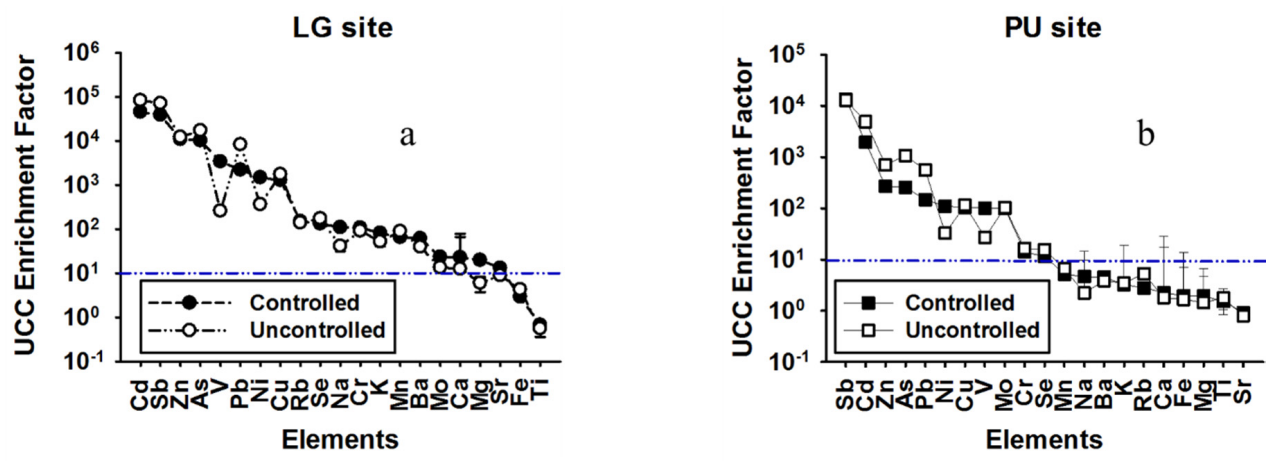

Figure 4. Enrichment factor (EF) for $\mathrm{PM}_{2.5}$ collected at: (a) LG site during controlled and uncontrolled periods; and (b) PU site during controlled and uncontrolled periods. The error bar represents the standard deviation of the samples.

As observed in Figure 4, almost every measured element appears to have some anthropogenic source at the LG site. Conversely, at the PU site, mainly the industrially-sourced elements have high EF. Specifically, As, Cd, Cr, Cu, Ni, Pb, Sb, $\mathrm{Se}, \mathrm{Pb}, \mathrm{V}$, and $\mathrm{Zn}$, as well as $\mathrm{K}$ and $\mathrm{Na}$ were highly enriched the LG site during both the controlled and uncontrolled periods (Figure 4a). Similarly, the elements As, $\mathrm{Cd}, \mathrm{Cr}, \mathrm{Cu}, \mathrm{Mo}, \mathrm{Ni}, \mathrm{Pb}, \mathrm{Sb}, \mathrm{Se}, \mathrm{Pb}, \mathrm{V}$, and $\mathrm{Zn}$ were associated with an anthropogenic source at the PU site during both the controlled and uncontrolled periods (Figure $4 \mathrm{~b}$ ). 
The fact that these elements are highly enriched is consistent with many other studies in urban areas $[44,45]$. It is also important to note that, while the concentrations were increased during uncontrolled periods, the EF essentially did not change. Significant differences in EF, however, were observed between the two sites.

\subsection{Soluble Fe Oxidation State Analysis}

As most atmospheric Fe is crustally-derived, Fe(III) dominates the major part of total iron in the PM but its relative importance also depends on local sources and the size fraction [46]. For example, crustal Fe is primarily in the Fe(III) oxidation state and shows a solubility of $<1 \%$ [47], while ambient urban Fe shows solubility $\sim 10 \%-20 \%$, with a mixture of Fe(II) and Fe(III) [46], and Fe emitted directly from vehicles has been shown to be up to $70 \%$ water-soluble, being mostly Fe(II) sulfate [48]. Consequently, different locations exhibit different Fe solubility, depending on the dominant sources [46]. Our study shows Fe solubility of $7 \%$ and $15 \%$ during the controlled and uncontrolled periods, consistent with other urban sources. The oxidation state of the soluble Fe is shown in Figure 5. The majority of the soluble fraction was comprised of Fe(II) at the two sites both during controlled and uncontrolled periods. As Fe(III) is the dominant form of soluble Fe under oxidizing conditions [49], this implies that the PM contained other compounds which allowed the Fe to be stabilized in the reduced state. Possibilities include small chain organic acids, or even polycyclic aromatic hydrocarbons [50-52].
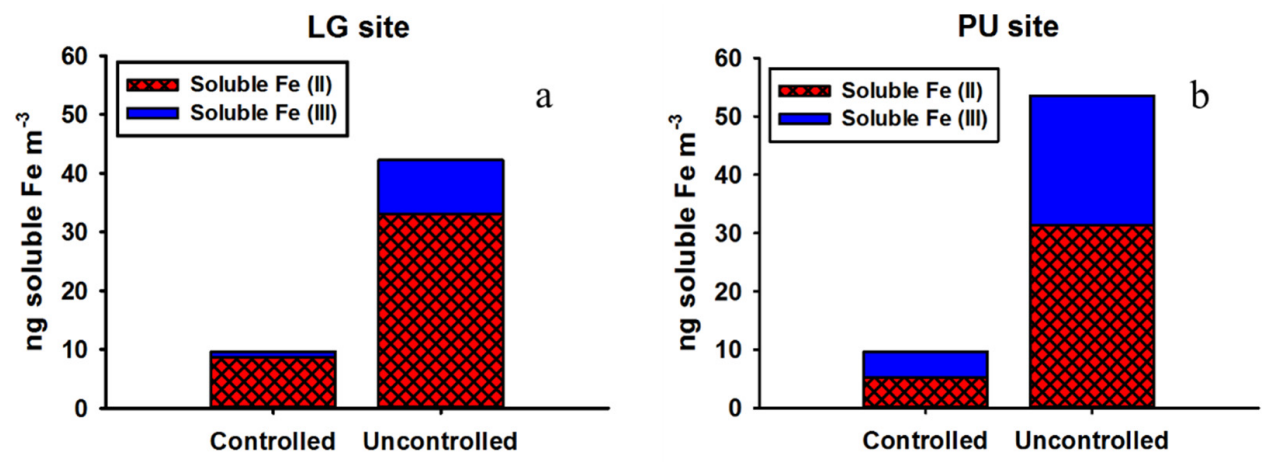

Figure 5. Soluble fractions of Fe(II) and Fe(III) at: (a) LG site; and (b) PU site.

At the LG site, the percent soluble Fe(II) of total iron collected on the filter was $5.9 \%$ during controlled periods and $12.2 \%$ during uncontrolled periods. Similarly, at the PU site, the percent soluble Fe(II) of total iron collected on the filter was $5.4 \%$ during controlled periods and $12.6 \%$ during uncontrolled periods. Of the soluble $\mathrm{Fe}, \mathrm{Fe}(\mathrm{II})$ was $82 \%$ during controlled periods and $86 \%$ during uncontrolled periods at the LG site. Similarly, at the PU site, Fe(II) was $56 \%$ of the total soluble, during 
controlled periods and $61 \%$ during uncontrolled periods. Significant differences in relative $\mathrm{Fe}(\mathrm{II}) / \mathrm{Fe}$ (III) solubility between the PU and LG site indicates different sources between sites. However, similarities in $\mathrm{Fe}(\mathrm{II}) / \mathrm{Fe}(\mathrm{III})$ solubility at each site suggest that the sources are similar during the controlled and uncontrolled periods.

\subsection{Stable Pb Isotope Ratios}

Anthropogenic activities like mining, industry, and utilization of fossil fuels and tetraethyl lead in gasoline significantly affect the $\mathrm{Pb}$ levels in the environment to varying degrees. In this study, the greatest differences in elemental concentrations were $\mathrm{Pb}$ (Figure 2). Thus, we focus on $\mathrm{Pb}$ isotope ratios to help determine if its origin was different during controlled and uncontrolled periods. $\mathrm{Pb}$ has four stable isotopes; ${ }^{204} \mathrm{~Pb},{ }^{206} \mathrm{~Pb},{ }^{207} \mathrm{~Pb}$, and ${ }^{208} \mathrm{~Pb}$ with the radioactive decay of ${ }^{238} \mathrm{U},{ }^{235} \mathrm{U}$, and ${ }^{232} \mathrm{Th}$ eventually producing ${ }^{206} \mathrm{~Pb},{ }^{207} \mathrm{~Pb}$, and ${ }^{208} \mathrm{~Pb}$, respectively. Depending on the geological history, different sources of $\mathrm{Pb}$ possess specific $\mathrm{Pb}$ isotopic signatures and these ratios do not fractionate during any chemical, physical, or biological process [53]. Therefore, $\mathrm{Pb}$ isotopic ratios are useful in distinguishing natural $\mathrm{Pb}$ from anthropogenic $\mathrm{Pb}$ and its origin in different ecosystems [53,54]. Stable $\mathrm{Pb}$ isotope ratios $\left({ }^{207} \mathrm{~Pb} /{ }^{206} \mathrm{~Pb}\right)$ in the range $0.7952-0.8405$ can be used as a tracer species to identify natural sources of $\mathrm{PM}$ whereas, ${ }^{207} \mathrm{~Pb} /{ }^{206} \mathrm{~Pb}$ ratio in the range of $0.8504-0.9651$ can be used to identify anthropogenic sources contributing to airborne PM $[55,56]$.

Ratios of ${ }^{207} \mathrm{~Pb} /{ }^{206} \mathrm{~Pb}$ versus ${ }^{206} \mathrm{~Pb} /{ }^{204} \mathrm{~Pb}$ are presented in Figure 6 for the airborne $\mathrm{PM}_{2.5}$ collected at the PU and LG sites during controlled and uncontrolled periods, with these ratios depending on local geology, rainfall, wind direction, and traffic $[57,58]$. The average ${ }^{207} \mathrm{~Pb} /{ }^{206} \mathrm{~Pb}$ ratios of the $\mathrm{PM}_{2.5}$ collected at the $\mathrm{LG}$ site during the controlled and uncontrolled periods are 0.8599 (range, $0.8567-0.8590$ ) and 0.8550 (range, $0.8536-0.8563$ ), respectively. Similarly, at the PU site, the average ${ }^{207} \mathrm{~Pb} /{ }^{206} \mathrm{~Pb}$ ratios during the controlled and uncontrolled periods are 0.8564 (range, $0.8525-0.8591$ ) and 0.8567 (range, $0.8539-0.8576$ ), respectively. These ratios suggest that $\mathrm{PM}_{2.5}$ has an anthropogenic $\mathrm{Pb}$ source [55], which is also in agreement with the high UCC EF. The ${ }^{206 \mathrm{~Pb}} /{ }^{204} \mathrm{~Pb}$ ratios at the PU and the LG sites during the controlled and uncontrolled periods were similar $(t$-test, $p<0.05)$, indicating similar $\mathrm{Pb}$ sources. The ${ }^{206} \mathrm{~Pb} /{ }^{204} \mathrm{~Pb}$ ratios between the two sites during the controlled and uncontrolled periods were also similar $(t$-test, $p<0.05)$. 


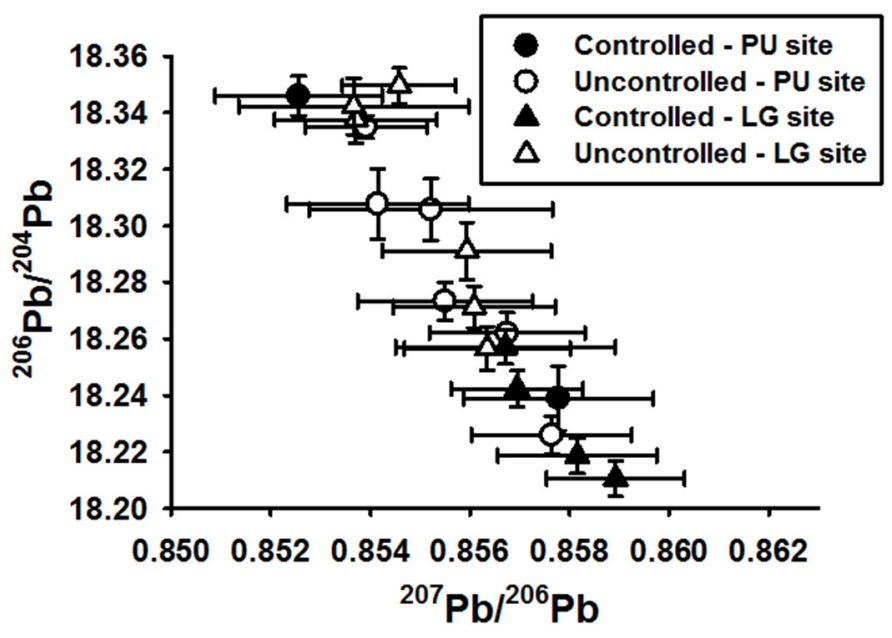

Figure 6. Isotopic composition of the $\mathrm{PM}_{2.5}$ collected at LG and PU sites during controlled and uncontrolled periods. The error bars represent the standard deviation of the $\mathrm{Pb}$ isotopic ratios for all samples.

Industry emissions, coal combustion, and vehicle exhaust are considered to be the three main sources of $\mathrm{Pb}$ pollution in China $[59,60]$. Previous studies have determined the ${ }^{207} \mathrm{~Pb} /{ }^{206} \mathrm{~Pb}$ ratios ranging from 0.850 to 0.872 for wide varieties of Chinese coal [61]. Leaded gasoline, which was phased out in the early 1990s [62], showed an average ${ }^{207} \mathrm{~Pb} /{ }^{206} \mathrm{~Pb}$ ratio of 0.901 , whereas unleaded exhaust showed the ratio of 0.872 in the PRD region [63]. The average ratio of ${ }^{206} \mathrm{~Pb} /{ }^{204} \mathrm{~Pb}$ observed for coal combustion and cement factories in Beijing ware 18.09 (range, 17.873-18.326) and 18.05 (range, 17.729-18.365), respectively [62]. There are about 26 coal power plants located in Guangdong Province, China [37]. Shenzhen is a major city in the Guangdong Province. These power plants are within $97 \mathrm{~km}$ of the sampling sites. A map of these power plants relative to the sampling sites is shown in Figure S1. Overall, the $\mathrm{PM}_{2.5} \mathrm{~Pb}$ ratios are similar to the $\mathrm{Pb}$ ratios observed for coal varieties, which implies that coal combustion may be the primary $\mathrm{Pb}$ source(s) between the sampling sites in this study and the previous study [61]. In addition, the Pb isotope ratios were significantly similar at each site during both controlled and uncontrolled periods. This suggests that local and regional sources affect these two sites in a similar manner.

\subsection{Source Identification Using Principal Component Analysis}

PCA was used to identify major sources of $\mathrm{PM}_{2.5}$. The results of the PCA for the combination of the two sites during controlled periods and uncontrolled periods are presented in the supplemental information (Tables S1 and S2). There were three 
factors contributing to the $\mathrm{PM}_{2.5}$ in Shenzhen during controlled periods whereas five factors were present during uncontrolled periods at the two sites. The difference in reported factors between two periods is determined on the basis of inflection point in the scree plots and, we have selected the interpretable factors.

At the two sampling sites, during controlled periods, the first principal component has elevated loadings of $\mathrm{Pb}, \mathrm{Zn}, \mathrm{K}^{+}, \mathrm{Al}, \mathrm{Na}^{+}, \mathrm{Se}$, and $\mathrm{OC}$, as shown in Table S1. The major sources of $\mathrm{PM}_{2.5}$ are categorized in several groups and these are: coal combustion (Se and $\mathrm{Pb}$ ), biomass burning $\left(\mathrm{K}^{+}\right.$and $\left.\mathrm{OC}\right)$, and vehicular abrasion ( $\mathrm{Zn}$ and $\mathrm{Sb}$ ) $[3,23,64]$. Therefore, we associate this factor with a mixture of combustion sources. We also note a potentially confounding correlation between Al and Se $\left(r^{2}=0.858\right)$, which is present at both sites and during both the controlled and uncontrolled periods. For the second factor, characteristic values for $\mathrm{V}$ and $\mathrm{Ni}$ are the highest, which are tracers of heavy oil combustion [65]. Apart from oil-fired power plants and industries, ship emissions may be a prominent source of such combustion in Shenzhen [66]. Also, the second factor has prominent values for $\mathrm{NH}_{4}{ }^{+}$and $\mathrm{SO}_{4}{ }^{2-}$, indicating the presence of secondary inorganic aerosols [67]. Sulfur dioxide would be emitted along with $\mathrm{Ni}$ and $\mathrm{V}$ during oil combustion. The third factor has high loadings of $\mathrm{Mg}^{2+}, \mathrm{Na}^{+}, \mathrm{NH}_{4}{ }^{+} \mathrm{SO}_{4}{ }^{2-}$, and $\mathrm{Cl}^{-}$, signifying this source was chiefly associated with partially aged sea salt [23], which is consistent with the fact that Shenzhen is a coastal city.

Table S2 represents the sources during the uncontrolled periods at the PU and LG sites. The first principal component shows high loadings of $\mathrm{NH}_{4}{ }^{+}, \mathrm{SO}_{4}{ }^{2-}$, and $\mathrm{Sb}$, which are associated with secondary inorganic aerosols and potentially brake wear [68]. The second factor has elevated $\mathrm{Al}, \mathrm{Se}$, and $\mathrm{K}^{+}$. $\mathrm{Al}$ is marker of crustal emissions and Se and $\mathrm{K}^{+}$are associated with coal combustion and biomass burning, respectively. Therefore, second factor is undetermined. High values of $\mathrm{Na}^{+}, \mathrm{Mg}^{2+}$, and $\mathrm{Cl}^{-}$are associated with sea salt spray for the third factor indicating that sea spray is a contributing factor to $\mathrm{PM}_{2.5}$ in Shenzhen regardless of wind direction. The fourth factor shows high values of $\mathrm{V}$ and $\mathrm{Ni}$, which are tracers of heavy oil combustion emissions. The fifth factor has high values of $\mathrm{Pb}$ and $\mathrm{OC}$, which is associated with combustion emission sources containing $\mathrm{Pb}$. This is consistent with the $\mathrm{Pb}$ isotope data that the source of $\mathrm{Pb}$ is similar at the two sites during controlled and uncontrolled periods.

\section{Conclusions}

The results of this study provide insights into the effects of pollution restrictions in Shenzhen, China. The average $\mathrm{PM}_{2.5}$ concentrations at the PU and LG sites during controlled periods were lower than 24-h mean ambient air quality standard of People's Republic of China of $75 \mu \mathrm{g} \cdot \mathrm{m}^{-3}$ [25]. Surprisingly, both Ni and V, markers for the residual oil combustion, had lower concentrations relative to other trace 
elements during uncontrolled periods at the two sampling sites, suggesting that oil combustion emissions were not controlled at all by the restrictions imposed during the Universiade event.

While it is possible that the soluble Fe(II)/Fe(III) ratio depends, to some extent, on the original Fe phases present in the PM, the equilibrium speciation in solution is primarily dependent on the immediate redox environment in the extract solution [49]. Thus, the presence of source-specific organic compounds [50] and ions [69] are the major determinants of Fe speciation and solubility. While this is the first study to measure Fe speciation and solubility in airborne $\mathrm{PM}_{2.5}$ in Shenzhen, China, it possesses similarities to previous Fe speciation studies. For instance, at the PU site, soluble Fe(II) and soluble Fe(III) were approximately equal, which was similar to the percentage of soluble Fe(II) at Waukesha, WI, USA [46]. Similarly, at the LG site, soluble Fe(II) was far greater than soluble Fe(III), which was similar to the results reported for Los Angeles, CA, USA [46] and Denver, CO, USA [70].

The ${ }^{206} \mathrm{~Pb} /{ }^{204} \mathrm{~Pb}$ ratios measured at the two sites during the controlled and uncontrolled periods, and between the two sites during the controlled and uncontrolled periods, were similar ( $t$-test, $p<0.05)$, representing a common anthropogenic $\mathrm{Pb}$ source. This suggests that airborne $\mathrm{PM}_{2.5}$ is dominated by local or regional combustion sources (as evidenced by the high $\mathrm{EF}$ ), which was in agreement with the principal component analysis.

Previous studies have presented elemental and water-soluble ion concentrations for airborne $\mathrm{PM}_{2.5}$ in southwest China [1,3]. The source apportionment based on positive matrix factorization (PMF) and chemical mass balances (CMB) revealed that coal combustion, secondary inorganic aerosols, biomass burning, metal industries, crustal dust, and sea spray were common sources in southwest China. The impact of control measures implemented before and during 2008 Olympics in Beijing showed $33 \%$ reduction in $\mathrm{BC}$ emissions [27] and controls implemented during the Universiade showed 30\% reduction in traffic [71,72] and 50\% reduction in $\mathrm{PM}_{2.5}$ [26]. Although the relative importance of each component varied, the major sources at the two sites during controlled and uncontrolled periods were identified as residual oil combustion, secondary inorganic aerosols, combustion, and sea spray which is also in agreement with the previous studies.

In our study, however, every metric was consistent (e.g., Pb isotopes, PM mass trends, EC/OC trends, and individual element trends) between sites. The $\mathrm{PM}_{2.5}$ levels in Shenzhen were mainly dominated by anthropogenic emissions. Reductions in emissions from point sources were observed, but it is unclear if this was due to the restrictions or from changes in meteorological conditions.

Supplementary Materials: The following are available online at http:/ /www.mdpi.com/ 2073-4433/7/4/57/s1, Figure S1: Map showing the location of the PU and LG sampling sites (shown as red stars) relative to the location of power plants in Guangdong Province; Table 
S1: Principal component loadings of selected elements and ions for PU and LG sites during controlled periods; Table S2: Principal component loadings of selected elements and ions for PU and LG sites during uncontrolled periods.

Acknowledgments: The authors thank Elizabeth Stone and Ibrahim Al-Naghemah for their help and guidance in water soluble ion measurements. We also thank Kate Smith at the Wisconsin State Lab of Hygiene for her assistance with the Pb isotopic ratios measurement. This study was supported by the National Natural Science Foundation of China (Grant No. 41375131 and 21307129) and the Key Research Program of Chinese Academy of Sciences (Grant No. KJZD-EW-TZ-G06-01-0). We thank the anonymous reviewers for their helpful input to improve the paper.

Author Contributions: For research articles with several authors, a short paragraph specifying their individual contributions must be provided. All authors conceived and designed the experiments; all authors performed the experiments; Nitika Dewan and Brian J. Majestic analyzed the data; all authors contributed reagents/materials/analysis tools; Nitika Dewan and Brian J. Majestic wrote the paper." Authorship must be limited to those who have contributed substantially to the work reported.

Conflicts of Interest: The authors declare no conflict of interest.

\section{References}

1. Hagler, G.S.; Bergin, M.H.; Salmon, L.G.; Yu, J.Z.; Wan, E.C.H.; Zheng, M.; Zeng, L.M.; Kiang, C.S.; Zhang, Y.H.; Lau, A.K.H.; et al. Source areas and chemical composition of fine particulate matter in the Pearl River Delta region of China. Atmos. Environ. 2006, 40, 3802-3815.

2. Yang, F.; Tan, J.; Zhao, Q.; Du, Z.; He, K.; Ma, Y.; Duan, F.; Chen, G.; Zhao, Q. Characteristics of $\mathrm{PM}_{2.5}$ speciation in representative megacities and across China. Atmos. Chem. Phys. 2011, 11, 5207-5219.

3. Tao, J.; Gao, J.; Zhang, L.; Zhang, R.; Che, H.; Zhang, Z.; Lin, Z.; Jing, J.; Cao, J.; Hsu, S.C. $\mathrm{PM}_{2.5}$ pollution in a megacity of southwest China: Source apportionment and implication. Atmos. Chem. Phys. 2014, 14, 8679-8699.

4. Dockery, D.W.; Pope, C.A.; Xu, X.; Spengler, J.D.; Ware, J.H.; Fay, M.E.; Ferris, B.G., Jr.; Speizer, F.E. An association between air pollution and mortality in six U.S. cities. N. Engl. J. Med. 1993, 329, 1753-1759.

5. Englert, N. Fine particles and human health-A review of epidemiological studies. Toxicol Lett. 2004, 149, 235-242.

6. Davidson, C.I.; Phalen, R.F.; Solomon, P.A. Airborne particulate matter and human health: A review. Aerosol. Sci. Tech. 2005, 39, 737-749.

7. Charlson, R.J.; Schwartz, S.E.; Hales, J.M.; Cess, R.D.; Coakley, J.A., Jr.; Hansen, J.E.; Hofmann, D.J. Climate forcing by anthropogenic aerosols. Science 1992, 255, 423-430.

8. Lee, Y.L.; Sequeira, R. Water-soluble aerosol and visibility degradation in Hong Kong during autumn and early winter, 1998. Environ. Pollut. 2002, 116, 225-233.

9. Deng, X.J.; Tie, X.X.; Wu, D.; Zhou, X.J.; Bi, X.Y.; Tan, H.B.; Li, F.; Hang, C.L. Long-term trend of visibility and its characterizations in the Pearl River Delta (PRD) region, China. Atmos. Environ. 2008, 42, 1424-1435. 
10. Chameides, W.L.; Yu, H.; Liu, S.C.; Bergin, M.; Zhou, X.; Mearns, L.; Wang, G.; Kiang, C.S.; Saylor, R.D.; Luo, C.; et al. Case study of the effects of atmospheric aerosols and regional haze on agriculture: an opportunity to enhance crop yields in China through emission controls? Proc. Natl. Acad. Sci. 1999, 96, 13626-13633.

11. Tsai, F.C.; Apte, M.G.; Daisey, J.M. An exploratory analysis of the relationship between mortality and the chemical composition of airborne particulate matter. Inhal. Toxicol. 2000, 12, 121-135.

12. Verma, V.; Polidori, A.; Schauer, J.J.; Shafer, M.M.; Cassee, F.R.; Sioutas, C. Physicochemical and toxicological profiles of particulate matter in Los Angeles during the October 2007 Southern California wildfires. Environ. Sci. Technol. 2009, 43, 954-960.

13. Valavanidis, A.; Fiotakis, K.; Bakeas, E.; Vlahogianni, T. Electron paramagnetic resonance study of the generation of reactive oxygen species catalysed by transition metals and quinoid redox cycling by inhalable ambient particulate matter. Redox Rep. 2005, 10, 37-51.

14. Shi, T.M.; Schins, R.P.F.; Knaapen, A.M.; Kuhlbusch, T.; Pitz, M.; Heinrich, J.; Borm, P.J.A. Hydroxyl radical generation by electron paramagnetic resonance as a new method to monitor ambient particulate matter composition. J. Environ. Monitor. 2003, 5, 550-556.

15. Prahalad, A.K.; Soukup, J.M.; Inmon, J.; Willis, R.; Ghio, A.J.; Becker, S.; Gallagher, J.E. Ambient air particles: Effects on cellular oxidant radical generation in relation to particulate elemental chemistry. Toxicol. Appl. Pharm. 1999, 158, 81-91.

16. Alloway, B.J. Heavy Metals in Soils; Blackie Academic \& Professional: Glasgow, UK, 1990.

17. Lee, C.S.; Li, X.D.; Shi, W.Z.; Cheung, S.C.; Thornton, I. Metal contamination in urban, suburban, and country park soils of Hong Kong: A study based on GIS and multivariate statistics. Sci. Total Environ. 2006, 356, 45-61.

18. Nriagu, J.O. A silent epidemic of environmental metal poisoning. Environ. Pollut. 1988, 50,139-161.

19. Thompson, C.M.; Markesbery, W.R.; Ehmann, W.D.; Mao, Y.X.; Vance, D.E. Regional Brain Trace-Element Studies in Alzheimers-Disease. Neurotoxicology 1988, 9, 1-8.

20. Bocca, B.; Alimonti, A.; Petrucci, F.; Violante, N.; Sancesario, G.; Forte, G.; Senofonte, O. Quantification of trace elements by sector field inductively coupled plasma mass spectrometry in urine, serum, blood and cerebrospinal fluid of patients with Parkinson's disease. Spectrochim Acta Part B At. Spectrosc. 2004, 59, 559-566.

21. Cao, J.J.; Lee, S.C.; Ho, K.F.; Zhang, X.Y.; Zou, S.C.; Fung, K.; Chow, J.C.; Watson, J.G. Characteristics of carbonaceous aerosol in Pearl River Delta Region, China during 2001 winter period. Atmos. Environ. 2003, 37, 1451-1460.

22. Cao, J.J.; Lee, S.C.; Ho, K.F.; Zou, S.C.; Fung, K.; Li, Y.; Watson, J.G.; Chow, J.C. Spatial and seasonal variations of atmospheric organic carbon and elemental carbon in Pearl River Delta Region, China. Atmos. Environ. 2004, 38, 4447-4456.

23. Dai, W.; Gao, J.; Cao, G.; Ouyang, F. Chemical composition and source identification of $\mathrm{PM}_{2.5}$ in the suburb of Shenzhen, China. Atmos. Res. 2013, 122, 391-400. 
24. Air quality Guidelines for Particulate Matter, Ozone, Nitrogen Dioxide and Sulfur Dioxide. Available online: http:/ /apps.who.int/iris/bitstream/10665/69477/1/WHO_ SDE_PHE_OEH_06.02_eng.pdf (accessed on 10 February 2016).

25. HORIBA Technical Reports-The Trends in Environmental Regulations in China. Available online: http://www.horiba.com/uploads/media/R41E_05_010_01.pdf (accessed on 10 February 2016).

26. Wang, Y.Q.; Zhang, Y.X.; Zhang, Y.; Li, Z.Q.; He, L.Y.; Huang, X.F. Characterization of carbonaceous aerosols during and post-Shenzhen UNIVERSIADE period. China Environ. Sci. 2014, 34, 1622-1632. (In Chinese)

27. Wang, X.; Westerdahl, D.; Chen, L.C.; Wu, Y.; Hao, J.M.; Pan, X.C.; Guo, X.B.; Zhang, K.M. Evaluating the air quality impacts of the 2008 Beijing Olympic Games: On-road emission factors and black carbon profiles. Atmos. Environ. 2009, 43, 4535-4543.

28. China. Available online: https://en.wikipedia.org/wiki/China (accessed on 13 April 2016).

29. Zhang, Y.; Zhang, Y.; Liu, H.; Wang, Y.; Deng, J. Design and application of a novel atmospheric particle sampler. Environ. Monit. China 2014, 30, 176-180.

30. NIOSH Manual of Analytical Methods. Available online: http://www.cdc.gov/niosh/ docs/2003-154/pdfs/5040.pdf (accessed on 2 February 2016).

31. Rolph, G.D. Real-Time Environmental Applications and Display System (READY); NOAA Air Resources Laboratory: Silver Spring, MD, USA, 2003.

32. Jayarathne, T.; Stockwell, C.E.; Yokelson, R.J.; Nakao, S.; Stone, E.A. Emissions of fine particle fluoride from biomass burning. Environ. Sci. Technol. 2014, 48, 12636-12644.

33. Stookey, L.L. Ferrozine-A new spectrophotometric reagent for iron. Anal. Chem 1970, 42, 779-781.

34. Majestic, B.J.; Schauer, J.J.; Shafer, M.M.; Turner, J.R.; Fine, P.M.; Singh, M.; Sioutas, C. Development of a wet-chemical method for the speciation of iron in atmospheric aerosols. Environ. Sci. Technol. 2006, 40, 2346-2351.

35. Schaug, J.; Rambaek, J.P.; Steinnes, E.; Henry, R.C. Multivariate-analysis of trace-element data from moss samples used to monitor atmospheric deposition. Atmos. Environ. Part A Gen. Top. 1990, 24, 2625-2631.

36. Elliott, A.C.; Woodward, W.A. IBM SPSS by Example: A Practical Guide to Statistical Data Analysis; SAGE Publications: Thousand Oaks, CA, USA, 2015.

37. List of major power stations in Guangdong. Available online: https://en.wikipedia.org/ wiki/List_of_major_power_stations_in_Guangdong (accessed on 1 March 2016).

38. Arimoto, R.; Duce, R.A.; Savoie, D.L.; Prospero, J.M.; Talbot, R.; Cullen, J.D.; Tomza, U.; Lewis, N.F.; Ray, B.J. Relationships among aerosols constituents from Asia and the North Pacific during PEM-West A. J. Geophys. Res. 1996, 101, 2011-2023.

39. Yao, X.; Chan, C.K.; Fang, M.; Cadle, S.; Chan, T.; Mulawa, P.; He, K.; Ye, B. The water-soluble ionic composition of $\mathrm{PM}_{2.5}$ in Shanghai and Beijing, China. Atmos. Environ. 2002, 36, 4223-4234.

40. Reimann, C.; Caritat, P.D. Intrinsic flaws of element Enrichment Factors (EFs) in environmental geochemistry. Environ. Sci. Technol. 2000, 34, 5084-5091. 
41. Buat-Menard, P.; Chesselet, R. Variable influence of the atmospheric flux on the trace metal chemistry of oceanic suspended matter. Earth Planet. Sci. Lett. 1979, 42, 399-411.

42. Taylor, S.R.; Mclennan, S.M. The geochemical evolution of the continental-crust. Rev. Geophys. 1995, 33, 241-265.

43. Cheung, K.; Daher, N.; Kam, W.; Shafer, M.M.; Ning, Z.; Schauer, J.J.; Sioutas, C. Spatial and temporal variation of chemical composition and mass closure of ambient coarse particulate matter $\left(\mathrm{PM}_{10-2.5}\right)$ in the Los Angeles area. Atmos. Environ. 2011, 45 , 2651-2662.

44. Clements, N.; Eav, J.; Xie, M.J.; Hannigan, M.P.; Miller, S.L.; Navidi, W.; Peel, J.L.; Schauer, J.J.; Shafer, M.M.; Milford, J.B. Concentrations and source insights for trace elements in fine and coarse particulate matter. Atmos. Environ. 2014, 89, 373-381.

45. Jiang, S.Y.N.; Yang, F.; Chan, K.L.; Ning, Z. Water solubility of metals in coarse PM and $\mathrm{PM}_{2.5}$ in typical urban environment in Hong Kong. Atmos. Pollut. Res. 2014, 5, 236-244.

46. Majestic, B.J.; Schauer, J.J.; Shafer, M.M. Application of synchrotron radiation for measurement of iron red-ox speciation in atmospherically processed aerosols. Atmos. Chem. Phys. 2007, 7, 2475-2487.

47. Cartledge, B.T.; Marcotte, A.R.; Herckes, P.; Anbar, A.D.; Majestic, B.J. The impact of particle size, relative humidity, and sulfur dioxide on iron solubility in simulated atmospheric marine aerosols. Environ. Sci. Technol. 2015, 49, 7179-7187.

48. Oakes, M.; Ingall, E.D.; Lai, B.; Shafer, M.M.; Hays, M.D.; Liu, Z.G.; Russell, A.G.; Weber, R.J. Iron solubility related to particle sulfur content in source emission and ambient fine particles. Environ. Sci Technol 2012, 46, 6637-6644.

49. Stumm, W.; Morgan, J.J. Aquatic Chemistry: An Introduction Emphasizing Chemical Equilibria in Natural Waters, 2nd ed.; Wiley: New York, NY, USA, 1981.

50. Pehkonen, S.O.; Siefert, R.; Erel, Y.; Webb, S.; Hoffman, M.R. Photoreduction of iron oxyhydroxides in the presence of important atmospheric organic compounds. Environ. Sci Technol 1993, 27, 2056-2062.

51. Barbas, J.T.; Sigman, M.E.; Buchanan, A.C.; Chevis, E.A. Photolysis of substituted naphthalenes on $\mathrm{SiO}_{2}$ and $\mathrm{Al}_{2} \mathrm{O}_{3}$. Photochem. Photobiol. 1993, 58, 155-158.

52. Paris, R.; Desboeufs, K.V. Effect of atmospheric organic complexation on iron-bearing dust solubility. Atmos. Chem. Phys. 2013, 13, 4895-4905.

53. Dickin, A.P. Radiogenic Isotope Geology, 2nd ed.; Cambridge University Press: Cambridge, UK, 2005.

54. Kendall, C.; McDonnell, J.J. Isotope Tracers in Catchment Hydrology, 1st ed.; Elsevier B.V.: Philadelphia, PA, USA, 1998; pp. 51-86.

55. Komerek, M.; Ettler, V.; Chrastny, V.; Mihailovic, M. Lead isotopes in environmental sciences: A review. Environ. Int. 2008, 34, 562-577.

56. Dewan, N.; Majestic, B.J.; Ketterer, M.E.; Miller-Schulze, J.P.; Shafer, M.M.; Schauer, J.J.; Solomon, P.A.; Artamonova, M.; Chen, B.B.; Imashev, S.A.; et al. Stable isotopes of lead and strontium as tracers of sources of airborne particulate matter in Kyrgyzstan. Atmos. Environ. 2015, 120, 438-446. 
57. Monna, F.; Lancelot, J.; Croudace, I.W.; Cundy, A.B.; Lewis, J.T. Pb isotopic composition of airborne particulate material from France and the southern United Kingdom: Implications for $\mathrm{Pb}$ pollution sources in urban areas. Environ. Sci. Technol. 1997, 31, 2277-2286.

58. Simonetti, A.; Gariepy, C.; Carignan, J. Pb and $\mathrm{Sr}$ isotopic compositions of snowpack from Quebec, Canada: Inferences on the sources and deposition budgets of atmospheric heavy metals. Geochim. Cosmochim. Acta 2000, 64, 5-20.

59. Chen, J.M.; Tan, M.G.; Li, Y.L.; Zhang, Y.M.; Lu, W.W.; Tong, Y.P.; Zhang, G.L.; Li, Y. A lead isotope record of shanghai atmospheric lead emissions in total suspended particles during the period of phasing out of leaded gasoline. Atmos. Environ. 2005, 39, 1245-1253.

60. Lee, C.S.L.; Li, X.D.; Zhang, G.; Li, J.; Ding, A.J.; Wang, T. Heavy metals and Pb isotopic composition of aerosols in urban and suburban areas of Hong Kong and Guangzhou, South China-Evidence of the long-range transport of air contaminants. Atmos. Environ. 2007, 41, 432-447.

61. Bollhofer, A.; Rosman, K.J.R. Isotopic source signatures for atmospheric lead: The Northern Hemisphere. Geochim. Cosmochim. Acta 2001, 65, 1727-1740.

62. Widory, D.; Liu, X.D.; Dong, S.P. Isotopes as tracers of sources of lead and strontium in aerosols (TSP \& $\mathrm{PM}_{2.5}$ ) in Beijing. Atmos. Environ. 2010, 44, 3679-3687.

63. Zhu, L.M.; Tang, J.W.; Lee, B.; Zhang, Y.; Zhang, F.F. Lead concentrations and isotopes in aerosols from Xiamen, China. Mar. Pollut. Bull. 2010, 60, 1946-1955.

64. Thurston, G.D.; Ito, K.; Lall, R. A source apportionment of U.S. fine particulate matter air pollution. Atmos. Environ. 2011, 45, 3924-3936.

65. Clayton, J.L.; Koncz, I. Petroleum Geochemistry of the Zala Basin, Hungary. Aapg. Bull. 1994, 78, 1-22.

66. Mueller, D.; Uibel, S.; Takemura, M.; Klingelhoefer, D.; Groneberg, D.A. Ships, ports and particulate air pollution-An analysis of recent studies. J. Occup. Med. Toxicol. 2011, 6, 1-6.

67. Zhang, R.; Jing, J.; Tao, J.; Hsu, S.C.; Wang, G.; Cao, J.; Lee, C.S.L.; Zhu, L.; Chen, Z.; Zhao, Y.; et al. Chemical characterization and source apportionment of $\mathrm{PM}_{2.5}$ in Beijing: Seasonal perspective. Atmos. Chem. Phys. 2013, 13, 7053-7074.

68. Garg, B.D.; Cadle, S.H.; Mulawa, P.A.; Groblicki, P.J. Brake wear particulate matter emissions. Environ. Sci. Technol. 2000, 34, 4463-4469.

69. Oakes, M.; Weber, R.J.; Lai, B.; Russell, A.; Ingall, E.D. Characterization of iron speciation in urban and rural single particles using XANES spectroscopy and micro $X$-ray fluorescence measurements: investigating the relationship between speciation and fractional iron solubility. Atmos. Chem. Phys. 2012, 12, 745-756.

70. Cartledge, B.T.; Majestic, B.J. Metal concentrations and soluble iron speciation in fine particulate matter from light rail activity in the Denver-Metropolitan area. Atmos. Pollut. Res. 2015, 6, 495-502. 
71. SZ News. Available online: http://sztqb.sznews.com/html/2011-08/08/content_1694922. htm (accessed on 8 February 2016). (In Chinese).

72. GD.Xinhuanet. Available online: http://www.gd.xinhuanet.com/newscenter/2011-06/ 01/content_22914683. htm (accessed on 8 February 2016). (In Chinese) 


\title{
Comparison of Land-Use Regression Modeling with Dispersion and Chemistry Transport Modeling to Assign Air Pollution Concentrations within the Ruhr Area
}

\author{
Frauke Hennig, Dorothea Sugiri, Lilian Tzivian, Kateryna Fuks, \\ Susanne Moebus, Karl-Heinz Jöckel, Danielle Vienneau, \\ Thomas A.J. Kuhlbusch, Kees de Hoogh, Michael Memmesheimer, \\ Hermann Jakobs, Ulrich Quass and Barbara Hoffmann
}

Abstract: Two commonly used models to assess air pollution concentration for investigating health effects of air pollution in epidemiological studies are Land Use Regression (LUR) models and Dispersion and Chemistry Transport Models (DCTM). Both modeling approaches have been applied in the Ruhr area, Germany, a location where multiple cohort studies are being conducted. Application of these different modelling approaches leads to differences in exposure estimation and interpretation due to the specific characteristics of each model. We aimed to compare both model approaches by means of their respective aims, modeling characteristics, validation, temporal and spatial resolution, and agreement of residential exposure estimation, referring to the air pollutants $\mathrm{PM}_{2.5}, \mathrm{PM}_{10}$, and $\mathrm{NO}_{2}$. Residential exposure referred to air pollution exposure at residences of participants of the Heinz Nixdorf Recall Study, located in the Ruhr area. The point-specific ESCAPE (European Study of Cohorts on Air Pollution Effects)-LUR aims to temporally estimate stable long-term exposure to local, mostly traffic-related air pollution with respect to very small-scale spatial variations $(\leqslant 100 \mathrm{~m})$. In contrast, the EURAD (European Air Pollution Dispersion)-CTM aims to estimate a time-varying average air pollutant concentration in a small area (i.e., $1 \mathrm{~km}^{2}$ ), taking into account a range of major sources, e.g., traffic, industry, meteorological conditions, and transport. Overall agreement between EURAD-CTM and ESCAPE-LUR was weak to moderate on a residential basis. Restricting EURAD-CTM to sources of local traffic only, respective agreement was good. The possibility of combining the strengths of both applications will be the next step to enhance exposure assessment.

Reprinted from Atmosphere. Cite as: Hennig, F.; Sugiri, D.; Tzivian, L.; Fuks, K.; Moebus, S.; Jöckel, K.-H.; Vienneau, D.; Kuhlbusch, T.A.J.; de Hoogh, K.; Memmesheimer, M.; Jakobs, H.; Quass, U.; Hoffmann, B. Comparison of Land-Use Regression Modeling with Dispersion and Chemistry Transport Modeling to Assign Air Pollution Concentrations within the Ruhr Area. Atmosphere 2016, 7, 48. 


\section{Introduction}

A large number of epidemiological studies have shown associations between short-and/or long-term exposure to outdoor air pollution and adverse health effects [1]. Traditionally, adverse health effects of air pollution have been divided into effects of short-term variations in air pollution concentrations, mainly influenced by meteorology, and effects of long-term exposure to air pollution, where contrasts rely on spatial variation of air pollution concentrations. Early approaches on assessing exposure to air pollution used average air pollution concentrations of the nearest monitoring station as a surrogate of personal exposure, assuming homogeneity among air pollution concentrations within the area surrounding the monitoring station, or even within the whole city [2]. Considering short-term health effects in ecological time-series studies on air pollution and mortality, it seems reasonable to assume such a spatially-uniform temporal elevation or reduction in air pollution concentration because they are dependent on the underlying meteorological conditions. When considering long-term health effects on an individual basis, however, the spatial and spatio-temporal variations are of great importance given that outdoor air pollution concentrations vary on a small spatial scale, e.g., within $100 \mathrm{~m}$ of a busy road [3]. More recent epidemiological studies have, thus, approached such small-scale intra-urban variation of air pollution concentrations by using different types of models, such as Land Use Regression (LUR) models, Dispersion Models (DM), chemistry Transport Model Models (CTM), a combination of DM+CTM (DCTM), hybrid models, or other alternatives [4,5].

The LUR method, first developed by Briggs et al. [6] in the Small Area Variations In Air quality and Health (SAVIAH study), uses linear (least squared) regression models to predict monitoring air pollution data with Geographic Information System (GIS)-based data reflecting pollutant conditions. Compared to other approaches, LUR models were built to predict temporally-stable long-term air pollution concentrations applicable to the smallest spatial scale (point-specific), e.g., home residences.

DMs are in general mathematical simulation models to estimate air pollution concentrations by means of numerical descriptions of deterministic (physical, chemical, and fluid dynamical) processes of the dispersion of air pollutants in the ambient atmosphere, and typically include data on emissions, meteorological conditions, and topography [3].

CTMs model the variability in space and time of chemical concentrations in the atmosphere, using three-dimensional numerical models to simulate processes of emission, transport, chemical transformation, diffusion and deposition, using emissions, meteorological information, and land use as input. Most often DMs and CTMs (DCTM) are combined in practice, resulting in spatio-temporal estimations. Usually DMs and CTMs estimate air pollution concentrations on a coarser spatial scale compared to the point-specific LUR, e.g., a grid of 1 or $5 \mathrm{~km}^{2}$. 
LUR models were developed to estimate exposure concentration at the finest spatial resolution and have been increasingly used in epidemiological studies due to their relatively low cost and easy implementation, developed either on the basis of purpose-designed monitoring campaigns or routine monitoring measurements and appropriate geographic predictors of sources [7]. In contrast, DCTMs have been developed for air quality, i.e., prediction, regulation and management, putting high demands on data requirements, costs and the complexity of modeling [6].

So far, only a few studies compared the performance of LUR and dispersion modeling for estimating exposure to nitrogen dioxide $\left(\mathrm{NO}_{2}\right)$. While some studies suggested that LUR models explained small-scale variations in air pollution concentrations as well or even better than various dispersion models [8-10], Beelen et al. [11] showed that the dispersion models performed better than LUR models regarding monitored and modeled concentrations on several validation sites. Most recently, de Hoogh et al. [12] investigated agreement between LUR and DM modeling approaches aiming to estimate residential exposure to $\mathrm{NO}_{2}$ and particulate matter $(\mathrm{PM})$ with an aerodynamic diameter $\leqslant 10 \mu \mathrm{m}$ and $\leqslant 2.5 \mu \mathrm{m}\left(\mathrm{PM}_{10}\right.$, $\mathrm{PM}_{2.5}$ ) within the European Study of Cohorts for Air Pollution Effects (ESCAPE). Comparisons across 4-13 cohorts, including the Heinz Nixdorf Recall (Risk Factors, Evaluation of Coronary calcium and Lifestyle) (HNR) study, located in the Ruhr area in Germany, yielded moderate to good correlations between LUR and DM (or DCTM) for $\mathrm{NO}_{2}(0.39-0.90)$ and for $\mathrm{PM}_{10}$ and $\mathrm{PM}_{2.5}$ (0.23-0.81). However, single correlation coefficients for the HNR study were below 0.4 for all three pollutants [12], raising the question of comparability of the two different exposure modelling approaches. So far, most studies on the comparison of different modeling strategies focused on the residential agreement of estimated exposure concentrations, disregarding the potential reasons for the disagreement between different modelling approaches, as well as respective strengths and limitations. Although all exposure metrics are equally used as a surrogate of personal exposure in epidemiological studies, exposure modeling is strongly influenced by the spatial and temporal variation of exposure and exposure sources [5]. Furthermore, aims, application, input data but also the complexity of models might differ, yielding not only different exposure estimates but consequently different health effect estimates in terms of magnitude and/or statistical significance [5,13].

In the Ruhr area in Germany, the location of multiple epidemiological studies, e.g., the Heinz Nixdorf Recall study, air pollution concentrations have been modeled with a LUR model as part of the European Study of Cohorts for Air Pollution Effects (ESCAPE-LUR), as well as with a European Air Quality and Dispersion Model which is a DCTM (EURAD-CTM) as part of several research projects investigating health effects of residential air pollution exposure. In this article, we aim to compare the ESCAPE-LUR model and the EURAD-CTM model focusing on their respective 
strengths and limitations. To do so, we compare model approaches by means of their respective aim, application characteristics, validation, temporal, and spatial resolution and by means of residential agreement. In addition, we evaluated the agreement of modeled air pollution concentrations by EURAD-CTM and measured air pollution concentrations at ESCAPE-LUR monitoring sites for overlapping time windows. Air pollutants of interest are $\mathrm{PM}_{2.5}, \mathrm{PM}_{10}$, and $\mathrm{NO}_{2}$.

\section{Methods}

\subsection{Study Area}

The Heinz Nixdorf Recall (Risk Factors, Evaluation of Coronary calcium and Lifestyle) (HNR) study area covers a region of approximately $600 \mathrm{~km}^{2}$ and is located in the highly urbanized Ruhr Area in the west of Germany, including the cities of Mülheim, Essen, and Bochum. In addition to that the HNR study area is located within N3, one of the smallest sequential nests developed for the air pollution modelling purposes of EURAD-CTM. We used locations $(\mathrm{x}, \mathrm{y})$ (Gauss-Krüger coordinates) of 4809 residences, located within the HNR study area. According to the Ruhr Regional Association, land use in the area can be roughly divided into agricultural $(\sim 40 \%)$, built-up $(\sim 40 \%)$, and forest and other regions (e.g., water) $(\sim 20 \%)$ [14]. The population density of the Ruhr area is about 2100 inhabitants per $1 \mathrm{~km}^{2}$, and in terms of traffic density the area is one of the densest in the whole of Europe (Figure 1). As an urban area, almost one fifth of the working population is occupied in the industrial sector. Among many industrial areas, the majority of steel and coal industry is located in Duisburg, in the west of the Ruhr area, including the biggest steelwork in Europe. Furthermore, Europe's largest inland harbor is located directly west of the study area in Duisburg. Intensive shipping takes place on the Rhine, which flows through Duisburg from south to north.

\subsection{Exposure Assesment}

\subsubsection{EURAD-CTM}

The EURAD-CTM model [15] is a validated time dependent three-dimensional chemistry transport model [16-19] developed to predict daily concentrations of air pollutants on a horizontal grid resolution of $1 \mathrm{~km}^{2}$ (Table 1). The EURAD-CTM model system is a multi-layer, multi-grid model system for the simulation of transport, chemical transformation, and deposition of tropospheric constituents [20], and consists of five major parts (Figure S1): (1) the meteorological driver version 3 (MM5V3) [21]; (2) two pre-processors for preparation of meteorological fields and observational data; (3) the EURAD Emission Model EEM [22], and (4) the Chemistry Transport Model (CTM); including (5) a model for aerosol dynamics in Europe 
(MADE) $[16,18,23,24]$. An additional procedure includes data assimilation on an hourly basis, using routine measurement data of monitoring sites in North Rhine-Westphalia (NRW) provided by the local environmental agency: State Agency for Nature, Environment, and Consumer Protection (LANUV-NRW) [25-27] (intermitted 3d-var) (Figure S1). EURAD-CTM calculations are performed using a one-way nesting scheme to take long-range transport into account. Nested grid domains ranged from a European scale (N0: $125 \mathrm{~km}$ ), to central Europe (N1: $25 \mathrm{~km}$ ), to NRW (N2: $5 \mathrm{~km}$ ) in Germany, to the Ruhr area $(\mathrm{N} 3: 1 \mathrm{~km})$, while the vertical resolution is the same for all model domains $(40 \mathrm{~m})([18,20])$. In addition to long-range transport, the formation of atmospheric gases and PM is also included in the model, i.e., the formation of secondary particles in the atmosphere from primary emitted gaseous pollutants from $\mathrm{NO}_{2}$, sulfur dioxide $\left(\mathrm{SO}_{2}\right)$, ammonia $\left(\mathrm{NH}_{3}\right)$, and Volatile Organic Compounds (VOC) during the transport [19]. Long-range transport and formation of secondary particles in the atmosphere can contribute considerably to the particle mass concentration in NRW and the Ruhr area, e.g., more than 50\% [28]. The EURAD-CTM is driven by emissions due to anthropogenic and biogenic sources [29]. Anthropogenic emissions are taken from officially-available databases as EMEP-grid [30] for Europe and from the LANUV-NRW. The EURAD-CTM emission input is further structured with respect to different source categories according to the Selected Nomenclature for Sources of Air Pollution (SNAP-97) [31], including traffic, industry, and other source categories.

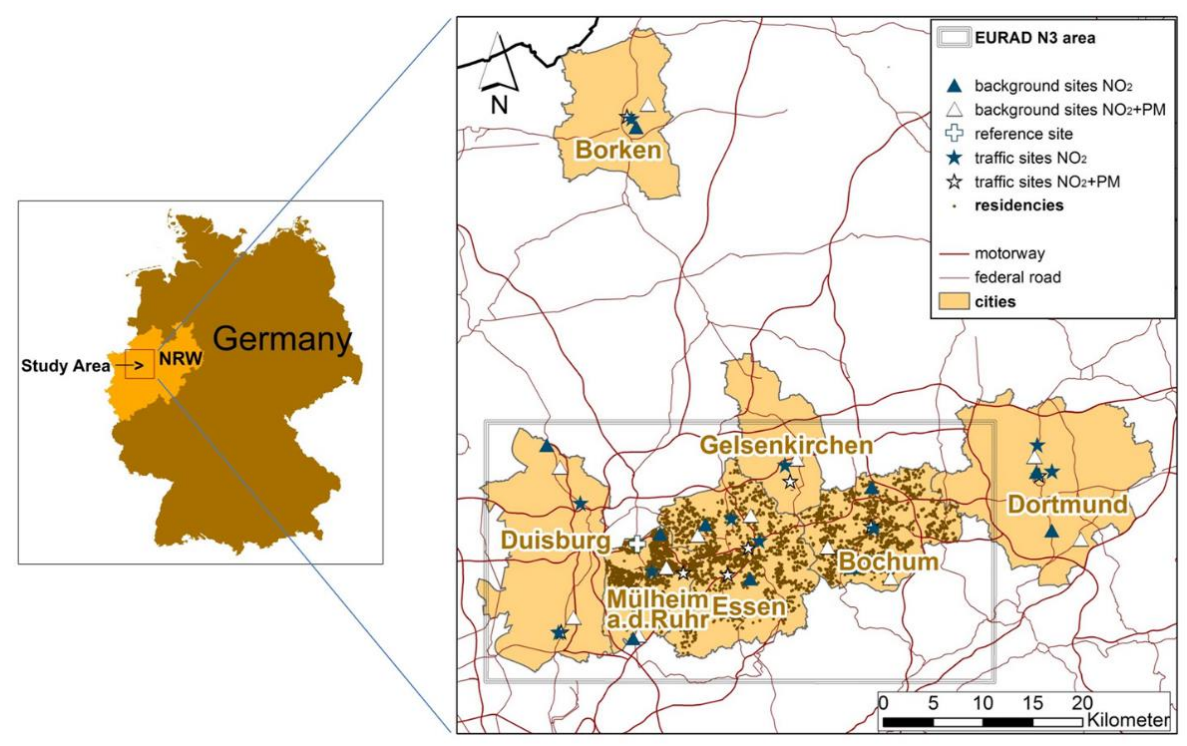

Figure 1. Study area, residences, and monitoring sites. 
Table 1. Characteristics of the ESCAPE-LUR and EURAD-CTM approaches to estimate air pollution concentrations.

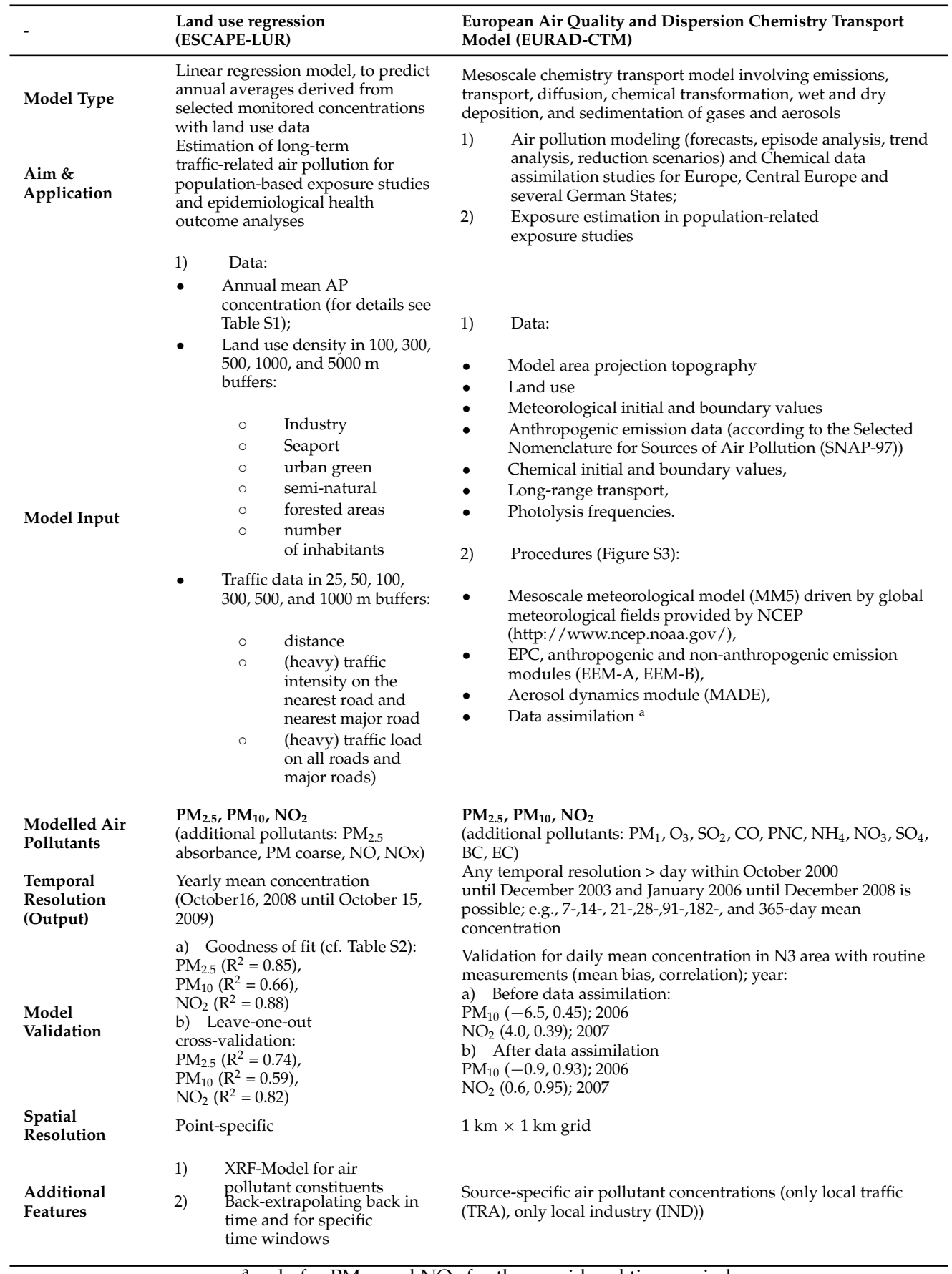

${ }^{\mathrm{a}}$ only for $\mathrm{PM}_{10}$ and $\mathrm{NO}_{2}$ for the considered time period. 
Output of the EURAD-CTM calculations consists of chemical compounds, such as atmospheric particle mass, number density, and particle size distribution, as well as concentration of atmospheric gases, photo oxidants, and a set of volatile organic compounds on an hourly basis for each grid. EURAD-CTM estimates of $\mathrm{PM}_{10}$ and $\mathrm{NO}_{2}$ concentrations are assimilated using measurements from all available routine monitoring sites within the region of interest. For the Ruhr area there exists a maximum of ten monitoring sites, including different air pollution data bases [25]. Using ArcView 9.2, location of residences were assigned to a $1 \times 1 \mathrm{~km}^{2}$-grid and then matched to the corresponding grid-based air pollutant concentration, allowing both short-term (daily mean concentrations) and long-term (annual mean concentrations) assignment of exposure. The basis of daily mean concentration allows us to calculate exposure for any temporal resolution with a minimum of one day. Model runs for the EURAD-CTM within N3 were done for the examination periods of the HNR study (2000-2003 and 2006-2008). Thus, we are able to assign exposure concentrations of yearly-mean concentrations for the years 2001, 2002, 2003, 2006, 2007, and 2008 and personalized exposure concentrations of 1-, 7-, 28-, 91-, 182-, and 365-day mean concentrations prior to the date of examination.

As an add-on feature it was possible to model source-specific Air Pollution (AP) concentration with EURAD-CTM [28]. Briefly, within EURAD-CTM we estimated AP concentration suppressing local sources within the smallest grid domain (N3), such as traffic and industry by setting to them to zero $\left(\mathrm{AP}_{\text {noTRA }}\right.$ or $\mathrm{AP}_{\text {noIND }}$ respectively). We then calculated local traffic-specific or industry-specific AP by taking the difference $\mathrm{AP}_{\mathrm{TRA}}=\mathrm{AP}-\mathrm{AP}_{\text {noTRA }}$ or $\mathrm{AP}_{\mathrm{IND}}=\mathrm{AP}-\mathrm{AP}_{\text {noIND }}$, respectively. In earlier studies, we applied this method to compare the health effects of PM, emitted from local traffic and local industrial sources within the Ruhr area on levels of highly-sensitive C-reactive protein, a marker of systemic inflammation [32].

\subsubsection{ESCAPE-LUR}

LUR models were developed to estimate temporally-stable spatial-variant concentrations of long-term exposure to traffic-related air pollutants as part of the ESCAPE study (Table 1). Following the definition of LUR describes a standardized model building procedure developed within the ESCAPE study, here the ESCAPE-LUR. The ESCAPE-LUR defines a linear prediction model for an air pollutant concentration, including annual mean air pollution concentrations as a dependent variable and geographic data on traffic, industry, and population density as potential predictors (independent variables). Predictor data were collected in a Geographical Information System (GIS), based on CORINE 2000 definitions [33]. The procedure of model development was standardized within the ESCAPE study and included a forward selection of predictors based on the incremental improvement in $\mathrm{R}^{2}$ [34-36]. A predictor was added if addition of 
the predictor yielded an improvement of $\mathrm{R}^{2}$ by more than $1 \%$, if the coefficient conformed to the pre-specified direction, and if the direction of previously selected predictors did not change. In addition, predictors with a $p$-value $>0.1$ were removed, while predictors with a variance inflation factor (VIF) $>3$ and Cook's Distance (Cook's D) >1 were further investigated. To avoid extrapolation, estimated concentrations were truncated at the highest observed value. Annual air pollution concentrations were based on a measurement campaign in the study area of interest, including three periods of a 14-day measurement to cover all seasons (cold, warm, and one intermediate temperature season) from October 2008 until October 2009. The reason for the choice of 14-days was the settings design of the ESCAPE-LUR measurement campaign, which was conducted with discontinuous particle measurement devices (Harvard impactors). Measurements were conducted at 20-40 monitoring sites, placed at locations which were characteristic of traffic and background pollutant concentrations to measure PM (at 20 sites) and $\mathrm{NO}_{2}$ (at 40 sites) (Figure 1, Table S1). One additional background reference site was chosen to measure $\mathrm{PM}$ and $\mathrm{NO}_{2}$ continuously during a complete year (starting in October 2008) so that all discontinuous site-specific measurements could be adjusted to derive a long-term annual average. Measurement data from the reference site was only used for adjustment and not for ESCAPE-LUR model development. A separate LUR model was developed for each air pollutant and validated via Leave-One-Out Cross Validation (LOOCV), excluding one monitoring site at a time. Other choices of model validation are possible, e.g., hold-out cross validation, which has recently been proposed to perform better [37]. However, in this manuscript we hold onto the ESCAPE-LUR.

Since ESCAPE included two cohorts located within NRW, namely the HNR study and the Study on the influence of air pollution on lung function, inflammation, and aging (SALIA), the ESCAPE-LUR measurement campaign was combined for both studies and ranged from the urban Ruhr area to the more rural city of Borken (Figure 1) [34,36]. ESCAPE-LUR for $\mathrm{PM}_{2.5}$ included heavy traffic load (1 km buffer), industry ( $5 \mathrm{~km}$ buffer), population density ( $1 \mathrm{~km}$ buffer), and the $\mathrm{x}$-coordinate of the location of interest as predictors with an explained variance of $\mathrm{R}^{2}$ $=0.85\left(\right.$ LOOCV-R $\left.{ }^{2}=0.74\right)$ (Table S2) [34]. ESCAPE-LUR for PM 10 included heavy traffic load (1 km buffer) and population density (1 km buffer) with an explained variance of $\mathrm{R}^{2}=0.66$ (LOOVC-R ${ }^{2}=0.59$ ) (Table S1) [34], ESCAPE-LUR for $\mathrm{NO}_{2}$ included industry (5 $\mathrm{km}$ buffer), population density (100 $\mathrm{m}$ buffer), inland or seaport (5 km buffer) and traffic load (100 m buffer) with an explained variance of $\mathrm{R}^{2}=0.88$ (LOOVC-R ${ }^{2}=0.82$ ) (Table S1) [36]. (Heavy) traffic load referred to total (heavy-duty) traffic load of all roads in a buffer (sum of (traffic intensity $\times$ length of all segments)), industry referred to industrial, commercial, and transport units in a certain buffer; inland or seaport referred to the respective area within a buffer and population 
density to the number of inhabitants in a certain buffer. Uncertainty was evaluated as residuum's mean squared error in the LOOCV-approach, which was 0.61 for $\mathrm{PM}_{2.5}$, 1.44 for $\mathrm{PM}_{10}$, and 3.19 for $\mathrm{NO}_{2}$.

Based on the coordinates of residence, located within the study area, annual mean concentrations were estimated using the ESCAPE-LUR prediction models and the relevant GIS predictors. In order to estimate AP concentration back in time, LUR modeling offers the method of back-extrapolation using a ratio or absolute difference method. Briefly, routine monitoring data should be available in order to account for differences of AP concentrations back in time [38]. Within the ESCAPE study, back-extrapolated AP estimations referred to a two year average ( \pm 365 days of the examination day) in order to avoid any time-specific outliers. An additional feature offered by ESCAPE-LUR is the possibility to estimate exposure concentration as an average per month or trimester, e.g., before pregnancy, which might be of interest when investigating birth cohorts.

\subsection{Statistical Analysis}

Conducted statistical analysis referred to air pollutants $\mathrm{PM}_{2.5}, \mathrm{PM}_{10}$, and $\mathrm{NO}_{2}$, estimated using the EURAD-CTM and the ESCAPE-LUR model. First, we described EURAD-CTM grid-based concentrations for the whole HNR study area for the years 2001-2003 and 2006-2008 by mean and standard deviation (mean \pm SD) as well as minimum and maximum (Min, Max). Secondly, we described residence-based exposures derived from the EURAD-CTM and from the ESCAPE-LUR by mean \pm SD (Min, Max) and Person's correlation coefficients for the most closely matched annual time-window: year 2008 for EURAD-CTM vs. annual mean ESCAPE-LUR (i.e., based on measurements from October 2008 until October 2009). Considered air pollutants were $\mathrm{PM}_{2.5}, \mathrm{PM}_{10}$, and the gas $\mathrm{NO}_{2}$. In addition, we calculated Spearman's correlation coefficient between 14-day mean air pollution concentrations measured at ESCAPE measurement sites (traffic and background) and 14-day mean air pollution concentrations calculated by EURAD-CTM for the grid cells that included an ESCAPE measurement site within the time period of October 2008-December 2008.

To evaluate an overall agreement between routinely measured air pollution concentrations, we compared annual mean concentrations of three routine monitoring stations provided by LANUV, located within the Ruhr area, and thus within EURAD specific grid cells (gc), with annual estimated air pollution concentrations estimated by EURAD-CTM and ESCAPE-LUR. Details of routine measurement stations are given in Table S3. Referred monitoring sites are the above mentioned reference site in Mülheim-Styrum (STYR) (gc: 679), an additional background site, located in Essen-Vogelheim (EVOG) (gc: 942), and one traffic site, located at a highly trafficked road in Essen (VESN) (gc: 690). For the comparison with the EURAD-CTM we considered annual mean concentrations from January 1, 2008 
until December 31, 2008, while for the comparison with the ESCAPE-LUR we considered annual means from October 16, 2008 until October 15, 2009 in order to match the time window of the ESCAPE measurement campaign. Annual mean concentrations modeled by the ESCAPE-LUR referred to the location (coordinate points) of monitoring sites. In addition to that we calculated Pearson's correlation coefficients between daily measurements of LANUV monitoring sites and daily estimations by EURAD-CTM for the year 2008.

With regard to different temporal resolution, we compared EURAD-CTM air pollution concentration estimates to measured air pollution concentrations on a monthly basis to yearly mean concentrations (2006, 2007, and 2008) estimated by EURAD-CTM in two of the above mentioned grid cells (679 and 690). In contrast we visualized time-dependent measurements of the two corresponding routine monitoring sites (STYR and VESN) on a monthly basis as well as the temporally stable air pollution concentration estimated by ESCAPE-LUR for the specific locations of routine monitoring sites. For ESCAPE-LUR values we used the original, not back-extrapolated values, since during the study period of 2006-2008, no substantial changes of long-term air pollutant concentrations were observed at the routine monitoring sites, therefore not having a meaningful influence on the back-extrapolated values.

With respect to the additional feature of source-specific estimation of air pollution concentrations, we further investigated the correlation of traffic-specific and industry-specific EURAD-CTM (EURAD-CTM TRA $_{\text {and EURAD-CTM }}$ IND, respectively) and ESCAPE-LUR concentrations at residence as well as at locations of specific ESCAPE measurement sites.

Statistical analysis were carried out with the statistical software R version 3.1.3 (2015-03-09) [39].

\section{Results and Discussion}

\subsection{Comparison of Residence-Based EURAD-CTM and ESCAPE-LUR}

Residence-based air pollution concentrations (for 4809 residences within the HNR study area) estimated by EURAD-CTM as yearly-mean air pollution concentrations for the years 2001-2003 (not including 2000 since modeling did not start before October 2000), 2006-2008 and estimated yearly mean air pollution concentrations by ESCAPE-LUR as well as back-extrapolated ESCAPE-LUR air pollution concentration estimates are presented in Table 2 for $\mathrm{PM}_{2.5}, \mathrm{PM}_{10}$, and $\mathrm{NO}_{2}$ and visualized in Figure 2 for the year 2008 (EURAD-CTM) and October 2008-October 2009 (ESCAPE-LUR), respectively. 
Table 2. Description of residence-based air pollutant exposure estimates $\mathrm{PM}_{2.5}$, $\mathrm{PM}_{10}$, and $\mathrm{NO}_{2}$ from EURAD-CTM and ESCAPE-LUR for 4809 residences within the HNR study area.

\begin{tabular}{|c|c|c|c|}
\hline- & $\begin{array}{c}\mathrm{PM}_{2.5} \\
\text { Mean } \pm \text { SD (Min, Max) }\end{array}$ & $\begin{array}{c}\text { PM }_{10} \\
\text { Mean } \pm \text { SD (Min, Max) }\end{array}$ & $\begin{array}{c}\mathrm{NO}_{2} \\
\text { Mean } \pm \mathrm{SD}(\mathrm{Min}, \mathrm{Max})\end{array}$ \\
\hline \multicolumn{4}{|c|}{ EURAD-CTM $\left(\mu \mathrm{g} / \mathrm{m}^{3}\right)$} \\
\hline 2001 year-mean & $16.6 \pm 1.5(14.0,21.6)$ & $21.2 \pm 2.9(17.0,30.1)$ & $42.2 \pm 4.2(28.2,55.4)$ \\
\hline 2002 year-mean & $16.8 \pm 1.4(14.3,21.2)$ & $20.4 \pm 1.9(16.7,27.0)$ & $39.3 \pm 3.8(27.5,50.2)$ \\
\hline 2003 year-mean & $18.2 \pm 1.4(15.5,22.7)$ & $22.4 \pm 3.3(17.8,32.4)$ & $42.7 \pm 4.1(30.1,56.1)$ \\
\hline 2006 year-mean & $16.2 \pm 1.3(13.9,21.2)$ & $21.0 \pm 3.7(16.5,34.2)$ & $40.0 \pm 4.8(27.1,57.2)$ \\
\hline 2007 year-mean & $15.7 \pm 1.3(13.4,20.3)$ & $19.8 \pm 2.9(15.7,30.8)$ & $37.7 \pm 4.5(26,53.7)$ \\
\hline 2008 year-mean & $14.6 \pm 1.1(12.5,19.0)$ & $18.0 \pm 2.3(14.9,25.1)$ & $37.5 \pm 3.9(26.3,47.9)$ \\
\hline \multicolumn{4}{|c|}{ ESCAPE-LUR $\left(\mu \mathrm{g} / \mathrm{m}^{3}\right)$} \\
\hline $\begin{array}{l}\text { back-extrapolated } \\
\text { (2-year averages) }\end{array}$ & - & $30.3 \pm 2.1(25.5,38.7)$ & $30.5 \pm 5.0(19.3,62.0)$ \\
\hline Year 2008-2009 & $18.4 \pm 1.0(16.0,21.4)$ & $27.7 \pm 1.8(23.9,34.7)$ & $30.1 \pm 4.9(19.8,62.4)$ \\
\hline \multicolumn{4}{|c|}{ Difference $\left(\mu \mathrm{g} / \mathrm{m}^{3}\right)$} \\
\hline $\begin{array}{c}\Delta \text { ESCAPE-LUR } \\
(2008-09) \\
\text { EURAD-CTM (2008) }\end{array}$ & $3.7 \pm 1.3(-0.7,7.0)$ & $9.8 \pm 2.4(0.9,16.5)$ & $-7.4 \pm 4.9(-26.8,18.9)$ \\
\hline
\end{tabular}

On a residential basis, estimated $\mathrm{PM}_{2.5}$ and $\mathrm{PM}_{10}$ concentrations revealed a consistent decline since 2006 (Table 2). Considering the back-extrapolated ESCAPE-LUR and ESCAPE-LUR, we also observed a decline over time. Observed declines are accounted for by ongoing nation- and state-wide air quality regulations.

Comparing EURAD-CTM (2008) and ESCAPE-LUR (2008-09), however, we saw that the overall mean of the ESCAPE-LUR was considerably higher compared to the overall yearly-mean of EURAD-CTM $\left(\Delta \mathrm{PM}_{2.5}=3.7 \pm 1.3 \mu \mathrm{g} / \mathrm{m}^{3}\right.$ and $\triangle \mathrm{PM}_{10}$ $9.8 \pm 2.4 \mu \mathrm{g} / \mathrm{m}^{3}$, respectively). Ranges for $\mathrm{PM}_{2.5}$ estimated by EURAD-CTM were slightly smaller than estimated by ESCAPE-LUR (5.4 vs. $\left.6.5 \mu \mathrm{g} / \mathrm{m}^{3}\right)$, while ranges for $\mathrm{PM}_{10}$ were more similar for both models $\left(10.8\right.$ vs. $\left.10.0 \mu \mathrm{g} / \mathrm{m}^{3}\right)$. Smaller ranges of air pollution concentrations from EURAD-CTM are not unexpected due to the smoothing pattern within $1 \mathrm{~km}^{2}$.

Explanations for the difference in mean concentrations for PM might be a consequence of the finer spatial resolution of the ESCAPE-LUR, since high exposure peaks in a very close proximity to busy roads are better captured with this model than with the EURAD-CTM, especially considering that residences are usually located close to the roads and not randomly distributed across a certain area. 


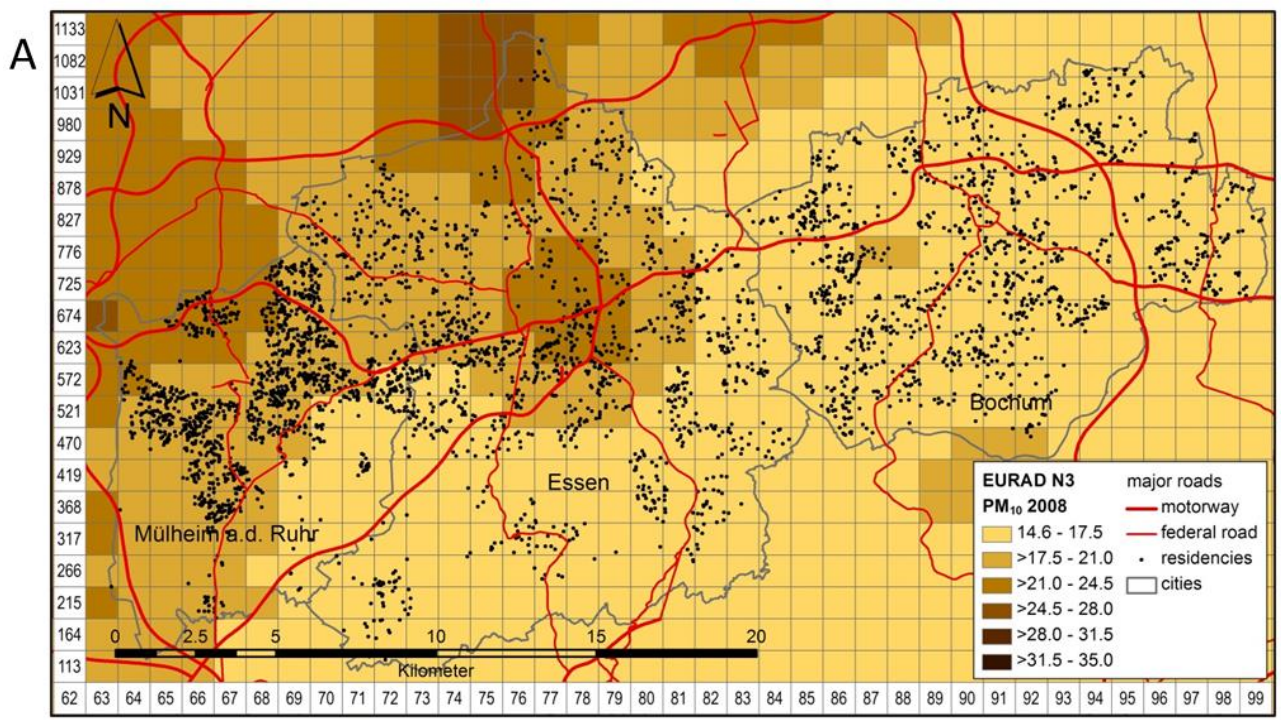

B

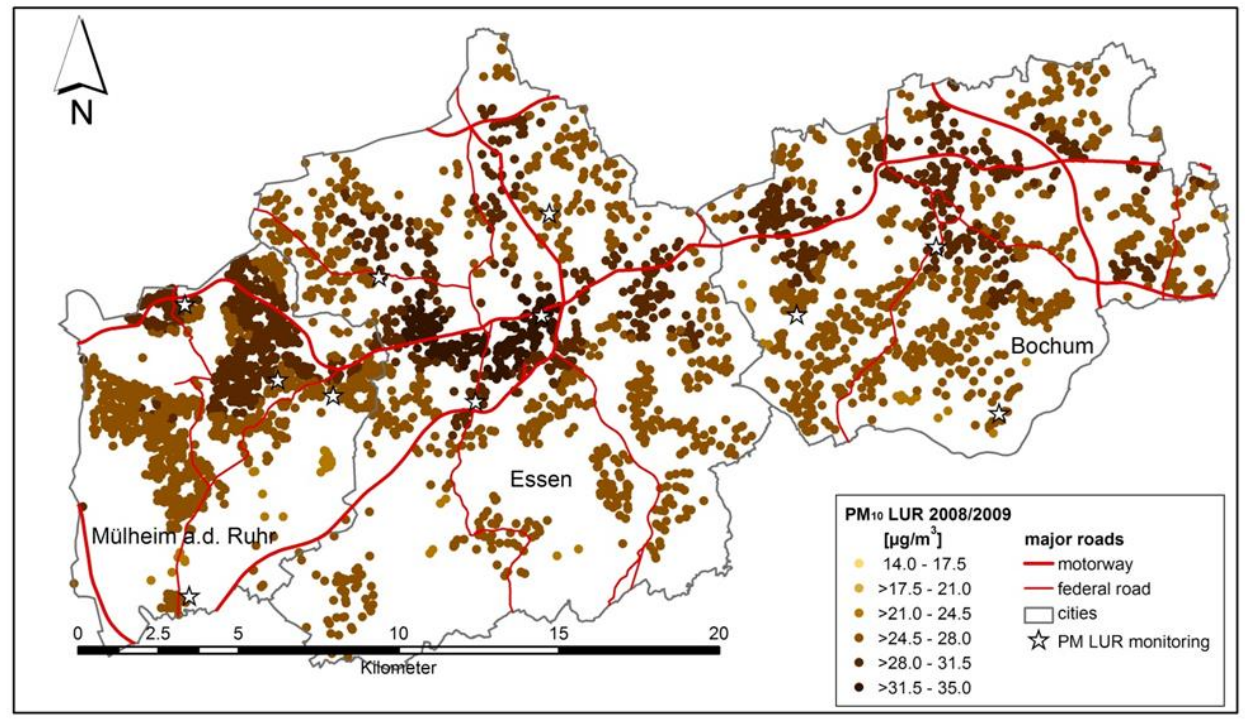

Figure 2. Spatial distribution of EURAD-CTM $\left(1 \mathrm{~km}^{2}\right.$, yearly mean $\left.2008,(\mathbf{A})\right)$ and ESCAPE-LUR (yearly mean October 2008-October 2009, (B)) at 4809 residences within the HNR study area for $\mathrm{PM}_{10}$.

Pearson's correlation coefficients between models were rather weak for both, $\mathrm{PM}_{2.5}$ and $\mathrm{PM}_{10}$, with 0.33 . This rather weak correlation has been reported earlier [12] and is not unexpected due to the different spatial resolution but also due to the different spatial distribution of PM concentrations for the two modelling approaches within the study area (Figure 2 and Figure S2): while we observed a west-to-east 
gradient for EURAD-CTM with higher concentrations in the west, estimated concentrations of ESCAPE-LUR revealed only a slight west-to-east gradient, which was prominently overlapped by an additional decreasing north-to-south and local hot spots, e.g., in Essen at a motorway intersection. In our study area the decreasing west-to-east gradient mirrors the distribution of industrial locations, e.g., metallurgical-industry and Europe's largest inland harbour in Duisburg, located to the west of the study area (Figure 1), as well as transported emissions from other countries in the west of study area, e.g., the Netherlands or Great Britain. The decreasing north-to-south gradient on the other hand is consistent with the population density and the location of major arterial roads within our study area [32].

$\mathrm{NO}_{2}$ concentrations estimated by EURAD-CTM showed an overall decrease between 2001 with $42.2 \mu \mathrm{g} / \mathrm{m}^{3}$ and 2008 with $37.7 \mu \mathrm{g} / \mathrm{m}^{3}$, while a change between the ESCAPE-LUR and the back-extrapolated ESCAPE-LUR was not observed. Yet, in contrast to $\mathrm{PM}$, temporally-stable $\mathrm{NO}_{2}$ concentrations estimated by ESCAPE-LUR were systematically lower than estimated by EURAD-CTM $\left(\Delta \mathrm{NO}_{2}=-7.4 \pm 4.9 \mu \mathrm{g} / \mathrm{m}^{3}\right)$. One explanation for this difference could be a misrepresentation of industrial sources within the ESCAPE modeling approach: "industry" referred to industrial, commercial and transport units in a certain buffer, giving no information of the emission of such sources. Ranges of concentrations, however, were twice as big for the ESCAPE-LUR compared to the EURAD-CTM (42.4 vs. $21.9 \mu \mathrm{g} / \mathrm{m}^{3}$ ), probably driven by greater small-scale variations due to point-specific estimates and the consideration of traffic load within a buffer of $100 \mathrm{~m}$. Unlike spatial gradients for $\mathrm{PM}_{2.5}$ and $\mathrm{PM}_{10}$, we observed a more pronounced northwest-to-southeast-gradient for EURAD-CTM for $\mathrm{NO}_{2}$, while the distribution of $\mathrm{NO}_{2}$ by ESCAPE-LUR did not reveal a clear gradient, but local hot spots near major roads or motorway intersections (Figure S2). Similar to PM, correlation between EURAD-CTM $\mathrm{NO}_{2}$ and ESCAPE-LUR $\mathrm{NO}_{2}$ was rather weak with a correlation coefficient of 0.4 .

\subsection{Comparison of Estimated and Measured Air Pollution Concentrations}

\subsubsection{Comparison between 14-Day Mean ESCAPE-LUR Measurements and EURAD-CTM Estimates}

In order to evaluate EURAD-CTM estimates we compared estimated 14-day mean AP concentrations by EURAD-CTM to available 14-day measurements taken during the ESCAPE measurement campaign. Descriptive statistics and correlation coefficients of these 14-day mean measured air pollution concentrations at ESCAPE measurement sites (background, traffic (cf. Table S2), and both) and the respective 14-day mean air pollution concentrations estimated by EURAD-CTM in 
the corresponding grid cells are shown in Table 3 for air pollutants $\mathrm{PM}_{2.5}, \mathrm{PM}_{10}$, and $\mathrm{NO}_{2}$.

Table 3. Description of 14-day mean measured air pollution concentrations at ESCAPE measurement sites (background and/or traffic) and 14-day mean air pollution concentration estimations of EURAD-CTM in the corresponding grid cells for $\mathrm{PM}_{2.5}, \mathrm{PM}_{10}$, and $\mathrm{NO}_{2}$.

\begin{tabular}{lccc}
\hline \multirow{2}{*}{ Background } & $\begin{array}{c}\text { ESCAPE Site } \\
\left(\mu \mathbf{g} / \mathbf{m}^{\mathbf{3}}\right)\end{array}$ & $\begin{array}{c}\text { EURAD-CTM } \\
\left(\mu \mathbf{g} / \mathbf{m}^{3}\right)\end{array}$ & $\begin{array}{c}\text { Spearman Correlation } \\
\text { Coefficient }(\boldsymbol{r})\end{array}$ \\
\cline { 2 - 3 } & Mean $\pm \mathbf{S D}$ & Mean $\pm \mathbf{S D}$ & 0.34 \\
\hline $\mathrm{PM}_{2.5}(\mathrm{~N}=9)$ & $17.78 \pm 2.40$ & $19.80 \pm 5.80$ & 0.93 \\
$\mathrm{PM}_{10}(\mathrm{~N}=9)$ & $26.12 \pm 4.70$ & $23.29 \pm 5.98$ & 0.34 \\
$\mathrm{NO}_{2}(\mathrm{~N}=16)$ & $37.85 \pm 6.21$ & $50.82 \pm 10.07$ & \\
\hline & \multicolumn{3}{c}{ traffic } \\
\hline $\mathrm{PM}_{2.5}(\mathrm{~N}=6)$ & $19.75 \pm 3.75$ & $21.78 \pm 6.96$ & 0.43 \\
$\mathrm{PM}_{10}(\mathrm{~N}=6)$ & $29.26 \pm 4.95$ & $26.97 \pm 7.68$ & 0.37 \\
$\mathrm{NO}_{2}(\mathrm{~N}=13)$ & $50.43 \pm 9.83$ & $58.04 \pm 10.33$ & 0.60 \\
\hline & \multicolumn{3}{c}{ Background + traffic } \\
\hline $\mathrm{PM}_{2.5}(\mathrm{~N}=15)$ & $18.57 \pm 3.05$ & $20.59 \pm 6.13$ & 0.45 \\
$\mathrm{PM}_{10}(\mathrm{~N}=15)$ & $27.37 \pm 4.89$ & $24.77 \pm 6.71$ & 0.77 \\
$\mathrm{NO}_{2}(\mathrm{~N}=29)$ & $43.49 \pm 10.13$ & $54.06 \pm 10.65$ & 0.55 \\
\hline
\end{tabular}

Overall, 14-day mean EURAD-CTM estimates for $\mathrm{PM}_{2.5}$ are slightly higher than mean of 14 daily measurements at the ESCAPE sites, while EURAD-CTM estimates for $\mathrm{PM}_{10}$ are slightly lower and EURAD-CTM estimates for $\mathrm{NO}_{2}$ are considerably higher, especially regarding the ESCAPE background site (Table 3).

The highest correlation coefficient $(r)$ was observed for $\mathrm{PM}_{10}$ between EURAD-CTM and ESCAPE background sites $(r=0.93)$, while the lowest correlation was observed for $\mathrm{PM}_{10}$ between EURAD-CTM and ESCAPE traffic sites $(r=0.37)$. This finding is not unexpected, regarding the aim, input, and construction of the two modeling approaches (Table 1): the EURAD-CTM aims to assess an average concentration in a $1 \mathrm{~km}^{2}$ grid cell, taking into account long-range transport rather than locally-emitted pollution, in contrast to the ESCAPE-LUR, which was specifically designed to assess mostly traffic-related differences in exposure concentration. For $\mathrm{PM}_{2.5}$, however, we did not observe a clear distinction between background and traffic sites, whereas correlation coefficients for $\mathrm{NO}_{2}$ were higher between EURAD-CTM and ESCAPE traffic sites $(r=0.60)$ than between EURAD-CTM and ESCAPE background sites $(r=0.34)$. One reason for the low to moderate correlation between $\mathrm{PM}_{2.5}$ modeled by EURAD-CTM and $\mathrm{PM}_{2.5}$ measured at ESCAPE sites could be the lack of the assimilation procedure within EURAD-CTM, since $\mathrm{PM}_{2.5}$ has 
only been measured at routine monitoring sites since 2009. So, for the considered period of time, estimated $\mathrm{PM}_{2.5}$ was only assimilated indirectly taking a (constant) proportion of $\mathrm{PM}_{10}$ and $\mathrm{PM}_{2.5}$ into account.

Overall, correlations between EURAD-CTM estimates and measured concentrations at all ESCAPE measurement sites were moderate for $\mathrm{PM}_{2.5}(r=0.45)$ and $\mathrm{NO}_{2}(r=0.55)$, and high for $\mathrm{PM}_{10}(r=0.77)$ and, therefore, slightly better than comparing residence-based modeled air pollution concentrations between EURAD-CTM and ESCAPE-LUR.

\subsubsection{Comparison between Routinely-Monitored and Estimated Air} Pollution Concentrations

Overall correlations between daily measurements at routine monitoring sites and EURAD-CTM estimations over one year (2008) were strong for $\mathrm{PM}_{10}$ and $\mathrm{NO}_{2}$ (>0.8) and moderate for $\mathrm{PM}_{2.5}(0.66-0.74)$ for both, background and traffic monitoring site (Table 4). This finding is a consequence of the assimilation procedure within EURAD-CTM for $\mathrm{PM}_{10}$ and $\mathrm{NO}_{2}$.

Taking into account absolute annual values, we observed several findings: annual averages for January 2008 until December 2008 differ considerably from annual averages from 16 October 2008 to 15 October 2009 (ESCAPE measurement period), for PM (Table 4). Generally, PM concentrations throughout Germany were at a minimum in 2008, as reported by the Federal Environment Agency [40]. This finding points to the importance of a fine temporal resolution even in medium- and long-term exposure estimations.

Considering uncertainty, the EURAD-CTM estimations underestimated PM and overestimated $\mathrm{NO}_{2}$ at background monitoring sites, while the ESCAPE-LUR estimations agreed well for $\mathrm{PM}_{2.5}$ (all sites) and $\mathrm{PM}_{10}$ (background sites), but tended to underestimate $\mathrm{NO}_{2}$ concentrations considerably (Table 4). The latter is supported by mean squared errors of the LOOCV, which were remarkably higher for $\mathrm{NO}_{2}$ than for PM. Furthermore, we observed considerable disagreement between predicted ESCAPE-LUR PM 10 and measured $\mathrm{PM}_{10}$ at the routine monitoring traffic-site. This finding might be a consequence of the disagreement between $\mathrm{PM}_{10}$ measured at the routine monitoring site and the measured $\mathrm{PM}_{10}$ at the closest ESCAPE site (26.64 vs. $32.70 \mu \mathrm{g} / \mathrm{m}^{3}$ ), which were located only $2.2 \mathrm{~m}$ away from each other. 


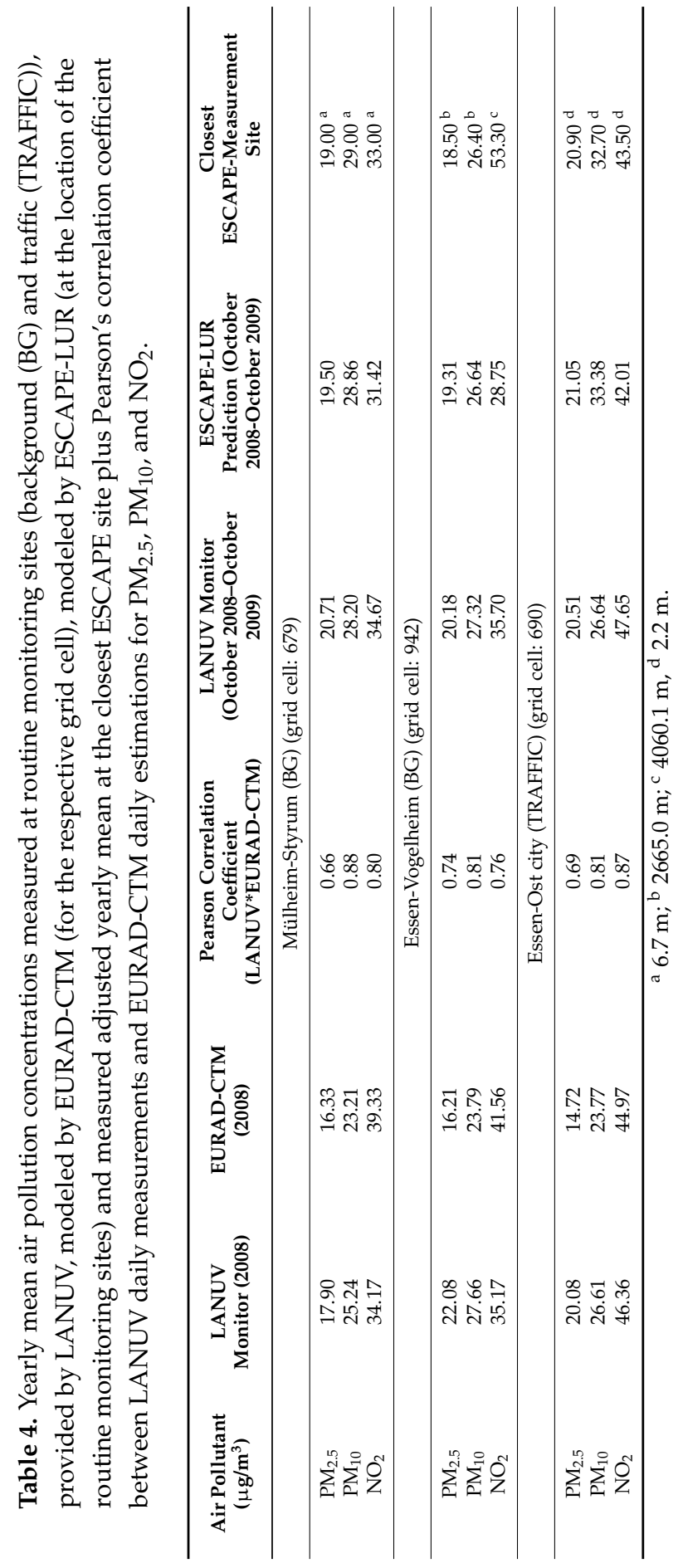




\subsection{Temporal Resolution of Air Pollution Concentrations}

Regarding different years (2006-2008) we saw a weak time-dependent decline in PM concentrations (Table 2), in line with the observed overall decline in PM concentrations from the year 2001 to 2008 within the HNR study area [29]. To examine the temporal resolution on a monthly basis, Figure 3 and Figure S3 present monthly distributions of EURAD-CTM estimated air pollution concentrations of $\mathrm{PM}_{10}, \mathrm{PM}_{2.5}$, and $\mathrm{NO}_{2}$ respectively, in two grid cells, including one background grid cell (679) and one traffic routine monitoring site grid cell (690), presenting spatial variation. For the purpose of comparison, yearly mean air pollution concentrations estimated with EURAD-CTM for the two grid cells as well as the temporally-stable ESCAPE-LUR air pollution concentrations estimated at the locations of the monitoring sites, and monthly-based measured air pollution concentration at routine monitoring sites are presented as lines. Overall, we observed strong seasonal variation (high in winter and low in summer) for estimated EURAD-CTM air pollution concentrations and measured air pollution concentrations, which cannot be detected when using the temporally stable ESCAPE-LUR estimates. While ESCAPE-LUR estimates are primarily designed to yield long-term exposure estimates without temporal resolution, the integration of other measurements (i.e., from routine monitoring sites), or other measurement periods (e.g., three month instead of one year), can be used to derive LUR-data for the analysis of medium-term health effects [41], although not covered in this manuscript.
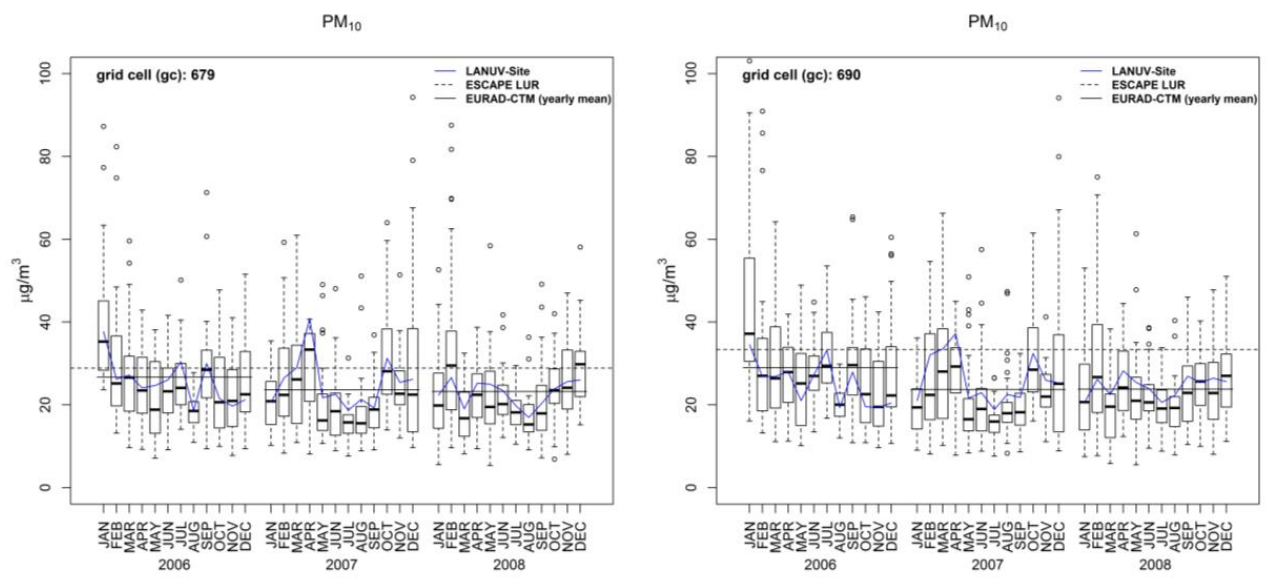

Figure 3. Box plots of air pollution concentrations of $\mathrm{PM}_{10}$ over time for two grid cells (gc), representing background (gc: 679) and traffic (gc: 690), estimated by EURAD-CTM on a monthly and yearly basis, long-term ESCAPE-LUR estimation and measured at monitoring sites on a monthly basis (median per month). 
The seasonal patterns differed slightly across years and air pollutants (Figure 3 and Figure S3). Reasons for such differences might be specific meteorological conditions during the observation period as well as different chemical processes differentially influencing the concentration of the examined air pollutants, e.g., regarding transport, deposition or physical and chemical aging. These observed seasonal changes underscore the importance of time-dependent air pollution models for the analysis of short- and medium-term health effects. When using a LUR for short- and medium-term exposures, a finer temporal resolution can be achieved using back-extrapolation based on routine monitoring sites, as has been applied for birth outcomes in the framework of ESCAPE [41]. Furthermore, estimated $\mathrm{PM}_{2.5}$ by EURAD-CTM, although following the seasonal pattern of measured $\mathrm{PM}_{2.5}$, was considerably under-estimated, reflecting the lack of data assimilation within this modeling procedure. In contrast to the temporal variation over the considered time period, the spatial variation, presented by the two locations of a background and traffic site, is considerably smaller. This finding is in line with earlier findings, indicating a slightly higher temporal, than spatial, variation of particle number concentrations within the Ruhr area [42].

\subsection{Source-Specific EURAD-CTM}

Estimated local traffic-specific (TRA) and local industry-specific (IND) air pollution concentrations take up only a small amount of all sources: for $\mathrm{PM}_{2.5}$ local traffic takes up $3.4 \%$ and local industry $9.6 \%$; for $\mathrm{PM}_{10}$ it is $2.7 \%$ and $10.5 \%$, respectively, and for $\mathrm{NO}_{2}$ it is $21.4 \%$ and $2.4 \%$, respectively. Correlation coefficients between PM concentrations, including all sources and including only local traffic, were weak (0.34-0.43), while all-sources PM and industry-specific PM correlated well (0.73-0.96) (Figure 4). Correlation coefficients for $\mathrm{NO}_{2}$ were, in contrast to PM, higher between all sources and local-traffic (0.63) and lower for industry-specific (0.44). The rather small amount of local traffic-and industry-specific concentrations is not surprising considering that long-range transport and formation of secondary particles in the atmosphere can contribute considerably to the particle mass concentration in North-Rhine-Westphalia and the Ruhr area, sometimes more than $50 \%$ depending on the meteorological situation [28]. The spatial distribution within the study area, represented by quintiles of respective $\mathrm{PM}_{10}$ distributions (Figure 4), illustrates that the agreement between all sources and industry-specific sources is better than between all sources and traffic-specific PM. Due to substantial industrial emissions from the Duisburg inland harbor and the adjacent industrial area west of the study region, a strong west-east gradient can be observed for industry-specific PM and for all sources PM. The spatial distribution traffic-specific PM follows closely the population-density in the study area, with a strong north-to-south gradient. 
The associations between residence-based exposure estimates derived from

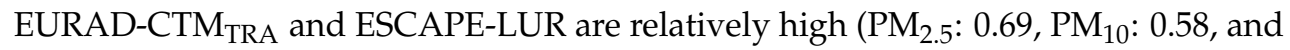
$\mathrm{NO}_{2}$ : 0.45), while they are expectedly considerably lower for EURAD-CTM IND and ESCAPE-LUR $\left(\mathrm{PM}_{2.5}: 0.16, \mathrm{PM}_{10}: 0.0\right.$, and $\left.\mathrm{NO}_{2}: 0.25\right)$ (Table 5). Such patterns are displayed for $\mathrm{PM}_{10}$ in the spatial distribution of traffic-specific EURAD-CTM and ESCAPE-LUR and industry-specific EURAD-CTM and ESCAPE-LUR, respectively (Figure 4). A similar pattern is observed taking into account correlations for 14-day mean measurements at ESCAPE monitoring stations (background and traffic) and estimated 14-day mean EURAD-CTM TRA within respective grid cells (Table 5).

Table 5. Spearman correlation coefficients between 14-day series of measurements at ESCAPE-LUR- monitoring stations and 14-day mean estimations of EURAD-CTM $_{\text {TRA }}$ in respective grid cells.

\begin{tabular}{cccc}
\hline $\begin{array}{c}\text { EURAD-CTM } \\
\text { (Traffic-Specific) }\end{array}$ & $\begin{array}{c}\text { ESCAPE Background } \\
\text { Sites }\end{array}$ & $\begin{array}{c}\text { ESCAPE Traffic } \\
\text { Sites }\end{array}$ & $\begin{array}{c}\text { All ESCAPE } \\
\text { Sites }\end{array}$ \\
\hline $\mathrm{PM}_{2.5}$ & $0.69(n=9)$ & $0.88(n=6)$ & $0.77(n=15)$ \\
$\mathrm{PM}_{10}$ & $0.02(n=9)$ & $0.83(n=6)$ & $0.32(n=15)$ \\
$\mathrm{NO}_{2}$ & $0.57(n=16)$ & $0.79(n=13)$ & $0.63(n=29)$ \\
\hline
\end{tabular}

These observations indicate that EURAD-CTM and ESCAPE-LUR do not represent identical aspects of air pollution: while EURAD-CTM represents an area average similar to urban background concentrations, the ESCAPE-LUR was designed to predominantly estimate variability in local traffic-related air pollution, leading to a comparatively high correlation with local traffic-specific air pollution concentrations modeled by EURAD-CTM. The very low correlation with local industry-specific air pollution concentration at the residences indicates, that ESCAPE-LUR represents industry rather poorly compared to EURAD-CTM, where the overall spatial distribution (Figure 3) is mainly driven by industrial sources as has been observed in a previous study [32]. 

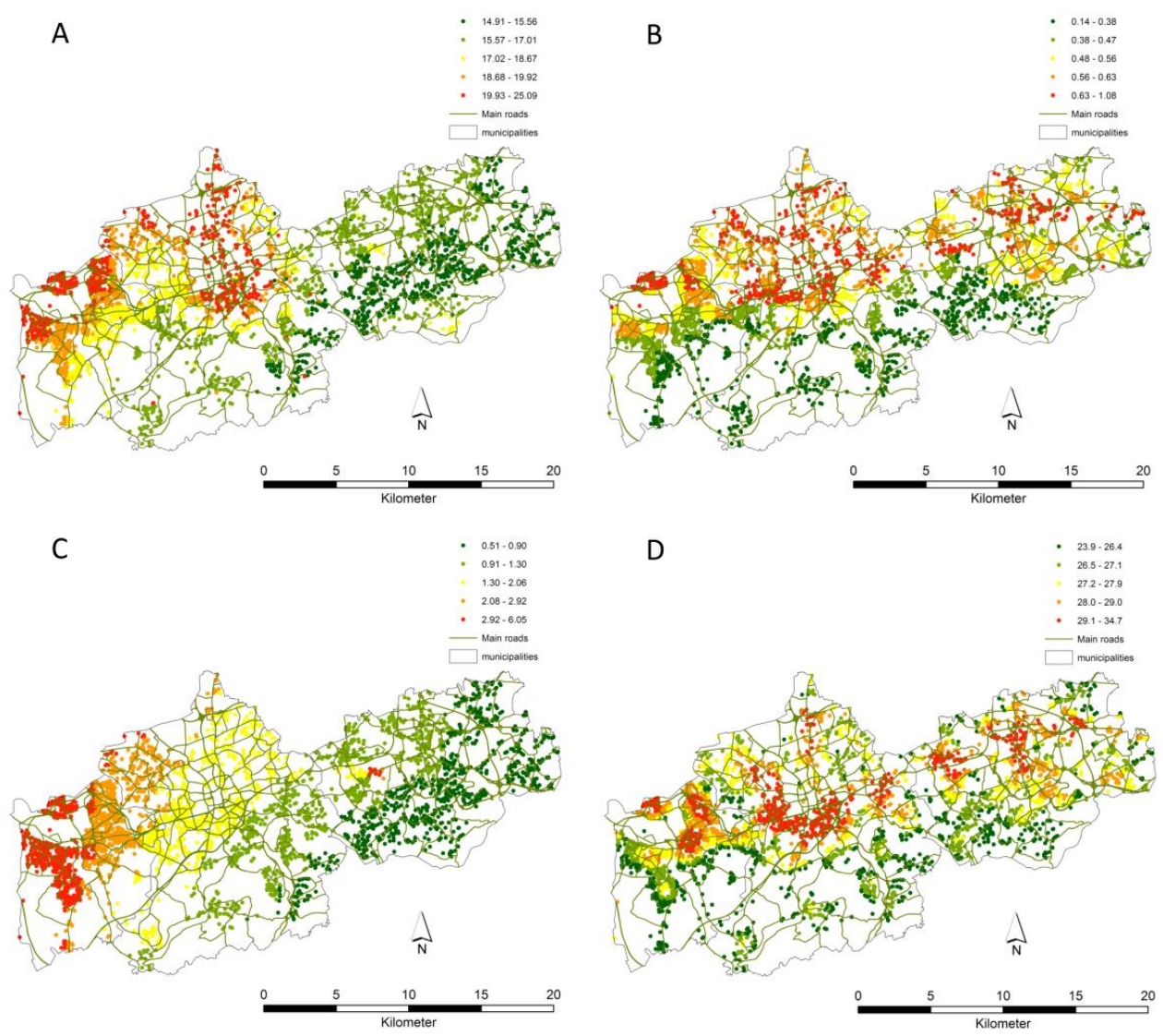

Figure 4. Residence-based spatial distribution of $\mathrm{PM}_{10}$ concentrations from EURAD-CTM: all-sources (A); local traffic (B) and local industry (C); and ESPCAPE-LUR (D).

\section{Conclusions}

Based on the comparison between air pollution concentrations modeled by ESCAPE-LUR and EURAD-CTM within the HNR study area, we showed that both model types have different input data as well as different temporal and spatial resolutions, driven by their different aims and application. While the point-specific ESCAPE-LUR primarily aims to estimate temporally stable and spatial variable long-term exposure to locally-emitted (mostly traffic-related) air pollution with a very high spatial resolution, the EURAD-CTM aims to estimate a spatio-temporal average air pollutant concentration in a small area (i.e., $1 \mathrm{~km}^{2}$ ), taking into account a range of major sources, e.g., traffic, industry, meteorological condition, and transport. While the observed weak to moderate overall agreement between the ESCAPE-LUR and the EURAD-CTM supports earlier findings [12], our analysis showed that the 
agreement between the two models improved considerably after restricting the EURAD-CTM to local traffic only. This finding was further supported by results comparing 14-day mean concentrations estimated by EURAD-CTM and measured at purpose-specific ESCAPE monitoring sites, yielding the highest correlations for traffic-specific EURAD-CTM estimates and measurements at traffic sites.

One of the principal strengths of the point-specific ESCAPE-LUR is to capture very small-scale variations in air pollution. Yet, this accuracy may be more error-prone than the coarser spatial resolution of $1 \mathrm{~km}^{2}$ used by EURAD-CTM, regarding exposure assignment in cases of high personal mobility within small distances, like daily chores around the residence. The biggest strength of an LUR approach in general is the wide-ranging applicability, like the relatively small requirements on measurement sites (low cost), the individual location of measurement sites, the easy assessment of land use data, and the straight forward model building procedure, based on linear regression modeling. In contrast, the EURAD-CTM, or chemical transport and dispersion modeling approaches in general, are less accessible to changes by the user due to the highly complex underlying mathematical, physical, and chemical modelling procedures. These complex procedures are, however, accompanied with benefit of including chemical transport actions, which allow modeling air pollution components that have not been measured. The LUR, on the other hand, is limited to modelling measured air pollutants. Moreover, CTMs enable the investigation of the role of meteorology and the prediction of air pollutant concentrations under hypothetical emission situations.

The comparatively easy applicability of LUR modeling and statistical model building procedure may come along with potential costs of wrong decisions: the initial choice of locations of the measurement sites limits the specificity of the model to capture those emission sources, whose concentration gradients are well captured by the chosen sites and may fail to capture all important source-specific concentration gradients across a study area, especially if important sources change over time. Restricting predictors to land use data might neglect important predictors of air pollution concentrations from other sources and processes, like chemical interaction and transport. Similarly, CTMs are only valid if based on a comprehensive and detailed emission database. To overcome limitations of each of the models and optimally make use of the respective strengths, we propose to combine the two approaches into a hybrid model $[43,44]$. These hybrid models are usually based on the LUR model since LURs are by design much easier to modify.

To conclude, our results show that ESCAPE-LUR and the EURAD-CTM are constructed to estimate complementary aspects of air pollution and both approaches have respective strengths and limitations, which need to be considered especially when investigating health effects. The possibility of combining the strengths of both, e.g., using hybrid models will be the next step to enhance exposure assessment. 
Supplementary Materials: The following are available online at www.mdpi.com/2073$4433 / 7 / 3 / 48 /$ s1. Figure S1: Flowchart of the EURAD model system containing the meteorological driver MM5, the pre-processors ECP and PREP, the emission model EEM and the chemistry transport model EURAD (input parameters are shaded in blue, output parameters are shaded in yellow and procedural parts are shaded in green or magenta), Figure S2: Spatial distribution of EURAD-CTM $\left(1 \mathrm{~km}^{2}\right.$, yearly mean 2008) and ESCAPE-LUR (point-specific yearly mean October 2008-October 2009) at 4809 residences within the HNR study area for $\mathrm{PM}_{10}(\mathrm{~A}+\mathrm{C})$ and $\mathrm{NO}_{2}(\mathrm{~B}+\mathrm{D})$, Figure S3: Boxplots of air pollution concentrations of monthly-mean $\mathrm{PM}_{10}$ and $\mathrm{NO}_{2}$ concentrations over three year for a traffic-specific (grid cell: 690), and a background-specific location (grid cell: 679) with annual mean ESCAPE-LUR estimates and annual measurements at LANUV monitoring sites, Table S1: Time and locations of the ESCAPE-measurement campaign, Table S2: ESCAPE-LUR for $\mathrm{PM}_{2.5}, \mathrm{PM}_{10}$ and $\mathrm{NO}_{2}$, Table S3: Time and Location of routine monitoring sites, provided by LANUV, within the HNR study area.

Acknowledgments: The research leading to these results has received funding from the European Community's Seventh Framework Program (FP7/2007-2011) under grant agreement number: 211250; The study was supported by the Heinz Nixdorf Foundation (chairman: M. Nixdorf; former chairman: G. Schmidt (deceased)) and the German Ministry of Education and Science, the German Research Foundation (DFG: HO 3314/2-1, HO 3314/2-3, HO 3314/4-3). Lilian Tzivian gratefully acknowledges support by a post-doctoral fellowship from the Environmental and Health Fund, Jerusalem, Israel.

Author Contributions: Frauke Hennig contributed to the design of study, the analysis and interpretation of the results and preparation of manuscript. Dorothea Sugiri contributed to the analysis and preparation of the manuscript. Kateryna Fuks, Lilian Tzivian, Danielle Vienneau, Kees de Hoogh, Susanne Moebus, Karl-Heinz Jöckel, Ulrich Quass and Thomas Kuhlbush contributed to the interpretation of results and preparation of manuscript. Hermann Jakobs and Michael Memmesheimer contributed to the preparation of the manuscript. Barbara Hoffmann contributed to the design of study, interpretation of the results and preparation of manuscript.

Conflicts of Interest: The authors declare no conflict of interest.

\section{References}

1. World Health Organization. The World Health Report 2013: Research for Universal Health Coverage; WHO: Geneva, Switzerland, 2013.

2. Dockery, D.W.; Pope, C.A.; Xu, X.; SPrengler, J.D.; Ware, J.H.; Fay, M.E.; Ferris, B.G.; Speizer, F.E. An association between air pollution and mortality in six U.S. cities. New Engl. J. Med. 1993, 329, 1753-1759.

3. Jerrett, M.; Arain, A.; Kanaroglou, P.; Beckerman, B.; Potoglou, D.; Sahsuvaroglu, T.; Morrison, J.; Giovis, C. A review and evaluation of intraurban air pollution exposure models. J. Expo. Anal. Environ. Epidemiol. 2005, 15, 185-204.

4. Health Effects Institute. HEI Panel on the Health Effect of Traffic-Related Air Pollution: A Critical Review of the Literature on Emissions, Exposure, and Health Effects; Health Effects Institute: Boston, MA, USA, 2010.

5. Özkaynak, H.; Baxter, L.K.; Dionisio, K.L.; Burke, J. Air pollution exposure prediction approaches used in air pollution epidemiology studies. J. Expo. Sci. Environ. Epidemiol. 2013, 23, 566-572. 
6. Briggs, D.J. The use of GIS to evaluate traffic-related pollution. Occup. Environ. Med. 2007, 64, 1-2.

7. Hoek, G.; Beelen, R.; de Hoogh, K.; Vienneau, D.; Gulliver, J.; Fischer, P.; Briggs, D. A review of land-use regression models to assess spatial variation of outdoor air pollution. Atmos. Environ. 2008, 42, 7561-7578.

8. Cyrys, J.; Hochadel, M.; Gehring, U.; Hoek, G.; Diegmann, V.; Brunekreef, B.; Heinrich, J. GIS-based estimation of exposure to particulate matter and $\mathrm{NO}_{2}$ in an urban area: Stochastic versus dispersion modeling. Environ. Health Perspect. 2005, 113, 987-992.

9. Marshall, J.D.; Nethery, E.; Brauer, M. Within-urban variability in ambient air pollution: Comparison of estimation methods. Atmos. Environ. 2008, 42, 1359-1369.

10. Briggs, D.J.; Collins, S.; Elliott, P.; Fischer, P.; Kingham, S.; Lebret, E.; Pryl, K.; Van Reeuwijk, H.; Smallbone, K.; van Der Veen, A. Mapping urban air pollution using GIS: A regression-based approach. Int. J. Geogr. Inf. Sci. 1997, 11, 699-718.

11. Beelen, R.; Voogt, M.; Duyzer, J.; Zandveld, P.; Hoek, G. Comparison of the performances of land use regression modelling and dispersion modelling in estimating small-scale variations in long-term air pollution concentrations in a Dutch urban area. Atmos. Environ. 2010, 44, 4614-4621.

12. De Hoogh, K.; Korek, M.; Vienneau, D.; Keuken, M.; Kukkonen, J.; Nieuwenhuijsen, M.J.; Badaloni, C.; Beelen, R.; Bolignano, A.; Cesaroni, G.; et al. Comparing land use regression and dispersion modelling to assess residential exposure to ambient air pollution for epidemiological studies. Environ. Int. 2014, 73, 382-392.

13. Perez, L.; Wolf, K.; Hennig, F.; Penell, J.; Basagaña, X.; Aguilera, I.; Agis, D.; Beelen, R.; Brunekreef, B.; Cyrys, J.; et al. Air pollution and atherosclerosis: A cross-sectional analysis of four European cohort studies in the ESCAPE study. Environ. Health Perspect. 2015, 123, 597-605.

14. Duisburg-Essen University. Ruhr \& Culture. Available online: https://www.uni-due.de/ welcome-services/en/rk_index.php (accessed on 3 December2015).

15. Ebel, A. The Eurad Project. Available online: http://www.uni-koeln.de/math-natfak/geomet/eurad/index_e.html (accessed on 30 November 2015).

16. Hass, H.; Ebel, A.; Feldmann, H.; Jakobs, H.J.; Memmesheimer, M. Evaluation studies with a regional chemical transport model (EURAD) using air quality data from the EMEP monitoring network. Atmos. Environ. A. Gen. Top. 1993, 27, 867-887.

17. Ebel, A.; Elbern, H.; Feldmann, H.; Jakobs, H.; Kessler, C.; Memmesheimer, M. Air Pollution Studies with the EURAD Model System (3): EURAD-European Air Pollution Dispersion Model SYSTEM; University of Cologne: Cologne, Germany, 1997.

18. Memmesheimer, M.; Friesse, E.; Ebel, A.; Jakobs, H.; Feldmann, H.; Kessler, C. Long-term simulations of particulate matter in Europe on different scales using sequential nesting of a regional model. Int. J. Environ. Pollut. 2004, 22, 108-132.

19. Schell, B.; Ackermann, I.; Hass, H.; Binkowski, F.; Ebel, A. Modeling the formation of secondary organic aerosol within a comprehensive air quality modeling system. J. Geophys. Res. 2001, 106, 28275-28293. 
20. Büns, C.; Klemm, O.; Wurzler, S.; Hebbinghaus, H.; Steckelbach, I.; Friesel, J.; Ebel, A.; Friese, E.; Jakobs, H.; Memmesheimer, M. Comparison of four years of air pollution data with a mesoscale model. Atmos. Res. 2012, 118, 404-417.

21. Grell, G.A.; Oceanic, N.; Administr, A.; Dudhia, J. A Description of the Fifth-Generation Penn State/NCAR Mesoscale Model (MM5); University Corporation for Atmospheric Research (UCAR): Boulder, CO, USA, 2016.

22. Memmesheimer, M.; Tippke, J.; Ebel, A.; Hass, H.; Jakobs, H.; Laube, M. On the use of EMEP emission inventories for European scale air pollution modelling with the EURAD model. In Proceedings of the 1991 EMEP Workshop on Photooxidant Modelling for Long Range Transport in Relation to Abatement Strategies, Berlin, Germany, 16-19 April 1991; pp. 307-324.

23. Elbern, H.; Strunk, A.; Schmidt, H.; Talagrand, O. Emission rate and chemical state estimation by 4-dimensional variational inversion. Atmos. Chem. Phys. 2007, 7, 3749-3769.

24. Petry, H.; Ebel, A.; Franzkowiak, V.; Hendricks, J.; Lippert, E.; Möllhoff, M. Impact of aircraft exhaust on atmosphere: Box model studies and 3-d mesoscale numerical case studies of seasonal differences. In Proceedings of 1996 Impact of Aircraft Emissions upon the Atmosphere, Paris, France, 15-18 October 1996; pp. 241-246.

25. Current concentrations of air pollutants in Germany. Available online: http:// www.umweltbundesamt.de/daten/luftbelastung/aktuelle-luftdaten (accessed 30 November 2015).

26. Stationen und Messwerte. Available online: http://www.lanuv.nrw.de/umwelt/luft/ immissionen/stationen-und-messwerte/ (accessed on 30 November 2015).

27. Elbern, H. The Objectives of Chemical Data Assimilation. Available online: http://db. eurad.uni-koeln.de/en/research/working_group_he/data_assimilation.php (accessed on 16 December 2015).

28. Hebbinghaus, H.; Wurzler, S.; Friese, E.; Jakobs, H.J.; Kessler, C.; Ebel, A. Determination of the contribution of different groups of emission sources on the concentration of PM10, PM2.5, and NO2 in North Rhine-Westphalia-A whodunnit. In Proceedings of the 2009 European Aerosol Conference, Karlsruhe, Germany, 6-11 September 2009.

29. Nonnemacher, M.; Jakobs, H.; Viehmann, A.; Vanberg, I.; Kessler, C.; Moebus, S.; Möhlenkamp, S.; Erbel, R.; Hoffmann, B.; Memmesheimer, M. Spatio-temporal modelling of residential exposure to particulate matter and gaseous pollutants for the Heinz Nixdorf Recall Cohort. Atmos. Environ. 2014, 91, 15-23.

30. Fagerli, H.; Dutcheak, S.; Torseth, K.; QAmman, M.; Ritter, M. EMEP. Available online: http:/ / www.emep.int/ (accessed on 30 November 2015).

31. European Environment Agency. Index to methodology chapters ordered by SNAP97 Activity. Available online: http://www.eea.europa.eu/publications/ EMEPCORINAIR4/page009-a.html (accessed on 30 November 2015). 
32. Hennig, F.; Fuks, K.; Moebus, S.; Weinmayr, G.; Memmesheimer, M.; Jakobs, H.; Bröcker-Preuss, M.; Führer-Sakel, D.; Möhlenkamp, S.; Erbel, R.; et al. Association between Source-Specific Particulate Matter Air Pollution and hs-CRP: Local Traffic and Industrial Emissions. Environ. Health Perspect. 2014, 122, 703-710.

33. Keil, M.; Bock, M.; Esch, T.; Metz, A.; Nieland, S.; Pfitzner, A. CORINE Land Cover Aktualisierung 2006 für Deutschland. Available online: http:/ /www.uba.de/ uba-info-medien/4086.html (accessed on 16 December 2015).

34. Eeftens, M.; Beelen, R.; de Hoogh, K.; Bellander, T.; Cesaroni, G.; Cirach, M.; Declercq, C.; Dedele, A.; Dons, E.; de Nazelle, A.; et al. Development of Land Use Regression Models for $\mathrm{PM}_{2.5}, \mathrm{PM}_{2.5}$ Absorbance, $\mathrm{PM}_{10}$ and $\mathrm{PM}_{\text {coarse }}$ in 20 European Study Areas; Results of the ESCAPE Project. Environ. Sci. Technol. 2012, 46, 11195-11205.

35. Cyrys, J.; Eeftens, M.; Heinrich, J.; Ampe, C.; Armengaud, A.; Beelen, R.; Bellander, T.; Beregszaszi, T.; Birk, M.; Cesaroni, G.; et al. Variation of $\mathrm{NO}_{2}$ and $\mathrm{NO}_{\mathrm{x}}$ concentrations between and within 36 European study areas: Results from the ESCAPE study. Atmos. Environ. 2012, 62, 374-390.

36. Beelen, R.; Hoek, G.; Vienneau, D.; Eeftens, M.; Dimakopoulou, K.; Pedeli, X.; Tsai, M.Y.; Künzli, N.; Schikowski, T.; Marcon, A.; et al. Development of $\mathrm{NO}_{2}$ and $\mathrm{NO}_{\mathrm{x}}$ land use regression models for estimating air pollution exposure in 36 study areas in Europe-The ESCAPE project. Atmos. Environ. 2013, 72, 10-23.

37. Wang, M.; Brunekreef, B.; Gehring, U.; Szpiro, A.; Hoek, G.; Beelen, R. A New Technique for Evaluating Land-use Regression Models and Their Impact on Health Effect Estimates. Epidemiology 2016, 27, 51-56.

38. ESCAPE manuals. Available online: http://www.escapeproject.eu/manuals/ (accessed on 16 December 2015).

39. R Development Core Team. R: A Language and Environment for Statistical Computing; R Foundation for Statistical Computing: Vienna, Austria, 2015.

40. Auswertung der Luftbelastungssituation 2009. Available online: http://www. umweltbundesamt.de/sites/default/files/medien/515/dokumente/3895.pdf (accessed on 16 December 2015).

41. Pedersen, M.; Giorgis-Allemand, L.; Bernard, C.; Aguilera, I.; Andersen, A.M. N.; Ballester, F.; Beelen, R.M.J.; Chatzi, L.; Cirach, M.; Danileviciute, A.; et al. Ambient air pollution and low birthweight: A European cohort study (ESCAPE). Lancet Respir. Med. 2013, 1, 695-704.

42. Hertel, S.; Viehmann, A.; Moebus, S.; Mann, K.; Bröcker-Preuss, M.; Möhlenkamp, S.; Nonnnemacher, M.; Erbel, R.; Jakobs, H.; Memmesheimer, M.; et al. Influence of short-term exposure to ultrafine and fine particles on systemic inflammation. Eur. J. Epidemiol. 2010, 25, 581-592.

43. Akita, Y.; Baldasano, J.M.; Beelen, R.; Cirach, M.; de Hoogh, K.; Hoek, G.; Nieuwenhuijsen, M.; Serre, M.L.; de Nazelle, A. Large Scale Air Pollution Estimation Method Combining Land Use Regression and Chemical Transport Modeling in a Geostatistical Framework. Environ. Sci. Technol. 2014, 48, 4452-4459. 
44. Vienneau, D.; de Hoogh, K.; Bechle, M.J.; Beelen, R.; van Donkelaar, A.; Martin, R.V.; Millet, D.B.; Hoek, G.; Marshall, J.D. Western European land use regression incorporating satellite- and ground-based measurements of $\mathrm{NO}_{2}$ and $\mathrm{PM}_{10}$. Environ. Sci. Technol. 2013, 47, 13555-13564. 


\title{
Forecasting Urban Air Quality via a Back-Propagation Neural Network and a Selection Sample Rule
}

\author{
Yonghong Liu, Qianru Zhu, Dawen Yao and Weijia Xu
}

\begin{abstract}
In this paper, based on a sample selection rule and a Back Propagation (BP) neural network, a new model of forecasting daily $\mathrm{SO}_{2}, \mathrm{NO}_{2}$, and $\mathrm{PM}_{10}$ concentration in seven sites of Guangzhou was developed using data from January 2006 to April 2012. A meteorological similarity principle was applied in the development of the sample selection rule. The key meteorological factors influencing $\mathrm{SO}_{2}, \mathrm{NO}_{2}$, and $\mathrm{PM}_{10}$ daily concentrations as well as weight matrices and threshold matrices were determined. A basic model was then developed based on the improved BP neural network. Improving the basic model, identification of the factor variation consistency was added in the rule, and seven sets of sensitivity experiments in one of the seven sites were conducted to obtain the selected model. A comparison of the basic model from May 2011 to April 2012 in one site showed that the selected model for $\mathrm{PM}_{10}$ displayed better forecasting performance, with Mean Absolute Percentage Error (MAPE) values decreasing by $4 \%$ and $\mathrm{R}^{2}$ values increasing from 0.53 to 0.68 . Evaluations conducted at the six other sites revealed a similar performance. On the whole, the analysis showed that the models presented here could provide local authorities with reliable and precise predictions and alarms about air quality if used at an operational scale.
\end{abstract}

Reprinted from Atmosphere. Cite as: Liu, Y.; Zhu, Q.; Yao, D.; Xu, W. Forecasting Urban Air Quality via a Back-Propagation Neural Network and a Selection Sample Rule. Atmosphere 2015, 6, 891-907.

\section{Introduction}

Air quality has recently become a serious issue in several of the large cities in China. This problem has significant potential for adverse impacts on human health and the environment [1-3]. Therefore, it is extremely important to accurately forecast the concentrations of pollutants to provide guidance for travel advice and governmental policies.

Forecasting the concentrations of air pollutants represents a difficult task due to the complexity of the physical and chemical processed involved. However, many researchers have been focusing on these types of forecasts [4-8]. The most common forecasting approaches are numerical models and statistical models. Numerical models do not require a large quantity of measured data, but they demand sound 
knowledge of pollution sources, the chemical composition of the exhaust gases, and the physical processes in the atmospheric boundary layer. This crucial knowledge is often limited. Thus, approximations and simplifications are often employed in the modeling process.

In contrast, statistical models usually necessitate a large quantity of measurement data under a large variety of atmospheric conditions. By applying regression and machine learning techniques, a number of functions can be used to fit the pollution data in terms of selected predictors. Neural networks, a subset of statistical models, are usually presented as systems of interconnected neurons that can compute values from inputs by feeding information through the network. Unlike other statistical models, neural networks make no prior assumptions concerning the data distribution. They can model highly nonlinear functions and can be trained for accurate generalization. These features of the neural network make it an attractive alternative to numerical and other statistical models [9-12].

There have been many applications of neural networks in air quality forecasting since the 1990s, and researchers have obtained fairly good results [13-16]. Despite the successful applications of neural networks in the area of atmospheric science, the method has its own weakness and limitations. Studies have shown that there are three main factors that affect neural network effectiveness: network topology, learning algorithm, and learning samples [17,18]. Previous research mainly concentrated on the network structure and learning algorithm, which improved the forecasting accuracy of the network [19-24]. However, when improvements in the network structure and learning algorithm reach a certain degree, improvements in the accuracy of the air quality forecasting models plateau. Therefore, the selection of learning samples has become a vital factor that determines the mapping ability and generalization of the network. This is because the selection can ensure the representativeness of the learning samples and remove unnecessary interference, and thereby improve the forecasting accuracy of the model. Harri Niska et al. [21] used a genetic algorithm for selecting the inputs and designing the high-level architecture of a multi-layer perceptron model for forecasting $\mathrm{NO}_{2}$ concentrations. Sousa et al. [22] predicted hourly ozone concentrations based on feed-forward artificial neural networks using principal components as inputs, and they improved the predictions of models by reducing their complexity and eliminating data collinearity.

The main objectives of this paper are to develop a sample filter method for the prediction of the daily $\mathrm{NO}_{2}, \mathrm{SO}_{2}$, and $\mathrm{PM}_{10}$ concentration in the Guangzhou Pearl River Delta region based on a similarity principle of weather and pollutant background concentration. During the development of the prediction models, the selection of parameters is conducted by means of sensitivity experiments and the Back Propagation (BP) neural network is used for data-driven computation. The above actions are all part of an integrated environmental strategy designed and run 
by the local authorities of Guangzhou, according to the demands of the Action Plan on Prevention and Control of Air Pollution. Currently, this action plan is the most rigorous and systematic framework for improving air quality in China.

\section{Data}

A significant quantity of observational data under a wide variety of atmospheric conditions was required for this study. The dataset in this paper includes meteorological parameters and pollutant concentrations in Guangzhou, which is located in the south central part of Guangdong Province, China $\left(23^{\circ} 06^{\prime} \mathrm{N}\right.$ Latitude, $113^{\circ} 15^{\prime}$ E Longitude).

Real-time monitoring meteorological parameters, including temperature, wind speed, wind direction, rainfall, atmospheric pressure, relative humidity, and solar radiation intensity, were obtained from an automatic air quality monitoring station at Sun Yat-Sen University, located in the Haizhu District of Guangzhou City. Forecasting meteorological data, including temperature, wind speed, wind direction, and rainfall, were obtained from Guangzhou Weather Forecasts [25]. All the data were processed into the daily mean value as needed, according to the National Ambient Air Quality Standards (GB 3095-2012) issued by Environment Protection Administration (EPA) of China [26]. The monitoring meteorological data were used as historical meteorological data in the model, and the forecasting meteorological data were used as the meteorological data of the forecasting day. To reduce the interference of different geographic locations on the monitoring meteorological data, pollutant concentration forecasting of seven state-controlled air quality monitoring sites in urban Guangzhou was performed. Thus, the applied monitoring data of the atmospheric environment were derived from the daily pollutant concentration data from seven state-controlled air quality monitoring sites as reported by the Guangzhou Environmental Protection [27]. These state-controlled air quality monitoring sites are the Guangya Middle School (Num. 1), the Guangzhou No. 5 Middle School (Num. 2), the Guangzhou Environmental Monitor Station (Num. 3), the Experimental Kindergarten of Tianhe Vocational School (Num. 4), Luhu Park (Num. 5), Guangdong University of Business Studies (Num. 6), and the Guangzhou No. 86 Middle School (Num. 7). The data span the period from January 2006 to April 2012, and a total of 23,195 valid samples were used for the paper.

\section{Methods}

In view of the small variation in weather during our study period, a similarity principle of weather and concentration parameters was applied. The multilayer selection rule for historical samples from Guanghzhou was then constructed. This step is very important for the development of predictive models. The selection of historical samples can improve the similarity between the occurrence of historical 
pollution and future pollution, and a proper selection can improve the efficiency of data-driven models (e.g., BP neural networks). This is also in line with the pollution formation, where the main factor affecting the diffusion and transport of pollutants is the different meteorological parameters, and every meteorological parameter has a different influence on $\mathrm{NO}_{2}, \mathrm{SO}_{2}$, and $\mathrm{PM}_{10}[28,29]$. Thus, the sample selection was based on meteorological similarity and the consistency of the variation trend. The rule was divided into two parts, namely the identification of meteorological parameter similarity and the consistency of the variation trend, i.e., the identification of similarity in background concentrations.

First, a comprehensive correlation analysis of pollutant concentration and meteorological parameters was performed to determine the key factors of the selection rule, and these parameters were also used as inputs into the BP neural network. Next, the three-layer selection sample rule was applied. Finally, we utilized the improved BP neural network for data-driven computation to establish the air quality forecasting model of urban Guangzhou.

\subsection{Identification of the Key Factors}

A comprehensive correlation analysis of pollutant concentration and meteorological factors was conducted. The number of related days was set to two: the meteorology for the forecasting day and for the day before the forecasting day. Meanwhile, the daily mean value of pollutant concentration two days before the forecasting day was used as an input factor in an attempt to counteract the lack of pollutant emission source data.

A comprehensive analysis of pollutant concentration and meteorological factors was conducted for different pollutants, mainly through correlation analysis and weight analysis of the influencing factors in each pollution scenario. The analysis was intended to identify the degree of influence of each meteorological factor on pollutants, thus resulting in the selection of the factors with the greatest impact on pollutants and the allocation of the corresponding influencing weights. The correlation analysis started with the comparison of two typical pollution scenarios, namely, the ascending or descending periods of each pollutant, and the serious pollution or slight pollution periods. In this way, the degree of influence that the meteorological factors had on pollutants under these two situations was obtained. The average value of the two scenarios was calculated and multiplied with a correlation coefficient to obtain the comprehensive weight of the influence of each meteorological factor on different pollutants.

The ascending and descending periods of each pollutant are defined as the periods when the change in the pollutant concentration between consecutive days exceeds $0.05 \mathrm{mg} / \mathrm{m}^{3}$. Serious pollution or slight pollution are defined as 
periods when the Air Pollution Index of the pollutant exceeds 100 or is lower than 20 , respectively.

The identification of the influencing weight of each meteorological factor under the above-mentioned periods was achieved using the following steps:

(a) Obtaining the representative data for the meteorological factorThe specific data include the average value of the ascending period $M_{i u}$, the average value of the descending period $M_{i d}$, the maximum value of the analysis period $M_{i \max }$, the minimum value $M_{i \min }$ of the analysis period, and the overall average value $M_{i \mathrm{adv}}$. The $i$ represents the specific meteorological factor.

(b) Numerical normalization

(c) Variation analysis of the meteorological factor $\left(D_{i}\right)$

$$
D_{i}=\frac{M_{i u}^{\prime}-M_{i d}^{\prime}}{M_{i a d v}^{\prime}}
$$

(d) Computation of the influencing weight

$$
w_{i}=\frac{D_{i}}{\sum_{i=1}^{n} D_{i}}
$$

Finally, the comprehensive influencing weights between meteorology factors and pollutant concentrations were determined by the following equation:

$$
r=R \times\left(w_{1}+w_{2}\right) / 2
$$

where $r$ is the comprehensive influencing weight between the meteorology factor and the pollutant concentration; $R$ is the correlation coefficient between the meteorology factor and the pollutant concentration; $w_{1}$ is the influencing weight in the ascending or descending period; and $w_{2}$ is the influencing weight in the serious or slight pollution periods.

\subsection{A Selection Sample Rule Based on the Similarity Principle}

Multiple meteorological factors create a variety of meteorological parameter spaces that impose different impacts on the transport and diffusion of pollutants. During air quality forecasting, if the appropriate meteorological space is found, the intrinsic relationship between multiple physical quantities and the pollutant will have a reference. An appropriate set of samples was selected for the main influencing factors such that forecasting could be targeted, and the mapping ability 
and generalization of the network could be improved. Thus, three-layer sample screening principles based on meteorological similarity criteria were proposed.

\subsubsection{The Basic Description}

The first level of screening identifies samples where the similarity of each meteorological factor reaches a certain threshold value range. The screened samples should conform to the following formula:

$$
\Delta y_{j} \leq y_{j_{s e t}}, \text { where, } \Delta y_{j}=\left|y_{j_{p r e}}-y_{j_{s a m}}\right|
$$

where $y_{j_{\text {pre }}}$ is the meteorological factor on the day of forecasting; $y_{j_{\text {sam }}}$ is the meteorological factor of the sample; $\Delta y_{j}$ is the meteorological similarity of the meteorology factors between the sample and the day of forecasting; $j$ is the specific meteorological factor; and $y_{j_{s e t}}$ is the threshold value screened by the meteorological factor, forming a primary threshold matrix Y. In this matrix, the threshold value can change dynamically according to the sample size demanded.

The second level of screening applies a threshold value range for total weighted meteorological similarity. The screened samples should conform to the following formula:

$$
\mathrm{S} \leq \mathrm{S}_{\text {set}}, \text { where, } S=\sum_{j \leq \text { Mnum }}\left(w_{j} \cdot \Delta y_{j}\right)
$$

where $S$ is the entire meteorological similarity; $S_{\text {set }}$ is the threshold value screened by the entire meteorological similarity; $w_{j}$ is the weight of each meteorological factor, forming the weight matrix $\mathrm{W}$; and $M_{\text {num }}$ is the number of meteorological factors.

The third level of screening identifies the n samples with the highest meteorological similarity. The screened samples should conform to the following formula:

$$
\mathrm{Q}_{\text {num }} \leq \mathrm{n}
$$

where $Q_{\text {num }}$ is the number of samples in the sequenced sample column, and $n$ is the number of samples needed.

Among these criteria, the selection of the weight matrices and the threshold matrices is key to obtaining high quality samples. Hence, the following identification approaches for weight matrices and threshold matrices were adopted.

\subsubsection{Identification of $w_{j}$}

The establishment of the weight matrix $w_{j}$ was integrated with the selection of model input factors, and a comprehensive correlation analysis of pollutant concentration and meteorological factors was performed. While choosing the input 
parameters of the neural network, the weight matrix of the selection sample rule was also established.

\subsubsection{Identification of $y_{j_{\text {set }}}$}

The establishment of the threshold matrix $y_{j_{s e t}}$ was accomplished via the orthogonal test method, which is a highly efficient experimental design method used for the arrangement of multi-factor experiments and the search for optimal horizontal combinations [30]. For the different pollutants, we set different levels of factors and selected some representative experimental points (horizontally mixed) for the experiments. The optimal horizontal combination was selected to generate the threshold matrix of the selection sample rule [31].

Based on the results of the above weight matrix $w_{j}$, the tested experimental factors were identified. In accordance with prior knowledge, the level of each experimental factor was confirmed. The minimum absolute error of the forecasting model was adopted as the experimental objective to seek the optimal combination and finally identify the sample optimization threshold matrix.

\subsection{Identification of the Variation Trend Consistency}

There will be some scenarios in which wind speed decreases in history but increases on the prediction day compared with the previous day, based on the selection rule stated above in Section 3.2. Such a scenario will lead to an error in the prediction model for use in the BP neural network. Therefore, it is necessary to identify the variation trend consistency.

The factors considered were deduced according to the weight matrix of the selection rule (see Section 3.1) and the principles of the pollution formation. The chosen factors were rainfall, wind speed, and background concentration. However, sensibility experiments were still needed to determine the key factor for $\mathrm{NO}_{2}$, $\mathrm{PM}_{10}$, and $\mathrm{SO}_{2}$. The details of the experimental results will be introduced in the following section.

\subsubsection{Variation Trend Consistency for Wind Speed}

Because wind speed is a vector, wind speed is described as $w_{x}, w_{y}$.

$$
w_{x}=w_{s} \cdot \cos \left(w_{d}\right) \text { and } w_{y}=w_{s} \cdot \sin \left(w_{d}\right)
$$

where $w_{s}$ is the recorded wind speed and $w_{d}$ is the recorded wind direction.

Thus, the steps for the identification of the variation trend consistency for wind speed are as follows: 
(1) Calculate the variation between the forecasting day and the day before.

$$
\Delta\left(w s_{1}\right)^{2}=\left[\left(w_{x-p}\right)^{2}+\left(w_{y-p}\right)^{2}\right]-\left[\left(w_{x-p-1}\right)^{2}+\left(w_{y-p-1}\right)^{2}\right]
$$

where $\Delta\left(w s_{1}\right)^{2}$ is the difference between the squared values of wind speed on the day of forecasting and the day before; $w_{x-p}$ and $w_{y-p}$ are the two wind vectors on the day of forecasting; and $w_{x-p-1}$ and $w_{y-p-1}$ represent the two wind vectors before the day of forecasting.

(2) Calculate the variation between the two adjacent days in the samples selected in Section 3.1,

$$
\Delta\left(w s_{2}\right)^{2}=\left[\left(w_{x-t}\right)^{2}+\left(w_{y-t}\right)^{2}\right]-\left[\left(w_{x-t-1}\right)^{2}+\left(w_{y-t-1}\right)^{2}\right]
$$

where $\Delta\left(w s_{2}\right)^{2}$ is the difference between the squared values of wind speed on the forecasting day and the day before $w_{x-t}$ and $w_{y-t}$ are the two wind vectors on the forecasting day; and $w_{x-t-1}$ and $w_{y-t-1}$ are the two wind vectors on the day before the forecasting day.

(3) Identify whether the wind speed in the forecasting data shows the same tendency of ascending or descending as that in the selected samples. If the tendency is the same, the samples are reserved; otherwise, the samples are removed.

\subsubsection{The Variation Trend Consistency Identification of Rainfall}

The variation in the rainfall levels in the forecasting data was calculated using the following formula:

$$
\Delta R F_{1}=R F_{p}-R F_{p-1}
$$

The variation in the historical rainfall levels was calculated using the following formula:

$$
\Delta R F_{2}=R F_{t}-R F_{t-1}
$$

We then identified whether the rainfall level in the forecasting data showed the same tendency of ascending or descending as that in the sample data. If similar, the samples are reserved; otherwise, the samples are removed.

\subsubsection{Similarity Identification of Background Concentration}

The following steps were used to conduct the similarity identification of the background concentration: 
(1) The background concentration on the day of forecasting is calculated as follows:

$$
B C_{1}=0.6 B C_{P-1}+0.4 B C_{P-2}
$$

(2) The background concentration in the sample data is calculated as follows:

$$
B C_{2}=0.6 B C_{\mathrm{t}-1}+0.4 B C_{\mathrm{t}-2}
$$

(3) Identify whether the background concentration in the forecasting data and the absolute difference of the background concentration on the day of forecasting is in the range of the threshold value. If they are in the range, the samples are reserved; otherwise, they are removed.

$$
A B S(B C 1-B C 2)<=\text { Set }
$$

\subsection{Improvements in BP Neural Network}

Due to its strong learning and generalization ability, a BP neural network was used as the data-driven computation method [32]. In this paper, a BP neural network with three layers was applied to predict the daily concentrations of $\mathrm{NO}_{2}, \mathrm{PM}_{10}$, and $\mathrm{SO}_{2}$. The layers included an input layer, a hidden layer, and an output layer. The data described in Section 2 were divided into training, validation and test sets. The training and validation sets were from January 2006 to April 2011 in seven air quality monitoring sites, of which $80 \%$ of these data were randomly selected for the training set; the remaining $20 \%$ of the data comprised the validation set. In addition, the data from May 2011 to April 2012 were used for the test set, aiming to test and compare the model performance in seven air quality monitoring sites. There are two main components affecting pollutant concentration: emission sources and pollutant transmission and diffusion conditions. The key factor that affects pollutant transmission and diffusion in a city is the meteorological conditions. Therefore, the meteorological factors identified in Section 3.1 were considered as the major input factors for the BP neural network. According to the conclusions in the literature [33,34], the daily concentrations of $\mathrm{NO}_{2}, \mathrm{PM}_{10}$, and $\mathrm{SO}_{2}$ for the two days before the forecasting day were also used as input factors for the BP neural network to reduce the influencefor lacking emissions data. The final number of variables used in the input layer (NInput) in each forecast model is shown in Table 1.

The neuron number of the hidden layer is half that of the input layer [35]. Different neural network structures were established for $\mathrm{NO}_{2}, \mathrm{PM}_{10}$, and $\mathrm{SO}_{2}$. The neuron in the output layer was regarded as the forecasted daily concentration of $\mathrm{NO}_{2}, \mathrm{PM}_{10}$, and $\mathrm{SO}_{2}$. 
The training termination conditions in the BP neural network were also changed to improve the overall accuracy of the forecasting model. When the average relative error of all training samples reached a specified error value, the training would cease. The specified error value was determined by experiments for different error. For $\mathrm{NO}_{2}$, $\mathrm{PM}_{10}$, and $\mathrm{SO}_{2}$, the optimal specified error values were $0.5,0.4$, and 0.35 , respectively. Every group training sample was processed five times, which means that five groups of models were developed. The model with the least average relative error was selected as the prediction model, reducing the randomness of the BP neural network.

Table 1. Forecasting results of the seven groups of sensitivity experiments.

\begin{tabular}{|c|c|c|c|c|c|c|c|c|c|}
\hline Pollutants & Experiments & N Input & $\begin{array}{c}\text { Mean } \\
\left(\mathrm{mg} / \mathrm{m}^{3}\right)\end{array}$ & $\begin{array}{c}\mathrm{MAE} \\
\left(\mathrm{mg} / \mathrm{m}^{3}\right)\end{array}$ & MAPE & $\mathbf{R}$ & TFA & Ef & Af \\
\hline \multirow{7}{*}{$\mathrm{SO}_{2}$} & Basic (Group 1) & 10 & 0.027 & 0.009 & 37.4 & 0.422 & 0500 & -0.322 & 1.513 \\
\hline & $\mathrm{RF}^{*}($ Group 2) & 10 & 0.027 & 0.009 & 36.6 & 0.510 & 0.536 & 0.010 & 1.543 \\
\hline & WS (Group 3) & 10 & 0.027 & 0.010 & 43.2 & 0.304 & 0.464 & -0.583 & 1.693 \\
\hline & BC (Group 4) & 10 & 0.027 & 0.009 & 40.3 & 0.345 & 0.483 & -0.937 & 1.577 \\
\hline & $\begin{array}{l}\text { RF + WS } \\
\text { (Group 5) }\end{array}$ & 10 & 0.027 & 0.009 & 38.5 & 0.430 & 0.482 & -0.192 & 1.501 \\
\hline & $\begin{array}{c}\mathrm{RF}+\mathrm{BC} \\
\text { (Group 6) }\end{array}$ & 10 & 0.027 & 0.011 & 49.7 & 0.118 & 0.464 & -1.726 & 1.575 \\
\hline & $\begin{array}{l}\text { WS + BC } \\
\text { (Group 7) }\end{array}$ & 10 & 0.027 & 0.012 & 52.8 & 0.178 & 0.393 & -1.174 & 1.716 \\
\hline \multirow{7}{*}{$\mathrm{PM}_{10}$} & basic(Group 1) & 7 & 0.105 & 0.025 & 26.6 & 0.536 & 0.492 & 0.210 & 1.297 \\
\hline & RF (Group 2) & 7 & 0.105 & 0.026 & 28.8 & 0.476 & 0.433 & 0.108 & 1.319 \\
\hline & WS (Group 3) & 7 & 0.105 & 0.025 & 26.2 & 0.527 & 0.483 & 0.190 & 1.289 \\
\hline & BC (Group 4) & 7 & 0.105 & 0.024 & 24.6 & 0.563 & 0.500 & 0.225 & 1.280 \\
\hline & $\begin{array}{l}\text { RF + WS } \\
\text { (Group 5) }\end{array}$ & 7 & 0.105 & 0.025 & 27.8 & 0.479 & 0.417 & 0.159 & 1.315 \\
\hline & $\begin{array}{l}\mathrm{RF}+\mathrm{BC} * \\
\text { (Group 6) }\end{array}$ & 7 & 0.105 & 0.023 & 22.7 & 0.672 & 0.550 & 0.348 & 1.269 \\
\hline & $\begin{array}{l}\text { WS + BC } \\
\text { (Group 7) }\end{array}$ & 7 & 0.105 & 0.024 & 26.9 & 0.581 & 0.417 & 0.317 & 1.290 \\
\hline \multirow{7}{*}{$\mathrm{NO}_{2}$} & Basic (Group 1) & 10 & 0.073 & 0.020 & 25.0 & 0.680 & 0.550 & 0.261 & 1.340 \\
\hline & RF (Group 2) & 10 & 0.073 & 0.020 & 24.1 & 0.660 & 0.533 & 0.199 & 1.345 \\
\hline & WS (Group 3) & 10 & 0.073 & 0.018 & 22.7 & 0.702 & 0.533 & 0.352 & 1.291 \\
\hline & BC (Group 4) & 10 & 0.073 & 0.019 & 23.7 & 0.715 & 0.517 & 0.337 & 1.315 \\
\hline & $\begin{array}{l}\text { RF + WS } \\
\text { (Group 5) }\end{array}$ & 10 & 0.073 & 0.018 & 23.7 & 0.723 & 0.617 & 0.386 & 1.298 \\
\hline & $\begin{array}{l}\mathrm{RF}+\mathrm{BC} \\
\text { (Group 6) }\end{array}$ & 10 & 0.073 & 0.019 & 24.3 & 0.716 & 0.483 & 0.380 & 1.306 \\
\hline & $\begin{array}{l}\text { WS + BC* } \\
\text { (Group 7) }\end{array}$ & 10 & 0.073 & 0.018 & 22.5 & 0.688 & 0.567 & 0.397 & 1.271 \\
\hline
\end{tabular}

Note: * the Selected Model determined by making experiments.

\subsection{Indices of Model Evaluation}

We used the following indicators to evaluate the models: Mean absolute error (MAE), Mean Absolute Percentage Error (MAPE), Correlation coefficient (R), tendency forecasting accuracy (TFA), Nash-Sutcliffe coefficient of efficiency (Ef), and Accuracy factor (Af) [36]. The TFA is the forecasting accuracy rate determination for 
the upward or downward trend of pollutant concentrations over two consecutive days on the basis of monitoring results. Ef, an indicator of the model fit, is a normalized measure $(-\infty$ to 1$)$ that compares the mean square error generated by a particular model simulation to the variance of the target output sequence. An Ef value closer to 1 indicates better model performance; an Ef value of zero indicates that the model is, on average, performing only as good as the use of the mean target value for prediction, and an Ef value $<0$ indicates an altogether questionable choice of the model. Af is a simple multiplicative factor indicating the spread of the results around the prediction. The larger the Af value, the less accurate the average estimate.

The MAE, MAPE, TFA, Af and Ef are defined as follows:

$$
\begin{gathered}
M A E=\frac{1}{N} \sum_{i=1}^{N}\left|y_{\text {pre }, i}-y_{\text {mon }, i}\right| \\
M A P E=\frac{1}{N} \sum_{i=1}^{N}\left(\frac{\left|y_{\text {pre }, i}-y_{\text {mon }, i}\right|}{y_{\text {mon }, i}} \times 100\right) \\
E_{f}=1-\frac{A}{\sum_{i=1}^{N}\left(y_{\text {pre }, i}-y_{\text {mon }, i}\right)^{2}} \\
\sum_{i=1}^{N}\left(y_{\text {pre }, i}-\bar{y}_{\text {mon }}\right)^{2} \\
A_{f}=10^{\sum_{i=1}^{N} \frac{\left|\log \left(\frac{y_{\text {pre }, i}}{y_{\text {mon }, i}}\right)\right|}{N}}
\end{gathered}
$$

where $y_{\text {pre }}$ and $y_{\text {mon }}$ are the predicted and measured values, respectively, and $\bar{y}_{\text {mon }}$ is the mean of the measured values of the response variable. $N$ is the total number of the observations. A is the number of correct forecasts for the upward or downward trend of pollutant concentrations over two consecutive days.

\section{Results and Discussion}

\subsection{The Results of the Sensitivity Experiments in Guangzhou No. 5 Middle} School (Num. 2)

As described in Section 3.3, sensitivity experiments were performed to determine the key factors. The data were obtained from the Guangzhou No. 5 Middle School site. Seven group experiments were performed for $\mathrm{SO}_{2}, \mathrm{PM}_{10}$, and $\mathrm{NO}_{2}$. The first experiment (called "Group 1") was made by the model based on the selection rules described in Section 3.2. That is to say, Group 1 was run using the Basic Model. Besides these selection rules, the second to fourth experiments were conducted based on the variation trend consistency identification of rainfall (RF), wind speed (WS), and background concentration (BC), while the fifth to seventh experiments were 
considerations of $\mathrm{RF}+\mathrm{WS}, \mathrm{RF}+\mathrm{BC}$, and $\mathrm{WS}+\mathrm{BC}$. These experiments were referred to as Group 2, Group 3, Group 4, Group 5, Group 6, and Group 7, respectively. Table 1 summarizes the results of the seven groups of sensitivity experiments. The models with the best performance were selected (termed the Selected Models).

For $\mathrm{PM}_{10}$, the value of Ef and Af of Group 6 were much closer to 1.0 compared with the other models. Compared with Group 1, the Mean Absolute Percentage Error (MAPE) of Group 6 was $4 \%$ lower (0.227), $\mathrm{R}$ increased by almost $14 \%$, and TFA increased by nearly $6 \%(0.550)$. For $\mathrm{NO}_{2}$, Group 7 had the best results with an MAPE of only 0.225 , an R value of 0.688 , and a TFA value of 0.567 . The Ef and Af of Group 7 were 0.397 and 1.271, respectively, which were much closer to 1.0 than the other experiments. Group 2 had the most ideal experimental results for $\mathrm{SO}_{2}$; the MAPE was $0.366, \mathrm{R}$ and TFA were both higher than 0.5 , and Ef was the only positive value. In contrast to the $\mathrm{PM}_{10}$ and $\mathrm{NO}_{2}$ results, the $\mathrm{SO}_{2}$ experiments based on $\mathrm{BC}$ did not produce the best results. This scenario is perhaps due to a non-obvious variation in daily $\mathrm{SO}_{2}$ concentrations.

\subsection{Errors of the Selected Models of Num. 2 for May 2011 to April 2012}

The forecasting results are shown in a scatter diagram of the predicted versus the observed concentrations (Figure 1). The distribution of $\mathrm{SO}_{2}$ is relatively dispersed, which is due to the diversity of the influencing factors and the complexity of dynamic processes. Singh et al. [36] forecast respirable suspended particulate matter (RSPM), $\mathrm{SO}_{2}$, and $\mathrm{NO}_{2}$. The results showed that compared with the two other pollutants, the degree of dispersion in the scatter diagram of the monitored and predicted $\mathrm{SO}_{2}$ values was higher. Kurt et al. [37] used a neural network to build models of $\mathrm{SO}_{2}$, $\mathrm{PM}_{10}$, and $\mathrm{CO}$. The error distribution of the $\mathrm{SO}_{2}$ forecasting model based on the data from two days prior ranged from $37 \%$ to $40 \%$, and the model was the least accurate of the three. The distributions of $\mathrm{PM}_{10}$ and $\mathrm{NO}_{2}$ were relatively better, i.e., the line fitted the correlation at 0.5 and above. The forecasting results were stable and the model performed well.

Errors in the selected model for Guangzhou No. 5 Middle School (Num. 2) from May 2011 to April 2012 are shown in Figure 2. Overall, the monthly prediction accuracy of $\mathrm{SO}_{2}$ was higher than $\mathrm{PM}_{10}$ and $\mathrm{NO}_{2}$, and the $\mathrm{NO}_{2}$ model performed better than the $\mathrm{PM}_{10}$ model. The highest errors for $\mathrm{SO}_{2}, \mathrm{PM}_{10}$, and $\mathrm{NO}_{2}$ were observed in February, where the daily concentrations were almost the highest due to the bad weather; the BP neural network is not sensitive to extremely high or low values $[33,34]$. However, the MAPE of the $\mathrm{SO}_{2}, \mathrm{PM}_{10}$, and $\mathrm{NO}_{2}$ models were $0.383,0.353$, and 0.290 , respectively. These MAPE values are acceptable for operational forecasts. 


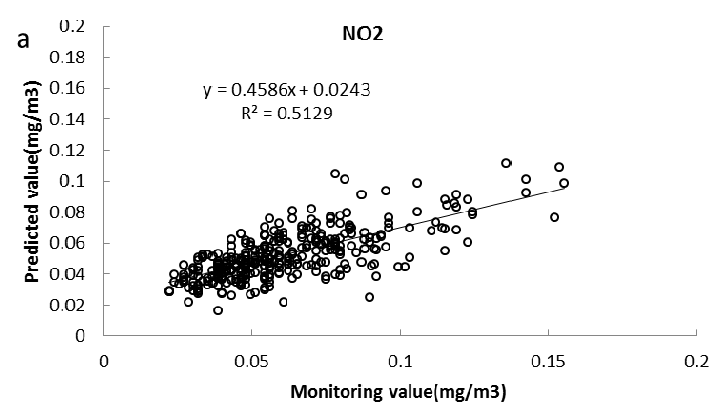

(a)

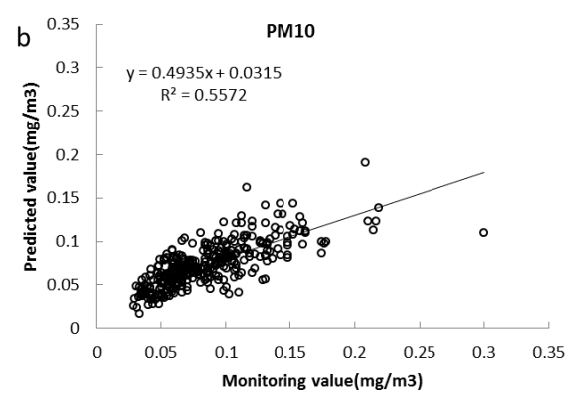

(b)

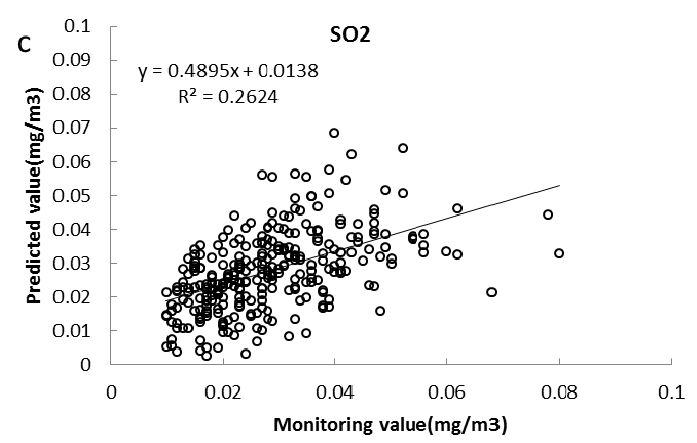

(c)

Figure 1. (a-c) Scatter plots of predicted versus observed $\mathrm{NO}_{2}, \mathrm{PM}_{10}, \mathrm{SO}_{2}$ concentrations for Num. 2.

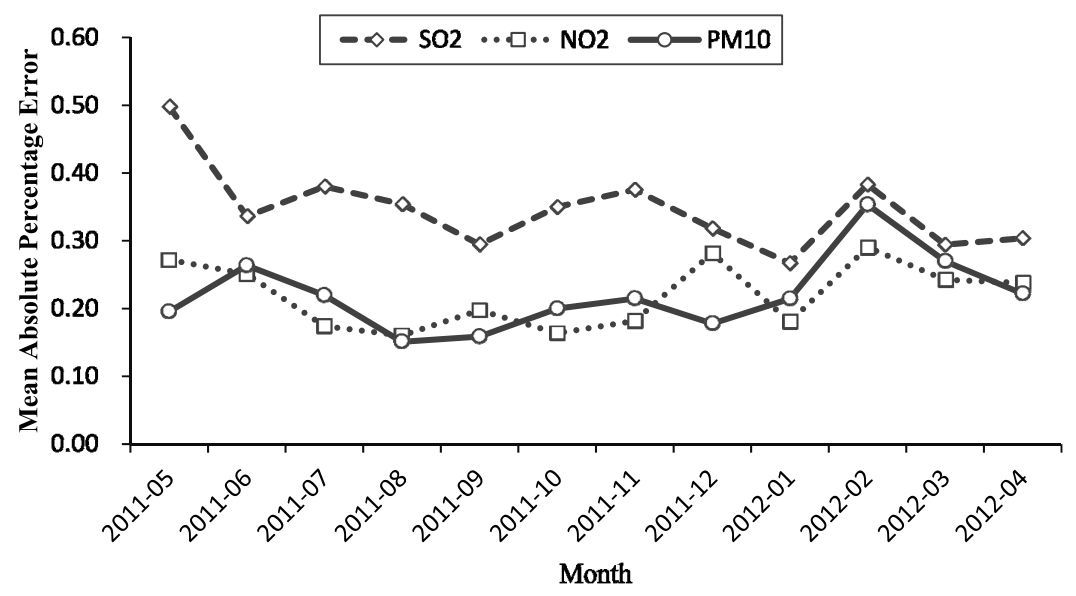

Figure 2. MAPE of models for Num. 2 from May 2011 to April 2012. 


\subsection{Errors in the Selected Models for Others Sites}

The selected model for $\mathrm{SO}_{2}, \mathrm{NO}_{2}$, and $\mathrm{PM}_{10}$ was tested in the remaining six sites (detailed description in Section 2) in the urban district of Guangzhou, and a comparison was made between the Selected Model and the Basic Model. The results are shown in Table 2. On the whole, the Selected Model was equal to or better than the Basic Model for $\mathrm{SO}_{2}, \mathrm{NO}_{2}$, and $\mathrm{PM}_{10}$. As for $\mathrm{SO}_{2}$, the MAPE of the Selected Model decreased from 0.417 to 0.377 , the correlation increased from 0.409 to 0.477 , the TFA increased from 0.490 to 0.517 . In addition, the Ef and Af were closer to 1 compared with the Basic Model. Adding the sample optimization rules to the variation tendency identification of the rainfall level changes improved the forecast accuracy of the different pollutants to different degrees at every site. For PM10, the MAPE of the Selected Model was 0.250 for the six sites, which was almost 0.10 lower than that of the Basic model. The correlation was greater than 0.7, and the TFA increased by $24 \%$, from 0.421 to 0.523 . Adding the variation tendency identification of the rainfall level changes and the similarity identification of the background concentrations to the model resulted in an effective improvement of the forecast accuracy of $\mathrm{PM}_{10}$. Regarding $\mathrm{NO}_{2}$, adding the variation tendency identification of the wind speed changes and the similarity identification of the background concentrations did not greatly improve the forecast results. The Selected Model is useful for the six sites, and the errors of the model are acceptable for application purposes.

Table 2. Comparisons between the Selected and Basic Model in the remaining six sites.

\begin{tabular}{|c|c|c|c|c|c|c|c|c|c|}
\hline Pollutant & Site & Model & $\begin{array}{c}\text { Mean } \\
\left(\mathrm{mg} / \mathrm{m}^{3}\right)\end{array}$ & $\begin{array}{c}\text { MAE } \\
\left(\mathrm{mg} / \mathrm{m}^{3}\right)\end{array}$ & MAPE & $\mathbf{R}$ & TFA & Ef & Af \\
\hline \multirow{16}{*}{$\mathrm{SO}_{2}$} & \multirow{2}{*}{ Num. 1} & Basic & 0.024 & 0.008 & 36.8 & 0.525 & 0.506 & 0.159 & 1.459 \\
\hline & & Selected & 0.024 & 0.008 & 34.9 & 0.614 & 0.525 & 0.237 & 1.451 \\
\hline & \multirow{2}{*}{ Num. 3} & Basic & 0.027 & 0.010 & 43.6 & 0.418 & 0.511 & -0.164 & 1.539 \\
\hline & & Selected & 0.027 & 0.010 & 40.4 & 0.409 & 0.475 & -0.181 & 1.548 \\
\hline & \multirow{2}{*}{ Num. 4} & Basic & 0.023 & 0.009 & 44.2 & 0.394 & 0.509 & -0.301 & 1.567 \\
\hline & & Selected & 0.023 & 0.009 & 41.3 & 0.456 & 0.527 & -0.332 & 1.541 \\
\hline & \multirow{2}{*}{ Num. 5} & basic & 0.022 & 0.007 & 35.6 & 0.441 & 0.455 & -0.019 & 1.468 \\
\hline & & Selected & 0.022 & 0.007 & 31.6 & 0.472 & 0.515 & 0.059 & 1.408 \\
\hline & \multirow{2}{*}{ Num. 6} & Basic & 0.027 & 0.011 & 42.8 & 0.355 & 0.466 & 0.055 & 1.587 \\
\hline & & Selected & 0.027 & 0.010 & 39.6 & 0.451 & 0.508 & 0.019 & 1.551 \\
\hline & \multirow{2}{*}{ Num. 7} & basic & 0.036 & 0.015 & 47.8 & 0.298 & 0.527 & -0.580 & 1.662 \\
\hline & & Selected & 0.036 & 0.013 & 41.2 & 0.422 & 0.561 & -0.239 & 1.563 \\
\hline & \multirow{2}{*}{ Num. 1} & Basic & 0.083 & 0.023 & 26.2 & 0.656 & 0.438 & 0.348 & 1.328 \\
\hline & & Selected & 0.083 & 0.022 & 24.9 & 0.713 & 0.509 & 0.397 & 1.335 \\
\hline & \multirow{2}{*}{ Num. 3} & Basic & 0.067 & 0.018 & 32.1 & 0.604 & 0.132 & 0.348 & 1.354 \\
\hline & & Selected & 0.067 & 0.018 & 26.8 & 0.694 & 0.542 & 0.459 & 1.322 \\
\hline \multirow{4}{*}{$\mathrm{PM}_{10}$} & \multirow{2}{*}{ Num. 4} & basic & 0.061 & 0.017 & 31.6 & 0.680 & 0.493 & 0.454 & 1.350 \\
\hline & & Selected & 0.061 & 0.017 & 26.4 & 0.741 & 0.506 & 0.523 & 1.317 \\
\hline & \multirow{2}{*}{ Num. 5} & basic & 0.067 & 0.016 & 24.7 & 0.742 & 0.465 & 0.537 & 1.268 \\
\hline & & Selected & 0.067 & 0.016 & 22.7 & 0.729 & 0.531 & 0.487 & 1.267 \\
\hline
\end{tabular}


Table 2. Cont.

\begin{tabular}{|c|c|c|c|c|c|c|c|c|c|}
\hline Pollutant & Site & Model & $\begin{array}{c}\text { Mean } \\
\left(\mathrm{mg} / \mathrm{m}^{3}\right)\end{array}$ & $\begin{array}{c}\text { MAE } \\
\left(\mathrm{mg} / \mathrm{m}^{3}\right)\end{array}$ & MAPE & $\mathbf{R}$ & TFA & Ef & Af \\
\hline \multirow{16}{*}{$\mathrm{NO}_{2}$} & \multirow{2}{*}{ Num. 6} & Basic & 0.063 & 0.018 & 30.4 & 0.583 & 0.493 & 0.301 & 1.358 \\
\hline & & Selected & 0.063 & 0.019 & 29.2 & 0.589 & 0.492 & 0.247 & 1.390 \\
\hline & \multirow{2}{*}{ Num. 7} & basic & 0.087 & 0.022 & 25.4 & 0.682 & 0.467 & 0.408 & 1.308 \\
\hline & & Selected & 0.087 & 0.022 & 23.3 & 0.717 & 0.525 & 0.431 & 1.288 \\
\hline & \multirow[b]{2}{*}{ Num. 1} & basic & 0.061 & 0.013 & 20.9 & 0.688 & 0.483 & 0.392 & 1.248 \\
\hline & & Selected & 0.061 & 0.013 & 20.5 & 0.715 & 0.500 & 0.448 & 1.243 \\
\hline & \multirow{2}{*}{ Num. 3} & Basic & 0.068 & 0.016 & 22.2 & 0.596 & 0.463 & 0.226 & 1.272 \\
\hline & & Selected & 0.068 & 0.015 & 21.5 & 0.676 & 0.557 & 0.320 & 1.266 \\
\hline & \multirow{2}{*}{ Num. 4} & Basic & 0.052 & 0.010 & 21.9 & 0.685 & 0.511 & 0.456 & 1.232 \\
\hline & & Selected & 0.052 & 0.010 & 19.3 & 0.722 & 0.541 & 0.502 & 1.215 \\
\hline & \multirow{2}{*}{ Num. 5} & Basic & 0.038 & 0.009 & 25.8 & 0.613 & 0.454 & 0.363 & 1.285 \\
\hline & & Selected & 0.038 & 0.009 & 23.0 & 0.599 & 0.462 & 0.308 & 1.267 \\
\hline & \multirow{2}{*}{ Num. 6} & Basic & 0.053 & 0.014 & 26.8 & 0.757 & 0.497 & 0.405 & 1.337 \\
\hline & & Selected & 0.053 & 0.015 & 24.6 & 0.728 & 0.528 & 0.310 & 1.334 \\
\hline & \multirow{2}{*}{ Num. 7} & Basic & 0.041 & 0.010 & 27.4 & 0.668 & 0.476 & 0.435 & 1.305 \\
\hline & & Selected & 0.041 & 0.009 & 23.1 & 0.700 & 0.505 & 0.465 & 1.269 \\
\hline
\end{tabular}

\section{Conclusions}

In this paper, based on a selection sample rule and BP neural network, a new model of forecasting daily $\mathrm{SO}_{2}, \mathrm{NO}_{2}$, and $\mathrm{PM}_{10}$ concentrations in seven Guangzhou sites was developed.

(1) A meteorological similarity principle was applied in the development of the selection sample rule. Key meteorological factors influencing the daily $\mathrm{SO}_{2}$, $\mathrm{NO}_{2}$, and $\mathrm{PM}_{10}$ concentrations were determined and weight matrices and threshold matrices were generated. A basic model was then developed based on the improved BP neural network. The selection sample rule consisted of three layers.

(2) In improving the basic model, identification of the variation consistency of some factors was added in the rule, and seven sets of sensitivity experiments (one in each of the seven sites) were conducted to obtain the selected model. These experiments determined that the variation consistency of the rainfall level added to the $\mathrm{SO}_{2}$ forecast model, the rainfall level variation tendency and the background concentration similarity identification added to the $\mathrm{PM}_{10}$ forecast model, while wind speed variation identification and background concentration similarity identification added to the $\mathrm{NO}_{2}$ forecast model. The improved BP neural network was also used for data-driven computation.

(3) Evaluations in the site by comparison of the basic model from May 2011 to April 2012 showed the selected model for $\mathrm{PM}_{10}$ displayed better forecasting performance, with MAPE values decreasing by $4 \%$ and $\mathrm{R}^{2}$ values increasing from 0.53 to 0.68 . The selected model for $\mathrm{NO}_{2}$ had little improvements 
compared with the basic model, while the MAPE values of the selected model for $\mathrm{SO}_{2}$ were as high as $36.6 \%$ with $\mathrm{R}^{2}$ values of 0.51 .

(4) Evaluations conducted at the six other sites revealed similar performances. The MAPE values of the selected models for $\mathrm{SO}_{2}, \mathrm{PM}_{10}$, and $\mathrm{NO}_{2}$ were $37.7 \%, 25.0 \%$, and $22.0 \%$, respectively. Of course, the above results showed that the $\mathrm{SO}_{2}$ model may be further improved in future research, by developing a combined model or by considering the interaction of atmospheric pollutants.

Acknowledgments: This work was completely supported by the National Natural Science Foundation of China (No. 51108471).

Author Contributions: Yonghong Liu, Qianru Zhu conceived and designed the model and experiments; Dawen Yao and Weijia Xu collected and analyzed the data; Yonghong Liu wrote the paper.

Conflicts of Interest: The authors declare no conflict of interest.

\section{References}

1. Dimitriou, K.; Kassomenos, P.A.; Paschalidou, A.K. Assessing air quality with regards to its effect on human health in the European Union through air quality indices. Ecol. Indic. 2013, 27, 108-115.

2. Pope, C.A., III; Burnett, R.T.; Thun, M.J.; Calle, E.E.; Krewski, D.; Ito, K.; Thurston, G.D. Lung cancer, cardiopulmonary mortality, and long-term exposure to fine particulate air pollution. JAMA 2002, 287, 1132-1141.

3. Li, G.; Sang, N. Delayed rectifier potassium channels are involved in $\mathrm{SO} 2$ derivative-induced hippocampal neuronal injury. Ecotoxicol. Environ. Saf. 2009, 72, 236-241.

4. Juhos, I.; Makra, L.; Tóth, B. Forecasting of traffic origin NO and NO2 concentrations by Support Vector Machines and neural networks using Principal Component Analysis. Simul. Model. Pract. Theory 2008, 16, 1488-1502.

5. Finardi, S.; de Maria, R.; D'Allura, A.; Cascone, C.; Calori, G.; Lollobrigida, F. A deterministic air quality forecasting system for Torino urban area, Italy. Environ. Model. Softw. 2008, 23, 344-355.

6. Dong, M.; Yang, D.; Kuang, Y.; He, D.; Erdal, S.; Kenski, D. PM2.5 concentration prediction using hidden semi-Markov model-based times series data mining. Expert Syst. Appl. 2009, 36, 9046-9055.

7. Pai, T.Y.; Ho, C.L.; Chen, S.W.; Lo, H.M.; Sung, P.J.; Lin, S.W.; Lai, W.J.; Tseng, S.C.; Ciou, S.P.; Kuo, J.L.; Kao, J.T. Using seven types of GM $(1,1)$ model to forecast hourly particulate matter concentration in Banciao City of Taiwan. Water Air Soil Pollut. 2011, 217, 25-33.

8. Pai, T.Y.; Hanaki, K.; Chiou, R.J. Forecasting Hourly Roadside Particulate Matter in Taipei County of Taiwan Based on First-Order and One-Variable Grey Model. CLEAN Soil Air Water 2013, 41, 737-742. 
9. Comrie, A.C. Comparing neural networks and regression models for ozone forecasting. J. Air Waste Manag. Assoc. 1997, 47, 653-663.

10. Schlink, U.; Dorling, S.; Pelikan, E.; Nunnari, G.; Cawley, G.; Junnine, H.; Greig, A.; Foxall, R.; Eben, K.; Chatterton, T.; et al. A rigorous inter-comparison of ground-level ozone predictions. Atmos. Environ. 2003, 37, 3237-3253.

11. Kukkonen, J.; Partanen, L.; Karppinen, A.; Ruuskanen, J.; Junninen, H.; Kolehmainen, M.; Niska, H.; Dorling, S.; Chatterton, T.; Foxall, R.; et al. Extensive evaluation of neural network models for the prediction of $\mathrm{NO}_{2}$ and PM10 concentrations, compared with a deterministic modelling system and measurements in central Helsinki. Atmos. Environ. 2003, 37, 4539-4550.

12. Diaz-Robles, L.A.; Ortega, J.C.; Fu, J.S.; Reed, G.D.; Chow, J.C.; Watson, J.G.; Moncada-Herrera, J.A. A hybrid ARIMA and artificial neural networks model to forecast particulate matter in urban areas: The case of Temuco, Chile. Atmos. Environ. 2008, 42, 8331-8340.

13. Yi, J.; Prybutok, V.R. A neural network model forecasting for prediction of daily maximum ozone concentration in an industrialized urban area. Environ. Pollut. 1996, 92, 349-357.

14. Grivas, G.; Chaloulakou, A. Artificial neural network models for prediction of PM10 hourly concentrations, in the Greater Area of Athens, Greece. Atmos. Environ. 2006, 40, 1216-1229.

15. Hooyberghs, J.; Mensink, C.; Dumont, G.; Fierens, F.; Brasseur, O. A neural network forecast for daily average PM10 concentrations in Belgium. Atmos. Environ. 2005, 39, 3279-3289.

16. Paschalidou, A.K.; Karakitsios, S.; Kleanthous, S.; Kassomenos, P.A. Forecasting hourly PM10 concentration in Cyprus through artificial neural networks and multiple regression models: Implications to local environmental management. Environ. Sci. Pollut. Res. 2011, 18, 316-327.

17. Zhang, G.; Eddy Patuwo, B.; Hu, Y.M. Forecasting with artificial neural networks: The state of the art. Int. J. Forecast. 1998, 14, 35-62.

18. Gardner, M.W.; Dorling, S.R. Artificial neural networks (the multilayer perceptron)-A review of applications in the atmospheric sciences. Atmos. Environ. 1998, 32, 2627-2636.

19. Kolehmainen, M.; Martikainen, H.; Ruuskanen, J. Neural networks and periodic components used in air quality forecasting. Atmos. Environ. 2001, 35, 815-825.

20. Lu, W.Z.; Fan, H.Y.; Lo, S.M. Application of evolutionary neural network method in predicting pollutant levels in downtown area of Hong Kong. Neurocomputing 2003, 51, 387-400.

21. Niska, H.; Hiltunen, T.; Karppinen, A.; Ruuskanen, J.; Kolehmainen, M. Evolving the neural network model for forecasting air pollution time series. Eng. Appl. Artif. Intell. 2004, 17, 159-167.

22. Sousa, S.I.V.; Martins, F.G.; Alvim-Ferraz, M.C.M.; Pereira, M.C. Multiple linear regression and artificial neural networks based on principal components to predict ozone concentrations. Environ. Model. Softw. 2007, 22, 97-103. 
23. Al-Alawi, S.M.; Abdul-Wahab, S.A.; Bakheit, C.S. Combining principal component regression and artificial neural networks for more accurate predictions of ground-level ozone. Environ. Model. Softw. 2008, 23, 396-403.

24. Pires, J.C.M.; Gonçalves, B.; Azevedo, F.G.; Carneiro, A.P.; Rego, N.; Assembleia, A.J.B.; Silva, P.A.; Lima, J.F.B.; Alves, C.; Martins, F.G. Optimization of artificial neural network models through genetic algorithms for surface ozone concentration forecasting. Environ. Sci. Pollut. Res. 2012, 19, 3228-3234.

25. Guangzhou Weather Forecasts. Available online: http://www.tqyb.com.cn/ (accessed on 1 January 2013).

26. Ministry of Environmental Protection of China. Ambient Air Quality Standards; China Environmental Science Press: Beijing, China, 2012.

27. Guangzhou Environmental Protection. Available online: http://www.gzepb.gov.cn/ comm/apidate.asp (accessed on 1 January 2013).

28. Elminir, H.K. Dependence of urban air pollutants on meteorology. Sci. Total Environ. 2005, 350, 225-237.

29. Pearce, J.L.; Beringer, J.; Nicholls, N.; Hyndman, R.J.; Tapper, N.J. Quantifying the influence of local meteorology on air quality using generalized additive models. Atmos. Environ. 2011, 45, 1328-1336.

30. Yu, Z.Y.; Yuan, J.Y.; Yu, Y.; Zhang, W.; Wu, Z.H. Research on Relationship of Control Parameters of Cement Concrete Strength by Orthogonal Test Method. J. Huangshi Inst. Technol. 2012, 3, 38-41.

31. Lin, Y.; Yang, X.G.; MA, Y.Y. An Analysis of Factors Causing Congestion with the Application of Orthogonal Experimental Design Method. Syst. Eng. 2005, 10, 39-43.

32. Hornik, K.; Stinchcombe, M.; White, H. Multilayer feedforward networks are universal approximators. Neural Netw. 1989, 2, 359-366.

33. Li, L. Study on urban air quality forecast model based on adaptive artificial neural network. M.Sc. Thesis, Sun Yet-Sen University, Guangzhou, China, 2011.

34. Zhu, Q.R. Study on combined urban air quality forecast model. M.Sc. Thesis, Sun Yet-sen University, Guangzhou, China, 2013.

35. Cai, M.; Yin, Y.; Xie, M. Prediction of hourly air pollutant concentrations near urban arterials using artificial neural network approach. Transp. Res. Part D Transp. Environ. 2009, 14, 32-41.

36. Singh, K.P.; Gupta, S.; Kumar, A.; Shukla, S.P. Linear and nonlinear modeling approaches for urban air quality prediction. Sci. Total Environ. 2012, 426, 244-255.

37. Kurt, A.; Oktay, A.B. Forecasting air pollutant indicator levels with geographic models 3days in advance using neural networks. Expert Syst. Appl. 2010, 37, 7986-7992. 


\title{
Source Apportionment of Sulfate and Nitrate over the Pearl River Delta Region in China
}

\author{
Xingcheng Lu and Jimmy C. H. Fung
}

Abstract: In this work, the Weather Research Forecast (WRF)-Sparse Matrix Operator Kernel Emission (SMOKE)-Comprehensive Air Quality Model with Extensions (CAMx) modeling system with particulate source apportionment technology (PSAT) module was used to study and analyze the source apportionment of sulfate and nitrate particulate matter in the Pearl River Delta region (PRD). The results show that superregional transport was an important contributor for both sulfates and nitrates in all 10 cities in this region in both February (winter) and August (summer). Especially in February, the average super-regional contribution of sulfate and nitrate reached up to $80 \%$ and $56 \%$ respectively. For the local and regional source category, power plant emissions (coal-fired and oil-fired) and industry emissions were important for sulfate formation in this region. Industry emissions and mobile emissions are important for nitrate formation in this region. In August, the sum of these two sources contributed around over $60 \%$ of local and regional nitrate. The contributions from power plant emissions and marine emissions became important in August due to the southerly prevailing wind direction. Area sources and biogenic emissions were negligible for sulfate and nitrate formation in this region. Our results reveal that cross-province cooperation is necessary for control of sulfates and nitrates in this region.

Reprinted from Atmosphere. Cite as: Lu, X.; Fung, J.C.H. Source Apportionment of Sulfate and Nitrate over the Pearl River Delta Region in China. Atmosphere 2016, 7,98 .

\section{Introduction}

Rapid and continuous economic growth has brought great wealth to China, and the material living conditions of its citizens have improved greatly. However, the large-scale urbanization process is modifying the landscape and turning more and more forests and wetlands into concrete surfaces. The urbanization process has also played a role in clustering vehicles and industrial factories, which leads to worsening environmental conditions. Since the implementation of the openness policy, the Pearl River Delta (PRD) region has become China's major engine for economic growth and one of the world's main manufacturing hubs. Although the incomes and convenience of living of the local residents have greatly improved, more and more people have complained about the smell of waste water, poor visibility, and inhalation of high 
levels of air pollutants. $\mathrm{PM}_{2.5}, \mathrm{NO}_{2}$, and $\mathrm{O}_{3}$ are the three major ambient pollutants in this region. According to the observation data, the peak ozone concentration exceeded $100 \mathrm{ppb}$ in 15 days during August 2011 at the Guangzhou Luhu station. In Hong Kong, the average $\mathrm{NO}_{2}$ concentration surpassed 80 ppb in February 2011 at Causeway Bay, a roadside station. At the Nansha station, the $\mathrm{PM}_{2.5}$ concentrations reached $150 \mathrm{\mu g} / \mathrm{m}^{3}$ during four episodes with high levels of particulate matter (PM) in January 2011. Once emitted or formed in the atmosphere, these pollutants can also be deposited onto the ground via wet deposition and dry deposition. Acid rain is another important problem caused by substantial emissions of $\mathrm{SO}_{2}$ and $\mathrm{NO}_{\mathrm{x}}$ in this region [1].

The air quality issues mentioned above have inspired many studies of these problems over this region. In the meteorological model MM5 simulation study, Lo et al. [2] found that urbanization played a significant role in trapping pollutants by influencing the land-sea breezes around the PRD region. Li et al. [3] applied the CAMx model coupled with ozone source apportionment technology (OSAT) to study the sources of ozone during episode days and found that superregional transport is an important source of ozone in this region. Wu et al. [4] also used the chemical transport model CAMx coupled with particulate source apportionment technology (PSAT) to study the source apportionment of fine PM and found that local mobile emissions and superregional transport were the dominant contributors of PM over this region. Yao et al. [5] found that the mountains to the north of the PRD region trapped pollutants and further worsened the air quality. Lu et al. [6] recently applied CAMx-OSAT to study the source apportionment of ambient $\mathrm{NO}_{\mathrm{x}}$ in this region and found that heavy duty diesel vehicles are the major contributor to this pollutant. Many observation-based studies have also been launched in this region. For example, Yuan et al. [7] applied a positive matrix factorization method to identify the major sources of $\mathrm{PM}_{10}$ in Hong Kong and found that vehicle emissions were the greatest contributor. Xue et al. [8] claimed that the liquid water content could determine the sulfate and nitrate abundance in $\mathrm{PM}_{2.5}$ at polluted sites in Hong Kong. With all of these studies, the generation mechanism and cause of episodes for related pollutants have been relatively well described in the PRD region.

$\mathrm{PM}_{2.5}$ is liquid or solid matter suspended in the air with a particle aerodynamic diameter of less than $2.5 \mu \mathrm{m}$. Long-term exposure to this pollutant may increase the risk of cardiovascular disease, respiratory disease, lung cancer, and other disorders. $\mathrm{PM}_{2.5}$ has several components, including sulfates, nitrates, biogenic components, and crustal dust. Wu et al. [4] performed a detailed source apportionment analysis for this pollutant over this region during April and December. However, this pollutant has several important components that may come from different regions or processes. Therefore, to further understand these sources, it is necessary to study the sources of its major components. Unlike some primary gaseous pollutants $\left(\mathrm{NO}_{\mathrm{x}}\right.$ and $\left.\mathrm{SO}_{2}\right)$, 
$\mathrm{PM}_{2.5}$ cannot be merely reduced by simply controlling specific single source. Sulfates and nitrates are the two important anthropogenic components of $\mathrm{PM}_{2.5}$ in this region and they can be controlled effectively once their sources are identified. Therefore, the $\mathrm{PM}_{2.5}$ concentration can be reduced gradually if the local government can first focus on controlling sulfate and nitrate. According to Huang et al. [9], $\mathrm{PM}_{2.5}$ in western Hong Kong consisted of 31\% secondary sulfate and 13\% secondary nitrate. Zhang et al. [10] studied sulfate and nitrate sources throughout China with the CMAQ model at a $36-\mathrm{km}$ grid resolution and found that power plant and mobile emissions were the dominant sources of these two components. In this study, we applied a Weather Research Forecast (WRF)-Sparse Matrix Operator Kernel Emission (SMOKE)-Comprehensive Air Quality Model with Extensions (CAMx) modeling system and PSAT to study the source apportionment of sulfates and nitrates in the PRD region with a 3-km model resolution, which is sufficiently fine to analyze local contribution, regional transport (from other cities within the PRD region), and superregional transport (from outside the PRD region). We chose February and August 2011 to represent both winter (northerly prevailing winds) and summer (southerly prevailing winds) conditions in this region.

The remainder of this article is organized as follows. Section 2 describes the model domain setting, the choice of the parameterization scheme, the emission inventory, and the PSAT module. Section 3 contains the model evaluation and a discussion of the source apportionment results; and the overall study is summarized in Section 4.

\section{Model and Methods}

\subsection{Model Description}

Weather Research Forecast v3.2 (WRF) was used to simulate the meteorology field in this study. The WRF scheme selection is listed as follows. We chose Grell-Devenyi ensemble cumulus parameterization for cumulus scheme, WRF single-moment six-class scheme for microphysics, the Yonsei University PBL scheme, Dudhia's shortwave radiation scheme, the rapid radiative transfer model for long-wave radiation and the Noah land-surface model. The observation data (wind and temperature) from Hong Kong Observatory were nudged to domain 3. The ambient pollutant concentration was simulated by CAMx v6.00, and Euler backward iterative (EBI) was used for chemical solver, the RADM scheme for aqueous phase chemistry, the K-theory for vertical diffusion, CB05 for gas phase chemistry, ISORROPIA v1.7 for the inorganic aerosol scheme, and SOAP for the secondary organic scheme.

The domain setting is shown in Figure 1. In general, our simulation had three nested domains with resolutions of $27 \mathrm{~km}, 9 \mathrm{~km}$, and $3 \mathrm{~km}$. The boundary 
conditions for domain 1 were generated from GEOS-Chem to better match the Asian pollutant background [11]. The outer domain covered a large part of China and some other countries, such as Korea, Japan, and Thailand. Domain 2 covered the entire Guangdong province, and domain 3 included all of the important cities in the PRD region. One should note that the domain for the meteorology model (in black) was intentionally larger than that for the air quality model (in red) because it can help to minimize the boundary effect for air quality simulation.
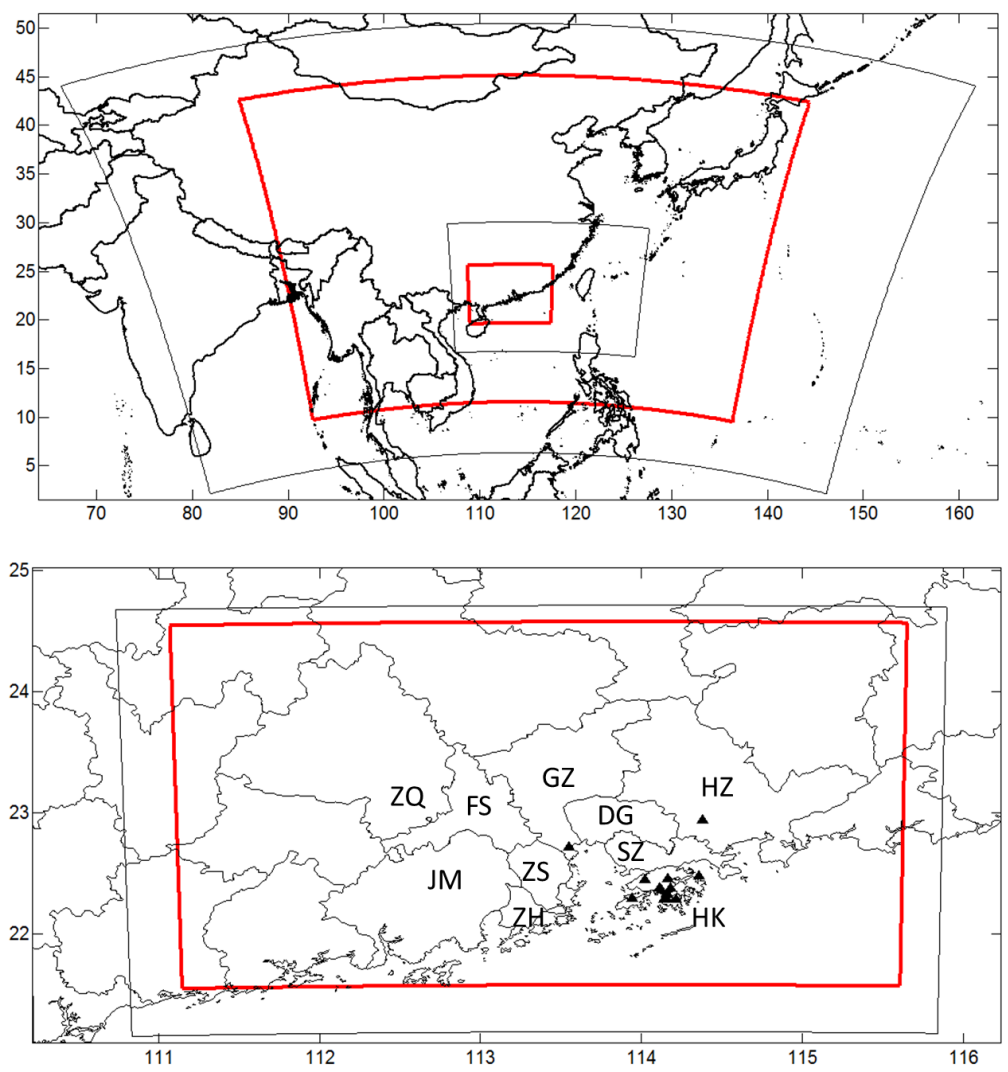

Figure 1. Model domain setting and air quality station location (triangles). HK, Hong Kong; SZ, Shenzhen; DG, Dongguan; HZ, Huizhou; GZ, Guangzhou; FS, Foshan; ZQ, Zhaoqing; JM, Jiangmen; ZH, Zhuhai; ZS, Zhuhai.

The emission inventory for domains 1 and 2 was based on the INTEX-B 2006 regional emission inventory with some updates according to the study from Zhang et al. [12]. For domain 3, the PRD region, a highly resolved emission inventory in this region for 2006 was implemented [13]. The PRD emission mapping for $\mathrm{SO}_{2}$ and $\mathrm{NO}_{\mathrm{x}}$ is shown in Figure 2. The emissions in this region are clustered in 
Shenzhen, Hong Kong, and Guangzhou. The emissions in some cities, such as Huizhou, Jiangmen, and Zhaoqing (see Figure 2), were much lower than those in the center of this region. The biogenic emissions were generated with the Model of Emission of Gases and Aerosols from Nature (MEGAN v2.04). The MEGAN inputs, such as the leaf area index and plant functional type, were all generated from MODIS satellite data. All emissions were processed and combined with the SMOKE (v2.4) system.
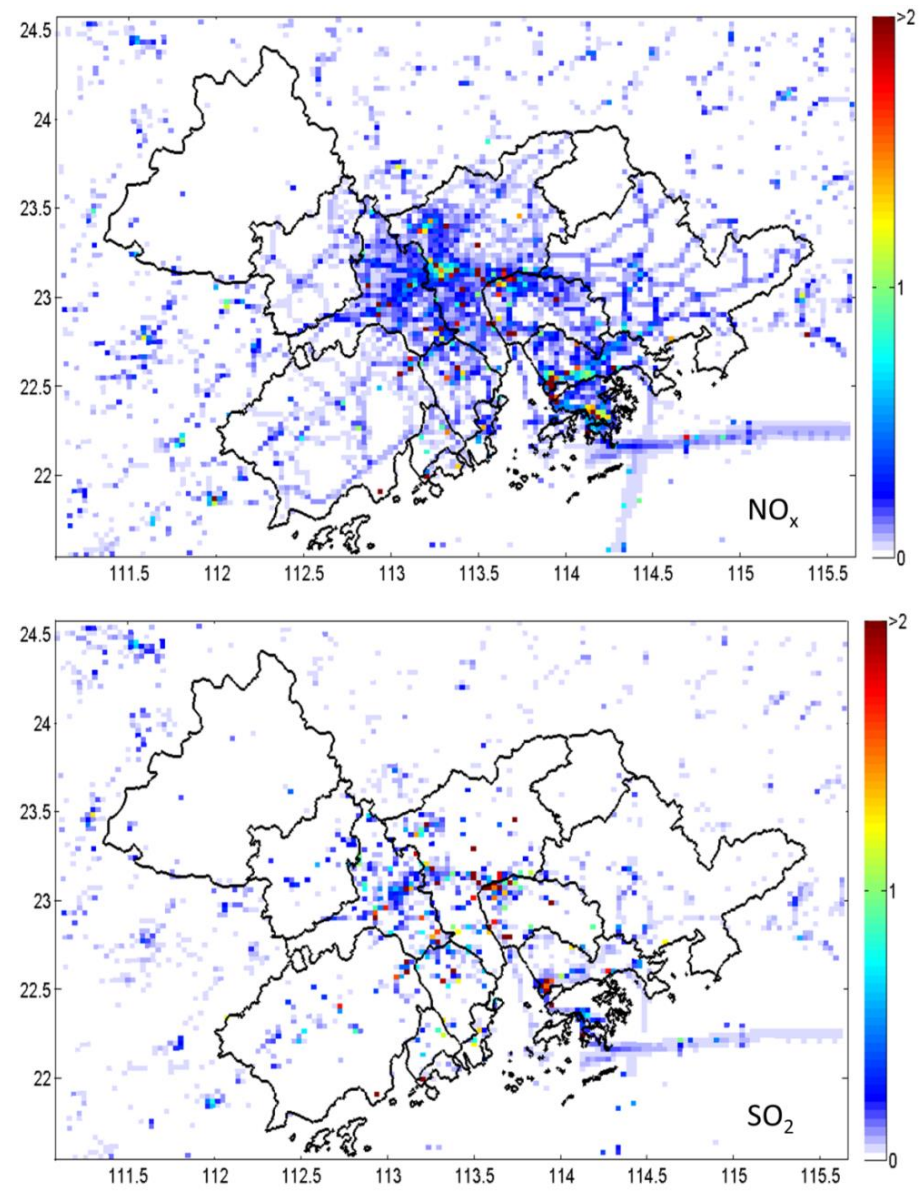

Figure 2. August and February averaged $\mathrm{SO}_{2}$ and $\mathrm{NO}_{x}$ emissions in the Pearl River Delta (PRD) region. Unit: moles/s.

\subsection{Particulate Source Apportionment Technology (PSAT)}

As a CAMx module, PSAT has been developed to track the sources (geographic regions and source categories) of PM components. PSAT can be used to track 
particulate sulfates, nitrates, ammonium, secondary organic aerosols, and six categories of primary PM. The locations at which secondary PM forms may not be the same as the locations at which the precursors are emitted into the atmosphere, and PSAT is able to track such process [14].

In this study, we separated the source into six categories and 10 regions. The categories include mobile sources, industrial point sources, power plant point sources, area sources, marine sources, and biogenic sources in the PRD region. As shown in Figure 3, we separated the region into 10 cities: Guangzhou (GZ), Shenzhen (SZ), Huizhou (HZ), Dongguan (DG), Jiangmen (JM), Zhuhai (ZH), Zhongshan (ZS), Zhaoqing (ZQ), Foshan (FS), and Hong Kong (HK). In addition to the source categories and source regions, the PSAT can automatically track pollutants at the southern, northern, western, and eastern boundaries. The source apportionment of sulfates and nitrates in the region can be expressed by Equation (1).

$$
\text { Sulfate/Nitrate }(n)=\sum_{i=1}^{10} \sum_{j=1}^{6} S(i, j)+B C_{E+W+S+N}+I C
$$

where sulfate/nitrate $(n)$ is the sulfate and nitrate concentration in city $n, S(i, j)$ represents the sulfates or nitrates from city $i$ and source $j, B C$ is the boundary source from each of the four directions, and IC is the initial condition. We used local sources, regional sources, and superregional sources to analyze the results. A local source indicates that the source is a local city, a regional source indicates that the source is another city within the PRD region, and a superregional source indicates that the source is outside the PRD region.

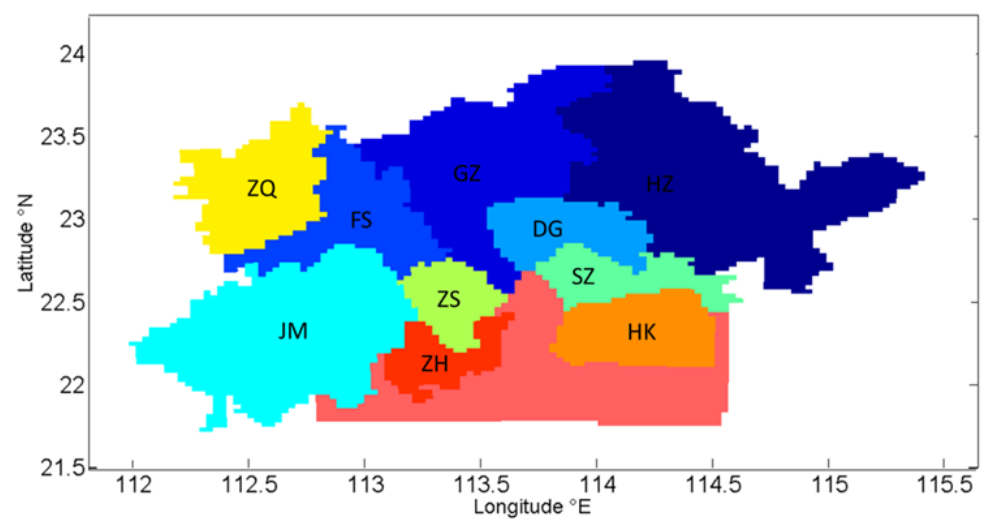

Figure 3. The source regions defined in the PRD region. 


\section{Results and Discussion}

\subsection{Model Evaluation}

Observation data from 37 meteorology stations in the PRD region were used in our evaluation. Table 1 presents the evaluation (37 stations on average) of the 2-m temperature, wind speed, and wind direction as simulated by WRF. The index of agreement (IOA) formula used for wind direction in this study differs from the formulation for scalar variables; it follows that introduced by Kwok et al. [9]. For the wind speed simulation results, the root-mean-square error (RMSE) ranged from 1.4 to 1.8 , the normalized mean bias (NMB) ranged from 0.29 to 0.37 , and the IOA ranged from 0.68 to 0.7 . The IOA for wind speed was better than 0.88 for both February and August. For the 2-m temperature, the NMB was 0.12 for February and -0.009 for August, which indicates that the temperature was slightly overestimated in winter and underestimated in summer. The simulated meteorology field can reveal the difference between rural area and urban area. The spatial wind mapping can be found in [6]. The results were good and acceptable for further use to drive the air quality model.

Table 1. Evaluation of hourly Weather Research Forecast (WRF) meteorology simulation.

\begin{tabular}{ccccc}
\hline & & RMSE & NMB & IOA \\
\hline \multirow{3}{*}{ February } & Wind speed & 1.8 & 0.29 & 0.70 \\
& Wind direction & - & -0.16 & 0.88 \\
& Temperature (2m) & 3 & 0.12 & 0.81 \\
\hline \multirow{3}{*}{ August } & Wind speed & 1.4 & 0.37 & 0.68 \\
& Wind direction & - & 0.05 & 0.88 \\
& Temperature (2m) & 2.2 & -0.009 & 0.73 \\
\hline
\end{tabular}

Table 2 shows the model evaluation statistics matrix for the hourly CAMx results for $\mathrm{PM}_{2.5}$, sulfates, and nitrates. We used 14 stations in the PRD region to evaluate the $\mathrm{PM}_{2.5}$ simulation; the station locations are shown in Figure 1. For sulfates and nitrates, we have only the hourly data from the Hong Kong University of Science and Technology supersite $\left(22.34^{\circ} \mathrm{N}, 114.27^{\circ} \mathrm{E}\right)$. Figure 4 shows the $\mathrm{PM}_{2.5}$ time series comparison between the simulation and the observations. In general, the model yielded a reasonable $\mathrm{PM}_{2.5}$ simulation; the RMSE ranged from 17.1 to 20.1 , the IOA ranged from 0.68 to 0.76 , and the NMB ranged from -0.24 to -0.012 . The sulfate simulation was also acceptable; the RMSE, IOA, and NMB ranged from 4.9 to 6.1, 0.60 to 0.81 , and -0.35 to -0.19 , respectively. However, the nitrate simulation was not as good as those for sulfates and $\mathrm{PM}_{2.5}$. This nitrate simulation discrepancy has also been noted in other studies [15], probably this is due to (1): the discrepancy 
in $\mathrm{HNO}_{3}$ and $\mathrm{NH}_{3}$ dry deposition velocity simulation [16]; (2): the emission of ammonium and $\mathrm{NO}_{x}$ had significant room for improvement from the spatial and temporal aspects; (3): the imperfect simulation for the chemical reaction involving $\mathrm{Ca}^{2+}, \mathrm{Na}^{+}$and $\mathrm{HNO}_{3}$ since these reactions are important for the coarse mode nitrate formation [17]. Nonetheless, the nitrate simulation by the CAMx model can catch the magnitude of the observation data in both August and February, as shown in Table 2.
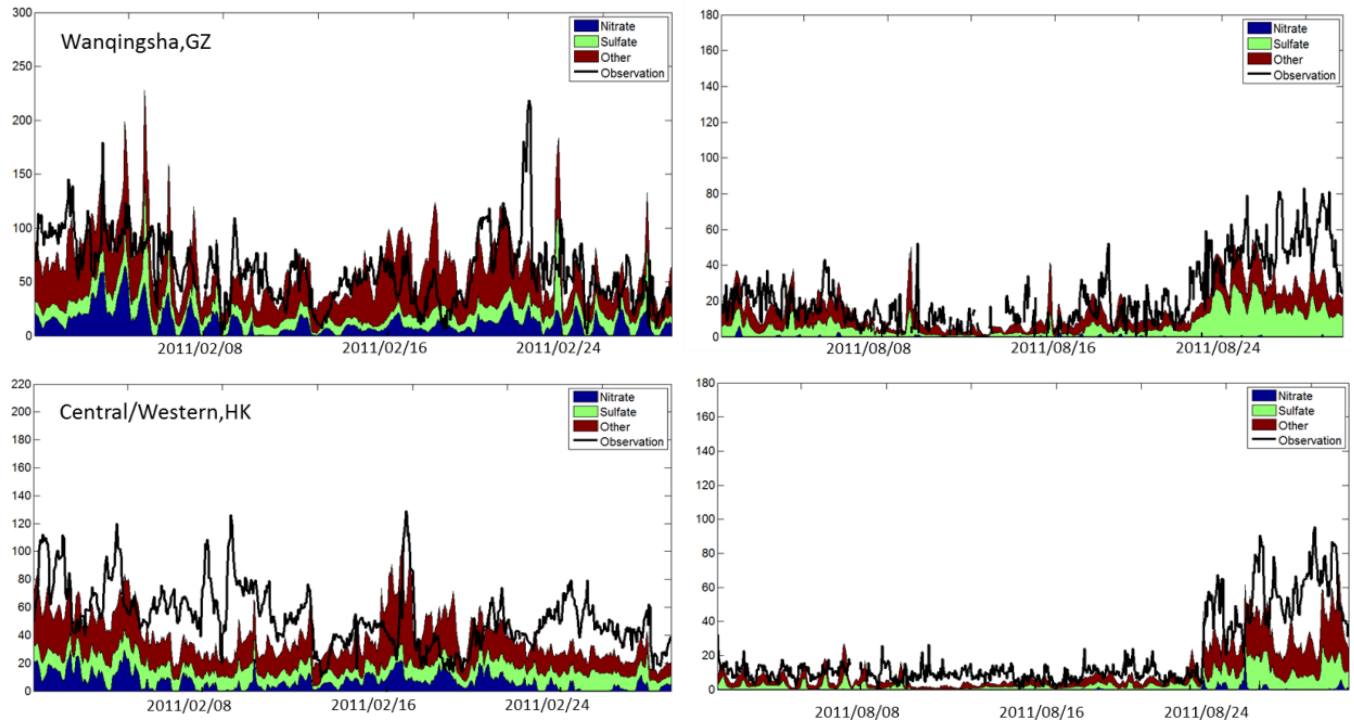

Figure 4. Model and observation comparison for two stations in the PRD region.

Table 2. Evaluation of hourly particulate matter $\left(\mathrm{PM}_{2.5}\right)$, sulfate and nitrate simulated by Comprehensive Air Quality Model with Extensions (CAMx).

\begin{tabular}{cccccc}
\hline PM $_{2.5}$ & RMSE & IOA & NMB & Mean-Sim & Mean-OBS \\
\hline February & 20.1 & 0.68 & -0.012 & 44.2 & 43.5 \\
August & 17.1 & 0.76 & -0.24 & 19.9 & 26.0 \\
\hline Sulfate & RMSE & IOA & NMB & Mean-Sim & Mean-OBS \\
\hline February & 6.1 & 0.60 & -0.19 & 10.6 & 13.2 \\
August & 4.9 & 0.81 & -0.35 & 4.2 & 6.6 \\
\hline Nitrate & RMSE & IOA & NMB & Mean-Sim & Mean-OBS \\
\hline February & 6.0 & 0.43 & 0.62 & 5.2 & 3.2 \\
August & 1.5 & 0.29 & -0.51 & 0.4 & 0.8 \\
\hline
\end{tabular}




\subsection{Local, Regional and Super-Regional Contribution}

Table 3 shows the local, regional, and superregional contributions of sulfates and nitrates in the 10 PRD cities during February and August. Table 4 shows the regional contribution to a specific city by other cities (the top 3 contributors are shown) in the PRD region. The superregional contribution is the dominant sulfate source in February over the 10 cities, ranging from 66.8\% (Foshan) to $94.0 \%$ (Huizhou), mainly because the northerly prevailing winds blew this pollutant from northern China into the PRD region during winter. Huizhou is in the northwestern part of the PRD region and has low local emissions. It is the first station reached by pollutants entering the PRD region; as a result, the superregional contribution of sulfates reached almost $100 \%$ in this city. The local contribution and regional contribution in Foshan were relatively higher than those in the other nine cities, mainly due to the substantial emissions from this city, as shown in Figure 2, and because Foshan is immediately adjacent to Guangzhou, which is the largest city in the region and also has substantial emissions. As shown in Table 4, Guangzhou contributed 49\% of the regional sulfate to Foshan in February. The superregional contributions for Shenzhen and Hong Kong were 82.4\% and 91.6\%, respectively. During August, the superregional contribution of sulfate decreased to half the level in February, mainly due to the southerly prevailing winds during summer in this region. In August, the superregional contributions ranged from 59.9\% (Shenzhen) to $77.4 \%$ (Zhuhai). The local contributions from Shenzhen and Guangzhou were the highest $-21.6 \%$ and $18.6 \%$, respectively-partly due to the large number of vehicles in these two major cities. In 2014, the number of vehicles in Guangzhou and Shenzhen reached 2.7 million and 2.9 million, respectively. From the analysis mentioned above and from Table 3, it can be seen that sulfates came mainly from sources outside the local city; hence, the pollutant issue cannot be solved by local government alone.

The average nitrate concentration in August in the PRD region was only $0.6 \mu \mathrm{g} / \mathrm{m}^{3}$. This low concentration was mainly a result of the partitioning of particulate nitrates to a gas phase at high temperatures. Due to the southerly prevailing winds, the regional contribution of nitrates from other cities in the PRD region was greater than the superregional contribution, except for in Jiangmen. In February, the superregional contribution of nitrate ranged from $42.2 \%$ in Foshan to $84.5 \%$ in Huizhou. As with sulfates, the high superregional nitrate contribution in Huizhou was mainly a result of its geographic location and the wind direction. There were relatively fewer nitrates from superregional sources. One reason for this finding is the rapid transformation of $\mathrm{NO}_{x}$ into $\mathrm{HNO}_{3}$, which increased the levels of locally and regionally generated nitrates [18]. The regional contribution ranged from $3.6 \%$ in Huizhou to $49.5 \%$ in Zhongshan. The northerly prevailing winds prevent much of the nitrates generated in the PRD (Shenzhen and Hong Kong) from entering Huizhou. In February, Hong Kong is downwind from Shenzhen and Huizhou; hence, the regional nitrates 
were mainly contributed by these two cities, whose contributions were $47 \%$ and $34 \%$, respectively, as shown in Table 4. As with sulfates, a substantial amount of nitrates came mainly from regional and superregional sources; therefore, the control policy for this pollutant requires intergovernmental cooperation. However, one should note that there exists uncertainty for the model simulation results. The uncertainty derived from emission inventory, meteorology field, and the chemical reaction mechanism. The overestimation of wind speed may lead to the possible overestimation of regional and super-regional transport contribution. Since not all the chemical reactions are included in the model, the uncertainty is not small for the source apportionment results. In the future, more observation data is needed to quantify the gap between the model simulation and true condition.

Table 3. Local, regional and super-regional contribution of sulfate and nitrate in 10 cities over the PRD region (in $\mu \mathrm{g} / \mathrm{m}^{3}$ ).

\begin{tabular}{|c|c|c|c|c|c|c|}
\hline \multicolumn{7}{|c|}{ Sulfate } \\
\hline & \multicolumn{3}{|c|}{ February } & \multicolumn{3}{|c|}{ August } \\
\hline & Local & Regional & S-Regional & Local & Regional & S-Regional \\
\hline $\mathrm{HZ}$ & $0.4(4 \%)$ & $0.2(2 \%)$ & $10.0(94 \%)$ & $0.3(6 \%)$ & $1.1(23 \%)$ & $3.4(71 \%)$ \\
\hline GZ & $1.5(12 \%)$ & $1.3(10 \%)$ & $9.5(78 \%)$ & $1.3(19 \%)$ & $1.6(23 \%)$ & $4.0(58 \%)$ \\
\hline FS & $1.6(11 \%)$ & $3.0(22 \%)$ & $9.3(67 \%)$ & $1.0(14 \%)$ & $1.8(26 \%)$ & $4.1(60 \%)$ \\
\hline DG & $1.2(10 \%)$ & $1.3(11 \%)$ & $9.7(79 \%)$ & $0.9(16 \%)$ & $1.4(24 \%)$ & $3.6(60 \%)$ \\
\hline JM & $1.0(8 \%)$ & $1.9(16 \%)$ & $9.0(76 \%)$ & $0.6(12 \%)$ & $0.8(15 \%)$ & $3.9(74 \%)$ \\
\hline SZ & $1.3(11 \%)$ & $0.7(7 \%)$ & $9.8(82 \%)$ & $1.2(22 \%)$ & $1.0(19 \%)$ & $3.3(60 \%)$ \\
\hline ZS & $0.7(6 \%)$ & $2.5(20 \%)$ & $9.3(74 \%)$ & $0.4(8 \%)$ & $1.2(23 \%)$ & $3.5(69 \%)$ \\
\hline ZQ & $0.8(6 \%)$ & $2.7(21 \%)$ & $9.2(73 \%)$ & $0.4(6 \%)$ & $1.9(27 \%)$ & $4.7(67 \%)$ \\
\hline HK & $0.4(4 \%)$ & $0.5(5 \%)$ & $10.0(92 \%)$ & $0.7(16 \%)$ & $0.5(12 \%)$ & $3.1(73 \%)$ \\
\hline $\mathrm{ZH}$ & $0.6(5 \%)$ & $1.6(14 \%)$ & $9.3(81 \%)$ & $0.3(7 \%)$ & $0.7(15 \%)$ & $3.3(77 \%)$ \\
\hline \multicolumn{7}{|c|}{ Nitrate } \\
\hline & \multicolumn{3}{|c|}{ February } & \multicolumn{3}{|c|}{ August } \\
\hline & Local & Regional & S-Regional & Local & Regional & S-Regional \\
\hline $\mathrm{HZ}$ & $0.7(12 \%)$ & $0.2(4 \%)$ & $5.0(85 \%)$ & $0.1(13 \%)$ & $0.4(49 \%)$ & $0.3(38 \%)$ \\
\hline GZ & $1.7(17 \%)$ & $3.2(33 \%)$ & $4.8(50 \%)$ & $0.2(22 \%)$ & $0.5(54 \%)$ & $0.2(24 \%)$ \\
\hline FS & 1.7 (14\%) & $5.4(44 \%)$ & $5.2(42 \%)$ & $0.2(23 \%)$ & $0.4(49 \%)$ & $0.2(28 \%)$ \\
\hline DG & $0.8(10 \%)$ & $2.7(34 \%)$ & $4.3(55 \%)$ & $0.04(11 \%)$ & $0.2(58 \%)$ & $0.1(31 \%)$ \\
\hline JM & $0.9(9 \%)$ & $4.3(47 \%)$ & $4.1(44 \%)$ & $0.2(25 \%)$ & $0.2(31 \%)$ & $0.3(44 \%)$ \\
\hline SZ & $1.0(13 \%)$ & $1.4(19 \%)$ & $5.0(68 \%)$ & $0.1(14 \%)$ & $0.2(51 \%)$ & $0.1(35 \%)$ \\
\hline ZS & $0.6(5 \%)$ & $5.4(50 \%)$ & $4.9(45 \%)$ & $0.1(11 \%)$ & $0.4(64 \%)$ & $0.2(25 \%)$ \\
\hline ZQ & $0.8(7 \%)$ & $5.5(48 \%)$ & $5.2(45 \%)$ & $0.1(8 \%)$ & $0.6(60 \%)$ & $0.3(32 \%)$ \\
\hline HK & $0.6(10 \%)$ & $0.8(14 \%)$ & $4.6(76 \%)$ & $0.1(30 \%)$ & $0.2(40 \%)$ & $0.1(30 \%)$ \\
\hline $\mathrm{ZH}$ & $0.5(6 \%)$ & $3.9(49 \%)$ & $3.6(45 \%)$ & $0.1(15 \%)$ & $0.3(59 \%)$ & $0.1(26 \%)$ \\
\hline
\end{tabular}


Table 4. Regional contribution of sulfates and nitrates by other cities (top 3 for each).

\begin{tabular}{lccccc}
\hline \multicolumn{5}{c}{ February } \\
\hline & Sulfate & & Nitrate & \\
\hline HZHK (24\%) & SZ (21\%) & DG (20\%) & SZ (34\%) & DG (22\%) & GZ (21\%) \\
GZDG (28\%) & HK (21\%) & SZ (18\%) & DG (24\%) & SZ (24\%) & HK (19\%) \\
FS GZ (49\%) & HK (12\%) & JM (9\%) & GZ (38\%) & HK (12\%) & DG (11\%) \\
DGSZ (31\%) & HZ (31\%) & HK (18\%) & HZ (34\%) & SZ (34\%) & HK (20\%) \\
JM GZ (27\%) & FS (21\%) & HK (15\%) & GZ (29\%) & FS (22\%) & DG (12\%) \\
SZ HK (36\%) & HZ (30\%) & DG (23\%) & HK (40\%) & HZ (39\%) & DG (17\%) \\
ZS HK (23\%) & SZ (17\%) & ZH (14\%) & HK (24\%) & GZ (20\%) & SZ (20\%) \\
ZQ FS (34\%) & GZ (19\%) & JM (14\%) & FS (28\%) & GZ (26\%) & JM (15\%) \\
HKSZ (55\%) & HZ (20\%) & DG (11\%) & SZ (47\%) & HZ (34\%) & DG (11\%) \\
ZHHK (26\%) & DG (15\%) & SZ (14\%) & HK (21\%) & GZ (20\%) & SZ (20\%) \\
\hline
\end{tabular}

\begin{tabular}{lccccc}
\hline \multicolumn{5}{c}{ August } \\
\hline Sulfate & & & Nitrate \\
\hline HZHK (36\%) & DG (21\%) & SZ (18\%) & HK (39\%) & SZ (27\%) & DG (17\%) \\
GZDG (30\%) & HK (16\%) & FS (14\%) & DG (21\%) & HK (16\%) & FS (14\%) \\
FS GZ (27\%) & JM (16\%) & DG (15\%) & JM (37\%) & GZ (17\%) & ZH (15\%) \\
DGSZ (32\%) & HK (27\%) & GZ (15\%) & SZ (27\%) & HK (25\%) & GZ (13\%) \\
JM HK (21\%) & FS (17\%) & ZH (16\%) & FS (27\%) & ZH (27\%) & GZ (20\%) \\
SZ HK (62\%) & DG (13\%) & GZ (7\%) & HK (51\%) & GZ (13\%) & DG (10\%) \\
ZS ZH (23\%) & HK (19\%) & GZ (18\%) & HK (20\%) & ZH (20\%) & GZ (19\%) \\
ZQ FS (23\%) & GZ (16\%) & JM (16\%) & JM (38\%) & FS (16\%) & ZH (12\%) \\
HKSZ (41\%) & DG (20\%) & GZ (15\%) & SZ (39\%) & GZ (16\%) & DG (14\%) \\
ZHHK (25\%) & GZ (18\%) & DG (16\%) & GZ (25\%) & SZ (21\%) & DG (14\%) \\
\hline
\end{tabular}

\subsection{Source Category Contribution}

Figure 5 shows the source categories of sulfates and nitrates for local and regional sources over the PRD region in August. As shown in Table 3, in February, most of the sulfate and nitrate are from the super-regional source. Therefore, we only show the source category for August in this part. In this month, power plants were the dominant regional and local sulfate source, followed by industrial sources. Because of the seasonal wind effect, the pollutants emitted from the power plants are blown to the north by the southerly winds, and the sulfate contribution from this source therefore became important. Contini et al. [19] also found that power plant emission can contribute to the sulfate emission in Italy. At the same time, the wind pattern can also influence the contribution of the marine sources. For example, as seen in Figure 2, the ocean channel is located at the southeastern part of this region, and the marine contribution of sulfates in Hong Kong exceeded 30\% under southerly wind conditions. The importance of marine emissions for the sulfate formation can also be found in European cities [20,21]. The sulfate contribution from mobile 
emissions is shown to be relatively large in this work when compared to another study which used the INTEX-B as the only emission inventory [10]. The reason for this is because the $\mathrm{SO}_{2}$ emitted by vehicles in the emission inventory we used [13] was relatively larger than that in INTEX-B [12]. In the PRD 2006 emission inventory, the ratio of mobile emitted $\mathrm{SO}_{2}$ over the power plant emitted $\mathrm{SO}_{2}$ was $10.5 \%$; while in INTEX-B, this ratio was only around $0.7 \%$. The area sources and biogenic sources contributed only a negligible amount of sulfates over this region in this month.

The main contributors of nitrates in August were mobile (average 33.9\%) and power plant (average 35.7\%) emissions. The sum of mobile and power plant contributions in all the cities is above $60 \%$. In this month, industrial and marine emissions also contributed a substantial amount of nitrate. As with sulfates, biogenic emissions of nitrates were also negligible over this region. Due to the southerly winds, marine sources contributed over 15\% of nitrate in Shenzhen and Hong Kong (including aged sea-spray sodium nitrate). In order to control the nitrate in this region, the local government should focus on two points: (1) take action to control mobile emissions (e.g., odd-even number restriction); (2) reduce the industrial emission by establishing stricter supervision regulation. However, as is the case with sulfate, super-regional contribution is of great importance and therefore cross regional cooperation is highly important.

\subsection{Source Apportionment in City Center}

The city center of an urban area is the commercial and geographical heart of the city. It has a high population density, and its air quality has important effects on the health of local citizens. Hence, to protect public health, it is also important for city government to formulate a specific control policy for these areas. In this study, we further analyzed the city centers in Guangzhou $\left(23.13^{\circ} \mathrm{N}, 113.26^{\circ} \mathrm{E}\right)$, Shenzhen $\left(22.55^{\circ} \mathrm{N}, 114.10^{\circ} \mathrm{E}\right)$ and Hong Kong $\left(22.28^{\circ} \mathrm{N}, 114.16^{\circ} \mathrm{E}\right)$, which are the three most densely populated cities in the PRD region. Table 5 shows the source apportionment results for sulfates and nitrates in the city centers of the three major cities mentioned above. In February, the superregional contribution of sulfates in the city center of Hong Kong was similar to the average value for the whole city. However, the super-regional contribution in the city center of the other two cities was lower than the average value for the whole cities. In the INTEX-B emission inventory, the $\mathrm{SO}_{2}$ from power plants and industrial emissions represented $59 \%$ and $31 \%$ of total $\mathrm{SO}_{2}$ emission respectively. Hence, most of the sulfate in this region is coming from power plants and industrial sources. In Guangzhou, the contributions from regional and local sources made up $32 \%$ and $9 \%$ of total sulfates, respectively. In the city center of Shenzhen, the regional contribution of sulfate formation is $6 \%$ and the local sulfate contribution is $16 \%$. The regional contribution is low in the city center during February. One of the main reasons for this was that in February the 
predominant wind is in north-east direction and an important power plant is located in the southern part of this region. In August, the superregional contribution of sulfates decreased due to the southerly prevailing wind direction. In this month, the super-regional contribution of sulfate in the city centers of Shenzhen, Guangzhou and Hong Kong were $55 \%, 47 \%$ and $67 \%$. The regional and local source contribution increased due to the southern prevailing wind that brought the sulfate from the power plant to the city centers. In February, the superregional contribution of nitrates comprised more than $70 \%$ of the levels in the city centers of Hong Kong and Shenzhen, but only 39\% of the level in Guangzhou. Compared to the sulfate in February, the sum of regional and local sources of nitrate is larger. One main reason for this was that a substantial amount of nitrate is from mobile emissions and large number of vehicles were clustering in the city center. Hence, it is anticipated that traffic control policy should be effective in controlling the urban nitrate level. In August, super regional contributions of nitrate in the three city centers were all below $50 \%$, which is due to the southern prevailing wind, as noted above. As with the average value for the whole city, the superregional contribution was the most important source of sulfates and nitrates in the city center. This result further indicates that cooperation with other provinces is necessary for sulfate and nitrate control over the PRD region.

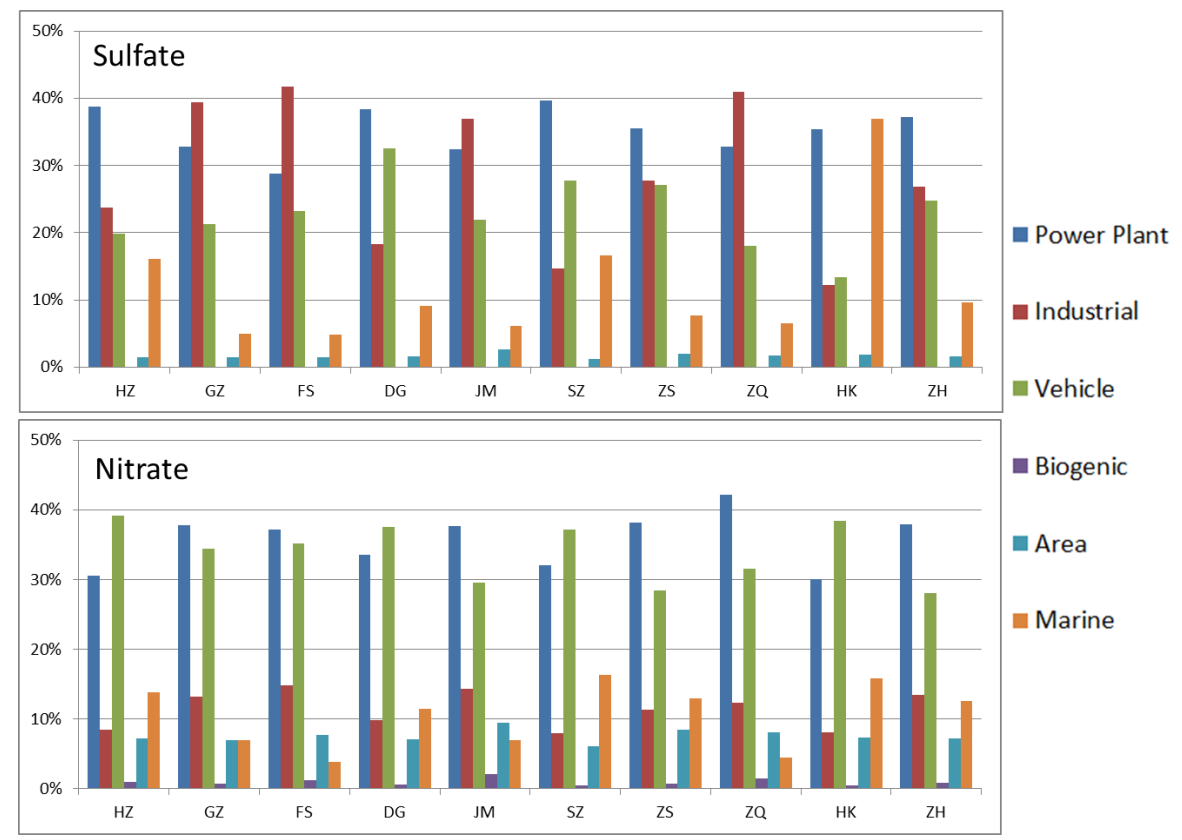

Figure 5. Source category of sulfates and nitrates over ten cities over the PRD region in August. 
Table 5. Source apportionment of sulfates and nitrates in the city centers of Guangzhou, Shenzhen and Hong Kong.

\begin{tabular}{cccc}
\hline February-Sulfates & GZ & SZ & HK \\
\hline Local & $32 \%$ & $16 \%$ & $6 \%$ \\
Regional & $9 \%$ & $6 \%$ & $3 \%$ \\
Super-regional & $59 \%$ & $78 \%$ & $91 \%$ \\
\hline August-Sulfates & GZ & SZ & HK \\
\hline Local & $32 \%$ & $25 \%$ & $23 \%$ \\
Regional & $18 \%$ & $20 \%$ & $10 \%$ \\
Super-regional & $47 \%$ & $55 \%$ & $67 \%$ \\
\hline February-Nitrates & GZ & SZ & HK \\
\hline Local & $27 \%$ & $15 \%$ & $12 \%$ \\
Regional & $34 \%$ & $14 \%$ & $9 \%$ \\
Super-regional & $39 \%$ & $71 \%$ & $79 \%$ \\
\hline August-Nitrates & GZ & SZ & HK \\
\hline Local & $33 \%$ & $24 \%$ & $11 \%$ \\
Regional & $47 \%$ & $43 \%$ & $49 \%$ \\
Super-regional & $20 \%$ & $33 \%$ & $40 \%$ \\
\hline
\end{tabular}

\section{Conclusions}

In this study, we applied the WRF-SMOKE-CAMx modeling system with PSAT to study the source apportionment of sulfates and nitrates in the PRD region. In both August and February, the superregional contribution was the dominant source of sulfates and nitrates in this region, although it was lower in August due to the southerly prevailing wind direction. The level of nitrates from superregional sources was lower than that of sulfates. The process and influencing conditions for this include: (1) the excess ammonia amount that can be reacted with nitric acid; (2) the temperature that is low enough to prevent the $\mathrm{HNO}_{3}$ vaporization [22]; (3) the wetness of the surface $\left(\mathrm{HNO}_{3}\right.$ can deposit quickly on the wet surface). Industrial sources and power plant emissions were the two major contributors among the regional and local sources. For nitrates, the contribution from mobile emissions was much greater than that from other sources and exceeded $40 \%$ in all 10 cities in this region during August. Given the high population density in the city centers, we also analyzed the source apportionment results in the city centers of Hong Kong, Guangzhou, and Shenzhen. As with the overall situation, the superregional contribution was very important in the city center, especially the city center of Hong Kong. With the exception of the superregional contribution, mobile sources contributed the most sulfates and nitrates in all three city centers during both months. Our results indicate that the sulfate and nitrate pollution issue cannot be 
solved by any single city or even by all 10 cities in the PRD region. A higher-level effort, such as interprovincial cooperation, is needed for a better control policy for this region. The $\mathrm{PM}_{2.5}$ pollution problem can be alleviated only when sulfates and nitrates are controlled effectively. Because the superregional contribution is important for these two pollutants, future study of the source apportionment over a larger area (e.g., including Hunan, Jiangxi, and Fujian provinces) with fine model resolution is necessary to better understand the sources from other provinces and their influence on the sulfate and nitrate levels in the PRD region. One of the limitations of this work was that we did not classify the source category in the super-regional contribution. Therefore, further work is needed to provide a more detailed source contribution for sulfate and nitrate formation in this region. This work focuses on sulfate and nitrate, the sources of other $\mathrm{PM}_{2.5}$ components, such as OC and EC, should be further studied once the sulfate and nitrate are controlled effectively over this region in the future.

Acknowledgments: This work was supported by the National Science Foundation of China (No. 41375103), NSFC/RGC Grant N_HKUST631/05, NSFC-GD Grant U1033001, and RGC Grant 16300715.

Author Contributions: Xingcheng Lu did the model simulation, analyzed the model results and wrote the paper. Xingcheng Lu and Jimmy Fung designed the framework of this paper and revised the paper.

Conflicts of Interest: The authors declare no conflict of interest.

\section{Appendix A.}

Model performance statistics formula:

$$
\begin{gathered}
\text { RMSE }=\sqrt{\frac{1}{n} \sum_{i=1}^{n}\left(S_{i}-O_{i}\right)^{2}} \\
I O A=1-\frac{\sum_{i=1}^{n}\left(O_{i}-S_{i}\right)^{2}}{\sum_{i=1}^{n}\left(\left|O_{i}-\bar{O}\right|+\left|S_{i}-\bar{S}\right|\right)^{2}} \\
N M B=\frac{\sum_{i=1}^{N}\left(S_{i}-O_{i}\right)}{\sum_{i=1}^{N} O_{i}} \times 100 \% \\
\text { Mean }-\operatorname{Sim}_{i} \frac{1}{n} \sum_{i=1}^{n} S_{i}
\end{gathered}
$$




$$
\begin{gathered}
\text { Mean }- \text { Obs }=\frac{1}{n} \sum_{i=1}^{n} O_{i} \\
I O A_{\text {wind }}=1-\frac{\sum_{i=1}^{N} f\left(\left|\theta_{i}-\phi_{i}\right|\right)}{180^{2}}, 0^{\circ} \leqslant \theta_{i} \leqslant 360^{\circ} \text { and } 0^{\circ} \leqslant \phi_{i} \leqslant 360^{\circ} \\
f\left(\left|\theta_{i}-\phi_{i}\right|\right)=\left|\theta_{i}-\phi_{i}\right|^{2},\left|\theta_{i}-\phi_{i}\right| \leqslant 180^{\circ} \\
f\left(\left|\theta_{i}-\phi_{i}\right|\right)=\left(360^{\circ}-\left|\theta_{i}-\phi_{i}\right|\right)^{2},\left|\theta_{i}-\phi_{i}\right|>180^{\circ}
\end{gathered}
$$

where "RMSE" represents root mean square error, "IOA" represents index of agreement, "IOAwind" represents the index of agreement for wind direction evaluation, "NMB" represents normalized mean bias, Mean-Sim represents the mean of the model simulation and Mean-Obs represents the mean of the observation results. $S_{i}$ is the hourly simulation, $O_{i}$ is the hourly observation value, $\theta_{i}$ is the observation wind direction and $\phi_{i}$ is the simulated wind direction at time $i$.

\section{References}

1. Lu, X.; Fung, J.C.H.; Wu, D. Modeling wet deposition of acid substances over the PRD region in China. Atmosp. Environ. 2015, 122, 819-828.

2. Lo, J.C.; Lau, A.K.; Fung, J.C.; Chen, F. Investigation of enhanced cross-city transport and trapping of air pollutants by coastal and urban land-sea breeze circulations. J. Geophys. Res. Atmos. 2006, 111.

3. Li, Y.; Lau, A.H.; Fung, J.H.; Zheng, J.Y.; Zhong, L.J.; Louie, P.K.K. Ozone source apportionment (OSAT) to differentiate local regional and super-regional source contributions in the Pearl River Delta region, China. J. Geophys. Res. Atmos. 2012, 117, D15-D16.

4. Wu, D.; Fung, J.C.H.; Yao, T.; Lau, A.K.H. A study of control policy in the Pearl River Delta region by using the particulate matter source apportionment method. Atmos. Environ. 2013, 76, 147-161.

5. Yao, T.; Fung, J.C.H.; Ma, H.; Lau, A.K.H.; Chan, P.W.; Yu, J.Z.; Xue, J. Enhancement in secondary particulate matter production due to mountain trapping. Atmos. Res. 2014, 147, 227-236.

6. Lu, X.; Yao, T.; Li, Y.; Fung, J.C.H.; Lau, A.K.H. Source apportionment and health effect of NOx over the Pearl River Delta region in southern China. Environ. Pollut. 2016, 212, 135-146.

7. Yuan, Z.; Lau, A.K.H.; Zhang, H.; Yu, J.Z.; Louie, P.K.; Fung, J.C. Identification and spatiotemporal variations of dominant $\mathrm{PM}_{10}$ sources over Hong Kong. Atmos. Environ. 2006, 40, 1803-1815. 
8. Xue, J.; Griffith, S.M.; Yu, X.; Lau, A.K.; Yu, J.Z. Effect of nitrate and sulfate relative abundance in $\mathrm{PM}_{2.5}$ on liquid water content explored through half-hourly observations of inorganic soluble aerosols at a polluted receptor site. Atmos. Environ. 2014, 99, 24-31.

9. Huang, X.H.; Bian, Q.; Ng, W.M.; Louie, P.K.; Yu, J.Z. Characterization of $\mathrm{PM}_{2.5}$ major components and source investigation in suburban Hong Kong: A one year monitoring study. Aerosol Air Qual. Res. 2014, 14, 237-250.

10. Zhang, H.; Li, J.; Ying, Q.; Yu, J.Z.; Wu, D.; Cheng, Y.; Jiang, J. Source apportionment of $\mathrm{PM}_{2.5}$ nitrate and sulfate in China using a source-oriented chemical transport model. Atmos. Environ. 2012, 62, 228-242.

11. Fu, J.; Lam, Y.; Gao, Y.; Jacob, D.; Carouge, C.; Dolwick, P.; Jang, C. Recent study of U.S. ozone background concentrations using GEOS-Chem. In Proceedings of the 5th GEOS-Chem Meeting, Cambridge, MA, USA, 2-5 May 2011.

12. Zhang, Q.; Streets, D.G.; Carmichael, G.R.; He, K.B.; Huo, H.; Kannari, A.; Klimont, Z.; Park, I.S.; Reddy, S.; Fu, J.S.; et al. Asian emissions in 2006 for the NASA INTEX-B mission. Atmos. Chem. Phys. 2009, 9, 5131-5153.

13. Zheng, J.; Zhang, L.; Che, W.; Zheng, Z.; Yin, S. A highly resolved temporal and spatial air pollutant emission inventory for the Pearl River Delta region, China and its uncertainty assessment. Atmos. Environ. 2009, 43, 5112-5122.

14. Yarwood, G.; Morris, R.E.; Wilson, G.M. Particulate matter source apportionment technology (PSAT) in the CAMx photochemical grid model. In Air Pollution Modeling and Its Application XVII; Springer US: New York, NY, USA, 2007; pp. 478-492.

15. Kwok, R.H.; Fung, J.C.; Lau, A.K.; Fu, J.S. Numerical study on seasonal variations of gaseous pollutants and particulate matters in Hong Kong and Pearl River Delta Region. J. Geophys. Res. Atmos. (1984-2012) 2010, 115.

16. Shimadera, H.; Hayami, H.; Chatani, S.; Morino, Y.; Mori, Y.; Morikawa, T.; Ohara, T. Sensitivity analysis of influencing factors on $\mathrm{PM}_{2.5}$ nitrate simulation. In Proceedings of the 11th Annual CMAS Conference, Chapel Hill, NC, USA, 15-17 October 2012.

17. Contini, D.; Cesari, D.; Genga, A.; Siciliano, M.; Ielpo, P.; Guascito, M.R.; Conte, M. Source apportionment of size-segregated atmospheric particles based on the major water-soluble components in Lecce (Italy). Sci. Total Environ. 2014, 472, 248-261.

18. Ying, Q.; Kleeman, M. Regional contributions to airborne particulate matter in central California during a severe pollution episode. Atmos. Environ. 2009, 43, 1218-1228.

19. Contini, D.; Cesari, D.; Conte, M.; Donateo, A. Application of PMF and CMB receptor models for the evaluation of the contribution of a large coal-fired power plant to $\mathrm{PM}_{10}$ concentrations. Sci. Total Environ. 2016, 560, 131-140.

20. Becagli, S.; Sferlazzo, D.M.; Pace, G.; Sarra, A.D.; Bommarito, C.; Calzolai, G.; Ghedini, C.; Lucarelli, F.; Meloni, D.; Monteleone, F.; et al. Evidence for heavy fuel oil combustion aerosols from chemical analyses at the island of Lampedusa: A possible large role of ships emissions in the Mediterranean. Atmos. Chem. Phys. 2012, 12, 3479-3492. 
21. Cesari, D.; Genga, A.; Ielpo, P.; Siciliano, M.; Mascolo, G.; Grasso, F.M.; Contini, D. Source apportionment of $\mathrm{PM}_{2.5}$ in the harbour-industrial area of Brindisi (Italy): Identification and estimation of the contribution of in-port ship emissions. Sci. Total Environ. 2014, 497, 392-400.

22. Griffith, S.M.; Huang, X.H.; Louie, P.K.K.; Yu, J.Z. Characterizing the thermodynamic and chemical composition factors controlling $\mathrm{PM}_{2.5}$ nitrate: Insights gained from two years of online measurements in Hong Kong. Atmos. Environ. 2015, 122, 864-875. 


\title{
Potential Sources of Trace Metals and Ionic Species in $\mathbf{P M}_{2.5}$ in Guadalajara, Mexico: A Case Study during Dry Season
}

\author{
Mario Alfonso Murillo-Tovar, Hugo Saldarriaga-Noreña, \\ Leonel Hernández-Mena, Arturo Campos-Ramos, Beatriz Cárdenas-González, \\ Jesús Efren Ospina-Noreña, Ricardo Cosío-Ramírez, José de Jesús Díaz-Torres \\ and Winston Smith
}

\begin{abstract}
This study was conducted from May 25 to June 6, 2009 at a downtown location (Centro) and an urban sector (Miravalle) site in the Metropolitan Zone of Guadalajara (MZG) in Mexico. The atmospheric concentrations of $\mathrm{PM}_{2.5}$ and its elemental and inorganic components were analyzed to identify their potential sources during the warm dry season. The daily measurements of $\mathrm{PM}_{2.5}(24 \mathrm{~h})$ exceeded the WHO (World Health Organization) air quality guidelines $\left(25 \mu \mathrm{g} \cdot \mathrm{m}^{-3}\right)$. The most abundant element was found to be Fe, accounting for $59.8 \%$ and $72.2 \%$ of total metals mass in Centro and Miravalle, respectively. The enrichment factor (EF) analysis showed a more significant contribution of non-crustal sources to the elements in ambient $\mathrm{PM}_{2.5}$ in Centro than in the Miravalle site. Particularly, the highest enrichment of $\mathrm{Cu}$ suggested motor vehicle-related emissions in Centro. The most abundant secondary ionic species $\left(\mathrm{NO}^{3-} ; \mathrm{SO}_{4}{ }^{2-}\right.$ and $\mathrm{NH}_{4}{ }^{+}$) and the ratio $\mathrm{NO}^{3-} / \mathrm{SO}_{4}{ }^{2-}$ corroborated the important impact of mobile sources to fine particles at the sampling sites. In addition, the ion balance indicated that particles collected in Miravalle experienced neutralization processes likely due to a higher contribution of geological material. Other important contributors to $\mathrm{PM}_{2.5}$ included biomass burning by emissions transported from the forest into the city.
\end{abstract}

Reprinted from Atmosphere. Cite as: Murillo-Tovar, M.A.; Saldarriaga-Noreña, H.; Hernández-Mena, L.; Campos-Ramos, A.; Cárdenas-González, B.; Ospina-Noreña, J.E.; Cosío-Ramírez, R.; de Jesús Díaz-Torres, J.; Smith, W. Potential Sources of Trace Metals and Ionic Species in $\mathrm{PM}_{2.5}$ in Guadalajara, Mexico: A Case Study during Dry Season. Atmosphere 2015, 6, 1858-1870.

\section{Introduction}

In urban environments, epidemiological studies suggest that particulate matter (PM) is an environmental pollutant with adverse effects on human health. In addition, the more meaningful association between PM exposure and occurrence of diseases are found for smaller airborne particles [1]. Short- and long-term exposure to particles with an aerodynamic diameter less than $2.5 \mu \mathrm{m}\left(\mathrm{PM}_{2.5}\right)$ is linked to an increased risk of cardiopulmonary and lung cancer mortality $[2,3]$ and reduced 
life expectancy [4]. Also, associations between chemical characteristics and PM toxicity tend to be stronger for the smaller PM size fractions [5]. Although air quality standards are used to control and manage exposure to its concentrations and emissions, a detailed understanding of the chemical composition of $\mathrm{PM}_{2.5}$ is essential, since chemical substances not only play a crucial role in toxicity but also could be employed as a fingerprint to identify its origin [6].

$\mathrm{PM}_{2.5}$ is constituted as a complex mixture of many different chemical substances resulting from distinct origin, either natural or anthropogenic, and from both primary and secondary particles with diverse effects on human health. Because diverse sources and multiple atmospheric processes are involved in the formation of $\mathrm{PM}_{2.5}$, its chemical characterization must be based on simultaneous chemical analysis. Since occurrence of inorganic ions and heavy metals is due to multiple atmospheric routes, and many of them are primarily present in fine particles $[7,8]$, these are very frequently analyzed to identify sources of $\mathrm{PM}_{2.5}$. In $\mathrm{PM}_{2.5}$, sulfate, nitrate and ammonium are the more abundant ionic species [9]; these can also indicate contribution either by direct emission or atmospheric reactions due to photochemical processes via gas-particle reactions involving their oxygenated precursors ( $\mathrm{NO}$ and $\mathrm{SO}_{2}$ ) [10-12]. Their occurrence in the urban environment can influence bioavailability of metals and exposure to fine particles may increase deposition of toxic compounds in the lungs $[13,14]$. Conversely, trace metals are minor components, and their origin is mainly by direct emission, either anthropogenic or/and geological [15]. With respect to their toxicity, transition metals such as Fe and $\mathrm{Cu}$ contribute to the oxidative capacity of PM [16]. Indeed, the ferrous ions in particle matter (PM) play an important role in the generation of hydroxyl radicals [17], a reactive oxygen species (ROS) that act synergistically with other PM-related chemical species. They can damage membrane lipids, proteins and DNA, which can alter respiratory immune responses in exposed individuals [18] and result in cell death via either necrotic or apoptotic processes and eventually cause and/or aggravate lung diseases [19]. Moreover, the element $\mathrm{Zn}$ has shown correlation with pulmonary inflammation by inhalation toxicology studies using animal models [20], and those elements with the lowest atmospheric concentration, such as $\mathrm{Cd}, \mathrm{Co}, \mathrm{Cr}, \mathrm{Ni}$ and $\mathrm{Pb}$, are known to be animal or human carcinogens [21].

The Metropolitan Zone of Guadalajara (MZG) that comprises Guadalajara City is located in the Atemajac valley in the western Mexican territory and has the second largest population in Mexico with around 4.4 million inhabitants in an urban area of about $2734 \mathrm{~km}^{2}$ [22]. Because the industry and vehicular traffic activities have rapidly risen from the nineties, the city of Guadalajara currently experiences a high stress on the environment, particularly in urban and peri-urban areas. There are frequent episodes of poor air quality in its urban area due to high atmospheric concentrations of ozone and particulate matter exceeding the Mexican 24-h standards, mainly 
occurring during dry seasons [23]. Therefore, the identification of emission sources is essential to finding effective methods to control exposure to air pollutants [24]. In addition, this can contribute to a better understanding of their formation mechanism in urban areas. So far, the earliest studies undertaken to identify sources suggest that $\mathrm{PM}_{2.5}$ in Guadalajara results from a mixture of anthropogenic and biogenic sources [25-28]. However, analysis of information on how particles are specifically emitted and how they respond to variations in their environment during the warm dry season is scarce.

Hence, the present study aims, with a short and intensive campaign, to identify the potential emission sources of $\mathrm{PM}_{2.5}$ collected at a downtown site and an urban site in Guadalajara City, based on spatial variation and the elemental and inorganic ions composition analysis during a dry season.

\section{Methods}

\subsection{Monitoring Sites and Meteorological Conditions}

The $\mathrm{PM}_{2.5}$ measurements were made on the flat roofs of two local health facilities: Centro (CEN), situated in the downtown, and Miravalle (MIR), located to the southwest in the Metropolitan Zone of Guadalajara (Figure 1). Both sites have atmospheric monitoring stations operated by the Jalisco State Government. The meteorological parameters used in this study were obtained from those stations. Centro is an urban site with commercial and services activities and surrounded by heavily traveled paved curbed surface streets with light duty vehicles and heavy-duty diesel buses. In addition to infrastructure streets and similar types of vehicles as those traveling in Centro, Miravalle is located $100 \mathrm{~m}$ from a major arterial street with fast vehicular traffic and a rapid transport system for passengers, and is surrounded by dense residential areas and some industrial facilities. In addition, Miravalle is an urban site with nearby green areas and an inactive volcano, called Cerro del Cuatro, about $270 \mathrm{~m}$ above surrounding ground level, located to the south-southwest $(\sim 2 \mathrm{~km})$.

During the sampling period (May 25 to June 6, 2009), the climate presented dry-warm characteristics and moderate winds. While in Miravalle the wind speed ranged from $0.1-9.1 \mathrm{~m} \cdot \mathrm{s}^{-1}$, in the Centro station it was between $0.1-5.5 \mathrm{~m} \cdot \mathrm{s}^{-1}$. The relative humidity $(\mathrm{RH})$ ranged $11 \%-82 \%$ and $16 \%-88 \%$ at Centro and Miravalle, respectively. In both, the temperature range was $17{ }^{\circ} \mathrm{C}-33{ }^{\circ} \mathrm{C}$. It was observed that the wind came from the west and west-southwest at the CEN and MIR sites, respectively (Figure 2). 


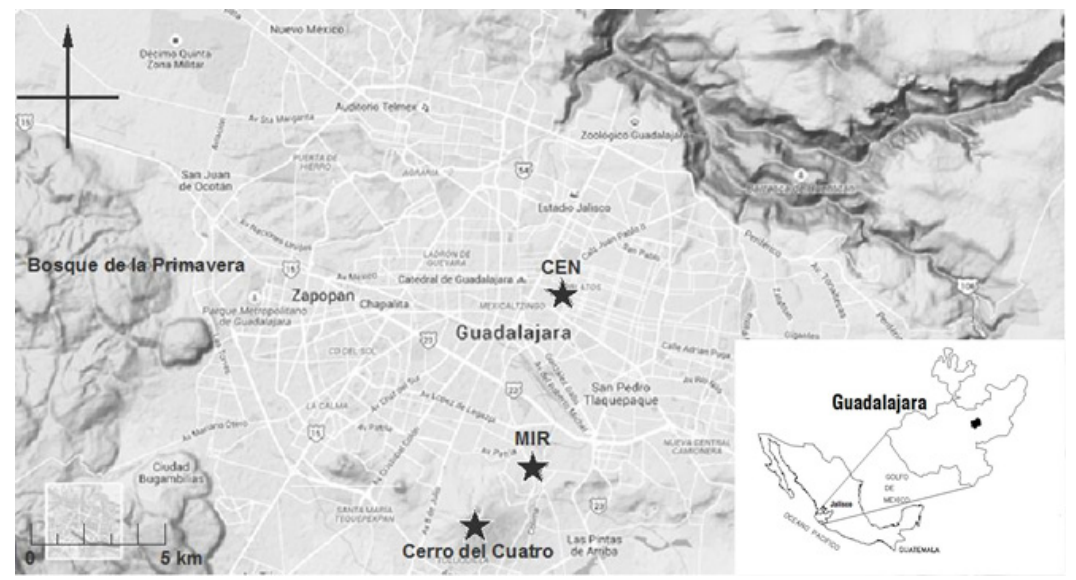

Figure 1. Locations of the sampling sites, CEN (Centro) and MIR (Miravalle).

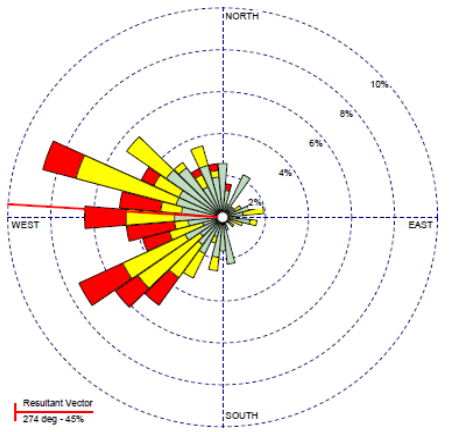

(a)

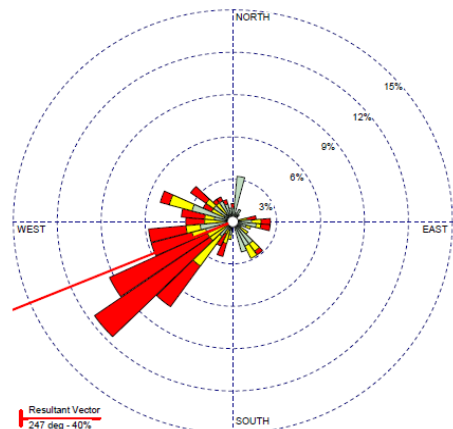

(b)

Figure 2. Wind roses during the study period in CEN (a) and MIR (b) sites. Wind speed $(\mathrm{m} / \mathrm{s})$ : $\geqslant 3.6,2.1-3.6$ and $0.5-2.1$.

\subsection{Sampling and Chemical Analysis}

In order to carry out the chemical characterization of $\mathrm{PM}_{2.5}$, the samples were obtained every third day using a Partisol 2300 sampler (Rupprecht and Patashnick Co.). The particles were collected simultaneously for $24 \mathrm{~h}$ (12:00-12:00) at 16.6 L $\cdot \mathrm{min}^{-1}$ flow on Nylon (MAGNA) membrane filters and at $10 \mathrm{~L} \cdot \mathrm{min}^{-1}$ flow on PTFE (PALL) discs ( $47 \mathrm{~mm}$ diameter and $0.2 \mu \mathrm{m}$ pore size) for ions and elements analysis, respectively. The respective field and laboratory blanks were included daily in each individual sample set. The filters were conditioned and stabilized under controlled relative humidity $\left(45 \pm 5 \%\right.$ ) and temperature (about $22{ }^{\circ} \mathrm{C}$ ) before and after the sampling for about $24 \mathrm{~h}$. The concentrations of $\mathrm{PM}_{2.5}$ in ambient air 
$\left(\mu \mathrm{g} \cdot \mathrm{m}^{-3}\right)$ were obtained from the ratio of the particle weight on the PTFE filter to its corresponding air sampling volume drawn through a cartridge filter holder corrected to EPA's [29] standard temperature and pressure $\left(25^{\circ} \mathrm{C}\right.$ and $\left.760 \mathrm{~mm} \mathrm{Hg}\right)$. The mass of each filter, with and without samples, was accurately measured in triplicate on a micro analytical balance SE2F (Sartorius) with a readability of $0.1 \mu \mathrm{g}$. Only mass averaged measurements with a repeatability less than $0.01 \%$ were included. As the mass of particles was validated and successfully recorded, filters were put in Petri dishes and stored in polyethylene zip-lock bags at $\sim{ }^{\circ} \mathrm{C}$ until chemical analysis.

The details of the samples' chemical analysis are described in Saldarriaga et al. [27] and Hernández et al. [28]. Briefly, for the analysis of metals, the PTFE filters were extracted in an ultrasonic bath for $3 \mathrm{~h}$ at about $60{ }^{\circ} \mathrm{C}-70{ }^{\circ} \mathrm{C}$, using $50 \mathrm{~mL}$ of $\mathrm{HNO}_{3}-\mathrm{HCl}(2.6: 0.9 \mathrm{M})$. The determination of the elements was carried out by ICP-MS equipment (ELAN Model 6100, Perkin Elmer, USA). For the quantification a multicomponent calibration curve was used for $\mathrm{Pb}, \mathrm{Cd}, \mathrm{Co}, \mathrm{Cr}, \mathrm{Cu}, \mathrm{Fe}, \mathrm{Mg}, \mathrm{Mn}$, $\mathrm{Ni}, \mathrm{Sb}, \mathrm{Se}, \mathrm{Sr}, \mathrm{Ti}$ and $\mathrm{Zn}$ with determination coefficients $\left(\mathrm{r}^{2}\right)$ greater than 0.999 , performed on a range of 1.0 to $100 \mathrm{ng} \cdot \mathrm{mL}^{-1}$. The concentrations of the elements in real samples were corrected with blanks and the recoveries $(80 \%-120 \%)$ obtained by extraction from SRM 1648 (NIST) [27]. The ion analysis was performed with the Nylon filters; samples were extracted with Milli-Q water (18.2 $\mathrm{M} \Omega$ ) in an ultrasonic bath (Branson 5510) for $1 \mathrm{~h}$. The aqueous extracts were passed through a nylon micropore membrane $(0.45 \mu \mathrm{m}$ diameter $)$ and the ionic chemical species were separated and subsequently identified by an ion chromatographer (IC) 861-Advanced Compact with conductivity detector (Metrohm). The anions $\left(\mathrm{SO}_{4}{ }^{2-}, \mathrm{NO}_{3}{ }^{-}, \mathrm{Cl}^{-}\right.$, $\mathrm{PO}_{4}{ }^{3-}$ and $\mathrm{NO}_{2}{ }^{-}$) were analyzed by chemical suppression with a Metrosep $\mathrm{A}$ Supp5-150 column (Metrohm); the mobile phase used was a carbonate solution of sodium-sodium bicarbonate $(8.0: 4.0 \mathrm{mM})$. The cations $\left(\mathrm{Na}^{+}, \mathrm{NH}_{4}^{+}, \mathrm{K}^{+}, \mathrm{Ca}^{2+}\right.$ and $\left.\mathrm{Mg}^{2+}\right)$ were determined without chemical suppression in a Metrosep C2_150 (Metrohm) column; the mobile phase was a solution of tartaric-dipicolinic acid (4.0:0.75 mM). For quantification of all species, calibration curves were performed at a concentration ranging $0.0625-10 \mu \mathrm{g} \cdot \mathrm{mL}^{-1}$ and with correlations coefficients $\left(\mathrm{r}^{2}\right)$ also greater than 0.999 .

\subsection{Statistical Analysis}

The normality of data per site was determined using the Shapiro-Wilk test. For the nonparametric and more robustness tests, the Mann-Whitney $U$ and the Spearman correlation coefficient were employed to make comparisons between sites and for the evaluation of association between variables, respectively. These were only applied when at least three observations were obtained and validated. In addition to statistical analysis, the simple linear least squares regression was performed for 
the presence of neutralizing events between ions. All tests were conducted using the STATISTICS 6 software.

\section{Results and Discussions}

\subsection{PM 2.5 Levels}

The epidemiological evidence has shown widely adverse effects of fine PM following both short-term and long-term exposures [30,31]. The results found in this study indicated that the urban population in Guadalajara was exposed to short-term $\mathrm{PM}_{2.5}$ concentrations highly hazardous to health. Although the $\mathrm{PM}_{2.5}$ Mexican ambient quality standard $\left(65 \mu \mathrm{g} \cdot \mathrm{m}^{-3}\right)$ was only exceeded once (Table 1$)$, almost all individual $\mathrm{PM}_{2.5}$ concentrations measured (99\%) exceeded the WHO Air quality guidelines [32] for that air pollutant $\left(25 \mu \mathrm{g} \cdot \mathrm{m}^{-3} 24\right.$-hour mean). For comparison, the $\mathrm{PM}_{2.5}$ average atmospheric concentrations in Guadalajara were higher than those in the Valley of Mexico $\left(29 \mu \mathrm{g} \cdot \mathrm{m}^{-3}\right)$ and slightly higher than the ones found for the Monterrey $\left(34 \mu \mathrm{g} \cdot \mathrm{m}^{-3}\right)$ Metropolitan Areas [33], which are Mexico's first and third biggest urban zones, respectively. Nevertheless, spatial variation must also be taken into account before emission control actions, since the $\mathrm{PM}_{2.5}$ average air concentrations \pm standard deviation found in Miravalle $\left(58.0 \pm 13.0 \mu \mathrm{g} \cdot \mathrm{m}^{-3}\right)$ were, on average, higher than those recorded in the Centro site $\left(39.3 \pm 12.0 \mu \mathrm{g} \cdot \mathrm{m}^{-3}\right)$. Saldarriaga-Noreña et al. [27] and Limon-Sanchez [34] similarly observed this spatial trend in May-Jun 2007 and 2008 in Guadalajara, indicating that, over that period, there has not been an effective action to mitigate this air pollution issue.

Since meteorological conditions reported by both monitoring stations were similar, it clearly shows that the high spatial variation could be attributed to differences between the emission sources in each study site. Thus, in addition to vehicular traffic intensity, in Miravalle those highest concentrations of $\mathrm{PM}_{2.5}$ could be attributed to the larger resuspension of dust from bare green areas surrounding the site during the dry season (Figure 1). The wind direction suggested emissions transport from the southwest. What most likely contributed to the ambient levels of $\mathrm{PM}_{2.5}$ found in Miravalle was either resuspended particles from the inactive volcano area located on this trajectory or the regional or long-range transport of air pollutants that traveled from areas situated to the southwest and southeast.

\subsection{Metals in $P M_{2.5}$}

The elemental analysis was performed for 14 metals (Table 1). In both sites, iron was the element most abundance in the $\mathrm{PM}_{2.5}$. In the Centro site, Fe accounts for $59.8 \%$ of total elemental mass, followed by $\mathrm{Cu}(15.6 \%), \mathrm{Mg}(9.5 \%)$ and $\mathrm{Zn}(5.9 \%)$, while in Miravalle it was 72.2\%, followed by $\mathrm{Mg}$ (11.4\%) and $\mathrm{Zn} \mathrm{(3.3 \% ).} \mathrm{The} \mathrm{other}$ metals account for $9.1 \%$ at Centro and $9.4 \%$ at Miravalle or sometimes were not 
quantified. The environmental levels of trace metals are of the same order of magnitude as those already reported in the earliest studies [27]. It is a concern to health, since the most abundant elements are heavy metals characterized by their toxicity.

Table 1. $\mathrm{PM}_{2.5}\left(\mu \mathrm{g} \cdot \mathrm{m}^{-3}\right)$ and trace metals concentrations $\left(\mathrm{ng} \cdot \mathrm{m}^{-3}\right)$ in Centro and Miravalle sites.

\begin{tabular}{|c|c|c|c|c|c|c|c|c|c|c|}
\hline & \multicolumn{5}{|c|}{ Centro } & \multicolumn{5}{|c|}{ Miravalle } \\
\hline & $\mathrm{n}$ & Mean & SD & Median & Range & $\mathrm{n}$ & Mean & SD & Median & Range \\
\hline $\mathbf{P M}_{2.5}$ & 6 & 39.3 & 12.0 & 43.0 & $16.0-49.2$ & 6 & 58.0 & 13.0 & 62.2 & $37.0-72.5$ \\
\hline $\mathrm{Pb}$ & 4 & 7.8 & 3.8 & 7.6 & $3.8-12.4$ & 4 & 12.8 & 7.6 & 12.7 & $3.6-21.9$ \\
\hline $\mathrm{Cd}$ & 5 & 8.0 & 4.1 & 8.6 & $3.5-13.3$ & 5 & 5.1 & 2.7 & 5.4 & $2.2-.4$ \\
\hline Co & - & n.d. & - & - & - & 3 & 0.4 & 0.0 & 0.4 & $0.3-0.4$ \\
\hline $\mathrm{Cr}$ & 6 & 9.2 & 2.4 & 10.2 & $5.2-11.1$ & 6 & 16.6 & 1.9 & 15.6 & $14.9-19.6$ \\
\hline $\mathrm{Cu}$ & 3 & 107.0 & 16.9 & 108.8 & $89.2-122.9$ & $1 * *$ & - & - & - & - \\
\hline $\mathrm{Fe}$ & 6 & 410.3 & 142.3 & 445.2 & $183.9-580.0$ & 6 & 653.7 & 236.8 & 588.6 & $345.4-961.1$ \\
\hline $\mathrm{Mg}$ & 5 & 65.2 & 32.5 & 56.5 & $30.8-116.1$ & 6 & 102.8 & 61.0 & 98.8 & $42.4-193.7$ \\
\hline Mn & 6 & 9.8 & 3.6 & 10.2 & $3.5-14.4$ & 6 & 16.1 & 5.2 & 17.6 & $7.4-21.2$ \\
\hline $\mathrm{Ni}$ & $1 *$ & - & - & - & - & 2 & 4.0 & - & - & $3.4-4.5$ \\
\hline $\mathrm{Sb}$ & 2 & 2.1 & 0.2 & - & $1.9-2.2$ & 5 & 2.0 & 1.0 & 1.5 & $1.4-3.7$ \\
\hline Se & 3 & 3.6 & 0.5 & 3.8 & $3.0-4.0$ & 4 & 1.8 & 0.8 & 1.8 & $0.8-2.8$ \\
\hline Sr & 6 & 3.9 & 1.9 & 3.5 & $1.6-6.9$ & 6 & 5.4 & 2.5 & 5.2 & $2.7-9.1$ \\
\hline $\mathrm{Ti}$ & 6 & 11.4 & 5.9 & 12.2 & $2.2-19.1$ & 6 & 21.8 & 8.4 & 20.5 & $10.4-32.0$ \\
\hline $\mathrm{Zn}$ & 5 & 47.5 & 37.8 & 36.3 & $14.4-107.7$ & 6 & 30.1 & 16.2 & 30.2 & $5.0-53.6$ \\
\hline
\end{tabular}

Thus, the characterization and identification of potential sources of trace elements within the fraction of $\mathrm{PM}_{2.5}$ in the Guadalajaran atmosphere could provide scientific evidence for setting up an air control strategy to decrease health risks due to inhalation of suspended particles. The most abundant species indicated that both sampling sites have a mixture of natural and anthropogenic sources, since Fe and $\mathrm{Mg}$ are primarily crustal elements, while $\mathrm{Zn}$ and $\mathrm{Cu}$ are primarily anthropogenic elements [35]. Spatial variation analysis by the Mann-Whitney test showed that the contribution from natural sources to $\mathrm{PM}_{2.5}$ in the Miravalle site could be more important than anthropogenic ones, since the medians of crustal elements [36], such as $\mathrm{Fe}, \mathrm{Mg}$ and $\mathrm{Mn}$, were found to be significantly $(p<0.05)$ higher or higher (Ti) only in the Miravalle site. Close in proximity to Miravalle, surfaces devoid of vegetation may be one of the possible causes of high levels of particles and anthropogenic elements such as Fe and Mg at this site. On the other hand, the Centro site seems to have a more important contribution from anthropogenic sources because the median concentration of primarily anthropogenic $\mathrm{Zn}$ and two elements ( $\mathrm{Cd}$ and Se) that are considered as partially anthropogenic [37] were greater here than in Miravalle (Table 1), although differences were not significant $(p>0.05)$. It might be due to the fact that the Centro site has a higher traffic intensity. The abundance of elemental species and the geological and anthropogenic origin coincides with those 
results previously found in 2007 at the same sites [27], including the atmospheric mean concentrations.

The analysis of potential sources contributing to metals in $\mathrm{PM}_{2.5}$ at both sites was based on the principle that the degree to which the trace elements are enriched or reduced in aerosols is related to a specific source. That Enrichment Factor (EF) is frequently used [38,39] and is a reliable analysis tool to determine the impact of the type of emission sources on the elemental composition of the particles. The estimation of EF is based on the average abundances of the elements in geological material. Iron is suggested to be used as a reference element [40]. The following expression (Equation (1)), proposed by Taylor [40], was used to calculate the EF:

$$
\mathrm{EF}=\left(\mathrm{C}_{\mathrm{xp}} / \mathrm{C}_{\mathrm{p}}\right) /\left(\mathrm{C}_{\mathrm{xc}} / \mathrm{C}_{\mathrm{c}}\right)
$$

where $C_{x p}$ and $C_{p}$ are the concentrations of trace metal " $x$ " and Fe in the aerosol, respectively, and $C_{x c}$ and $C_{c}$ are their average concentrations in soil. It has been established that a value of $\mathrm{EF}<10$ is an indicator of trace metal from the soil; if it is between 10-100, it is a natural and anthropogenic mixture. In contrast, a value of EF $>100$ is considered to be of an anthropogenic origin [41,42].

The EF patterns were very similar at the two sampling sites, indicating that both non-crustal and crustal emissions are contributing to mass of $\mathrm{PM}_{2.5}$. The EF analysis (Table 2) showed that atmospheric concentrations of Fe, $\mathrm{Mg}, \mathrm{Mn}, \mathrm{Sr}$ and $\mathrm{Ti}$ found in $\mathrm{PM}_{2.5}$ are likely from natural sources $(\mathrm{EF}<10)$. Furthermore, it is indicated that $\mathrm{Cr}$ and $\mathrm{Zn}$ may come from natural and anthropogenic sources $(10>\mathrm{EF}<100)$ and $\mathrm{Se}, \mathrm{Cd}$, $\mathrm{Sb}$ and $\mathrm{Cu}$ are mainly from anthropogenic sources $(\mathrm{EF}>100)$. Most elements from anthropogenic sources were more highly enriched in Centro than those found in the Miravalle site, suggesting that the Centro site is being more impacted by non-crustal pollution emissions than Miravalle. The higher enrichment of elements in Centro by non-crustal sources could be explained by either industrial activities, since $\mathrm{Cd}$ comes from metallurgical processes [43], or traffic, because $\mathrm{Zn}$ and $\mathrm{Pb}$ are markers of vehicular emissions [44]. In urban areas, road traffic (diesel engines and brake wear) could be the most important source of $\mathrm{Cu}$ [45]. Conversely, an earlier study suggested that geological sources significantly influenced the generation of $\mathrm{PM}_{2.5}$ as much in Miravalle as they did in Centro [27].

\subsection{Potential Sources of Ionic Species in $P_{2.5}$}

In both sampling sites, nitrate $\left(\mathrm{NO}_{3}{ }^{-}\right)$, sulfate $\left(\mathrm{SO}_{4}{ }^{-}\right)$and ammonium $\left(\mathrm{NH}_{4}{ }^{+}\right)$ were the dominant inorganic ions species followed by $\mathrm{Ca}^{2+}, \mathrm{K}^{+}, \mathrm{Cl}^{-}$(Table 3). The environmental levels of inorganic species are of the same order of magnitude as those already reported in an earlier study [28]. The statistical analysis, via the Mann-Whitney $\mathrm{U}$ test, showed that the higher median concentration of $\mathrm{NO}_{3}{ }^{-}$was 
in Miravalle. This is unlike the sulfate and ammonium species that showed similar median concentrations between sites ( $p>0.05)$.

Table 2. Estimated values for EF.

\begin{tabular}{ccc}
\hline Element & Centro & Miravalle \\
\hline $\mathrm{Pb}$ & 86.0 & 87.9 \\
$\mathrm{Cd}$ & 5464.7 & 2193.0 \\
$\mathrm{Co}$ & n.c. & 1.2 \\
$\mathrm{Cr}$ & 12.6 & 14.0 \\
$\mathrm{Cu}$ & 266.9 & n.c. \\
$\mathrm{Fe}{ }^{*}$ & 0.1 & 0.1 \\
$\mathrm{Mg}$ & 0.4 & 0.4 \\
$\mathrm{Mn}$ & 1.4 & 1.5 \\
$\mathrm{Ni}$ & n.c. & n.c. \\
$\mathrm{Sb}$ & n.c. & 907.6 \\
$\mathrm{Se}$ & 9795.1 & 3686.4 \\
$\mathrm{Sr}$ & 1.4 & 1.3 \\
$\mathrm{Ti}$ & 0.3 & 0.3 \\
$\mathrm{Zn}$ & 80.4 & 37.0 \\
\hline
\end{tabular}

* EF calculated with crustal concentration of Ca; n.c.: not calculated.

In Miravalle, nitrate accounts for $68.2 \%$, followed by sulfate $(11.9 \%)$ and ammonium $(11.9 \%)$ of the total mass of inorganic ionic species. In Centro, nitrate account for $57.3 \%$, followed by sulfate (17.1\%) and ammonium (14.5\%). Overall, while the spatially similar abundance (Figure 3 ) indicated likely common sources, the most abundant anions showed the important role that secondary sources played in the chemical composition of $\mathrm{PM}_{2.5}$. This is due to oxidation processes in the atmosphere that mainly form in the particle phase involving their directly emitted precursors, nitrogen oxides (NOx), sulfur dioxide $\left(\mathrm{SO}_{2}\right)$ and ammonia $\left(\mathrm{NH}_{3}\right)$ [46]. However, the order followed by these major inorganic ions and the urban characteristics of the sites suggested that the contribution of vehicular emission to formation of nitrate is also important and substantial. Because a significant portion of nitrate came from the atmospheric conversion of nitrogen oxides (NOx) and ammonia $\left(\mathrm{NH}_{3}\right)$ [47], the high emissions of nitrogen oxides from heavy traffic in the urban environment could enhance the formation of nitrate in both sites. In addition, vehicle emissions of NOx and local combustion processes have been suggested as the biggest sources of nitrate in urban areas [48]. 
Table 3. Atmospheric concentrations $\left(\mu \mathrm{g} \cdot \mathrm{m}^{-3}\right)$ for ionic species.

\begin{tabular}{cccccc}
\hline Site & Mean & Standard Deviation & Median & Minimum & Maximum \\
\hline Centro & & & & & \\
$\mathrm{Na}^{+}$ & 0.29 & 0.05 & 0.28 & 0.22 & 0.35 \\
$\mathrm{NH}_{4}{ }^{+}$ & 2.71 & 2.11 & 2.01 & 1.31 & 6.85 \\
$\mathrm{~K}^{+}$ & 0.36 & 0.13 & 0.38 & 0.18 & 0.57 \\
$\mathrm{Ca}^{2+}$ & 0.98 & 0.10 & 1.01 & 0.82 & 1.07 \\
$\mathrm{Mg}^{2+}$ & 0.08 & 0.06 & 0.07 & 0.002 & 0.15 \\
$\mathrm{Cl}^{-}$ & 0.23 & 0.08 & 0.26 & 0.14 & 0.28 \\
$\mathrm{NO}_{2}{ }^{-}$ & 0.05 & 0.02 & 0.04 & 0.03 & 0.08 \\
$\mathrm{PO}_{4}{ }^{3-}$ & - & - & - & - & - \\
$\mathrm{SO}_{4}{ }^{2-}$ & 3.21 & 1.26 & 2.85 & 1.92 & 5.57 \\
$\mathrm{NO}_{3}{ }^{-}$ & 10.74 & 14.34 & 4.72 & 1.33 & 38.22 \\
$\mathrm{Miravalle}^{-}$ & & & & & \\
$\mathrm{Na}^{+}$ & 0.33 & 0.16 & 0.34 & 0.06 & 0.54 \\
$\mathrm{NH}_{4}{ }^{+}$ & 4.18 & 5.41 & 2.22 & 1.36 & 15.19 \\
$\mathrm{~K}^{+}$ & 0.38 & 0.30 & 0.25 & 0.18 & 0.97 \\
$\mathrm{Ca}^{2+}$ & 1.55 & 0.45 & 1.40 & 1.07 & 2.31 \\
$\mathrm{Mg}^{2+}$ & 0.05 & 0.05 & 0.06 & 0.05 & 0.12 \\
$\mathrm{Cl}^{-}$ & 0.36 & 0.06 & 0.35 & 0.30 & 0.42 \\
$\mathrm{NO}_{2}{ }^{-}$ & 0.06 & 0.04 & 0.05 & 0.03 & 0.11 \\
$\mathrm{PO}_{4}{ }^{3-}$ & 0.12 & 0.05 & 0.09 & 0.09 & 0.18 \\
$\mathrm{SO}_{4}{ }^{2-}$ & 4.18 & 1.77 & 3.83 & 1.89 & 7.12 \\
$\mathrm{NO}_{3}{ }^{-}$ & 24.07 & 33.27 & 7.02 & 1.70 & 83.92 \\
\hline
\end{tabular}

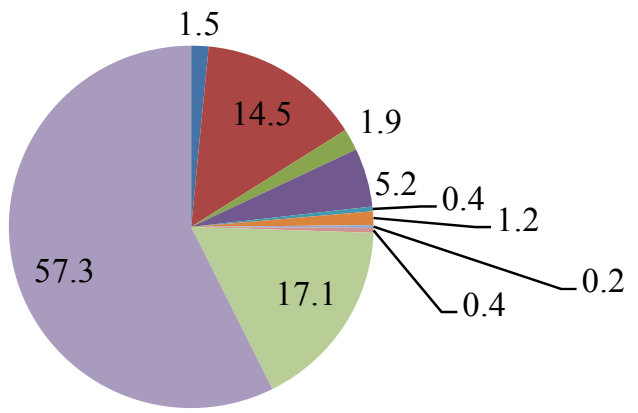

(a)

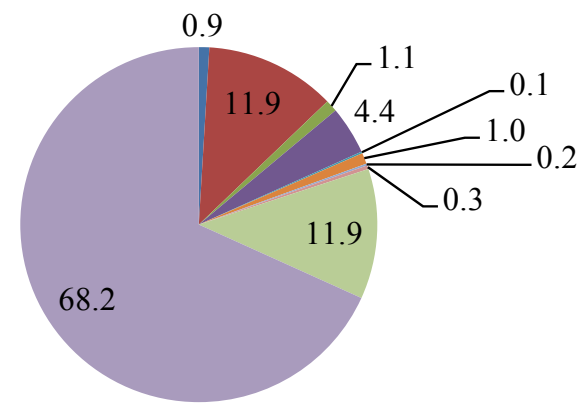

(b)

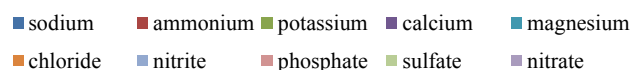

Figure 3. Relative contributions of ionic species to $\mathrm{PM}_{2.5}$ in $\mathrm{CEN}(\mathbf{a})$ and MIR (b).

Furthermore, higher $\mathrm{NO}_{3}{ }^{-}$mass than $\mathrm{SO}_{4}{ }^{2-}$ suggested that the influences of motor vehicle emissions exceed those from coal combustion [49]. In this study, the average mass ratio $\left(\mathrm{NO}_{3}{ }^{-} / \mathrm{SO}_{4}{ }^{2-}\right)$ at the Centro and Miravalle sites was 3.3 and 
5.8, respectively. The high mass ratios indicated that mobile sources predominated significantly over stationary sources at both sites. These measured ratios were similar to those reported for urban areas such as Guangzhou (3.4-10.0), China [50] and for the city of Los Angeles ( 2.0). The latter results emphasize that such findings may be due to no coal being used in this area [51]. These results were higher than the mass ratio observed for the city of Philadelphia (0.9), USA [52], which is due to that city having power plants that use coal as fuel. Nevertheless, the order of the less abundant ions $\mathrm{Ca}^{2+}>\mathrm{K}^{+}>\mathrm{Cl}^{-}$also indicated a contribution to particles from natural sources either by geological origin or burning biomass, which could be attributed to the presence of $\mathrm{Ca}^{2+}$ and $\mathrm{K}^{+}$, respectively $[53,54]$. Therefore, the highest atmospheric concentration of $\mathrm{Ca}^{2+}$ in Miravalle could have resulted from dust resuspension due to surfaces being devoid of vegetation surrounding this sampling site, a frequent occurrence in the dry season. Conversely, higher $\mathrm{K}^{+}$concentrations in Centro could have come from forest fires that occurred during the sampling period in the Primavera Forest located west of Guadalajara [55]. It was further noted that, during the sampling period, predominant westerly winds were observed, supporting the hypothesis that the $\mathrm{K}^{+}$concentration could have been transported from the forest into the city.

Table 4. Correlation among inorganic ions (bold correlations are significant at $p<0.05)$.

\begin{tabular}{|c|c|c|c|c|c|c|c|c|c|c|}
\hline & $\mathrm{Cl}^{-}$ & $\mathrm{NO}_{2}{ }^{-}$ & $\mathrm{PO}_{4}{ }^{3-}$ & $\mathrm{SO}_{4}{ }^{2-}$ & $\mathrm{NO}_{3}{ }^{-}$ & $\mathrm{Na}^{+}$ & $\mathrm{NH}_{4}{ }^{+}$ & $\mathrm{K}^{+}$ & $\mathrm{Ca}^{2+}$ & $\mathrm{Mg}^{2+}$ \\
\hline \multicolumn{11}{|c|}{ Miravalle } \\
\hline $\mathrm{Cl}^{-}$ & 1.00 & & & & & & & & & \\
\hline $\mathrm{NO}_{2}{ }^{-}$ & 0.13 & 1.00 & & & & & & & & \\
\hline $\mathrm{PO}_{4}{ }^{3-}$ & - & - & - & & & & & & & \\
\hline $\mathrm{SO}_{4}^{2-}$ & 0.05 & -0.20 & - & 1.00 & & & & & & \\
\hline $\mathrm{NO}_{3}{ }^{-}$ & -0.71 & -0.53 & - & -0.28 & 1.00 & & & & & \\
\hline $\mathrm{Na}^{+}$ & -0.68 & 0.17 & - & -0.28 & 0.71 & 1.00 & & & & \\
\hline $\mathrm{NH}_{4}^{+}$ & -0.47 & -0.40 & - & 0.80 & 0.28 & 0.14 & 1.00 & & & \\
\hline $\mathrm{K}^{+}$ & -0.43 & -0.50 & - & 0.77 & 0.18 & -0.11 & 0.95 & 1.00 & & \\
\hline $\mathrm{Ca}^{2+}$ & -0.46 & 0.61 & - & -0.64 & 0.14 & 0.54 & -0.48 & -0.52 & 1.00 & \\
\hline $\mathrm{Mg}^{2+}$ & -0.18 & -0.47 & - & 0.44 & 0.54 & 0.41 & 0.66 & 0.46 & -0.54 & 1.00 \\
\hline \multicolumn{11}{|l|}{ Centro } \\
\hline $\mathrm{Cl}^{-}$ & 1.00 & & & & & & & & & \\
\hline $\mathrm{NO}_{2}{ }^{-}$ & -0.32 & 1.00 & & & & & & & & \\
\hline $\mathrm{PO}_{4}{ }^{3-}$ & -0.69 & 0.11 & 1.00 & & & & & & & \\
\hline $\mathrm{SO}_{4}^{2-}$ & -0.19 & -0.48 & 0.41 & 1.00 & & & & & & \\
\hline $\mathrm{NO}_{3}{ }^{-}$ & -0.66 & -0.33 & 0.46 & 0.76 & 1.00 & & & & & \\
\hline $\mathrm{Na}^{+}$ & 0.05 & -0.23 & -0.63 & -0.25 & 0.06 & 1.00 & & & & \\
\hline $\mathrm{NH}_{4}^{+}$ & -0.64 & -0.34 & 0.51 & 0.82 & 0.99 & -0.01 & 1.00 & & & \\
\hline $\mathrm{K}^{+}$ & -0.49 & 0.05 & 0.60 & 0.65 & 0.67 & -0.61 & 0.70 & 1.00 & & \\
\hline $\mathrm{Ca}^{2+}$ & 0.18 & 0.60 & -0.33 & -0.95 & -0.76 & 0.01 & -0.81 & -0.42 & 1.00 & \\
\hline $\mathrm{Mg}^{2+}$ & 0.32 & -0.14 & 0.43 & 0.06 & -0.36 & -0.80 & -0.28 & 0.12 & 0.05 & 1.00 \\
\hline
\end{tabular}


The possible chemical forms of the ionic species were suggested by bivariate correlations with all the anions and cations analyzed. The correlation coefficients can be observed in Table 4. For Miravalle $\mathrm{NH}_{4}{ }^{+}$with $\mathrm{K}^{+}$and $\mathrm{SO}_{4}{ }^{2-}$ correlated significantly $(\mathrm{p}<0.05)$, while in Centro $\mathrm{SO}_{4}{ }^{2-}$ and $\mathrm{NO}_{3}{ }^{-}$correlated with $\mathrm{NH}_{4}{ }^{+}$. This indicated that compounds such as $\left(\mathrm{NH}_{4}\right)_{2} \mathrm{SO}_{4}$ and $\mathrm{K}_{2} \mathrm{SO}_{4}$ can coexist in Miravalle, while in Centro $\left(\mathrm{NH}_{4}\right)_{2} \mathrm{SO}_{4}$ and $\mathrm{NH}_{4} \mathrm{NO}_{3}$ are possible [56]. For the Centro site, a good correlation was observed between $\mathrm{SO}_{4}{ }^{2-}$ and $\mathrm{NO}_{3}{ }^{-}$(0.76), which can likely be attributed to a similarity in formation conditions either from a shared emission source or a chemical conversion of their precursors through atmospheric processes [57].

To evaluate the acidic nature of particles, a balance of ions was realized. Figure 4 shows the sum of cations plotted versus the sum of anions for each one of the sites sampled during the period of study $\left(\mu \mathrm{eq} \cdot \mathrm{m}^{-3}\right)$. In Centro, the slope $<1.0$ indicated that the concentration of anions was higher than that of the cations. Thus, those atmospheric particles had acidic properties during this sampling period. These results are consistent with those previously reported [28] for the Centro site in 2007, taking into account the same ionic species, while in Miravalle a slope of about 1.0 (1.08) was obtained, indicating neutralization processes, which is different than that observed during a previous study [28]. Thus, there were enough cations to neutralize the sulfate and nitrate present in the Miravalle environment, which likely originated either by contribution of additional cations from resuspended particles $\left(\mathrm{Ca}^{2+}, \mathrm{Mg}^{2+}\right)$ or from being buffered by the higher average concentrations of $\mathrm{NH}_{4}{ }^{+}$found in Miravalle [58], which were almost two-fold of that measured in Centro (Table 4). Since $\mathrm{NH}_{4}{ }^{+}$formation on particles responds to variations in environmental conditions and availability of precursors [59], the similar atmospheric conditions found in Centro and Miravalle during the study suggested that the highest average atmospheric concentration of ammonium in Miravalle could be controlled by factors other than temperature and relative humidity. Therefore, there could be a contribution by secondary particles transported from traveled areas situated to the southeast; although the volcanic hill is a geographic barrier for the air mass from that direction (southwest), its elevation and the geography of the area could be causing some turbulence and channeling of winds near the study area [34]. 


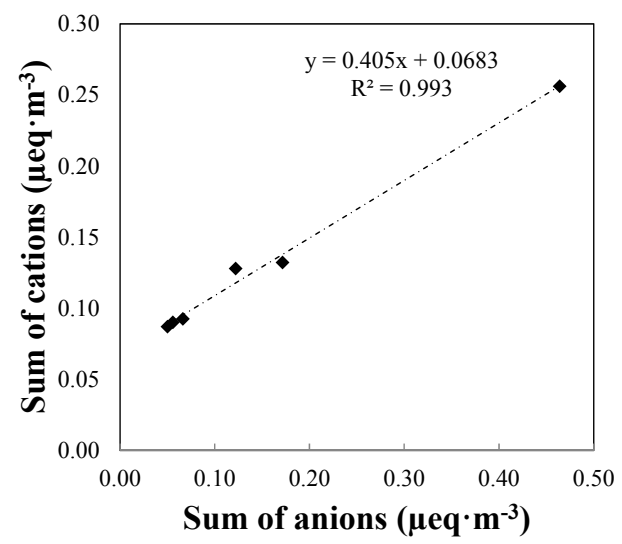

(a)

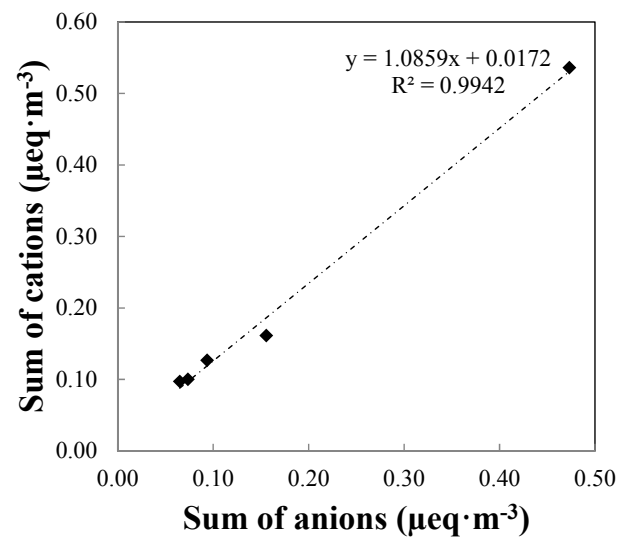

(b)

Figure 4. Ions balances for CEN (a) and MIR (b).

\section{Conclusions}

The results of this study suggested that anthropogenic and natural sources influenced the measured $\mathrm{PM}_{2.5}$ in the Centro and Miravalle sites during the short warm dry season campaign realized in Guadalajara, Mexico. In addition to spatial variation, the chemical characterization of $\mathrm{PM}_{2.5}$ allowed us to identify and distinguish some of the main emission sources contributing to particles in each site in the warm dry season in Guadalajara. The enrichment factor analysis indicated that road traffic mainly contributed to the $\mathrm{PM}_{2.5}$ of Centro, and the highest abundance of $\mathrm{K}^{+}$suggested that biomass burning is an important source from the Primavera Forest located to the west. Despite the ratio $\left(\mathrm{NO}_{3}{ }^{-} / \mathrm{SO}_{4}{ }^{2-}\right)$ indicating that the influences of motor vehicle emissions exceed those from the coal combustion in both sites, in Miravalle the resuspended particles from an inactive volcano (Cerro del Cuatro) to the southwest was suggested as significantly contributing to the mass of $\mathrm{PM}_{2.5}$ and could have caused neutralization processes by a higher incorporation of cations on particles. Additionally, $\mathrm{PM}_{2.5}$ at the Miravalle site apparently undergoes an impact from secondary particles of ammonium transported from areas located to the southeast, favored by a channeled-wind effect caused by elevations located to the southwest. Therefore, actions to be taken must focus mainly on both vehicular activity to reduce the emission of fine particles and undertaking campaigns of reforestation in the southwest of Guadalajara. In addition, for future studies the sampling must be seasonally extended and include analysis of sources based on other chemical species such as organic components. 
Acknowledgments: The authors would like to express their appreciation to Secretaría del Medio Ambiente para el Desarrollo Sustentable del Estado de Jalisco (SEMADES) and Universidad Autónoma de Guadalajara for allowing the installment of the equipment in their locations. Special thanks go to Silvia Montiel Palma (UAEM), who provided valuable assistance in organizing maps for this paper, and to Sandra Daniela Bravo (CIATEJ), Rosalva Cuevas (CIATEJ) and Ma. Gregoría Medina Píntor (UAEM) for their valuable assistance in laboratory analysis.

Author Contributions: All authors contributed equally to this work.

Conflicts of Interest: The authors declare no conflict of interest.

\section{References}

1. Englert, N. Fine particles and human health-A review of epidemiological studies. Toxicol. Lett. 2004, 149, 235-242.

2. Kappos, A.D.; Bruckmann, P.; Eikmann, T.; Englert, N.; Heinrich, U.; Höppe, P.; Koch, E.; Krause, G.H.M.; Kreyling, W.G.; Rauchfuss, K.; et al. Health effects of particles in ambient air. Int. J. Hyg. Environ. Health 2004, 207, 399-407.

3. Pope, C.A., III; Burnett, R.T.; Thun, M.J.; Calle, E.E.; Krewski, D.; Ito, K.; Thurston, G.D. Lung cancer, Cardiopulmonary Mortality, and long-term exposure to fine particulate air pollution. JAMA 2002, 287, 1132-1141.

4. Kampa, M.; Castanas, E. Human Health effects of air pollution. Environ. Pollut. 2007, 151, 362-367.

5. Ramgolam, K.; Favez, O.; Cachier, H.; Gaudichet, A.; Marano, F.; Martinon, L.; Baeza-Squiban, A. Size-partitioning of an urban aerosol to identify particle determinants involved in the proinflammatory response induced in airway epithelial cells. Part. Fibre Toxicol. 2009, 6, 1-12.

6. de Kok, T.M.C.M.; Driece, H.A.L.; Hogervorst, J.G.F.; Briedé, J.J. Toxicological assessment of ambient and traffic-related particulate matter: A review of recent studies. Rev. Mutat. Res. 2006, 613, 103-122.

7. Cabada, J.C.; Rees, S.; Takahama, S.; Khlystov, A.; Pandis, S.; Davidson, C.I.; Robinson, A.L. Mass size distributions and size resolved chemical composition of fine particulate matter at the Pittsburgh supersite. Atmos. Environ. 2004, 38, 3127-3141.

8. Pan, Y.; Tian, S.; Li, X.; Sun, Y.; Li, Y.; Wentworth, G.R.; Wang, Y. Trace elements in particulate matter from metropolitan regions of Northern China: Sources, concentrations and size distributions. Sci. Total Environ. 2015, 537, 9-22.

9. Young-Ji, H.; Tae-Sik, K.; Hakap, K. Ionic constituents and source analysis of $\mathrm{PM}_{2.5}$ in three Korean cities. Atmos. Environ. 2008, 42, 4735-4746.

10. Sitaras, I.E.; Siskos, P.A. The role of primary and secondary air pollutants in atmospheric pollution: Athens urban area as a case study. Environ. Chem. Lett. 2008, 6, 59-69.

11. Sharma, M.; Kishore, S.; Tripathi, S.N. Role of atmospheric ammonia in the formation of inorganic secondary particulate matter: A study at Kanpur, India. J. Atmos. Chem. 2007, $58,1-17$. 
12. Bari, A.; Ferraro, V.; Wilson, L.R.; Luttinger, D.; Husain, L. Measurements of gaseous $\mathrm{HONO}, \mathrm{HNO}_{3}, \mathrm{SO}_{2}, \mathrm{HCl}, \mathrm{NH}_{3}$, particulate sulfate and $\mathrm{PM}_{2.5}$ in New York, NY. Atmos. Environ. 2003, 37, 2825-2835.

13. Ghio, A.J.; Stoneheurner, J.; McGee, J.K.; Kinsey, J.S. Sulfate content correlates with iron concentration in ambient air pollution particles. Inhal. Toxicol. 1999, 11, 293-307.

14. Friedlander, S.K.; Yeh, E.K. The submicron atmospheric aerosols as a carrier of reactive chemical species: Case of peroxide. Appl. Occup. Environ. Hyg. 1998, 13, 416-420.

15. Wang, X.; Sato, T.; Xing, B.; Tamamura, S.; Tao, S. Source identification, size distribution and indicator screening of airborne trace metals in Kanazawa, Japan. J. Aerosol Sci. 2005, $36,197-210$.

16. Clarke, R.W.; Coull, B.; Reinisch, U.; Catalano, P.; Killingsworth, C.R.; Koutrakis, P.; Kavouras, I.; Murthy, G.G.; Lawrence, J.; Lovett, E.; et al. Inhaled concentrated ambient particles are associated with hematologic and bronchoalveolar lavage changes in canines. Environ. Health Perspect. 2000, 108, 1179-1187.

17. Valavanidis, A.; Fiotakis, K.; Bakeas, E.; Vlahogianni, T. Electron paramagnetic resonance study of the generation of reactive oxygen species catalysed by transition metals and quinoid redox cycling by inhalable ambient particulate matter. Redox Rep. 2005, 10, 37-51.

18. Carter, J.D.; Ghio, A.J.; Samet, J.M.; Devlin, R.B. Cytokine production by human airway epithelial cells after exposure to an air pollution particles is metal-dependent. Toxicol. Appl. Pharm. 1997, 146, 180-188.

19. Brown, R.K.; Wyatt, H.; Price, J.F.; Kelly, F.J. Pulmonary dysfunction in cystic fibrosis is associated with oxidative stress. Eur. Respir. J. 1996, 9, 334-339.

20. Saldiva, P.H.N.; Clarke, R.W.; Coull, B.A.; Stearns, R.C.; Lawrence, J.; Murthy, G.G. Lung inflammation induced by concentrated ambient air particles is related to particle composition. Am. J. Respir. Crit. Care Med. 2002, 165, 1610-1617.

21. Agency for Toxic Substances and Disease Registry. Toxicological profile information sheet 2003. Available online: http:/ / www.atsdr.cdc.gov/toxprofiles (accessed on 15 July 2015).

22. Instituto Nacional de Estadística, Geografía e Informática (INEGI). Available online: http:/ / www.censo2010.org.mx/ (accessed on 15 May 2015).

23. Sistema de Monitoreo Atmosférico de Jalisco (SIMAJ). Available online: http://siga. jalisco.gob.mx/aire/Reportes.html (accessed on 9 July 2015).

24. PROAIRE 1997-2001. Available online: http:/ / www.semarnat.gob.mx/gestionambiental/ calidaddelaire/Documents (accessed on 17 June 2015).

25. Hernández-Mena, L.; Murillo-Tovar, M.A.; Ramírez-Muñíz, M.; Colunga-Urbina, E.; de la Garza-Rodríguez, I.; Saldarriaga-Noreña, H. Enrichment Factor and Profiles of Elemental Composition of $\mathrm{PM}_{2.5}$ in the City of Guadalajara, Mexico. Bull. Environ. Contam. Toxicol. 2011, 87, 545-549.

26. Saldarriaga-Noreña, H.; Hernández-Mena, L.; Murillo-Tovar, M.A.; López-López, A.; Ramírez-Muñíz, M. Elemental contribution to the mass of $\mathrm{PM}_{2.5}$ in Guadalajara City, Mexico. Bull. Environ. Contam. Toxicol. 2011, 86, 490-494. 
27. Saldarriaga-Noreña, H.; Hernández-Mena, L.; Ramírez-Muñíz, M.; Carbajal-Romero, P.; Cosío-Ramírez, R.; Esquivel-Hernández, B. Characterization of trace metals of risk to human health in airborne particulate matter $\left(\mathrm{PM}_{2.5}\right)$ at two sites in Guadalajara, Mexico. J. Environ. Monitor. 2009, 11, 887-894.

28. Hernández, M.L.; Saldarriaga, N.H.; Carbajal, R.P.; Cosío, R.R.; Esquivel, H.B. Ionic species associated with $\mathrm{PM}_{2.5}$ in the City of Guadalajara, Mexico during 2007. Environ. Monit. Assess. 2010, 161, 281-293.

29. Environmental Protection Agency. Available online: http://www3.epa.gov/ttnamti1/ files/ambient/inorganic/mthd-2-4.pdf (accessed on 6 June 2015).

30. Dockery, D.W. Health effects of particulate air pollution. Ann. Epidemiol. 2009, 19, 257-263.

31. Polichetti, G.; Cocco, S.; Spinalia, A.; Trimarcoa, V.; Nunziatab, A. Effects of particulate matter $\left(\mathrm{PM}_{10}, \mathrm{PM}_{2.5}\right.$ and $\left.\mathrm{PM}_{1}\right)$ on the cardiovascular system. Toxicology 2009, 261, 1-8.

32. World Health Organization. Air quality Guidelines for particulate matter, ozone, nitrogen dioxide and sulfur dioxide. Global up date 2005. Summary of risk assessment. Available online: http://www.who.int/phe/health_topics/outdoorair/outdoorair_aqg/en/ (accessed on 10 July 2015).

33. Cuarto Almanaque de datos y tendencias de la calidad del aire en 20 ciudades mexicanas. Available online: http:/ /www2.inecc.gob.mx/publicaciones/new.portada. html?id_tema=\&idb=652\&img=652.jpg (accessed on 1 July 2015).

34. Limon-Sanchez, M.T.; Carvajal-Romero, P.; Hernández-Mena, L.; Saldarriaga-Noreña, H.; López-López, A.; Cosío-Ramírez, R.; Arriaga-Colina, J.L.; Smith, W. Black carbón in $\mathrm{PM}_{2.5}$, data from two urban sites in Guadalajara, Mexico during 2008. Atmost. Pol. Res. 2011, 2, 358-365.

35. Odabasi, M.; Muezzinoglu, A.; Bozlaker, A. Ambient concentrations and dry deposition fluxes of trace elements in Izmir, Turkey. Atmos. Environ. 2002, 36, 5841-5851.

36. Haritash, A.K.; Kaushik, C.P. Assessment of seasonal enrichment of heavy metals in respirable suspended particulate matter of a sub-urban Indian city. Environ. Monit. Assess. 2007, 128, 411-420.

37. Fukai, T.; Kobayashi, T.; Sakaguchi, M.; Aoki, M.; Saito, T.; Fujimori, A.; Haraguchi, H. Chemical characterization of airborne particulate matter in ambient air of Nagoya, Japan, as studied by the multielement determination with ICP-AES and ICP-MS. Anal. Sci. 2007, 23, 207-213.

38. Guor-Cheng, F.; Yuh-Shen, W.; Shih-Yu, C.; Shih-Han, H.; Jui-Yeh, R. Size distributions of ambient air particles and enrichment factor analyses of metallic elements at Taichung harbor near the Taiwan Strait. Atmos. Res. 2006, 81, 320-333.

39. Gao, Y.; Nelsonb, E.D.; Fielda, M.P.; Dinga, Q.; Lia, H.; Sherrella, R.M.; Gigliottib, C.L.; Van Ryb, D.A.; Glennb, T.R.; Eisenreich, S.J. Characterization of atmospheric trace elements on $\mathrm{PM}_{2.5}$ particulate matter over the New York-New Jersey harbor estuary. Atmos. Environ. 2002, 36, 1077-1086.

40. Taylor, S.R. Abundance of chemical elements in the continental crust: A new table. Geochim. Cosmochim. Acta 1964, 28, 1273-1285. 
41. Chester, R.; Nimmo, M.; Alarcon, M.; Saydam, C.; Murphy, K.J.T.; Sanders, G.; Corcoran, P. Defining the chemical character of aerosols from the atmosphere of the Mediterranean Sea and surrounding regions. Oceanol. Acta 1993, 16, 231-246.

42. Herut, B.; Nimmo, M.; Medway, A.; Chester, R.; Krom, M.D. Dry atmospheric inputs of trace metals at the Mediterranean coast of Israel (SE Mediterranean): Sources and fluxes. Atmos. Environ. 2001, 35, 803-813.

43. Pacyna, J.M. Source inventories for atmospheric trace metals. In Atmospheric Particles; IUPAC series on analytical and physical chemistry of environmental systems; Harrison, R.M., van Grieken, R.E., Eds.; Wiley: Chichester, UK, 1998; pp. 385-423.

44. Huang, X.; Olmez, I.; Aras, N.K. Emissions of trace elements from motor vehicles: Potential marker elements and source composition profile. Atmos. Environ. 1994, 28, 1385-1391.

45. Rajšić, S.; Mijić, Z.; Tasić, M.; Radenković, M.; Joksić, J. Evaluation of levels and sources of trace elements in urban particulate matter. Environ. Chem. Lett. 2008, 6, 95-100.

46. Finlayson-Pitts, B.J.; Pitts, J.N. Upper and Lower Atmosphere: Theory, Experiments and Applications; Academic Press: San Diego, SD, USA, 2000; pp. 86-126.

47. Seinfeld, J.H.; Pandis, S.P. Atmospheric Chemistry and Physics: from Air Pollution to Climate Change, 2nd ed.; John Wiley \& Sons, INC: Hoboken, NJ, USA, 2006; pp. 33-38.

48. Zhao, W.; Hopke, P.K.; Zhou, L. Spatial distribution of source locations for particulate nitrate and sulfate in the upper-midwestern United States. Atmos. Environ. 2007, 41, 1831-1847.

49. Arimoto, R.; Duce, R.A.; Savoie, D.L. Relationships among aerosol constitutes from Asia and the North Pacific During PEM-West A. J. Geophys. Res. 1996, 101, 2011-2023.

50. Yang, F.; Tan, J.; Zhao, Q.; Du, Z.; He, K.; Ma, Y.; Duan, F.; Chen, G.; Zhao, Q. Characteristics of $\mathrm{PM}_{2.5}$ speciation in representative megacities and across China. Atmos. Chem. Phys. 2011, 11, 5207-5219.

51. Kim, B.M.; Teffera, S.; Zeldin, M.D. Characterization of PM2.5 and PM10 in the south coast air basin of southern California: Part 1-Spatial variations. J. Air Waste Manag. Assoc. 2000, 50, 2034-2044.

52. Tolocka, M.P.; Solomon, P.A.; Mitchell, W.; Norris, G.A.; Gemmill, D.B.; Wiener, R.W.; Vanderpool, R.W.; Homolya, J.B.; Rice, J. East versus west in the US: chemical characteristics of $\mathrm{PM}_{2.5}$ during the winter of 1999. Aerosol Sci. Technol. 2001, 34, 88-96.

53. Na, K.; Cocker, D.R. Characterization and source identification of trace elements in $\mathrm{PM}_{2.5}$ from Mira Loma, Southern California. Atmos. Res. 2009, 93, 793-800.

54. Watson, J.G.; Chow, J.C. Source characterization of major emission sources in the Imperial and Mexicali Valleys along the US/Mexico border. Sci. Total Environ. 2001, 276, 33-47.

55. Comisión Nacional Forestal. Resumen Anual del reporte semanal 2009. Reportes semanales/esta- dísticos. Available online: http://www.conafor.gob.mx:8080/ documentos/ver.aspx?articulo=87\&grupo=10 (accessed on 15 July 2015).

56. Khan, F.M.; Shirasuna, Y.; Hirano, K.; Masunaga, S. Characterization of $\mathrm{PM}_{2.5}, \mathrm{PM}_{2.5-10}$ and $\mathrm{PM}_{>10}$ in ambient air, Yokohama, Japan. Atmos. Environ. 2010, 96, 159-172. 
57. Liu, G.; Li, J.; Wu, D.; Xu, H. Chemical composition and source apportionment of the ambient $\mathrm{PM}_{2.5}$ in Hangzhou, China. Particuology 2015, 18, 135-143.

58. Shen, Z.; Cao, J.; Arimoto, R.; Han, Z.; Zhang, R.; Han, Y.; Liu, S.; Okuda, T.; Nakao, S.; Tanaka, S. Ionic composition of TSP and PM2.5 during dust storms and air pollution episodes at Xi'an, China. Atmos. Environ. 2009, 43, 2911-2918.

59. Park, S.S.; Ondov, J.M.; Harrison, D.; Nair, N.P. Seasonal and shorter-term variations in particulate atmospheric nitrate in Baltimore. Atmos. Environ. 2005, 39, 2011-2020. 


\title{
Reconstructing Fire Records from Ground-Based Routine Aerosol Monitoring
}

\author{
Hongmei Zhao, Daniel Q. Tong, Pius Lee, Hyuncheol Kim and Hang Lei
}

Abstract: Long-term fire records are important to understanding the trend of biomass burning and its interactions with air quality and climate at regional and global scales. Traditionally, such data have been compiled from ground surveys or satellite remote sensing. To obtain aerosol information during a fire event to use in analyzing air quality, we propose a new method of developing a long-term fire record for the contiguous United States using an unconventional data source: ground-based aerosol monitoring. Assisted by satellite fire detection, the mass concentration, size distribution, and chemical composition data of surface aerosols collected from the Interagency Monitoring of Protected Visual Environments (IMPROVE) network are examined to identify distinct aerosol characteristics during satellite-detected fire and non-fire periods. During a fire episode, elevated aerosol concentrations and heavy smoke are usually recorded by ground monitors and satellite sensors. Based on the unique physical and chemical characteristics of fire-dominated aerosols reported in the literature, we analyzed the surface aerosol observations from the IMPROVE network during satellite-detected fire events to establish a set of indicators to identify fire events from routine aerosol monitoring data. Five fire identification criteria were chosen: (1) high concentrations of $\mathrm{PM}_{2.5}$ and $\mathrm{PM}_{10}$ (particles smaller than 2.5 and 10 in diameters, respectively); (2) a high $\mathrm{PM}_{2.5} / \mathrm{PM}_{10}$ ratio; (3) high organic carbon $\left(\mathrm{OC} / \mathrm{PM}_{2.5}\right)$ and elemental carbon $\left(\mathrm{EC} / \mathrm{PM}_{2.5}\right)$ ratios; (4) a high potassium $\left(\mathrm{K} / \mathrm{PM}_{2.5}\right)$ ratio; and (5) a low soil $/ \mathrm{PM}_{2.5}$ ratio. Using these criteria, we are able to identify a number of fire episodes close to 15 IMPROVE monitors from 2001 to 2011. Most of these monitors are located in the Western and Central United States. In any given year within the study period fire events often occurred between April and September, especially in the two months of April and September. This ground-based fire climatology is also consistent with that derived from satellite retrievals. This study demonstrates that it is feasible to reconstruct historic records of fire events based on continuous ground aerosol monitoring. This dataset can provide not only fire activity information but also fire-induced aerosol surface concentrations and chemical composition that can be used to verify satellite-based products and evaluate air quality and climate modeling results. However, caution needs to be exercised because these indicators are based on a limited number of fire events, and the proposed methodology should be further tested and confirmed in future research. 
Reprinted from Atmosphere. Cite as: Zhao, H.; Tong, D.Q.; Lee, P.; Kim, H.; Lei, H. Reconstructing Fire Records from Ground-Based Routine Aerosol Monitoring. Atmosphere 2016, 7, 43.

\section{Introduction}

Biomass burning, including both wildfires and prescribed burns, converts a sizeable amount of vegetation into burned ashes, fugitive gases, vapor, and particles [1]. The emitted gases, water vapor, and fine particles exert myriad effects on atmospheric chemistry, the Earth's radiative budget, and the hydrological cycle [2-4]. Due to the significant effects of wildfire on air quality and climate, wildfire biomass burning events have been extensively studied through ground observations [5,6], satellite sensor detection [5,7-9], and model simulations [10,11]. The continuous accumulation of fire-related data makes it possible for the scientific community to examine long-term trends in fire activity and the driving forces underlying these variations. Using satellite data and a biogeochemical model, van der Werf and colleagues [12] have examined the interannual variability in global biomass burning emissions, which exhibited large variations (with a range of more than $1 \mathrm{Pg} \mathrm{C} \cdot$ year $^{-1}$ ) from 1997 to 2004. Westerling et al. [13] have compiled an extensive wildfire database and found that large wildfire activity in the Western United States (U.S.) has increased considerably since the mid-1980s, likely driven by increased spring/summer temperatures and an earlier snowmelt in the mid-elevation forests of the Northern Rockies. Development of long-term fire climatology, while holding great promise for climate analysis, presents substantial challenges due to the difficulty of obtaining accurate fire observations and the diverse requirements of fire indices. Polar-orbiting satellite sensors, such as the Moderate Resolution Imaging Spectroradiometer (MODIS) [5,8], the Along Track Scanning Radiometer (ATSR) [10], and the Visible and Infrared Scanner (VIIRS) [12], can provide global coverage of fire counts, burned areas, and fire's radiative power. High temporal resolution fire detection could be derived from National Oceanic and Atmospheric Administration (NOAA) Geostationary Operational Environmental Satellite (GOES)-based observations [9]. For both polar-orbiting and stationary satellites, wildfires can be difficult to observe due to cloud cover or fire induced convection. Furthermore, to quantify fire-related emissions, several important assumptions have to be made to convert satellite fire observations into fire emissions data, such as fuel loading, burn duration, emission factors, and plume vertical structure. However, the conversion process is not straightforward or intuitive. For instance, van der Werf et al. [12] reported that burned areas and total fire emissions are largely decoupled because forested areas dominate fire emissions, whereas savanna burning contribute disproportionally to burned area statistics globally. Uncertainty in these procedures hinders emission estimations and needs to be investigated 
with independent data sources, such as ground and aircraft observations. Ground surveys of fire counts and burned areas have been compiled (e.g., m [13]), but these datasets cannot be directly used to derive fire emissions without further processing. Finally, air quality research and regulatory communities are interested in surface concentrations of pollutants elevated by wildfires. However, there is no direct satellite observation of fire-induced $\mathrm{PM}_{2.5}$ (particles smaller than 2.5 in diameters) surface concentrations and chemical composition. Lately, efforts have been made to convert column aerosol loading into surface concentrations [14]. A previous study focused on surface concentrations without chemical compositions, and sources of $\mathrm{PM}_{2.5}$ were not considered. Clearly, there is need to develop ground-based fire observations.

This study proposes a new method of developing long-term wildfire records from traditional ground aerosol monitoring networks. This dataset, if successfully built, can provide not only fire activity information but also fire-induced aerosol surface concentrations and chemical composition data that can be used to verify satellite-based products, evaluate fire models (e.g., model fire occurrence and characteristics), evaluate biomass burning aerosol properties simulated by chemical transport, evaluate general circulation aerosol models using satellite-derived fire emissions, evaluate air quality and climate modeling results, and assess human exposure to fire pollution. The aerosol data are obtained from the Interagency Monitoring of Protected Visual Environments (IMPROVE) network. IMPROVE is a long-term, continuous aerosol monitoring network that measures the mass concentrations, size distribution, and chemical composition of ambient aerosols, and it provides 24-hour aerosol data every third day.

The main challenge of the new method lies in how to design effective criteria to identify fire events from mixed aerosol records. Routine aerosol networks such as IMPROVE were not designed exclusively for fire detection. Instead, IMPROVE observes aerosol levels originating from all sources, such as fires, dust storms, and anthropogenic sources. We use concurrent satellite fire detection and IMPROVE data to examine the distinct physical and chemical characteristics of aerosols during fire episodes, so that a set of indicators can be established to separate fire-influenced samples from those dominated by other sources.

\section{Data Sources}

\subsection{IMPROVE Aerosol Data}

There are two reasons for choosing aerosol observation data from the IMPROVE network. First, the IMPROVE network is one of two national air quality monitoring networks in the U.S. It has been providing both mass concentrations and chemical compositions of aerosols every three days since 1988, which makes it ideal for long-term studies. Second, the IMPROVE monitors are mostly deployed in the 
national parks and remote areas in the U.S. [15], making it suitable for fire detection due to their distance from possible anthropogenic contamination. Locations of IMPROVE monitors over the contiguous United States (CONUS) are shown in Figure 1. There are other monitoring networks, such as the U.S. EPA Air Quality System (AQS) network, which has a national coverage but no aerosol composition data, and the Chemical Speciation Network (CSN), mostly deployed in urban areas and thus possibly affected by anthropogenic contamination. Hence, the IMPROVE network is selected for developing a ground-based fire detection method over the CONUS.

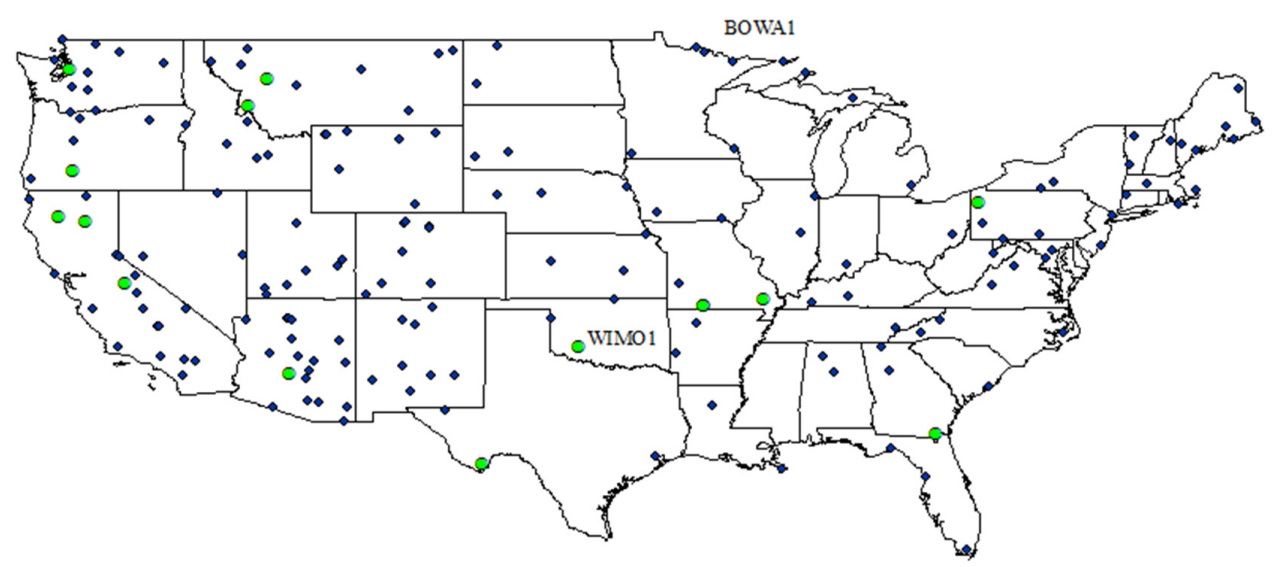

Figure 1. Locations of IMPROVE monitors (marked as $\bullet$ ) over the contiguous United States. The 15 sites (marked as ${ }^{\circ}$ ) indicate the locations where most fire events have been identified from 2001 to 2011 using the approach developed in this work.

\subsection{Satellite Data}

To train the fire detection algorithm, independent fire information is required. A typical source of fire data is satellite remote sensing. Fire events independently recorded by the U.S. National Aeronautics and Space Administration (NASA) Earth Observatory's Natural Hazards Products and other MODIS fire products are used here to assist with the ground-based analysis. These products provide fire information, including start time, end time, duration, burned scar area, and plume direction during fire events. These data are important for establishing fire identification criteria through analysis of the chemical and physical characteristics of fire events using concurrent ground observations. Therefore, we selected some satellite-detected fire events and examined the corresponding IMPROVE data collected around those fires to analyze the characteristics of the filter-based aerosol sample. 


\section{Identifying Fire Events}

\subsection{Selecting Fire Identification Criteria}

Fire identification criteria were proposed based on the chemical and physical characteristics of biomass burning-dominated aerosol data reported in the literature. Prior studies have provided a collective view of particle mass emission factors [5,16-18], size distributions [19], and optical and physical properties of biomass burning emissions [2,3]. These studies formed the basis for particle mass and concentration characterization in accordance with: $\mathrm{PM}_{2.5}$ and $\mathrm{PM}_{10}$ (particles smaller than $10 \mu \mathrm{m}$ in diameter) mass concentrations, ratio of $\mathrm{PM}_{2.5}$ to $\mathrm{PM}_{10}$, percentages of Organic Carbon (OC), Elemental Carbon (EC), potassium (K), and soil in $\mathrm{PM}_{2.5}$. During a fire episode, heavy smoke and low visibility are common, due to the large amount of fine and coarse particles emitted into the ambient air. Therefore, Particulate Matter (PM) concentration in the source region register elevated spikes when a fire event occurs. However, these spikes are not unique to fire events. Had there been a dust event or a volcanic plume, there would have been equal or higher PM concentration spikes. Therefore, to reliably attribute PM concentration spikes to a fire event rather than to a dust event, other indicators must be considered. A previous study documented that approximately $95 \%$ of the particles emitted from biomass burning are fine particles, and the dominant chemical components are carbonaceous [20]. Some reports also suggest that carbon accounts for $50 \%$ to $70 \%$ of the total mass of fire-emitted aerosols, with $55 \%$ and $8 \%$ of the fine particle mass attributed to OC and EC, respectively [3]. Therefore, a high $\mathrm{PM}_{2.5} / \mathrm{PM}_{10}$ ratio, dominated by high OC/PM 2.5 and $\mathrm{EC} / \mathrm{PM}_{2.5}$ ratios, are additional aerosol characteristics pertinent to a fire event. Furthermore, trace inorganic species account for approximately $10 \%$ of the fine mass of fresh smoke, mostly enriched in $\mathrm{K}[3,21]$. Consequently, a high $\mathrm{K} / \mathrm{PM}_{2.5}$ ratio can also be considered as a fire event indicator.

\subsection{Determining Threshold Values for Fire Identification Criteria}

Next, we focus on a number of satellite-detected fire events to determine proper thresholds for each fire identification criterion. We checked the locations and times of some large fire events detected by satellites. We examined satellite imageries for fire events from the NASA Earth Observatory's Natural Hazards fire products [22], and MODIS fire maps [23]. We then merged these fire maps with the corresponding geographic coverage from IMPROVE network sites using the geo-spatial software in ArcGIS.

First, we focused on the BOWA1 site (marked in Figure 1) with a case study. A lightning strike in the Boundary Waters Canoe Area Wilderness Region of northeastern Minnesota started a forest fire. On 12 September 2011, fire event imageries were captured by MODIS aboard the Terra satellite (Figure 2). The fire was 
a plume-driven event, and it ultimately burned more than 60,000 acres. According to the IMPROVE aerosol data, during the fire event between September 9th and 18th (no data on 6th and 12th September 2011), the average concentrations of $\mathrm{PM}_{2.5}, \mathrm{PM}_{10}, \mathrm{OC}$, and EC were 14.89, 18.31, 7.49, and $0.62 \mu \mathrm{g} \cdot \mathrm{m}^{-3}$, respectively. By contrast, during average background conditions, these values were $4.39,6.38,1.77$, and $0.13 \mu \mathrm{g} \cdot \mathrm{m}^{-3}$, respectively. Although there were no data during part of this fire episode, these results suggest that there was a fire event detected by the IMPROVE monitor.

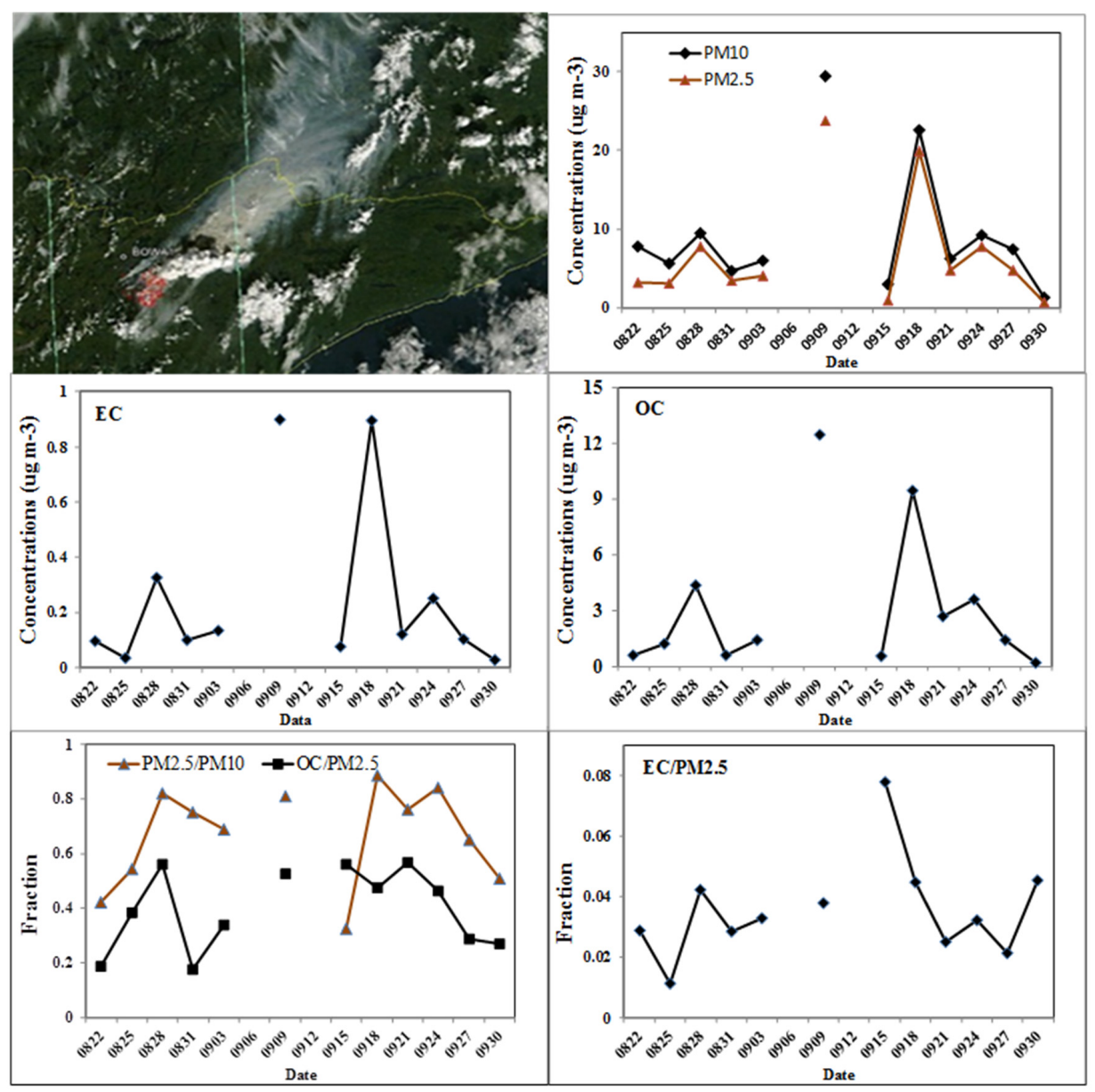

Figure 2. A case study of a fire event in September 2011 at the BOWA1 site. The MODIS on NASA's Terra satellite captured the top left image on 12th September 2011. Red outlines show areas of high surface temperatures associated with active burning, near the BOWA1 site. Characteristics of fire-dominated aerosol $\left(\mathrm{PM}_{2.5}\right.$, $\mathrm{PM}_{10}, \mathrm{OC}$, and $\mathrm{EC}$ concentrations, ratios of $\mathrm{EC}, \mathrm{OC}$ in $\mathrm{PM}_{2.5}$ ) during the fire event episode are shown in other figures. 
We analyzed aerosol observation data from the IMPROVE sites during the satellite-detected fire episodes. We analyzed the temporal variability of these indicators (concentrations of $\mathrm{PM}_{10}$ and $\mathrm{PM}_{2.5}$ and the ratios of $\mathrm{PM}_{2.5} / \mathrm{PM}_{10}$, $\mathrm{OC} / \mathrm{PM}_{2.5}, \mathrm{EC} / \mathrm{PM}_{2.5}, \mathrm{~K} / \mathrm{PM}_{2.5}$, and soil/ $\mathrm{PM}_{2.5}$ ) before, during, and after the fire episode for a span of 15 days. Compared with the no-fire period conditions, the concentrations of $\mathrm{PM}_{10}$ and $\mathrm{PM}_{2.5}$ and the ratios of $\mathrm{PM}_{2.5} / \mathrm{PM}_{10}, \mathrm{OC} / \mathrm{PM}_{2.5}$, $\mathrm{EC} / \mathrm{PM}_{2.5}$, and $\mathrm{K} / \mathrm{PM}_{2.5}$ were higher, and the ratio of soil $/ \mathrm{PM}_{2.5}$ was lower (Figure 3) during fire conditions. Finally, we determined the thresholds of fire identification criteria (Table 1) by summarizing aerosol characteristics from both prior studies and measurements from the IMPROVE sites.
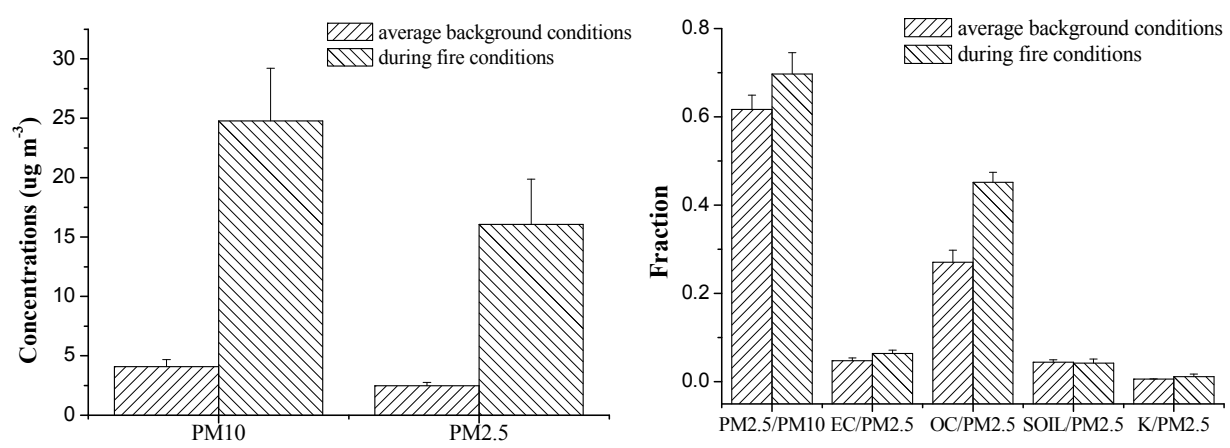

Figure 3. Comparison of fire identification criteria values during fire conditions and average background concentrations or conditions sampled by the monitoring site.

Table 1. Thresholds of fire identification criteria used in this study.

\begin{tabular}{|c|c|c|c|c|c|c|c|}
\hline Indicator & $\begin{array}{c}\mathrm{PM}_{2.5} \\
\left(\mu \mathrm{g} / \mathrm{m}^{3}\right)\end{array}$ & $\begin{array}{c}\mathbf{P M}_{10} \\
\left(\mu \mathrm{g} / \mathbf{m}^{3}\right)\end{array}$ & $\mathrm{PM}_{2.5} / \mathrm{PM}_{10}$ & $\mathrm{OC} / \mathrm{PM}_{2.5}$ & $\mathrm{EC} / \mathrm{PM}_{2.5}$ & $\mathrm{~K} / \mathbf{P M}_{2.5}$ & Soil/PM 2.5 \\
\hline $\begin{array}{c}\text { Static } \\
\text { threshold }\end{array}$ & $>15$ & $>18$ & $>0.6$ & $>0.35$ & $>0.05$ & $>0.003$ & $<0.03$ \\
\hline
\end{tabular}

\subsection{Applying the Approach to Identify Fire Events}

Finally, we applied the fire identification criteria and the corresponding thresholds to all IMPROVE sites to identify fire events between 2001 and 2011. A large number of fire events were identified at 15 IMPROVE sites (marked in Figure 1). Most of these events were located in the Western U.S., particularly in the states of California and Montana, and the Central U.S., especially in the states of Missouri, Oklahoma, and Texas. A previous study based on the GOES burned area product also documented that fires occurred most frequently in the Western and Southeastern U.S., and along the Central and Southern Mississippi Valley [9]. In the Western U.S., due to the dry climate and dense forests (or shrubs), the increased threat of larger, longer, and more intensive forest fires has become a concern $[13,24]$. 
A previous study documented that California, dominated by shrubland, was a high-intensity fire event area, with fires extending to sizes of 10,000 ha or more [25]. The surface-monitor-based methodology shows that fire has a great impact on local air quality. Unlike satellite-retrievals, our method can provide information about aerosol concentrations and chemical composition attributed to these fire events. The changes in $\mathrm{PM}_{2.5}$ levels and composition caused by fire emissions vary over time and space [24]. For example, the concentrations of $\mathrm{PM}_{2.5}$ were higher in the Eastern U.S. and lower in the central regions, with strong seasonal patterns [26]. In the Western U.S., the annual average percentage of OC in $\mathrm{PM}_{2.5}$ is $40 \%$, whereas in the eastern U.S. it is $25 \%$, with an annual average of $28 \%$ for the whole U.S. For the entire year, the average in summer is higher than that in winter for the U.S., both regionally and CONUS-wide [26]. Therefore, the indicators should be specific for region and season.
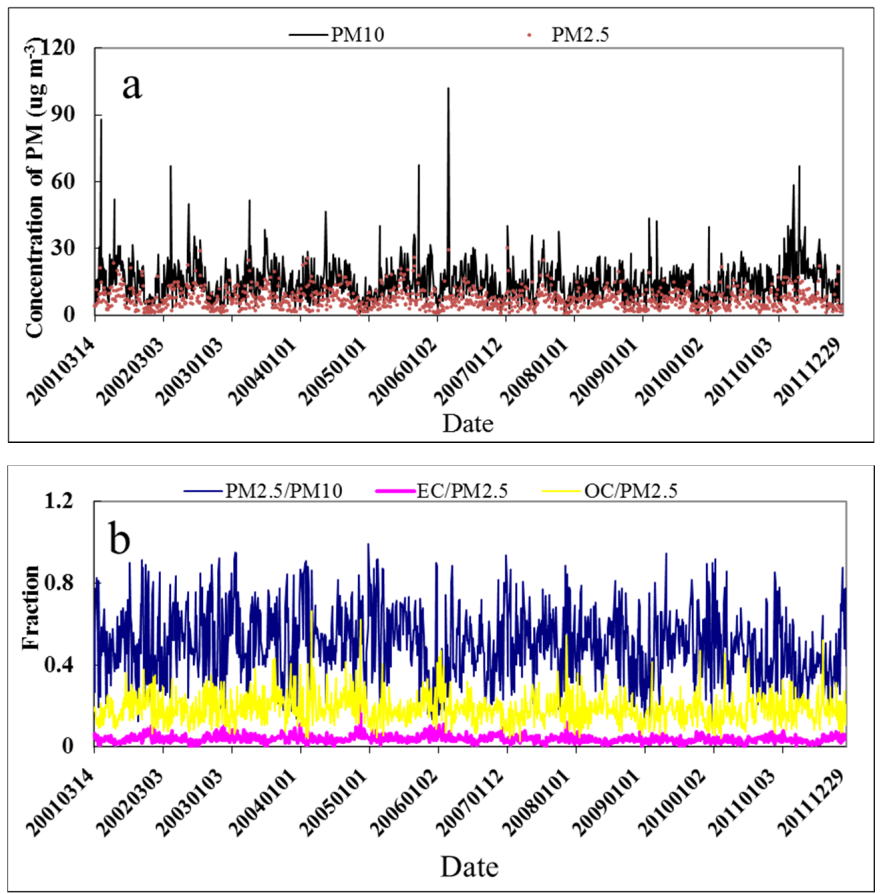

Figure 4. Characteristics of aerosols (a) Concentrations of $\mathrm{PM}_{2.5}$ and $\mathrm{PM}_{10}$; (b) Fractions of $\mathrm{PM}_{2.5} / \mathrm{PM}_{10}, \mathrm{EC} / \mathrm{PM}_{2.5}, \mathrm{OC} / \mathrm{PM}_{2.5}$ ) at the WIMO1 site from 2001 to 2011.

Due to the differences in PM concentration and composition over time and space, regional and seasonal characteristics should be considered when applying fire indicators. Here we analyzed the temporal pattern of PM and the ratios of some species in $\mathrm{PM}_{2.5}$ at the WIMO1 site (Figure 4). The results showed that $\mathrm{PM}_{2.5}$, 
$\mathrm{PM}_{10}$ concentrations, and the $\mathrm{PM}_{2.5} / \mathrm{PM}_{10}$ ratio were seasonally distinctive: higher in summer and lower in winter, with annual means of $7.3 \mu \mathrm{g} \cdot \mathrm{m}^{-3}, 14.9 \mu \mathrm{g} \cdot \mathrm{m}^{-3}$, and $0.5 \mu \mathrm{g} \cdot \mathrm{m}^{-3}$, respectively. However, the $\mathrm{EC} / \mathrm{PM}_{2.5}$ ratio was higher in fall and lower in summer during the study period. Compared to the annual mean values, the data during the identified fire episodes were higher. This result suggested that the identification criteria worked well. Furthermore, we analyzed the monthly mean values of all indicators at the WIMO1 site (Figure 5). The results showed that $\mathrm{OC} / \mathrm{PM}_{2.5}$ and $\mathrm{EC} / \mathrm{PM}_{2.5}$ ratios are higher in March and October, but lower in July. Especially in July, the lower mean values of $\mathrm{OC} / \mathrm{PM}_{2.5}$ and $\mathrm{EC} / \mathrm{PM}_{2.5}$ ratios indicated that some fire events may have been missed. This result suggested that applying month-specific indicator values could enhance the method to generate more consistent reporting.

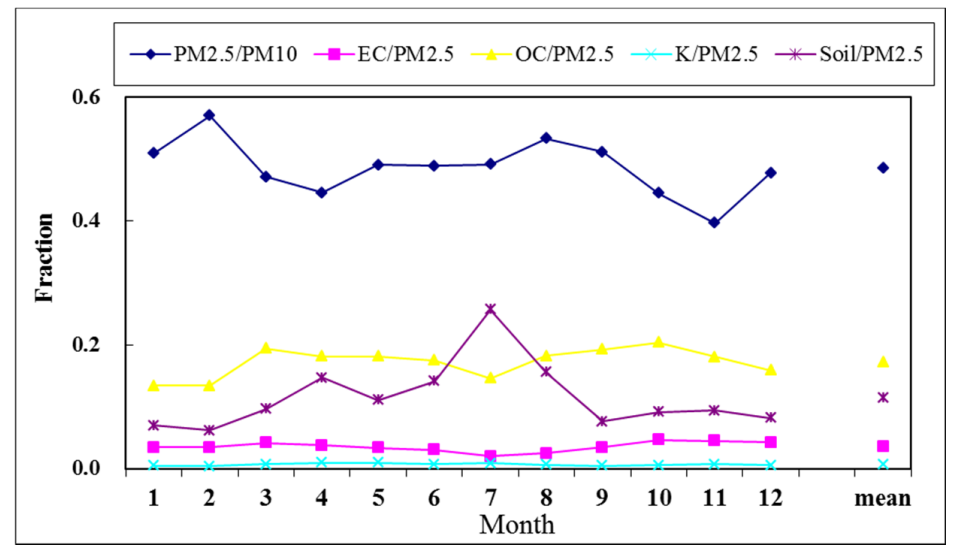

Figure 5. The monthly average of fire indicators at the WIMO1 site.

\subsection{Testing Fire Identification Criteria}

Finally, we analyzed the temporal and spatial characteristics of fire events to test this methodology. Following the suggested procedures, we were able to identify fire events in the proximity of 15 IMPROVE monitoring sites from 2001 to 2011. We compared those identified fire events with the HYbrid Single-Particle Lagrangian Integrated Trajectory (HYSPLIT) back-trajectory model $[27,28]$ prediction, wildland fire summary and statistics annual report by the National Interagency Fire Center [29], and USGS's (United States Geological Survey) record of fire events [30] to confirm these events. We looked at trajectories from the locations of fires identified in satellite imageries and compared fire reports with these results. Most of fires identified by this method were consistent with the records. In fact, there were some fire events detected by this method but missed by satellite due to cloud cover. Furthermore, some fire events were missed by the annual report due to the small size of the burned 
areas, and only fires over 40,000 acres were marked in the wildland fire summary and statistics annual report. For example, we identified a fire event at the WIMO1 site on 30 May 2011, according to fire identification criteria. Then, we compared this result with the HYSPLIT simulation on the same day (provided by the NOAA ARL READY online platform). Fire points, light smoke, medium smoke, and heavy smoke can be found in the HYSPLIT simulation picture. From the picture, we found that there were fire events in Texas and the Gulf of Mexico USA, but no fire located near the WIMO1 site. Heavy smoke from Texas and the Gulf of Mexico may have caused this fire event to be missed by satellite. In addition, we analyzed the temporal and spatial characteristics of aerosols in identified fire events, and found that most of them were located in the Western U.S. (including California and Montana) and the Central U.S. (including Missouri, Oklahoma and Texas).

We chose the WIMO1 site $\left(34.7315^{\circ} \mathrm{N}, 98.7155^{\circ} \mathrm{W}\right)$ in the case study for two reasons: (1) Frequent fires were detected at this site both by satellite and by this method; (2) this site is located in the Wichita Mountains in Oklahoma State, and Oklahoma and Texas are the two states with the most fire events recorded (Figure 1). Here, we calculated days of fire and numbers of fire events from 2001 to 2011. Because a fire can last for several days, if some fire events were identified by indicators for several consecutive days, we considered this one event. There were 83 fire events (161 days) identified between 2001 and 2011 at the WIMO1 site. We analyzed the characteristics of fire-dominated aerosol at the WIMO1 site between 2001 and 2011 (Figure 6). The results showed that concentrations of $\mathrm{PM}_{2.5}$ and $\mathrm{PM}_{10}$ were 14.2 and $21.2 \mu \mathrm{g} \cdot \mathrm{m}^{-3}$ during fire events, respectively. Compared with background conditions, these values were elevated by $42.7 \%$ and $94.6 \%$, respectively. The mean fraction of $\mathrm{PM}_{2.5}$ in $\mathrm{PM}_{10}$ was $66.4 \%$ during fire events, whereas the value was $50.0 \%$ during average background conditions, which also increased by $32.8 \%$. Compared with the variations in PM concentrations, the fractions of some species in the aerosol were more stable. Because aerosol concentrations in smoke plumes were affected by fire intensity, severity, duration, fuel loading, wind direction, and site location, the ratios of species in aerosol were strongly dependent on the sources of aerosols (fire, dust or other natural and anthropogenic sources).

Temporal patterns of fires at the WIMO1 site were distinctive. Between 2001 and 2011, the number of days with fires declined at the WIMO1 site (Figure 7). From 2001 to 2005 , there were more than 16 days with fire records every year, including up to 26 days in 2005. However, from 2006 to 2011, the number of fire days declined, and there were fewer than 10 days in 2006. In any given year within the study period, fire events often occurred between April and September, especially in the two months of September and April (Figure 8). The spatial and temporal patterns of fires were often affected by topography, vegetation, climate, and human activity [31]. Previous studies of burned areas, which used data from the AVHRR (the Advanced 
Very High Resolution Radiometer) and GOES satellite, also documented that fire exhibits a distinctive seasonality, with a peak from June to August. In croplands, peak burning occurred from April to September because agricultural fires were set during pre-planting and post harvesting periods [9,32]. In this study, peak fire events in September may be related to agricultural burnings.
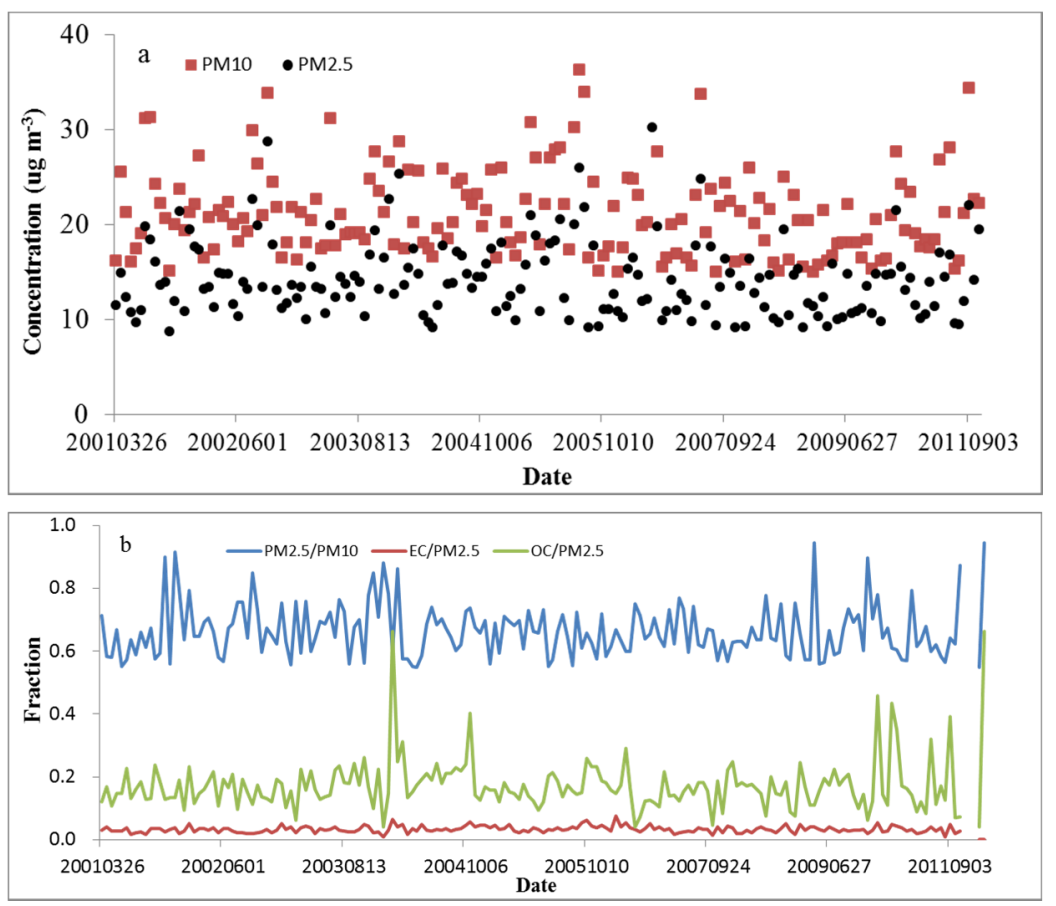

Figure 6. Characteristics of aerosols. (a) Concentrations of $\mathrm{PM}_{2.5}$ and $\mathrm{PM}_{10}$; (b) Fractions of $\mathrm{PM}_{2.5} / \mathrm{PM}_{10}, \mathrm{EC} / \mathrm{PM}_{2.5}, \mathrm{OC} / \mathrm{PM}_{2.5}$ ) during fire events at the WIMO1 site between 2001 and 2011.

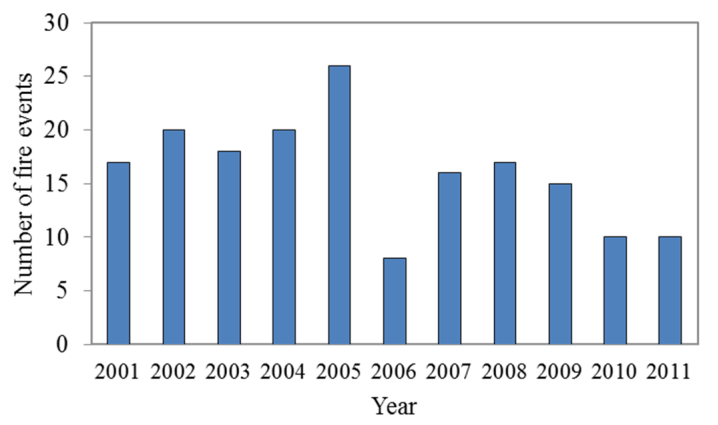

Figure 7. Number of fire events in every year from 2001 to 2011 at the WIMO1 site. 


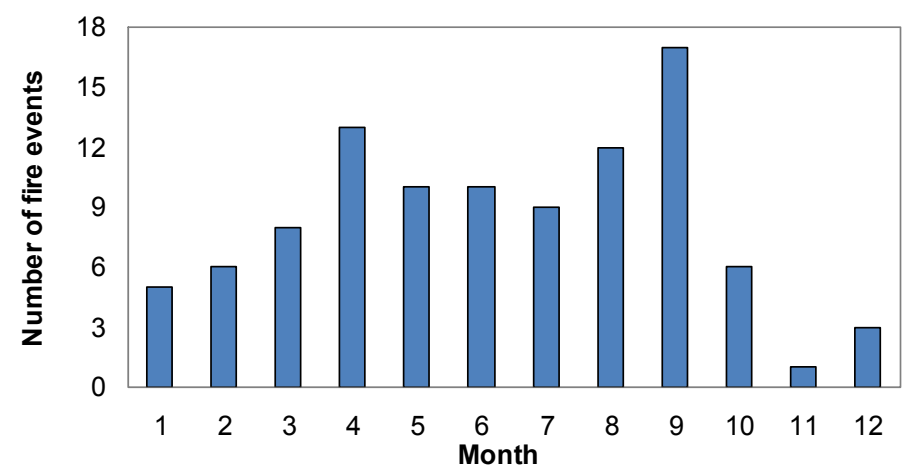

Figure 8. Number of fire events in every month between 2001 and 2011 at the WIMO1 site.

\section{Discussion of Uncertainties and Limitations}

The above results confirm that the proposed methodology has the potential to identify a fire event and quantify its impact on air quality. However, caution needs to be exercised because the indicators discussed here are based on a limited number of fire events. We should take note of the uncertainties and limitations of the methodology, which are caused by the following factors: (1) the sampling frequency (every third day) and the rather sparse distribution of the IMPROVE sites limit the capability of the IMPROVE network to detect all fires, especially for regions with high fire frequency but few IMPROVE sites; (2) neighboring monitoring sites may detect the same fires, resulting in double-counting; (3) excessive loading of smoke ash and other aerosols may disable the instruments; and finally (4) interference by background aerosols makes it difficult to clearly determine thresholds for the fire identification criteria. Aerosol concentrations and chemical composition are intrinsically highly variable over time and space. Consequently, one uniform threshold may not be applicable to all sites at all times. Low thresholds may cause false detection, whereas high thresholds may cause omission of some fire counts. For example, the results of this study showed that there were fewer fire events during winter compared with other seasons. This result can be explained by winter's vegetation and climate conditions, which are unfavorable for fires. Another reason may be that the concentrations of PM in winter are near the annual minimum. They cannot reach the threshold concentration level to trigger a fire count by the identification algorithm. If we use the average concentrations of the entire year as a cutoff value, the winter data will be omitted, and few fires will be identified. However, especially in the southern U.S., such as in Florida, fire events also occur in winter, but cannot be identified by this method due to low seasonal 
aerosol concentrations. Therefore, thresholds for these indicators should be adjusted according to region and season instead of adopting one uniform value.

\section{Summary}

Fire is a major source of aerosol. However, few observation sites are designed to record fire events and to track aerosol emissions from biomass burning. This work proposed a new approach to the reconstruction of historic fire records based on observations collected by a continuous ground-based aerosol monitoring network over the contiguous United States. Using five fire identification criteria, we were able to identify a number of fire episodes recorded by 15 IMPROVE monitors from 2001 to 2011. Most of these fire events were located in the Western and Central United States. In any given year within the study period, fire events often occurred between April and September, especially in the two months of April and September. There were 83 fire events (161 days) at WIMO1 sites between 2001 and 2011. This study demonstrates that it is feasible to reconstruct historic records of fire events based on continuous ground aerosol monitoring. This dataset would provide not only fire activity information but also fire-induced aerosol surface concentrations and chemical composition data that can be used to verify satellite-based products, evaluate air quality and climate modeling results, and assess human exposure to fire pollution. However, caution needs to be exercised because these indicators are based on a limited number of fire events, and the proposed methodology should be further tested and confirmed by future research.

Acknowledgments: We thank the three anonymous reviewers for their constructive comments and helpful suggestions. This work is financially supported by the National Key Technology R\&D Program (No. 2014BAC16B03), the National Natural Science Foundation of China (No. 41201495), the Chinese Academy of Sciences/State Administration of Foreign Experts Affairs (CAS/SAFEA) International Partnership Program for Creative Research Teams (No. KZZD-EW-TZ-07), and the Natural Science Foundation of Jilin Province (No. 20150101010JC). The assistance of the U.S. NOAA Air Resources Laboratory is also gratefully acknowledged.

Author Contributions: The study was completed with cooperation among all authors: Daniel Q. Tong and Hongmei Zhao conceived and designed the research topic. Hongmei Zhao conducted the research and wrote the manuscript. Pius Lee, Hyuncheol Kim, and Hang Lei collaborated in discussing the results and providing editorial advice.

Conflicts of Interest: The authors declare no conflicts of interest.

\section{References}

1. Crutzen, P.L.; Andteae, M.O. Biomass burning in the tropics: Impact on atmospheric chemistry and biogeochemical cycles. Science 1990, 250, 1669-1678. 
2. Reid, J.S.; Eck, T.F.; Christopher, S.A.; Koppmann, R.; Dubovik, O.; Eleuterio, D.P.; Holben, B.N.; Reid, E.A.; Zhang, J. A review of biomass burning emissions part III: Intensive optical properties of biomass burning particles. Atmos. Chem. Phys. 2005, 5, 827-849.

3. Reid, J.S.; Koppmann, R.; Eck, T.F.; Eleuterio, D.P. A review of biomass burning emissions part II: Intensive physical properties of biomass burning particles. Atmos. Chem. Phys. 2005, 5, 799-825.

4. Mielonen, T.; Aaltonen, V.; Lihavainen, H.; Hyvarunen, A.; Arola, A.; Komppula, M.; Kivi, R. Biomass burning aerosols abserved in Northern Finland during the 2010 wildfires in Russia. Atmosphere 2013, 4, 17-34.

5. Wiedinmyer, C.; Quayle, B.; Geron, C.; Belote, A.; McKenzie, D.; Zhang, X.; O’Neill, S.; Wynne, K.K. Estimating emissions from fires in North America for air quality modeling. Atmos. Environ. 2006, 40, 3419-3432.

6. Burling, I.R.; Yokelson, R.J.; Akagi, S.K.; Urbanski, S.P.; Wold, C.E.; Griffith, D.W.T.; Johnson, T.J.; Reardon, J.; Weise, D.R. Airborne and ground-based measurements of the trace gases and particles emitted by prescribed fires in the United States. Atmos. Chem. Phys. 2011, 11, 12197-12216.

7. Hsu, N.C.; Herman, J.R.; Bhartia, P.K.; Seftor, C.J.; Torres, O.; Thompson, A.M.; Gleason, J.F.; Eck, T.F.; Holben, B.N. Detection of biomass burning from TOMS measurements. Geophys. Res. Lett. 1996, 23, 745-748.

8. Ichoku, G.; Giglio, L.; Wooster, M.J.; Remer, L.A. Global characterization of biomass-burning patterns using satellite measurements of fire radiative energy. Remote Sens. Environ. 2008, 112, 2950-2962.

9. Zhang, X.Y.; Kondragunta, S. Temporal and spatial variability in biomass burned area across the USA derived from the GOES fire product. Remote Sens. Environ. 2008, 112, 2886-2897.

10. Duncan, B.N.; Martin, R.V.; Staudt, A.C.; Yevich, R.; Logan, J.A. Interannual and seasonal variability of biomass burning emissions constrained by satellite observations. J. Geophys. Res. 2003, 108.

11. Wang, J.; Christopher, S.A.; Nair, U.S.; Reid, J.S.; Prins, E.M.; Szykman, J.; Hand, J. Mesoscale modeling of Central American smoke transport to the United States: 1. "Top-down" assessment of emission strength and diurnal variation impacts. J. Geophys. Res. Atmos. 2006, 111.

12. Van der Werf, G.R.; Randerson, J.T.; Giglio, L.; Collatz, G.J.; Mu, M.; Kasibhstla, P.S.; Morton, D.C.; DeFries, R.S.; Jin, Y.; van Leeuwen, T.T. Global fire emission and the contribution of deforestation, savanna, forest, agricultural, and peat fires (1997-2009). Atmos. Environ. 2010, 40, 3419-3432.

13. Westerling, A.L.; Hidalgo, H.G.; Cayan, D.R.; Swetnam, T.W. Warming and earlier spring increase western U.S. forest wildfire activity. Science 2006, 313, 940-943.

14. Boys, B.L.; Martin, R.V.; van Donkelaar, A.; MacDonell, R.J.; Hsu, N.C.; Cooper, M.J.; Yantosca, R.M.; Lu, Z.; Streets, D.G.; Zhang, Q.; et al. Fifteen-year global time series of satellite-derived fine particulate matter. Environ. Sci. Technol. 2014, 48, 11109-11118. 
15. Pitchford, M.L.; Malm, W.C. Development and applications of a standard visual index. Atmos. Environ. 1994, 28, 1049-1054.

16. Akagi, S.K.; Yokelson, R.J.; Wiedinmyer, C.; Alvarado, M.J.; Reid, J.S.; Karl, T.; Crounse, J.D.; Wennberg, P.O. Emission factors for open and domestic biomass burning for use in atmospheric models. Atmos. Chem. Phys. 2011, 11, 4039-4072.

17. Yokelson, R.J.; Burling, I.R.; Gilman, J.B.; Warneke, C.; Stockwell, C.E.; de Gouw, J.; Akagi, S.K.; Urbanski, S.P.; Veres, P.; et al. Coupling field and laboratory measurements to estimate the emission factors of identified and unidentified trace gases for prescribed fires. Atmos. Chem. Phys. 2013, 13, 89-116.

18. Urbanski, S. Wildland fire emissions, carbon, and climate: Emission factors. Forest Ecol. Manag. 2014, 317, 51-60.

19. Janhall, S.; Andreae, M.O.; Poschl, U. Biomass burning aerosol emissions from vegetation fires: Particle number and mass emission factors and size distributions. Atmos. Chem. Phys. 2010, 10, 1427-1439.

20. Deng, C.R. Identification of Biomass Burning Source in Aerosols and the Formation Mechanism of Haze. Ph.D. Thesis, University of Fudan, Shanghai, China, 15 April 2011. (in Chinese).

21. Amodio, M.; Andriani, E.; Dambruoso, P.R.; Daresta, B.E.; de Gennaro, G.; di Gilio, A.; Intini, M.; Palmisani, J.; Tutino, M. Impact of biomass burning on $\mathrm{PM}_{10}$ concentrations. Fresen. Environ. Bull. 2012, 21, 3296-3300.

22. The NASA Earth Observatory's Natural Hazards fire products. Available online: http: / / earthobservatory.nasa.gov /NaturalHazards / category.php?cat_id=8\&m=01\&y=2013 (accessed on 23 July 2013).

23. MODIS fire maps. Available online: http://reverb.echo.nasa.gov $/$ reverb $/ \# u t f 8=\% E 2 \% 9 C \%$ 93\&spatial_map= satellite\&spatial_type=rectangle\&keywords=MOD14 (accessed on 23 July 2013).

24. Schoennagel, T.; Veblen, T.T.; Romme, W.H. The interaction of fire, fuels, and climate across Rocky Mountain forests. BioScience 2004, 54, 661-676.

25. Keeley, J.E.; Zedler, P.H. Large, high-intensity fire events in southern California shrublands: Debunking the fine-grain age patch model. Ecol. Appl. 2009, 19, 2254.

26. Bell, M.L.; Dominici, F.; Ebisu, K.; Zeger, S.L.; Samet, J.M. Spatial and temporal variation in $\mathrm{PM}_{2.5}$ chemical composition in the United States for health effects studies. Environ. Health Perspect. 2007, 115, 988-995.

27. Draxler, R.R.; Rolph, G.D. HYbrid Single-Particle Lagrangian Integrated Trajectory (HYSPLIT) Model access via NOAA ARL READY. Available online: http:/ /www.arl.noaa.gov /HYSPLIT_info.php (accessed on 23 July 2012).

28. Rolph, G.D. Real-time Environmental Applications and Display System (READY). Available online: http:/ / ready.arl.noaa.gov/index.php (accessed on 23 July 2012).

29. The National Interagency Fire Center. Available online: http://www.nifc.gov/fireInfo/ fireInfo_statistics. html (accessed on 23 July 2013).

30. The United States Geological Survey record of fire events. Available online: http:/ / wildfire.cr.usgs.gov/ firehistory/data.html (accessed on 23 July 2013). 
31. Iniguez, J.M.; Swetnam, T.W.; Baisan, C.H. Spatially and temporally variable fire regime on Rincon Peak, Arizona, USA. Fire Ecol. 2009, 5, 3-21.

32. Pu, R.; Li, Z.; Gong, P.; Csiszar, I.; Fraser, R.; Hao, W.; Kondragunta, S.; Weng, F. Development and analysis of a 12-year daily 1-km forest fire dataset across North America from NOAA/AVHRR data. Remote Sens. Environ. 2007, 108, 198-208. 
Section 2:

Detailed Organic Aerosol

Composition and

Source Apportionment 



\title{
Composition and Sources of Particulate Matter Measured near Houston, TX: Anthropogenic-Biogenic Interactions
}

\author{
Jeffrey K. Bean, Cameron B. Faxon, Yu Jun Leong, Henry William Wallace, \\ Basak Karakurt Cevik, Stephanie Ortiz, Manjula R. Canagaratna, \\ Sascha Usenko, Rebecca J. Sheesley, Robert J. Griffin and Lea Hildebrandt Ruiz
}

\begin{abstract}
Particulate matter was measured in Conroe, Texas ( $60 \mathrm{~km}$ north of downtown Houston, Texas) during the September 2013 DISCOVER-AQ campaign to determine the sources of particulate matter in the region. The measurement site is influenced by high biogenic emission rates as well as transport of anthropogenic pollutants from the Houston metropolitan area and is therefore an ideal location to study anthropogenic-biogenic interactions. Data from an Aerosol Chemical Speciation Monitor (ACSM) suggest that on average 64 percent of non-refractory $\mathrm{PM}_{1}$ was organic material, including a high fraction $(27 \%-41 \%)$ of organic nitrates. There was little diurnal variation in the concentrations of ammonium sulfate; however, concentrations of organic and organic nitrate aerosol were consistently higher at night than during the day. Potential explanations for the higher organic aerosol loadings at night include changing boundary layer height, increased partitioning to the particle phase at lower temperatures, and differences between daytime and nighttime chemical processes such as nitrate radical chemistry. Positive matrix factorization was applied to the organic aerosol mass spectra measured by the ACSM and three factors were resolved - two factors representing oxygenated organic aerosol and one factor representing hydrocarbon-like organic aerosol. The factors suggest that the measured aerosol was well mixed and highly processed, consistent with the distance from the site to major aerosol sources, as well as the high photochemical activity.
\end{abstract}

Reprinted from Atmosphere. Cite as: Bean, J.K.; Faxon, C.B.; Leong, Y.J.; Wallace, H.W.; Cevik, B.K.; Ortiz, S.; Canagaratna, M.R.; Usenko, S.; Sheesley, R.J.; Griffin, R.J.; Ruiz, L.H. Composition and Sources of Particulate Matter Measured near Houston, TX: Anthropogenic-Biogenic Interactions. Atmosphere 2016, 7, 73.

\section{Introduction}

Air quality in the United States has received increased attention in recent years as regulations tighten and cities strive to reduce concentrations of airborne pollutants. Ozone and atmospheric particulate matter (PM) are two pollutants that have received increased attention as health effects become clearer [1]. Particulate matter is linked to a range of respiratory and cardiovascular diseases [2]. High ozone levels can also lead 
to respiratory problems [3]—especially in more sensitive groups such as children, the elderly, and those with asthma. Many regions struggle to meet compliance with the National Ambient Air Quality Standard (NAAQS) [4] for ozone and PM set by the U.S. Environmental Protection Agency (EPA).

The U.S. EPA recently lowered the annual NAAQS for $\mathrm{PM}_{2.5}$ (particulate matter with diameter below $2.5 \mu \mathrm{m}$ ) from 15 to $12 \mu \mathrm{g} \cdot \mathrm{m}^{-3}$ [5]. This new annual standard brings numerous additional metropolitan regions including Houston, TX to near non-attainment for $\mathrm{PM}_{2.5}$. This underlines the importance of understanding the composition and sources of $\mathrm{PM}_{2.5}$ in these areas. The EPA has also announced that the NAAQS for ozone will be lowered from 75 to $70 \mathrm{ppb}$ [6] —a level that will require action for many metropolitan regions. Houston is an important area for air quality research as the fourth largest U.S. city and one that struggles to meet air quality standards. As a major center for the energy and chemical industry, Houston must continuously inspect, analyze, and improve its air quality in order to stay below the NAAQS and improve the health of its inhabitants. Regional photo-chemical models are used to inform policy makers, but these models must be validated with ambient measurements. Measurements can also be used for source apportionment of air pollution.

Recognizing the importance of ambient measurements, several large-scale ambient measurement campaigns have been conducted in Texas [7]. The biggest campaign was the Texas Air Quality Study in 2000 (TexAQS 2000). A key discovery of this campaign was the important role of highly reactive volatile organic compounds (HRVOCs) in ozone production [8]. The Gulf Coast Aerosol Research and Characterization Study (GC-ARCH), a companion study to TexAQS, was focused on spatial and temporal variability in PM, as well as understanding its formation and transformation in southeast Texas [9]. The TexAQS 2000 campaign was followed up with TexAQS II in 2005-2006, a key finding of which was the magnitude of background concentrations of pollutants in Texas, which adds to the complexity of understanding and improving air quality. The 2009 Study of Houston Atmospheric Radical Precursors (SHARP) campaign uncovered the previously underestimated role of nitrous acid (HONO) in Texas air [10]. Since 2010, many smaller-scale studies in Texas have added to our understanding of the complex effects of oil and gas activity on air quality [11-13]. The amount of effort that has been applied towards understanding air quality in Texas highlights the importance of this research in meeting NAAQS and improving human health.

Previous studies have found that a large fraction of particulate matter in Houston is organic aerosol (OA) $[9,14]$. Sources of OA in Houston include primary organic aerosol (POA) and secondary organic aerosol (SOA) [15] from urban anthropogenic activity, the petrochemical industry, and fires, as well as SOA from biogenic volatile organic compounds (VOCs) $[9,14,16]$. Understanding the sources 
and formation of $\mathrm{OA}$ is therefore very complex, and significant uncertainties remain. Conroe, TX, the location of the measurements reported here, is located $\sim 60 \mathrm{~km}$ north of the urban center of Houston. The measurement site is in an area that is influenced by anthropogenic emissions from Houston that have been diluted and atmospherically processed since emission. The area is subject to high biogenic emission rates and is located near the start of the piney woods that extend through the US Southeast-a big difference from the grassy prairies that extend west and south throughout Texas. This ecosystem transition near Conroe makes it an interesting place to explore the effects of the ecosystems on observed PM. The interaction of biogenic VOCs and anthropogenic oxidants is very important as it helps explain why radiocarbon analysis in places like the U.S. Southeast show that biogenic (modern) carbon constitutes more than half of SOA, yet SOA correlates with anthropogenic tracers like CO [17]. Recent work [18-20] has begun to explore these interactions and their implications for air quality in places with high levels of biogenic VOCs.

Here we report measurements taken as part of Deriving Information on Surface Conditions from Column and Vertically Resolved Observations Relevant to Air Quality (DISCOVER-AQ) [21] during the period of 24 August-1 October 2013. A main purpose of this most recent large-scale ambient measurement campaign, which was organized through NASA, was to improve the interpretation of ground-level pollutant concentrations from satellite data by taking simultaneous measurements from space, by plane and on the ground. This manuscript focuses on measurements taken at a ground site in Conroe, TX, where various instruments were deployed. The focus of this work is the composition and size distribution of $\mathrm{PM}_{1}$ (particulate matter with diameter below $1 \mu \mathrm{m}$ ), which was measured with an Aerosol Chemical Speciation Monitor (ACSM) and a Scanning Electrical Mobility Spectrometer (SEMS). The purpose of these measurements was to better characterize the sources and processes which influence the concentrations of PM in this area. An improved understanding of Houston PM is essential in formulating ways to decrease concentrations and more generally manage the air quality in this region.

\section{Experimental}

\subsection{Site Description}

The data were obtained at an air quality monitoring ground site in Conroe, TX $\left(30.350278^{\circ} \mathrm{N}, 95.425000^{\circ} \mathrm{W}\right)$ situated next to the Lone Star Executive Airport in Montgomery county. The site is located approximately $60 \mathrm{~km}$ NNW from the Houston, TX urban center and approximately $125 \mathrm{~km} \mathrm{NW}$ of the nearest coastline. The area surrounding Conroe, TX is primarily affected by pollution in the outflow of air from Houston, which hosts significant energy and petrochemical industries in addition to a large urban population. The regional atmospheric chemistry is 
also influenced by marine air from the Gulf of Mexico. The site itself is located in the middle of a field adjacent to the airport, with a gravel parking lot nearby and bordered by trees approximately $200 \mathrm{~m}$ to the North. The Conroe region is where the ecosystem transforms from prairie and marsh to piney woods, which then extend north and east through much of the Southeastern United States.

\subsection{Instrumentation and Data Analysis}

A permanent Texas Commission on Environmental Quality (TCEQ) ambient measurement station exists at this site and provided continuous meteorological data for the duration of the campaign [22]. Measured parameters included wind speed, wind direction, solar irradiance, temperature, and relative humidity. The site also housed $\mathrm{NO}_{\mathrm{x}}$ and $\mathrm{O}_{3}$ monitors, as well as a Tapered Element Oscillating Microbalance (TEOM) for measurements of $\mathrm{PM}_{2.5}$ mass concentrations. During DISCOVER-AQ a temporary ground site (an air-conditioned trailer) was set up adjacent to the permanent station. This temporary site housed an $\mathrm{NO}_{2}$ monitor (Model AS32M from Environnement) which utilizes cavity attenuated phase shift spectroscopy (CAPS) to provide a direct absorption measurement of nitrogen dioxide [23]. $\mathrm{NO}_{\mathrm{x}}$ was measured using a chemiluminescence $\mathrm{NO}_{x}$ monitor (Teledyne Model 200E), and $\mathrm{O}_{3}$ was measured by direct UV absorption (Teledyne, 400E). An Aerosol Chemical Speciation Monitor (ACSM, Aerodyne Research) [24] was used to measure the mass concentrations of non-refractory species in $\mathrm{PM}_{1}$ including sulfate, nitrate, ammonium, and organics. A Scanning Electrical Mobility System (SEMS, Brechtel Manufacturing) was used to characterize particle size distributions and mass concentrations of $\mathrm{PM}_{1}$. A High Resolution Time-of-Flight Chemical Ionization Mass Spectrometer (HR-ToF-CIMS, Aerodyne Research) [25-28] was employed to measure gas-phase species. All sample lines extended out the trailer and to a vertical level of approximately 10 feet. Teflon ${ }^{\circledR}$ tubing $(1 / 4$ inch) was used to sample all gas-phase compounds and copper tubing (1/2 inch) was used for particle-phase instruments.

Filter measurements of $\mathrm{PM}_{2.5}$ were taken on site as described in Section 2.2.4. During approximately $61 \mathrm{~h}$ of the campaign the University of Houston-Rice University mobile air quality laboratory (MAQL) was parked at the measurement site. The instrumentation on the MAQL included a suite of photochemical trace gas instrumentation, a photoacoustic spectrometer for measurement of particle-phase polycyclic aromatic hydrocarbons, and a High-Resolution Time-of-Flight Aerosol Mass Spectrometer (HR-ToF-AMS, Aerodyne Research). The HR-ToF-AMS measures the same $\mathrm{PM}_{1}$ species as the ACSM but in a size-resolved manner based on the vacuum aerodynamic diameter, and the time of flight mass spectrometer enables measurements at much higher mass and time resolution. The co-location of the HR-ToF-AMS and the ACSM enables comparison of $\mathrm{PM}_{1}$ measurements. 


\subsubsection{Aerosol Chemical Speciation Monitor}

Data analysis and instrument operation were performed in IGOR Pro (WaveMetrics) using the "ACSM Local" software package. The ACSM was set to scan between $m / z 12$ and 159 with a dwell time of $0.5 \mathrm{~s}$, resulting in a scan time of $80 \mathrm{~s}$. The instrument was set to alternate between sampling mode and filter mode, where the filter sample is used to characterize the gas-phase background. This results in a cycle time of $160 \mathrm{~s}$. Further averaging over 25 min intervals was performed in the post-analysis of the data (see Appendix A). The vaporizer temperature was set at $600{ }^{\circ} \mathrm{C}$ (as is standard) for fast vaporization of ammonium sulfate. The ACSM measures only non-refractory (NR) $\mathrm{PM}_{1}$, i.e., compounds that flash vaporize at the heater temperature of $600{ }^{\circ} \mathrm{C}$. Quantification of aerosol concentrations measured by the ACSM is complicated by incomplete transmission of larger particles through the aerodynamic lens and particle bounce at the vaporizer. The ACSM collection efficiency (CE) for these data was estimated to be 0.5 , which resulted in good agreement with ancillary measurements (Figure A1). Additional details on instrument calibration, data preparation, and adjustments to the standard fragmentation table [29] are provided in Appendix A. The HR-ToF-AMS operates similarly to the ACSM but at higher mass and time resolution due to its time of flight mass spectrometer (as opposed to the quadrupole mass spectrometer used by the ACSM). Details on the HR-ToF-AMS operation and data collected during the DISCOVER-AQ campaign will be presented in a forth coming publication [30].

The ACSM provides two main measures of $\mathrm{PM}_{1}$ : bulk composition (concentrations of organics, nitrate, sulfate, and ammonium) and the total mass spectrum from which the organic mass spectrum can be derived. The organic mass spectrum can be used to characterize the extent of oxidation of the measured organic aerosol. The organic mass at $m / z 44$ mostly correspond to the $\mathrm{CO}_{2}{ }^{+}$ion [31] and can therefore be used as a semi-empirical measure of the extent of oxidation in the system. Aiken et al. [31] showed that $f_{44}$, the fraction of the total organic signal due to mass at $m / z 44$, can be used to estimate the oxygen to carbon ratio (O:C) in the organic aerosol. The correlation between $\mathrm{O}: \mathrm{C}$ and $f_{44}$ was recently updated to [32]:

$$
(\mathrm{O}: \mathrm{C})_{\mathrm{f} 44}=4.31 \times f_{44}+0.079
$$

Aiken et al. [31] also found a significant correlation between the ratio of organic mass to organic carbon (OM:OC) and O:C. This relationship was found to be applicable to field data as well as laboratory data and is described by:

$$
(\mathrm{OM}: \mathrm{OC})=1.29 \times \mathrm{O}: \mathrm{C}+1.17
$$


Thus, the observed $f_{44}$ can be used to estimate O:C and OM:OC of the organic aerosol measured at Conroe. These estimates can be compared with values from the HR-ToF-AMS, which directly computes O:C and OM:OC from elemental analysis of the high resolution measurements (see Appendix B).

\subsubsection{Positive Matrix Factorization}

Positive Matrix Factorization (PMF) was applied to the organic aerosol mass spectra measured by the ACSM [33]. The PMF2 algorithm (version 4.2) by P. Paatero was used to solve the bilinear unmixing problem as represented and described below. PMF has proven useful in the analysis of ambient organic aerosol data, and details of the mathematical model, its application, output evaluation, and factor interpretation have been described elsewhere [34-38]. A key assumption is that the measured dataset can be separated into a number of constant components (here, ACSM mass spectra) contributing varying concentrations over time. The problem is represented in matrix form by:

$$
X=G F+E
$$

where $X$ is an $\mathrm{m} \times \mathrm{n}$ matrix of the measured data with $\mathrm{m}$ rows of average mass spectra (number of time periods $=\mathrm{m}$ ) and $\mathrm{n}$ columns of time series of each $\mathrm{m} / \mathrm{z}$ sampled (number of $m / z$ sampled and fit $=\mathrm{n}$ ). $\mathrm{F}$ is a $\mathrm{p} \times \mathrm{n}$ matrix with $\mathrm{p}$ factor profiles (constant mass spectra), $\mathrm{G}$ is an $\mathrm{m} \times \mathrm{p}$ matrix with the corresponding factor contributions, and $E$ is the $m \times n$ matrix of residuals. $G$ and $F$ are fit to minimize the sum of the squared and uncertainty-scaled residuals [33]. The number of factors is chosen by determining when added factors fail in explaining additional dataset variability.

The ACSM dataset was prepared for PMF analysis by first selecting only organic fragments below $m / z$ 100, as higher $m / z$ fragments exhibited very low concentrations and added significant error to the analysis. Peaks with a signal to noise ratio below 2 were downweighted by a factor of 2 . The peaks, which are calculated from $\mathrm{m} / \mathrm{z}$ $44(\mathrm{~m} / \mathrm{z}$ 16-18.44), were downweighted to remove the extra influence of $\mathrm{m} / \mathrm{z} 44$ on PMF solutions. The PMF2 algorithm was used in exploration mode with fpeak set from -1 to 1 by 0.2 increments.

\subsubsection{High Resolution Time of Flight Chemical Ionization Mass Spectrometer}

The HR-ToF-CIMS was set to alternate between positive (hydronium-water clusters) and negative (iodide-water clusters) chemical ionization in half hour intervals. Hydronium-water cluster ionization is more sensitive than iodide-water cluster ionization to less oxidized compounds such as early oxidation products from terpenes and isoprene. For both cases ultra-high purity $\mathrm{N}_{2}$ was first passed through water, then across a methyl iodide permeation tube, and then ionized as it passed through a radioactive source of Po-210. The increased humidity helped dampen 
the effects of the changing $\mathrm{RH}$ in the sample gas. Ionized compounds were pulsed in a "V" shape through a time-of-flight region during measurement to obtain a mass spectrum. Some data obtained through iodide ionization have been described previously [39] and here we focus on data from water cluster ionization.

Data from the HR-ToF-CIMS were analyzed in Igor Pro (Wavemetrics) using Tofware, the software provided with the instrument. The data were first mass calibrated based on HR-ToF-CIMS reagent ions and other known ions. The baseline was subtracted and the average peak shape was found so it could be used for high resolution analysis, through which multiple ions can be identified at any given integer mass to charge ratio $(\mathrm{m} / \mathrm{z}$ ). Analyte ion concentrations were then normalized by dividing by the reagent ion concentrations, the sum of $\mathrm{H}_{3} \mathrm{O}^{+}, \mathrm{H}_{3} \mathrm{O}^{+}\left(\mathrm{H}_{2} \mathrm{O}\right)$ and $\mathrm{H}_{3} \mathrm{O}^{+}\left(\mathrm{H}_{2} \mathrm{O}\right)_{2}$, and then multiplying by the average sum of the three reagent signals (to maintain the units of ion counts $\mathrm{s}^{-1}$ ).

\subsubsection{Filter Measurements}

A high volume $\mathrm{PM}_{2.5}$ sampler (Tisch Environmental, Cleves, OH, USA; 226 lpm), on loan from the US EPA, was used to collect daily samples. $\mathrm{PM}_{2.5}$ samples were collected over $23.5 \mathrm{~h}$ (6 a.m. to 5:30 a.m.). Sample media consisted of quartz fiber filters (QFF) which were baked at $550{ }^{\circ} \mathrm{C}$ for $12 \mathrm{~h}$ in individual foil packets prior to sampling. QFF were stored in freezers $\left(-10^{\circ} \mathrm{C}\right)$ pre- and post-sampling. $\mathrm{PM}_{2.5}$ was collected on $102 \mathrm{~mm}$ diameter QFF (Pall Corporation, Port Washington, NY, USA), and samplers were calibrated prior to field deployment. Field blanks were collected throughout the campaign for each type of sampler and handled in the same manner as ambient samples. The QFF were analyzed for organic and elemental carbon (OCEC) using a thermal-optical method (NIOSH-5040) on Baylor University's thermo-optical transmission (TOT) carbon analyzer (Sunset Laboratories, Tigard, OR, USA) [40]. Sample aliquots were also sent to the Desert Research Institute (DRI-Nevada) for inorganic ion analysis (sulfate, nitrate, ammonium, chloride and potassium).

Radiocarbon abundance $\left({ }^{14} \mathrm{C}\right)$ was analyzed on filter samples in order to determine the contributions of contemporary and fossil emissions to Houston's ground-based carbonaceous PM. Contemporary sources include biomass burning and biogenic emissions, and they include the presence of ${ }^{14} \mathrm{C}$. Fossil sources include combustion and non-combustion emission sources with depleted ${ }^{14} \mathrm{C}$. Ambient $\mathrm{PM}_{2.5}$ filter subsamples were taken for analysis to give $\sim 60 \mu \mathrm{g}$ of total organic carbon [41] for measurement of the ${ }^{14} \mathrm{C}$ signal on the accelerator mass spectrometer. Subsamples were acidified over hydrochloric acid using a desiccator for $12 \mathrm{~h}$ to remove carbonate, and dried in a muffler oven at $60{ }^{\circ} \mathrm{C}$ for one hour. ${ }^{14} \mathrm{C}$ abundance measurements were performed at the National Oceanic Sciences Accelerator Mass Spectrometry (NOSAMS) facility at Woods Hole Oceanographic Institute (Woods Hole, MA, USA). 
In order to apportion total organic carbon (TOC) based on ${ }^{14} \mathrm{C}$ abundance, $\Delta^{14} \mathrm{C}$ end members are chosen based on the sampling region and used in the following equation:

$$
\Delta^{14} C_{\text {sample }}=\Delta^{14} C_{\text {contemporary }} \times f_{\text {contemporary }}+\Delta^{14} C_{\text {fossil }} \times\left(1-f_{\text {contemporary }}\right)
$$

The contemporary end member used for this study was $67.5 \%$, an average of the 2010 biomass burning end member $\left(\Delta^{14} \mathrm{C}=107.5 \%\right)$ corresponding to wood smoke and the 2010 biogenic end member $\left(\Delta^{14} \mathrm{C}=28 \%\right.$ ) corresponding to primary and secondary biogenic emissions, meat cooking and combustion of grass, prunings and agricultural waste [42,43]. The fossil fuel end member was $-1000 \%$ [44]. Results from NOSAMS are reported as \% contemporary, with contribution from fossil carbon equaling $1-f_{\text {contemporary }}$.

\subsubsection{Diurnal Patterns: Analysis of Statistical Significance and Patterns}

We conducted one-way analysis of variance (ANOVA) tests for organics, sulfate, nitrate and each PMF factor as dependent variables with time of day as the independent variable. ANOVA tests determine whether there are statistically significant differences in the mean values of the dependent variables [45]. While ANOVA tests determine statistical significance of variation by time of day, they cannot quantify or characterize the diurnal cycle. Thus, we also conducted harmonic analysis $[45,46]$ to characterize the diurnal cycle. In brief, the general harmonic function is given by:

$$
y_{t}=\bar{y}+C_{k} \cos \left(2 \pi t / n-\varnothing_{k}\right)
$$

where $t$ is the time (1-24 in our diurnal analysis), $\bar{y}$ is the mean of the time series (e.g., $y_{t}$ is the mean value of $f_{44}$ during hour $t, \bar{y}$ is the mean value for the whole campaign), $C_{k}$ is the amplitude of the $k$ th harmonic, $n$ is the period ( $n=24$ here) and $\varphi$ is the phase. Using only the first harmonic, we can estimate the amplitude by $[45,46]$ :

$$
C_{1}=\left[A_{1}^{2}+B_{1}^{2}\right]^{1 / 2}
$$

where

$$
\begin{aligned}
& A_{1}=2 / n \times \sum y_{t} \cos (2 \pi t / n) \\
& B_{1}=2 / n \times \sum y_{t} \sin (2 \pi t / n)
\end{aligned}
$$

The phase is then given by:

$$
\begin{array}{cc}
\varphi_{1}=\tan ^{-1}\left(B_{1} / A_{1}\right) \pm \pi & \text { if } A_{1}<0 \\
\varphi_{1}=\tan ^{-1}\left(B_{1} / A_{1}\right) & \text { if } A_{1}>0
\end{array}
$$




$$
\varphi_{1}=\pi / 2 \quad \text { if } A_{1}=0
$$

The portion of the variance explained by the first harmonic, analogous to a correlation coefficient $\left(\mathrm{R}^{2}\right)$ commonly computed in regression analysis, is given by:

$$
V_{1}=C_{1}^{2} / 2 s^{2}
$$

where $s$ is the standard deviation of the $n$ values. The phase simply describes to what extent the observed cycle is offset from a standard cosine curve. The amplitude describes the magnitude of the diurnal cycle.

\section{Results}

This work combines PM measurements from several different instruments. Measurements from different instruments generally agreed well as discussed in Appendix B.

\subsection{Bulk Concentrations and Diurnal Cycle}

Figure 1 shows a time series of particle size distributions (top), a time series of bulk concentrations measured by the ACSM (bottom), and the campaign-average bulk concentration (right). The ACSM nitrate measurements (sum of $\mathrm{NO}^{+}$and $\mathrm{NO}_{2}{ }^{+}$fragments) can be attributed to inorganic nitrate and/or $-\mathrm{ONO}_{2}$ functional groups on organic nitrates. Measurements indicate that the nitrate measured by the ACSM in Conroe is mostly organic. One indication of this is the $\mathrm{NO}^{+}: \mathrm{NO}_{2}{ }^{+}$ratio in ACSM measurements, which is estimated from the fragmentation table-corrected unit mass resolution data. In the ACSM used for this study a ratio of 2.6-3.9 has been measured for ammonium nitrate. For organic nitrate this ratio has varied but has always been greater than 5 for this instrument. The average $\mathrm{NO}^{+}: \mathrm{NO}_{2}{ }^{+}$ratio for this data set is 13.4, which is consistent with organic nitrate (and inconsistent with ammonium nitrate). Filter measurements also indicate that nitrate measured by the ACSM was mostly organic (see Appendix B): filter measurements of inorganic nitrate are significantly lower than ACSM measurements of total nitrate (Figure A4C). Further, the molar ratio of $\mathrm{NH}_{4}: \mathrm{SO}_{4}$ indicates that on average there was no excess $\mathrm{NH}_{4}$ as required for the formation of ammonium nitrate.

As seen in Figure 1, a large portion of $\mathrm{PM}_{1}$ measured in Conroe was organic $(64 \%$ on average, including nitrate). PM composition from filter measurements agreed with ACSM measurements-71\% of PM from the filter samples was OM, with most of the remainder being ammonium and sulfate (as well as $1.7 \% \mathrm{EC}$ ). Sulfate is a significant part of $\mathrm{PM}_{1}$ in Conroe. Ammonium concentrations were often below the detection limit of the ACSM but when it was measured, the aerosol had an average ammonium/sulfate molar ratio of 2 . Figure 1 also shows the $\mathrm{PM}_{1}$ number 
distributions from the SEMS. Nucleation events are not easily identified and do not seem to play a major role in PM concentrations in this area during this time period.

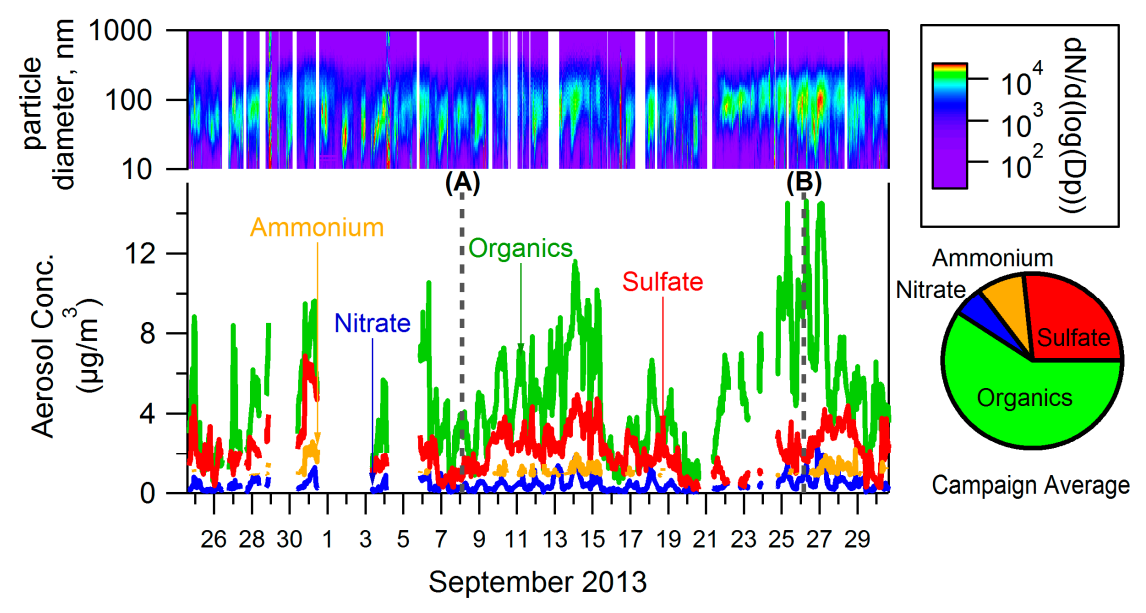

Figure 1. Campaign measurements from ACSM, SEMS.

Consistent diurnal profiles were seen for both organics and nitrate in $\mathrm{PM}_{1}$ measurements. Figure 2 shows the average (median) diurnal variation of organics, nitrate, sulfate and total $\mathrm{PM}_{1}$ measured by the SEMS; the error bars indicate the 25th and 75th percentiles. ANOVA reveals statistically significant variation by time of day for organic, nitrate, and total $\mathrm{PM}_{1}$ concentrations $\left(p<10^{-16}\right)$, but no statistically significant variation by time of day for sulfate concentrations $(p=0.65)$. Harmonic analysis suggests that the phase (between 0 and $2 \pi$ ) for these diurnal trends is 0.4, 0.7, and 0.5 for organics, nitrate, and (SEMS) $\mathrm{PM}_{1}$ respectively-indicating that concentrations of these species increase and decrease at approximately the same time. The first harmonic explains $78 \%, 88 \%$ and $87 \%$ of the variance for organics, nitrate, and (SEMS) $\mathrm{PM}_{1}$, respectively. The analysis further reveals that the amplitude-to-mean ratio of the nitrate diurnal is 0.55, compared to the amplitude-to-mean ratio of the organics and $\mathrm{PM}_{1}$ diurnal profiles which are 0.29 and 0.20 , respectively. 

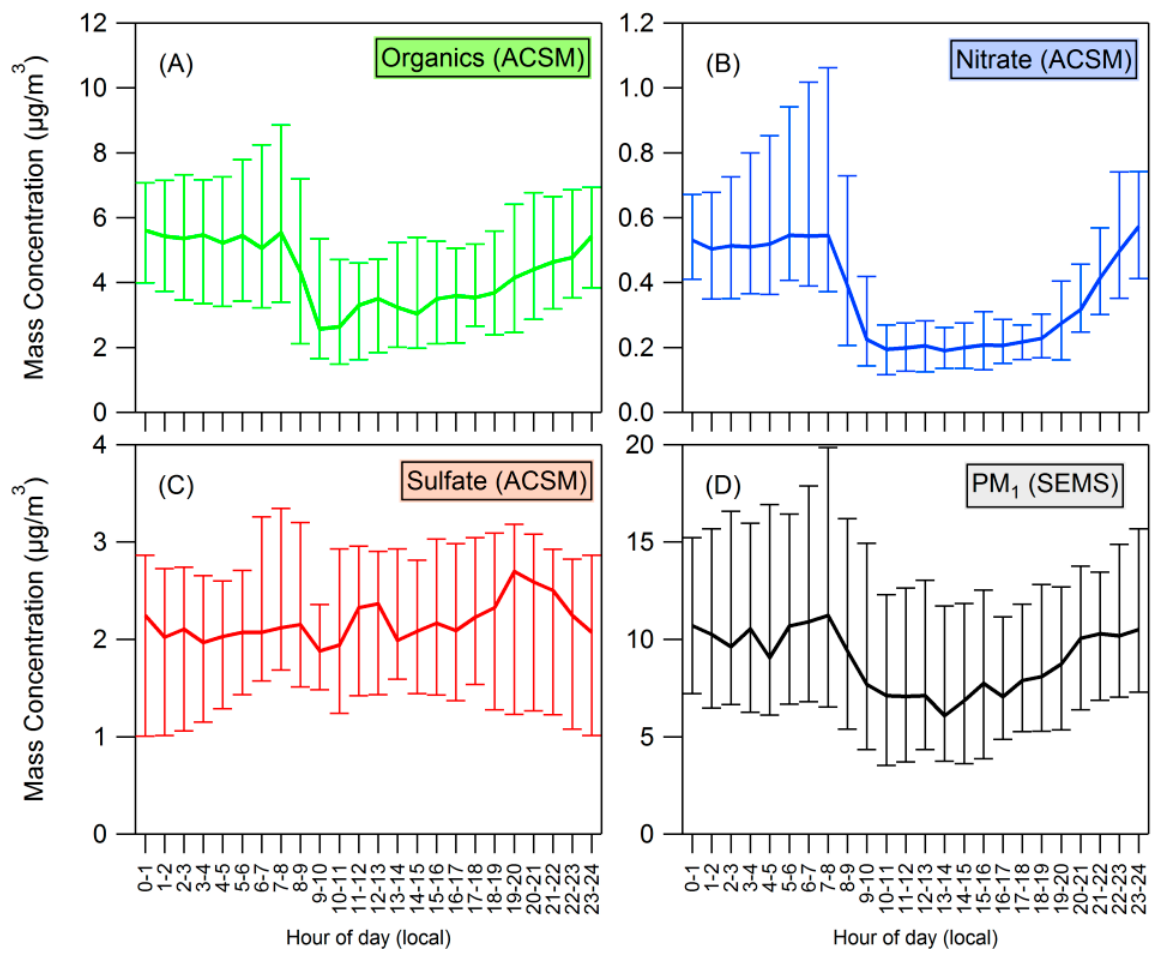

Figure 2. (A-C) Diurnal plots for organics, nitrate, and sulfate measured by the ACSM; (D) $\mathrm{PM}_{1}$ measured by the SEMS. Median values are plotted, with error bars showing the 25 th and 75 th percentiles.

\subsection{Positive Matrix Factorization}

Various PMF solutions (obtained by varying the number of factors and other PMF settings, See Section 2.2.2) were examined and evaluated with respect to mathematical diagnostics and ancillary data (not included in the PMF analysis, e.g., ACSM-sulfate). The three-factor solution was found to best represent these data. Possible solutions of up to 8 factors were considered but factor splitting was observed and no additional information was obtained from the use of more than three factors.

The mass spectra and diurnal cycles of the three factors are shown in Figure 3. Two of the factors resemble oxygenated organic aerosol (OOA), the other factor resembles fresher organic aerosol. We name the more oxidized OAA factor $\left(f_{43}=4.4 \%\right.$, $f_{44}=22.7 \%$ ) MO-OOA (more oxidized OOA) and the less oxidized OOA factor $\left(f_{43}=14.8 \%, f_{44}=7.6 \%\right)$ LO-OOA (less oxidized OOA). The third factor has mass spectral signatures representative of hydrocarbon like organic aerosol (HOA) and 
biomass burning organic aerosol (BBOA), but we refer to the third factor $\left(f_{43}=4.6 \%\right.$, $f_{44}=3.2 \%$ ) as HOA for simplicity.

The time series of MO-OOA showed a correlation with the time series of sulfate measured by the ACSM $\left(R^{2}=0.46\right)$, whereas LO-OOA did not $\left(R^{2}=0.10\right)$. Thus, $\mathrm{MO}-\mathrm{OOA}$ correlated with a low-volatility inorganic component (sulfate). LO-OOA and HOA showed correlation with $\mathrm{NO}_{x}\left(\mathrm{R}^{2}=0.35\right.$ and 0.34 , respectively), a proxy for fresh anthropogenic emissions, while MO-OOA did not $\left(\mathrm{R}^{2}=0.06\right)$. We also examined correlations of the factor profiles with factor profiles identified in previous work [47]. The MO-OOA profile correlated most strongly with previously identified MO-OOA $\left(\mathrm{R}^{2}=0.92\right)$, the LO-OOA profile correlated most strongly with previously identified LO-OOA $\left(\mathrm{R}^{2}=0.92\right)$, and the HOA correlated most strongly to previously identified $\operatorname{HOA}\left(\mathrm{R}^{2}=0.67\right)$ and $\operatorname{BBOA}\left(\mathrm{R}^{2}=0.74\right)$.
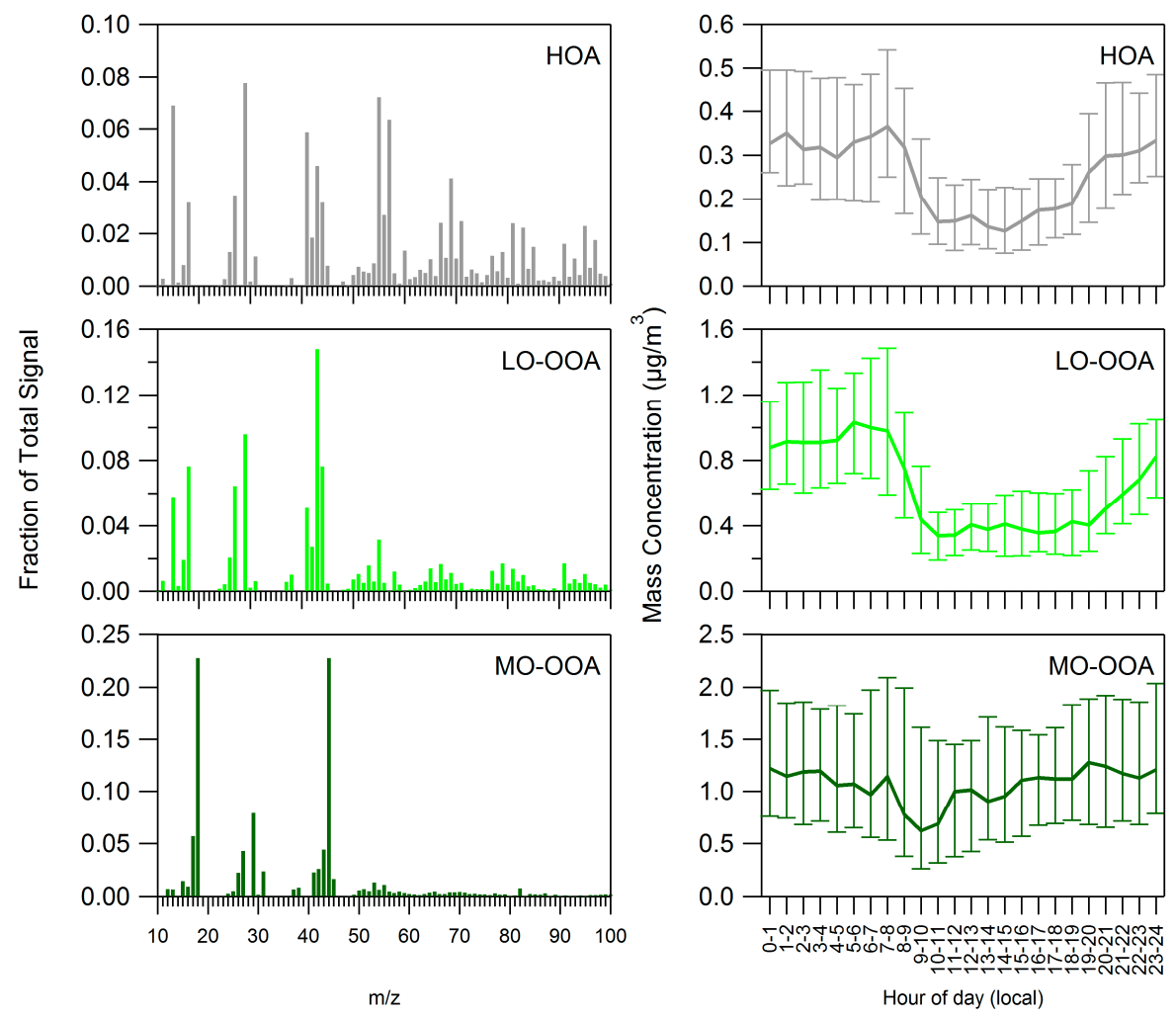

Figure 3. Mass spectra (left) and diurnal profiles (right) of PMF factors.

Figure 3 (right panel) shows the diurnal cycle of the three PMF factors. According to ANOVA, all three factors exhibited statistically significant variation by time of day ( $p<10^{-16}$ for HOA and LO-OOA, $p=6 \times 10^{-8}$ for MO-OOA). 
LO-OOA and HOA exhibited a clear pattern with higher concentrations at night, the same pattern exhibited by total OA (see Section 3.1). MO-OOA did not show this clear pattern, presumably because during the afternoon some LO-OOA and HOA is converted to the MO-OOA, which is more highly oxidized. MO-OOA can also form directly from oxidized VOCs. Harmonic analysis suggests that the diurnal cycle of LO-OOA has an amplitude-to-mean ratio of 0.53 and phase of 0.8 and can explain $84 \%$ of the variance; the diurnal cycle of HOA has an amplitude-to-mean ratio of 0.41 , phase of 0.5 and can explain $79 \%$ of the variance. These two PMF factors (LO-OOA and HOA) hence have diurnal cycles of similar phase, which is also similar to the phase of the diurnal cycle of total OA (Section 3.1).

Figure 4 shows time series of the factors in terms of fraction of total organics (the sum of all 3 factors). The 12 days before 6 September were included in PMF calculations but excluded from Figure 4 to facilitate viewing of radiocarbon results. HOA can constitute $30 \%$ or more of OA on days when overall PM concentrations are low (7 September, 16-21 September). However, fresh emissions represented by HOA constitute a smaller fraction (less than 20\%) of PM on high concentrations days, such as 10-15 September and 25-28 September. On these higher concentration days a larger fraction of the increased PM levels are due to MO-OOA (and LO-OOA to a lesser extent), consistent with atmospheric conditions which transport highly processed OA or allow existing OA to become highly oxidized. The results of radiocarbon analysis (see Section 2.2.4) are also shown in Figure 4. Fossil carbon constituted as little as $10 \%$ of carbon in OA during the low concentration period from 21-23 September but was approximately $30 \%$ of carbon during the high concentration period from 25-28 September, suggesting that a higher fraction of OA originates from fossil sources of carbon on higher concentrations days.

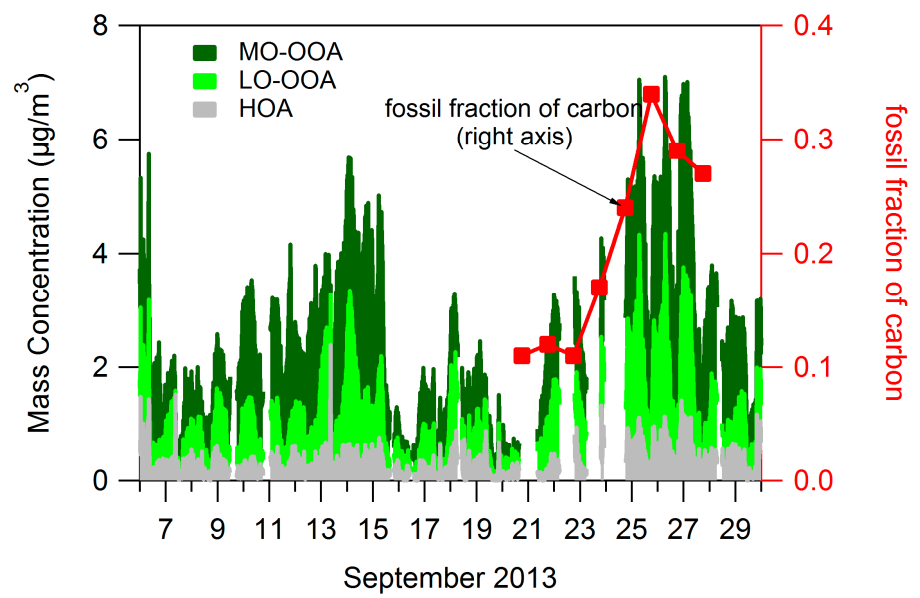

Figure 4. Time series of PMF factors in terms of fractional concentrations. 


\section{Discussion}

\subsection{Composition of PM and Source Regions}

Because very little inorganic nitrate appears to be present (see Section 3.1), we assume that all nitrate measured by the ACSM is organic in order to estimate the organic nitrate contribution to organic aerosol. For an assumed MW range of $200-300 \mathrm{~g} \cdot \mathrm{mol}^{-1}$ [48] organic nitrates constitute $27 \%-41 \%$ of organic aerosol. If nitrate was overestimated by up to $60 \%$ (Figure A3) then organic nitrates would still constitute $18 \%-27 \%$ of OA. Either estimate would suggest that organic nitrates play a larger role in Conroe than has been measured in other areas. Using the same estimate for molecular weight of organic nitrates, $\mathrm{Xu}$ et al. [19] estimated that organic nitrates constitute $5 \%-16 \%$ of OA during the summer in Alabama and Georgia locations. Mylones et al. [49] assumed an average molecular weight of $150 \mathrm{~g} \cdot \mathrm{mol}^{-1}$ for organic nitrates and calculated that they are 13\% of OA in Los Angeles. Studies in Houston using the same methods as Mylones et al. have observed an organic nitrate fraction similar to the one observed in Los Angeles [50,51]. O'Brien et al. [52] estimated organic nitrates constituted 17\% of OA in Los Angeles in 1975. The prominence of organic nitrates in OA highlights the importance of anthropogenic emissions for this region as nitrate formation requires anthropogenic $\mathrm{NO}_{x}$ or $\mathrm{NO}_{3}$ in addition to VOCs.

Concentrations of $\mathrm{PM}_{1}$ vary both diurnally and over the course of several days. Increases and decreases in $\mathrm{PM}_{1}$ concentrations in the timeframe of days and weeks are often associated with changes in regional air flow. Figure 5 shows 72-h back trajectories calculated using the Hybrid Single Particle Lagrangian Integrated Trajectory Model (HYSPLIT) [53]. Figure 5A,B shows the trajectory for characteristic lower and higher concentration days, respectively. HYSPLIT uses archived meteorological data to compute the back trajectory of a particle or parcel of air which arrives at a location at a specified time. The trajectory ensemble method is used, in which grid points are offset by small amounts to produce multiple potential trajectories as shown in Figure 5. Back trajectories for times indicated by vertical dashed lines " $\mathrm{A}$ " and " $\mathrm{B}$ " in Figure 1 are shown in Figure 5A,B, respectively. The air source of a characteristic high concentration day is slower moving continental air (Figure 5B) while a low concentration day is supplied with quickly moving oceanic air with significant vertical mixing (Figure 5A). PMF results (Section 3.2) suggest that high concentration days are the result of increased levels of OOA but not HOA. The 7-day period of radiocarbon results (Figure 4) shows higher portions of fossil carbon in OA during times of increased concentrations. The fact that fossil carbon increases along with MO-OOA and LO-OOA while HOA does not suggests that oxidized anthropogenic emissions are a larger contributor during this time of increased PM levels, consistent with transport of pollutants from the Houston metropolitan and/or 
industrial centers. On average, $87 \%$ of the measured $\mathrm{PM}_{1}$ organics was due to OOA, which is representative of organic aerosol that has been processed in the atmosphere, highlighting the importance of atmospheric processing on controlling fine PM concentrations in Conroe.

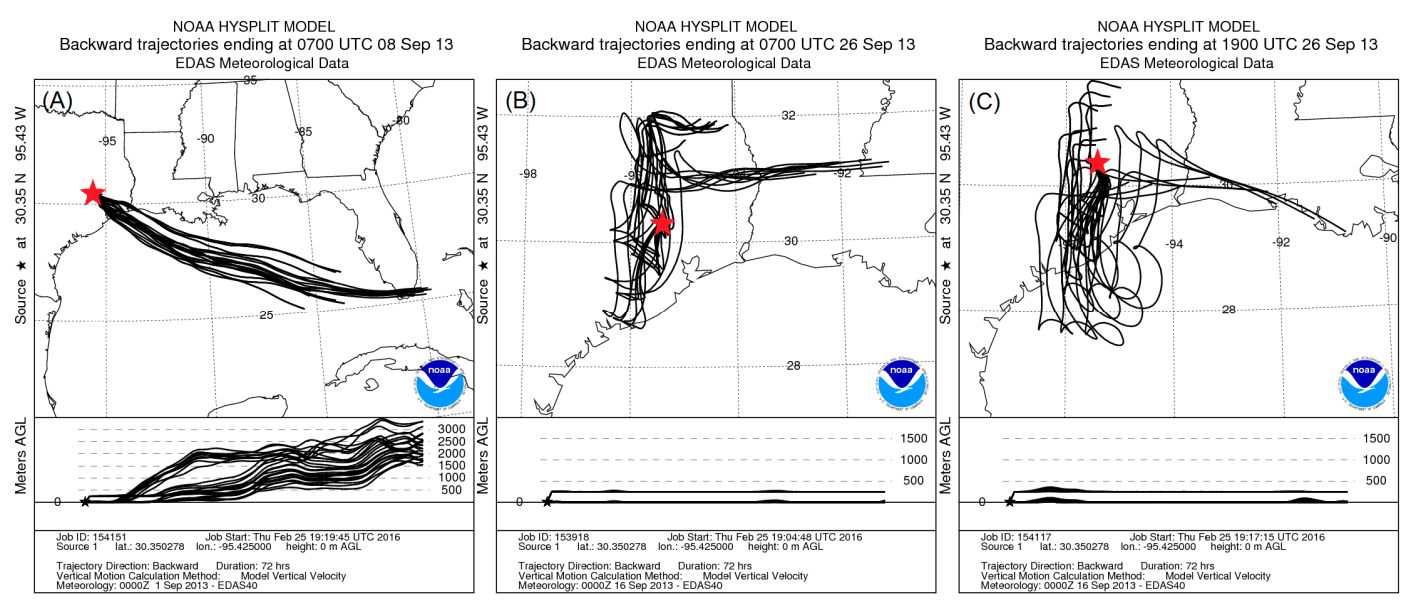

Figure 5. HYSPLIT 72-h back trajectories showing the differences between lower (A) and higher (B) concentration days. The low and high trajectories correspond to 2:00, 8 September and 2:00 26 September, respectively. Seventy-two-hour back trajectories are also shown for 14:00 26 September $(\mathbf{C})$, so $(\mathbf{B}, \mathbf{C})$ show a typical $12 \mathrm{~h}$ difference.

While the source of air mass can explain variation in OA over the course of days and weeks, it does not adequately explain the consistent diurnal variation that was observed. HYSPLIT back-trajectories (Figure 5B,C) show that there are often only small differences between day and night air sources. During the measurement campaign, the average nighttime (0:00-6:00) winds were more easterly (average $48^{\circ}$ ) and daytime (12:00-18:00) winds were more southerly (average $137^{\circ}$ ). Daytime winds were typically stronger (average $6.3 \mathrm{miles} / \mathrm{h}$ ) than nighttime winds (average $2.7 \mathrm{miles} / \mathrm{h}$ ). Despite these differences between day and night Figure 6 shows that there is significant variation in wind speed and direction during the day and night. This variation suggests that regional air flow is not a main factor in the observed diurnal cycle. In addition, the higher nighttime concentrations were observed when wind was predominantly from the east, which would likely be a cleaner air mass than the daytime, southeastern winds which pass through Houston. Thus, for Conroe the source of the air mass appears to play a large role in multi-day and weekly high and low concentration trends but has significantly less influence on the daily trends in OA levels. 
(A) Nighttime Wind Rose

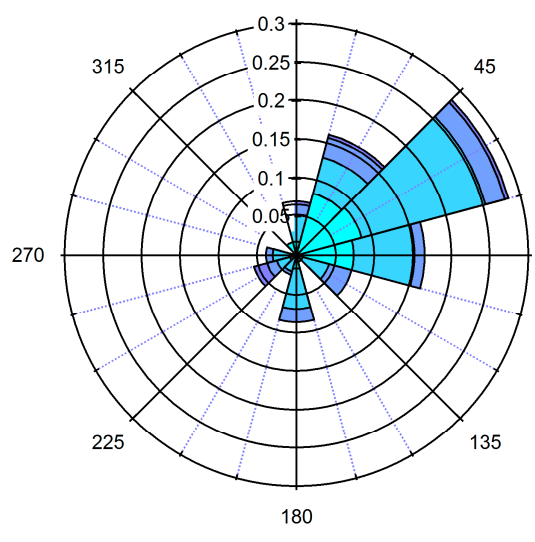

(B) Daytime Wind Rose

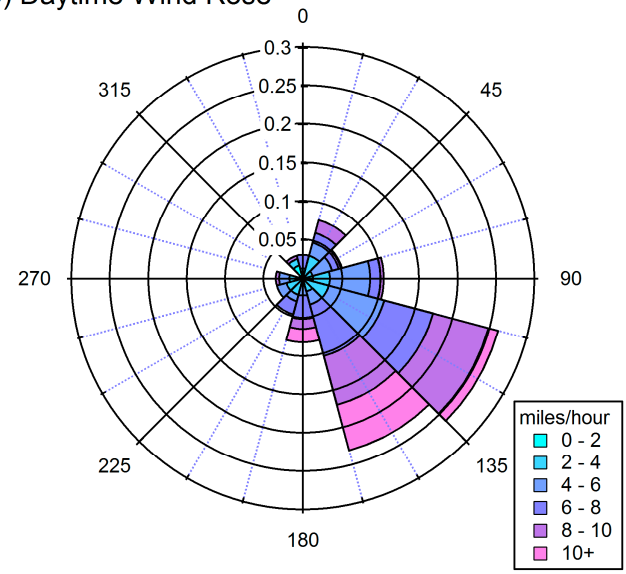

Figure 6. Wind rose plots for (A) night (0:00-6:00) and (B) day (12:00-18:00) averaged over the course of the campaign.

\subsection{Influences on Diurnal Cycle}

The strong diurnal cycle for organics and nitrate but lack of diurnal cycle for sulfate is consistent with a more regional source of sulfate and a more local source of organics and organic nitrates. The higher amplitude-to-mean ratio of nitrate indicates that the diurnal trend is especially prominent for nitrate and suggests that organic nitrates play a large role in the observed diurnal trends. The more pronounced diurnal changes in organic nitrates could be attributed to evaporation with increasing daytime temperatures or nighttime growth due to $\mathrm{NO}_{3}$ chemistry. $\mathrm{NO}_{3}$, formed from the reaction of $\mathrm{NO}_{2}$ and $\mathrm{O}_{3}$, is considered a night-time oxidant because it photolyzes quickly during the day.

The shape of the diurnal profile shows highest concentrations at night and quick decreases in concentration during daylight hours. Photo-oxidation of organics predominantly decreases their vapor pressure and can result in overall increases of organic particulate matter during the day. The diurnal cycle of the organic aerosol $\mathrm{O}: \mathrm{C}$ ratio (Figure 7) suggests that organic aerosol is more oxygenated during daylight hours, as expected with increasing photochemical activity. PMF results also support this, as daytime decreases are seen in HOA and LO-OOA, potentially indicating conversion to MO-OOA. However, total organic concentrations also decrease during this time, indicating that photochemical activity is not the main factor affecting concentrations of OA.

Some meteorological factors may play a significant role in diurnal trends. Temperature and boundary layer height (BLH) effects on concentrations of PM are explored in Figure 8. Temperature increases when the sun rises, increasing 
the saturation vapor pressure of particle-phase compounds which causes the higher vapor-pressure species to evaporate. According to absorptive partitioning theory [54,55], the gas-particle partitioning of an organic species depends on its vapor pressure and the concentration of organic material already in the condensed phase. The fraction of a compound $i$ in the particle phase $\left(\mathrm{Y}_{\mathrm{i}}\right)$ is given by [55]:

$$
Y_{i}=\left(1+\frac{C_{i}^{*}}{C_{O A}}\right)^{-1}
$$

where $C_{i}^{*}$ is a function of the vapor pressure, If $C_{i}^{*}$ is known at one temperature then it can be predicted at a second temperature if $\Delta H_{\text {vap }}$ is known using the Clausius-Clapeyron equation [48]:

$$
C^{*}\left(T_{2}\right)=C^{*}\left(T_{1}\right) \exp \left(\frac{\Delta H_{\text {vap }}}{R}\left(\frac{1}{T_{1}}-\frac{1}{T_{2}}\right)\right)
$$

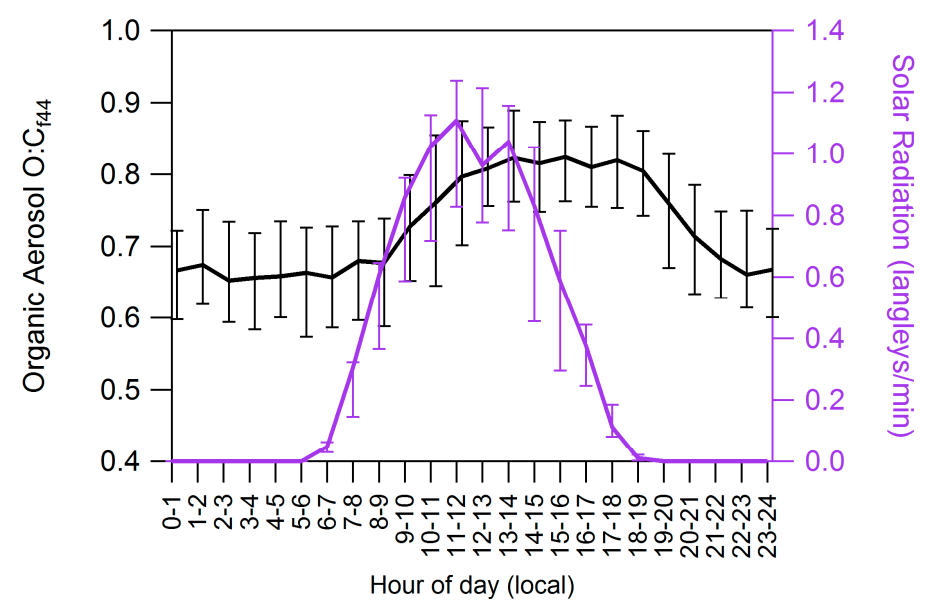

Figure 7. Diurnal cycle of organic aerosol oxygen to carbon ratio $\left(\mathrm{O}: \mathrm{C}_{\mathrm{f} 44}\right)$ and solar radiation.

In a simplified yet illustrative calculation, we assume that $\Delta H_{\text {vap }}=40 \mathrm{~kJ} \cdot \mathrm{mol}^{-1}$ [55] and assume an initial set of $C_{i}^{*}$ values of those used by Murphy and Pandis [56] for high-NO $\mathrm{N}_{\mathrm{x}}$ terpene SOA. We assume this set of $C_{i}^{*}$ values applies to the average OA concentration (including both the organics and nitrate measured by the ACSM) measured from 0:00 to 6:00 (the time period when concentrations and temperatures were stable) at the average temperature from 0:00 to 6:00 and then calculate the expected OA concentrations, based on observed temperature changes, for the entire day as seen in Figure 8C. Though these assumptions greatly simplify evaporation 
behavior of the organic aerosol, it is illustrative to see that the resulting predicted OA concentrations match the observed trend. Temperature is likely to be partially responsible for the observed diurnal cycle.
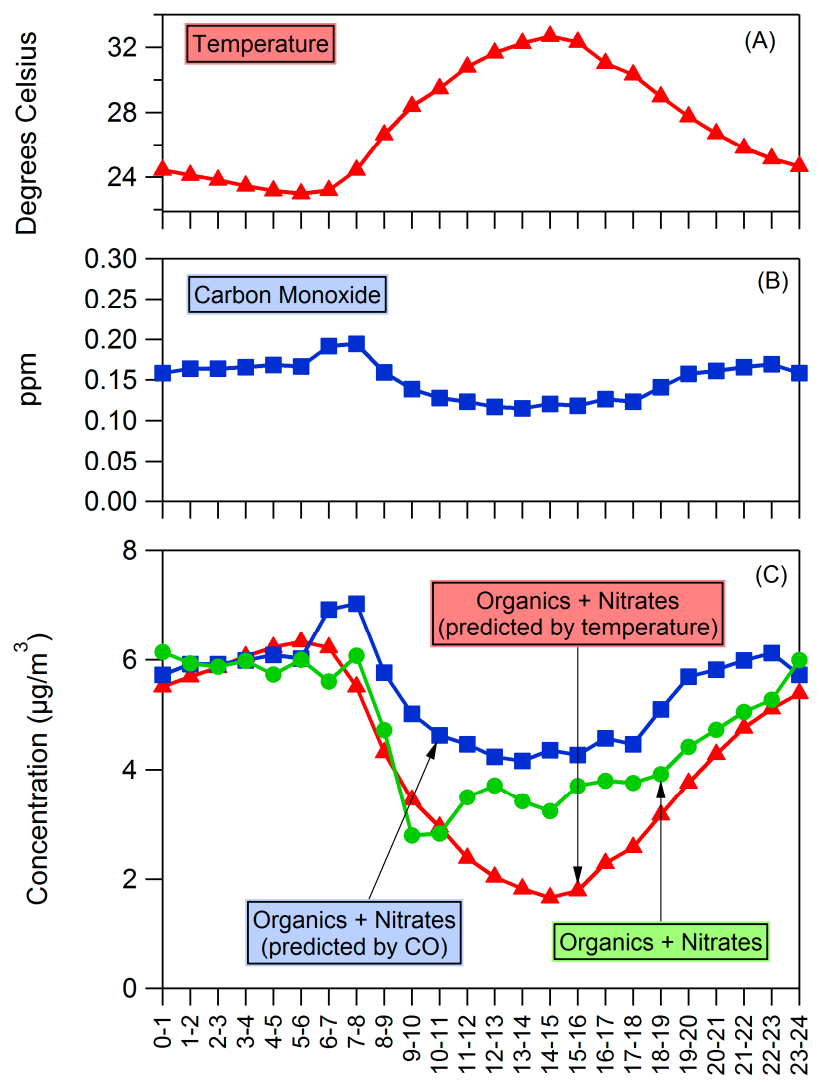

Figure 8. Diurnal profiles of (A) temperature and (B) carbon monoxide. (C) shows the diurnal profile of OA as well as the diurnal profile of OA predicted by temperature and boundary layer height changes. Starting concentrations in predictions are the average of measured concentrations between 0:00 and 6:00.

The effect of BLH on atmospheric mixing may also play a role, and a similar estimate was performed to illustrate the effect this might have. Carbon monoxide (CO) measurements from the TCEQ Jones Forest site ( 10 miles southwest of Conroe site) were used for an estimate of mixing effects. The average $\mathrm{CO}$ and OA concentrations between 0:00 and 6:00 were used as a baseline, and then this baseline was diluted or concentrated based on the $\mathrm{CO}$ concentrations as seen in Figure $8 \mathrm{C}$. The increase in predicted OA from 6-8 a.m. is most likely a reflection of traffic conditions, but otherwise the $\mathrm{CO}$-predicted OA concentrations match the 
trend of measurements and show the effect that BLH and mixing may have had on daytime concentrations as the air mass was diluted. Tucker et al. [57] observed that BLH effects on pollutant concentrations in the Houston region are complicated and depend on many factors including the location of source air and turbulence levels. The lack of significant diurnal variation of sulfate could suggest that the effect of BLH on observed concentrations is lower than suggested by our analysis, and/or that $\mathrm{BLH}$ and daytime oxidation of $\mathrm{SO}_{2}$ leading to sulfate had opposite effects. It is also consistent with a more regional source of sulfate and similar concentrations above and below the boundary layer. Daytime oxidation of organics is also expected to increase concentrations of OA and partially offset the changes due to temperature and BLH. Nonetheless, the shape of the organic aerosol diurnal variation is consistent with changes in either BLH or temperature, and both are potential influences on the observed diurnal trend.

In order to further explore this diurnal trend we considered $\mathrm{PM}_{2.5}$ (TEOM) measurements at four Houston area sites operated by the TCEQ [22]. Figure 9 shows diurnal cycles of $\mathrm{PM}_{2.5}$ measurements averaged over the month of September and January taken at Conroe (Figure 9A, same site as our location), Kingwood (Figure 9B, midway between Conroe and downtown Houston), Clinton (Figure 9C, downtown Houston location), and Fayette County (Figure 9D, a rural Texas location). Figure 9 shows that the diurnal trend observed in Conroe is not specific to that area; similar patterns are observed in all three of the other areas, and use of ANOVA reveals statistically significant variation by time of day at all four of these monitoring sites. A similar trend is seen in the winter at all locations as also shown in Figure 9. This indicates that colder temperatures and shorter daylight hours do not eliminate the trend, though the decrease in PM concentration starts later in the day.

Variation in the hourly averaged $\mathrm{PM}_{2.5}$ concentrations measured at the Conroe location are reasonably well described with first order harmonic analysis, which can explain $54 \%$ of the variation in TEOM readings. Only $15 \%, 14 \%$ and $6 \%$ of the variation is explained by first-order harmonic analysis for Clinton, Kingwood, and Fayette County, respectively. We estimate the magnitude of the diurnal cycle as $\left(A v g_{\text {high }}-\mathrm{Avg}_{\text {low }}\right) /$ Mean, where $A v g_{\text {high }}$ and $\mathrm{Avg}_{\text {low }}$ are calculated as the mean of the six highest and lowest concentrations in the diurnal trend, respectively. The magnitude of diurnal variation using this method is 0.57 for Conroe and $0.45,0.39$, and 0.39 for Kingwood, Clinton, and Fayette County, respectively, suggesting that $\mathrm{PM}_{2.5}$ concentrations measured at Conroe exhibited the strongest diurnal cycle. It is notable that neither Clinton, which has the most anthropogenic influence, nor Fayette County, which has the least anthropogenic influence, has the most pronounced diurnal profile. Distance from the coast can affect diurnal temperature patterns, with coastal areas having milder temperature swings. However, TCEQ data show that the Conroe and Fayette County sites have nearly identical diurnal temperature profiles, 
suggesting that more than temperature is needed to describe the observed diurnal trend in organic aerosol concentrations. The strong diurnal cycle in Conroe may in part be due to the interaction of anthropogenic oxidants with biogenic hydrocarbons. Vegetation type may play a large role in this as the Conroe area is where the ecosystem transforms from prairie and marsh to the piney woods of the US Southeast, which are known to have higher biogenic emissions [58]. Xu et al. [19] saw a similar diurnal pattern for a less oxidized OA factor in PMF analysis from measurements in Alabama and Georgia, places that have a piney woods ecosystem.

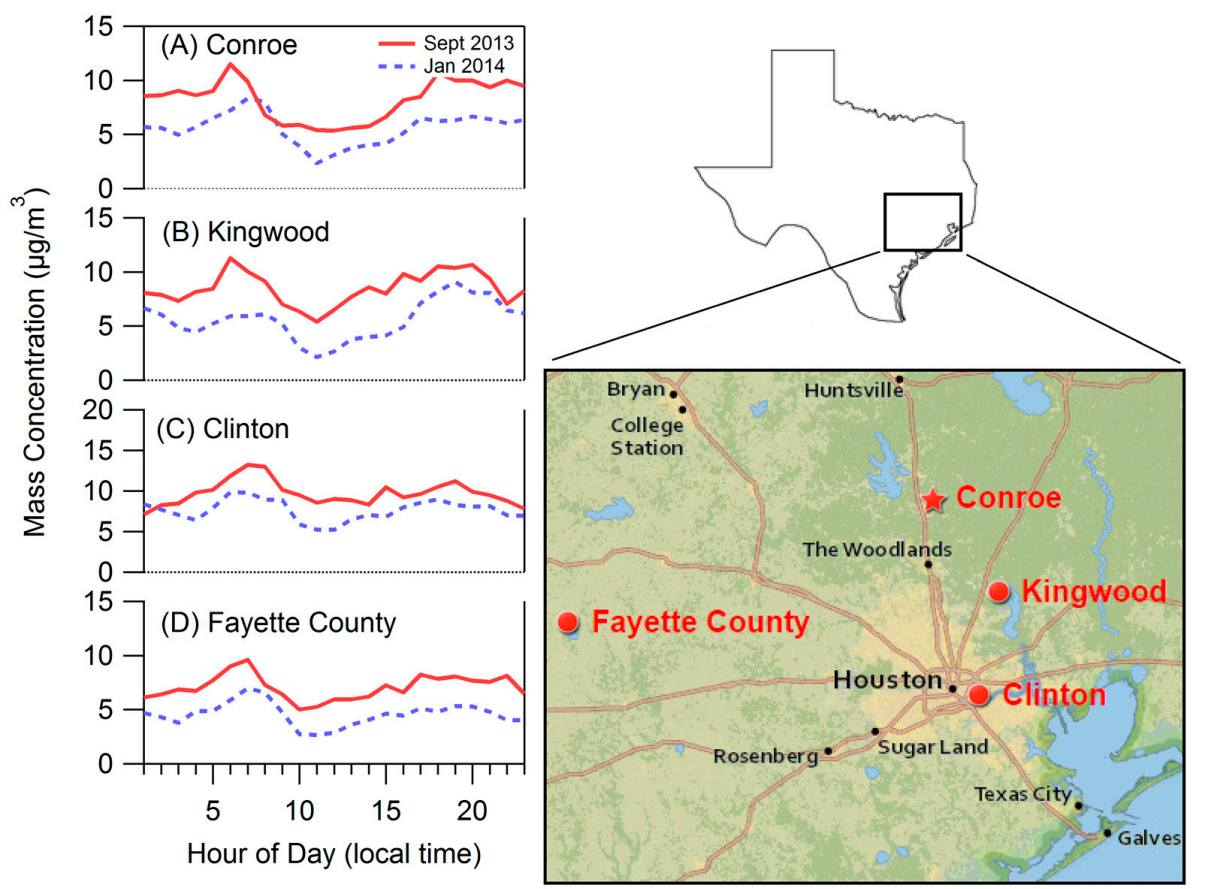

Figure 9. Diurnal plots for Conroe and neighboring areas based on tapered element oscillating microbalance (TEOM) measurements of $\mathrm{PM}_{2.5}$ by the Texas Commission on Environmental Quality (TCEQ). (A) Conroe, (B) Kingwood, (C) Clinton, (D) Fayette County.

Observations from the HR-ToF-CIMS support the hypothesis that biogenic VOCs are an important contributor to the diurnal cycle seen in OA in Conroe. Recent work $[19,20]$ has suggested that monoterpene reactions with the $\mathrm{NO}_{3}$ radical at night are a significant source of SOA. Gas-phase organic nitrates observed during DISCOVER-AQ, which likely formed from monoterpenes $\left(C_{10}\right)$, also exhibited a diurnal trend of elevated concentrations at night. Data from the HR-ToF-CIMS in Figure 10 show increased levels of monoterpene organic nitrates at night, the time 
when monoterpene and $\mathrm{NO}_{3}$ concentrations are typically highest [59]. Increasing concentrations are also seen in the time just after sunrise when monoterpene concentrations are still high and NO concentrations are increasing. Lee et al. [59] observed a similar increase in gas phase concentrations of biogenic organic nitrates in the hours following sunrise in the SOAS campaign.

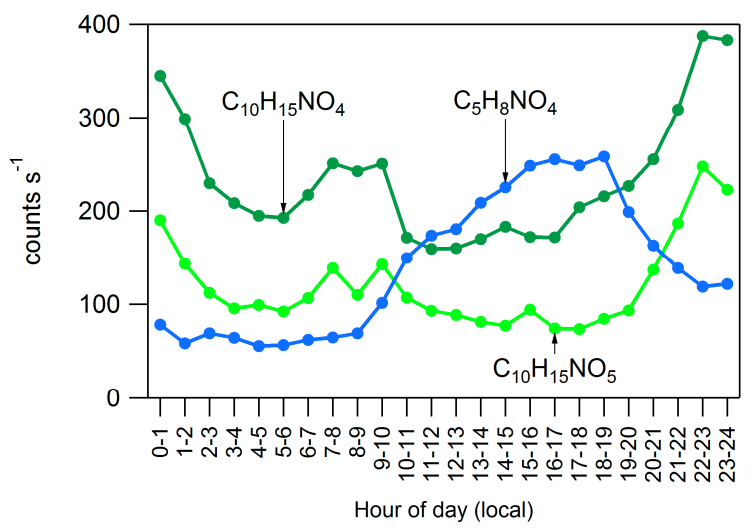

Figure 10. Diurnal plot of gas-phase organic nitrates which appear to have formed from biogenic compounds. These HR-ToF-CIMS data are taken from the high-concentration period of 11-14 September.

The SIMPOL.1 model [60] was used to estimate changes in volatility from the oxidation of VOCs. The SIMPOL.1 model predicts vapor pressure based on molecular functional groups and in this case was used to predict changes in vapor pressure to biogenic VOCs due to the addition of nitrate and hydroxyl functional groups. Using Equation (10) and conditions in Conroe we find that $\alpha$-pinene or $\beta$-pinene which have been oxidized to $\mathrm{C}_{10} \mathrm{H}_{16} \mathrm{NO}_{4}$ would partition less than $1 \%$ to the particle phase. $\mathrm{C}_{10} \mathrm{H}_{16} \mathrm{NO}_{5}$ would partition $11 \%-25 \%$, and $\mathrm{C}_{10} \mathrm{H}_{16} \mathrm{NO}_{6}$ would partition $95 \%-98 \%$ to the particle phase. Thus, $\mathrm{C}_{10} \mathrm{H}_{16} \mathrm{NO}_{6}$ and compounds that are more oxidized are not likely found at high concentrations in the gas phase but may be important components of the particle phase as was observed by Lee et al. [59]. Most oxidized gas-phase hydrocarbons observed with the HR-ToF-CIMS have a diurnal cycle with elevated daytime concentrations due to photochemistry similar to $\mathrm{C}_{5} \mathrm{H}_{8} \mathrm{NO}_{4}$ shown on Figure 10. $\mathrm{C}_{5} \mathrm{H}_{8} \mathrm{NO}_{4}$ is likely an isoprene hydroxyl-nitrate that is formed through an isoprene peroxy-radical and $\mathrm{NO}$, a similar mechanism to the early morning formation of monoterpene nitrates but different from the night-time monoterpene nitrate formation mechanism through reaction with $\mathrm{NO}_{3}$. Isoprene nitrates could be partially responsible for the diurnal trend in $\mathrm{OA}$ in the region. Though they mostly form during the day when isoprene concentrations are highest, according to the SIMPOL.1 model a compound such as $\mathrm{C}_{5} \mathrm{H}_{8} \mathrm{NO}_{6}$ would partition $15 \%$ to the particle 
phase during the day but nearly double that (28\%) during the night, which would increase total organic nitrate concentrations.

\section{Conclusions}

Measurements were taken in Conroe, TX during 24 August-1 October 2013, as part of DISCOVER-AQ. Organic aerosol (OA) was a major component of the measured particulate matter, constituting $64 \%$ of $\mathrm{PM}_{1}$, and up to $41 \%$ of the measured $\mathrm{OA}$ in the region was organic nitrates. Through PMF the OA was divided into three factors: Two factors were classified as OOA-one more oxidized (MO-OOA) and one less (LO-OOA). A third factor, named HOA, had similarities to hydrocarbon-like $\mathrm{OA}$ and biomass burning OA. The LO-OOA and the HOA displayed diurnal cycles in which concentrations increased in the evening and decreased in the morning. This pattern was also seen in the bulk ACSM measurements of organics and nitrate. Night-time chemistry between biogenic compounds (isoprene, terpenes) and anthropogenic oxidants $\left(\mathrm{O}_{3}, \mathrm{NO}_{3}\right)$ appears to contribute to this variation. Temperature and changes in boundary layer height also appear to contribute to the trend.

Understanding diurnal and multi-day trends in PM levels is crucial as regions continue to strive to achieve lower PM levels. Both the anthropogenic and biogenic drivers that cause concentrations to fluctuate need to be understood and correctly modeled for policy-makers to make informed decisions about regulations. Decreasing PM formation can be especially challenging in locations such as Conroe, TX where organic aerosol formation appears to be strongly influenced by the interaction of biogenic hydrocarbons and anthropogenic oxidants.

Acknowledgments: This work was financed in part through six grants from the Texas Commission on Environmental Quality (TCEQ), administered by The University of Texas through the Air Quality Research Program (Projects 12-012, 12-032, 13-022, 14-009, 14-024 and 14-029). The contents, findings opinions and conclusions are the work of the authors and do not necessarily represent findings, opinions or conclusions of the TCEQ. The authors would like to thank the US EPA for the loan of the PM2.5 high volume sampler. The authors gratefully acknowledge the NOAA Air Resources Laboratory (ARL) for the provision of the HYSPLIT transport and dispersion model and/or READY website (http:/ /www.ready.noaa.gov) used in this publication.

Author Contributions: Jeffrey Bean, Cameron Faxon, and Lea Hildebrandt Ruiz planned, prepared and conducted the ambient measurements. Jeffrey Bean analyzed the ambient ACSM and SEMS data presented in this work. Under the guidance of Robert Griffin, Yu Jun Leong, Basak Karakurt Cevik, and H. William Wallace operated the HR-ToF-AMS and analyzed the subsequent data. Under the guidance of Rebecca Sheesley and Sascha Usenko, Stephanie Ortiz analyzed the filter samples, which were collected by Jeffrey Bean and Cameron Faxon. Under the guidance of Lea Hildebrandt Ruiz and Manjula Canagaratna, Jeffrey Bean conducted and interpreted PMF. The manuscript was written by Jeffrey Bean with the guidance of Lea Hildebrandt Ruiz.

Conflicts of Interest: The authors declare no financial conflict of interest. 


\section{Appendix A: ACSM Calibration and Data Preparation}

\section{A1. ACSM Calibration}

The nitrate ionization efficiency (IE) of the ACSM, as well as the relative ionization efficiencies (RIEs) of sulfate and ammonium were measured four times between 24 August and 30 September (the time period during which ACSM data were acquired) using dried ammonium nitrate and ammonium sulfate particles with a diameter of $300 \mathrm{~nm}$. The ratio of IE to the MS airbeam (AB) was constant for these calibrations (within noise), so the average IE/AB value of $3.29 \times 10^{-11} \mathrm{~Hz}^{-1}$ was used for the whole campaign, and the IE was determined at any point by multiplying $\mathrm{IE} / \mathrm{AB}$ by the current $\mathrm{AB}$. The RIE of ammonium measured during the IE calibrations ranged from 4.57 to 5.82, and the measured RIE of sulfate ranged from 0.49 to 0.67 . The variation in the values appeared random; therefore the average values of 5.02 and 0.57 were used for the entire campaign for ammonium and sulfate, respectively. The flow rate in the ACSM was $100 \mathrm{~cm}^{3} \cdot \mathrm{min}^{-1}$. Lens alignment and flow calibrations were performed at the beginning of the campaign.

\section{A2. Adjustments to the Standard Fragmentation Table}

The collected data were analyzed using a standard AMS fragmentation table and batch table [29], with a few modifications: The fragmentation patterns of air at $m / z 44\left(\mathrm{CO}_{2}^{+}\right), m / z 29\left(\mathrm{~N}^{15} \mathrm{~N}^{+}\right)$and $m / z 16\left(\mathrm{O}^{+}\right)$were evaluated using filter data that were collected continuously throughout the campaign. $\mathrm{N}^{15} \mathrm{~N}^{+}$and $\mathrm{CO}_{2}{ }^{+}$were calculated as constant fractions of the $\mathrm{N}_{2}{ }^{+}$signal at $\mathrm{m} / \mathrm{z} 28$; the calculated fractions were $7.3 \times 10^{-3}$ and $1.2 \times 10^{-3}$ for $\mathrm{N}^{15} \mathrm{~N}^{+}$and $\mathrm{CO}_{2}{ }^{+}$, respectively. $\mathrm{O}^{+}$was calculated as a constant fraction of $\mathrm{N}^{+}$; the calculated ratio was 0.48 . The correction for $\mathrm{CO}_{2}{ }^{+}$ from air using the $\mathrm{N}_{2}{ }^{+}$signal was calculated by averaging the filter measurements throughout the campaign when particle-phase organics were below $1 \mu \mathrm{g} \cdot \mathrm{m}^{-3}$ in order to avoid interference of organics being interpreted as $\mathrm{CO}_{2}{ }^{+}$from air. The correction for $\mathrm{N}^{15} \mathrm{~N}^{+}$was calculated as an average of all filter data throughout the campaign.

\section{A3. Data Averaging}

For bulk composition analysis (organics, sulfate, ammonium, nitrate), every 10 ACSM data points were averaged, resulting in a time resolution of approximately $25 \mathrm{~min}$ (including $12.5 \mathrm{~min}$ of averaged sample and $12.5 \mathrm{~min}$ of averaged filter data), and 1475 data points throughout the campaign. (ACSM measurements were taken 24 August-30 September 2013). The following detection limits were then calculated considering the $12.5 \mathrm{~min}$ sample averaging time [24]: $0.440 \mu \mathrm{g} \cdot \mathrm{m}^{-3}$ (ammonium), $0.229 \mu \mathrm{g} \cdot \mathrm{m}^{-3}$ (organics), $0.037 \mu \mathrm{g} \cdot \mathrm{m}^{-3}$ (sulfate), $0.017 \mu \mathrm{g} \cdot \mathrm{m}^{-3}$ (nitrate). Application of the detection limits resulted in removal of $68 \%$ of the ammonium data, no 
removal of sulfate data, and removal of $0.3 \%$ and $0.7 \%$ of organics and nitrate data, respectively. A $42-\mathrm{h}$ period (4-5 September) in which the airbeam was abnormally high and a 68-h period (1-3 September) during which the vaporizer temperature was set to $700{ }^{\circ} \mathrm{C}$ were also removed. The $f_{44}$ data were cleaned as follows: first, every five data points were averaged. Then datapoints for which $f_{44}<0$ or $f_{44}>1$ were removed since these are not physically possible. ( 7 data points were below zero, and 1 data point was above 1). Then, every four data points were averaged again for an overall time resolution of approximately $50 \mathrm{~min}$. Then data were removed for which the signal of organics at $m / z 44$ (i.e., $f_{44} \times$ org) was below the detection limit of organics for the $25 \mathrm{~min}$ averaging time. This resulted in removal of $17 \%$ of the final averaged data.

\section{Appendix B: Comparison of Co-Located Instruments}

Measurements across different instruments generally agreed throughout the campaign. In Figure A1 we show the comparison between $\mathrm{PM}_{1}$ mass concentrations measured by the ACSM (corrected for CE) and by the SEMS. The volume concentration from the SEMS was converted to mass concentration using the density $1.77 \mathrm{~g} \cdot \mathrm{cm}^{-3}$ for ammonium and sulfate and $1.4 \mathrm{~g} \cdot \mathrm{cm}^{-3}$ for organics and nitrate [61]. On average the SEMS measured higher $\mathrm{PM}_{1}$ mass (slope $=1.35$ ), which could be due to uncertainties in the density estimate and the SEMS measurement including refractory compounds which are not measured by the ACSM.
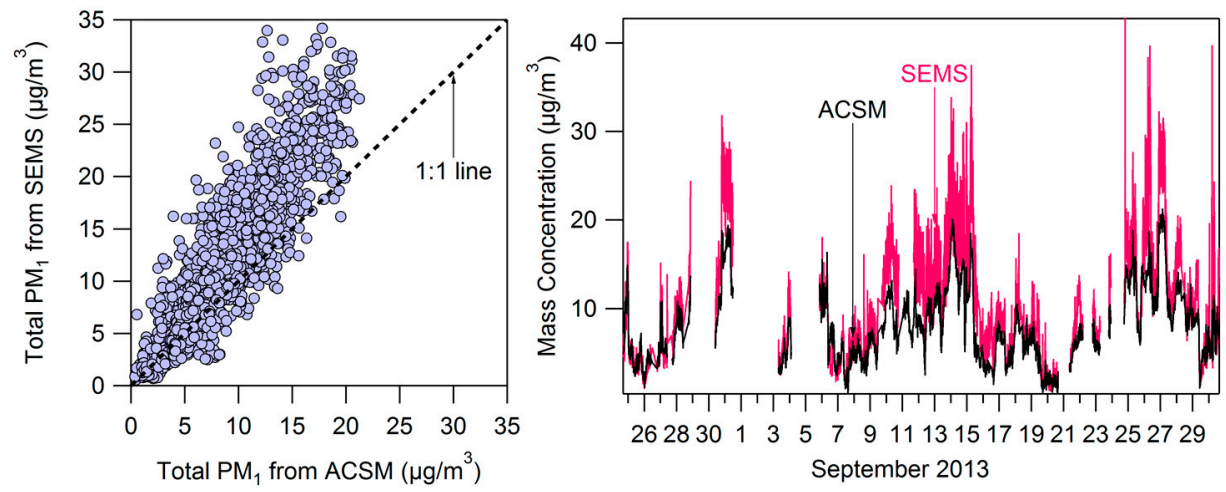

Figure A1. Comparison of $\mathrm{PM}_{1}$ mass measured by the SEMS and ACSM throughout the campaign.

Figure A2 compares O:C and OM:OC measurements and estimations by the ACSM and HR-ToF-AMS when the HR-ToF-AMS was at the Conroe site (see Section 2.2.1). There is relatively good agreement in $f_{44}$ and total organic aerosol mass (Figures A2A and $\mathrm{A} 3 \mathrm{~A}$ ); however, the $\mathrm{O}: \mathrm{C}$ calculated from measured $f_{44}$ using 
Equation (1) $\left(\mathrm{O}: \mathrm{C}_{f 44}\right)$ is significantly higher than the $\mathrm{O}: \mathrm{C}$ calculated from elemental analysis of the high resolution HR-ToF-AMS spectra (Figure A2B). Despite this difference the calculated OM:OC is similar to the OM:OC from elemental analysis of the co-located HR-ToF-AMS (Figure A2C). This is important as OM:OC is used to convert filter measurements of organic carbon to organic mass (as described below).
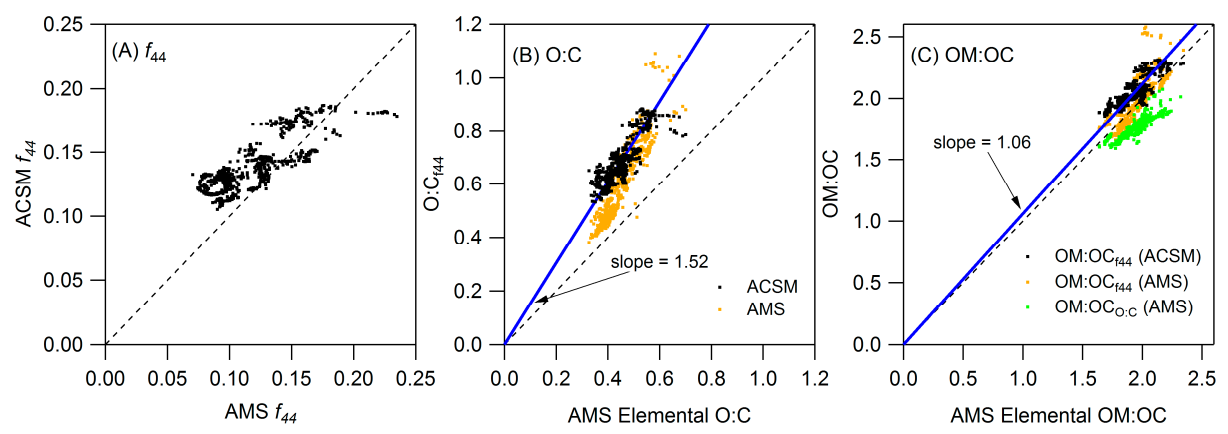

Figure A2. Comparison of (A) $f_{44}$; (B) O:C and (C) OM:OC between the HR-ToF-AMS and ACSM.

ACSM PM 1 measurements are also compared with $\mathrm{PM}_{2.5}$ measurements from filter samples (see Section 2.2.4) and the TCEQ-operated TEOM (see Figure A4). The filter measurements of $\mathrm{OC}$ are converted to organic mass using the calculated OM:OC ratio described in Section 2.2.1. In general, measurements from the filters are consistent with those from the ACSM, suggesting that the majority of the mass in $\mathrm{PM}_{2.5}$ is found in particles with a diameter below $1 \mu \mathrm{m}$ (Figure A4A,B,D). The total concentrations from the ACSM and filter measurements are also consistent with the TCEQ-operated TEOM (Figure A4D). The total filter measurement also includes elemental carbon (about 7\% of total carbon), which is not measured by the ACSM.

Figure A3 shows that, with the exception of nitrate, speciated measurements between the HR-ToF-AMS (high resolution) and ACSM (unit mass resolution) were reasonably consistent during the times when the HR-ToF-AMS was co-located (61 h over the course of the campaign). Nitrate was measured $60 \%$ higher by the ACSM, on average, than by the HR-ToF-AMS. Unit mass resolution measurements of nitrate from the ACSM rely on the standard fragmentation table to estimate the split of $\mathrm{m} / \mathrm{z}$ 30 between nitrate $\left(\mathrm{NO}^{+}\right)$and organics $\left(\right.$mostly $\left.\mathrm{CH}_{2} \mathrm{O}^{+}\right)$. Conditions with high levels of $\mathrm{CH}_{2} \mathrm{O}^{+}$can result in over-prediction of nitrate by the ACSM. The HR-ToF-AMS directly measures $\mathrm{NO}^{+}$and $\mathrm{CH}_{2} \mathrm{O}^{+}$. In this campaign, the ACSM measurements of nitrate were, on average, $60 \%$ higher than the high resolution measurements of nitrate by the HR-ToF-AMS; ACSM measurements were only $20 \%$ higher than unit mass resolution measurements by the HR-ToF-AMS, which rely on the same fragmentation table as the ACSM. 

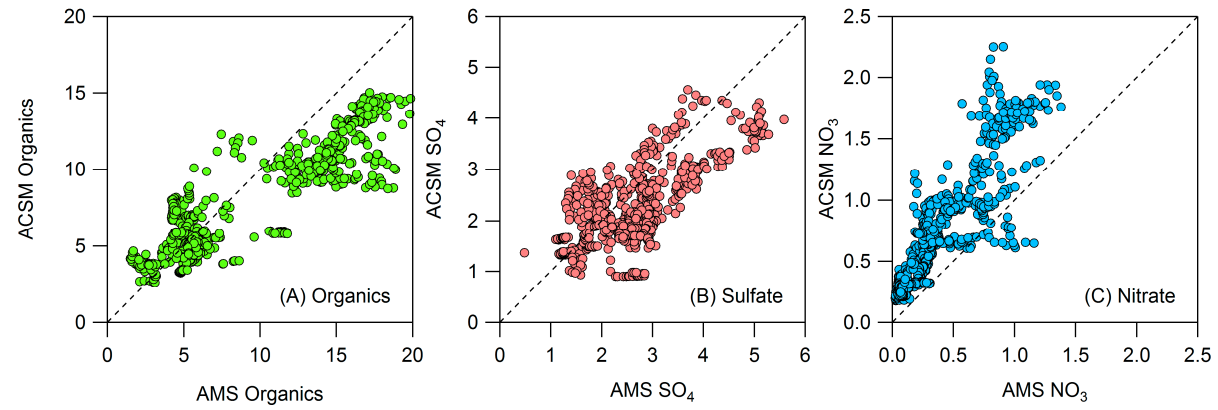

Figure A3. ACSM and HR-ToF-AMS comparison of (A) organics, (B) sulfate, and (C) nitrate. HR-ToF-AMS measurements are high resolution while ACSM measurements are unit mass resolution.

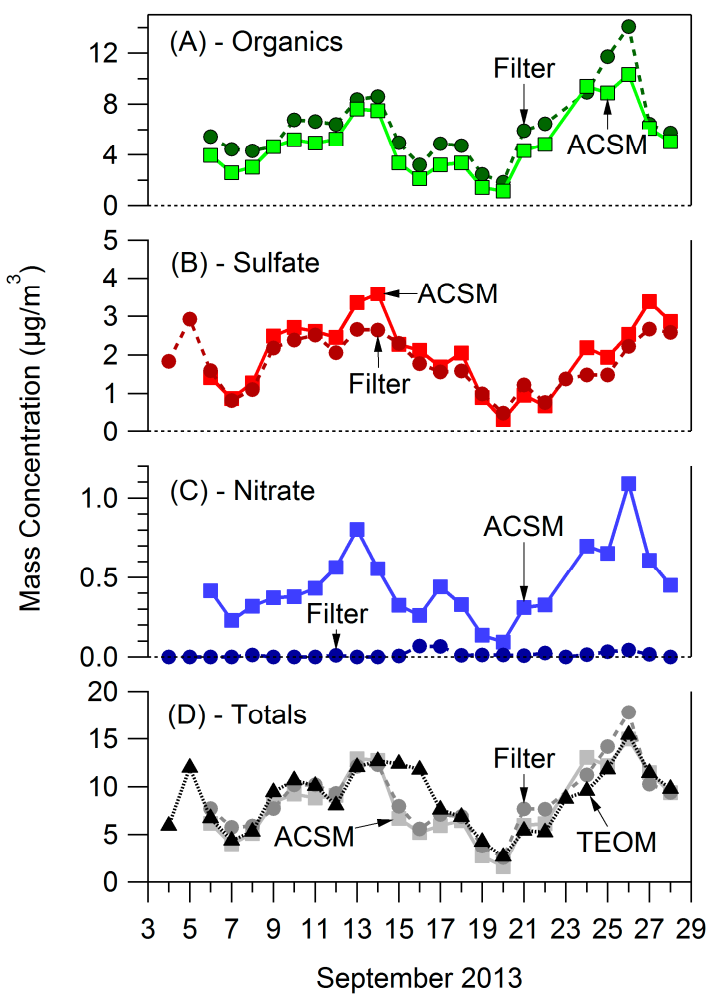

Figure A4. Instrument comparisons between the $\mathrm{PM}_{1} \mathrm{ACSM}, \mathrm{PM}_{2.5}$ filter, and $\mathrm{PM}_{2.5}$ TEOM measurements for. (A) Organics, (B) Sulfate, (C) Nitrate, (D) Totals. 


\section{References}

1. Lim, S.S.; Vos, T.; Flaxman, A.D.; Danaei, G.; Shibuya, K.; Adair-Rohani, H.; Amann, M.; Anderson, H.R.; Andrews, K.G.; Aryee, M.; et al. A comparative risk assessment of burden of disease and injury attributable to 67 risk factors and risk factor clusters in 21 regions, 1990-2010: A systematic analysis for the Global Burden of Disease Study 2010. Lancet 2012, 380, 2224-2260.

2. Dockery, D.; Pope, C.A.; Xiping, X.; Spengler, J.D.; Ware, J.H.; Fay, M.E.; Ferris, B.G.; Speizer, F.E. An association between air pollution and mortality in six U.S. cities. N. Engl. J. Med. 1993, 329, 1753-1759.

3. Tong, D.Q.; Yu, S.; Kan, H. Ozone exposure and mortality. N. Engl. J. Med. 2009, 360, 2788-2789.

4. NAAQS Table. Available online: https://www.epa.gov/criteria-air-pollutants/naaqstable (accessed on 26 February 2016).

5. United States Environmental Protection Agency. National Ambient Air Quality Standards for Particulate Matter. Fed. Reg. 2013, 78, 3085-3287.

6. United States Environmental Protection Agency. National ambient air quality standards for ozone. Fed. Reg. 2015, 80, 75233-75411.

7. Allen, D.T.; McDonald-Buller, E.C.; McGaughey, G.R. State of the Science of Air Quality in Texas: Scientific Findings from the Air Quality Research Program (AQRP) and Recommendations for Future Research; Air Quality Research Program: Austin, TX, USA, 2016.

8. Allen, D.; Estes, M.; Smith, J.; Jeffries, H. Accelerated Science Evaluation of Ozone Formation in the Houston-Galveston Area; University of Texas: Austin, TX, USA, 2001.

9. Allen, D.T.; Fraser, M. An overview of the gulf coast aerosol research and characterization study: The Houston fine particulate matter supersite. J. Air Waste Manag. Assoc. 2006, 56, 456-466.

10. Olaguer, E.; Kolb, C.; Lefer, B.; Rappenglueck, B.; Zhang, R.; Pinto, J. Overview of the SHARP campaign: Motivation, design, and major outcomes. J. Geophys. Res. Atmos. 2014, $119,2597-2610$.

11. Allen, D.T.; Torres, V.M.; Thomas, J.; Sullivan, D.W.; Harrison, M.; Hendler, A.; Herndon, S.C.; Kolb, C.E.; Fraser, M.P.; Hill, A.D.; et al. Measurements of methane emissions at natural gas production sites in the United States. Proc. Natl. Acad. Sci. USA 2013, 110, 17768-17773.

12. Pasci, A.; Kimura, Y.; McGaughey, G.; McDonald-Buller, E.; Allen, D.T. Regional ozone impacts of increased natural gas use in the Texas power sector and development in the Eagle Ford shale. Environ. Sci. Technol. 2015, 49, 3966-3973.

13. Zavala-Araiza, D.; Sullivan, D.W.; Allen, D.T. Atmospheric hydrocarbon emissions and concentrations in the Barnett Shale natural gas production region. Environ. Sci. Technol. 2014, 48, 5314-5321.

14. Bahreini, R.; Ervens, B.; Middlebrook, A.M.; Warneke, C.; de Gouw, J.A.; DeCarlo, P.F.; Jimenez, J.L.; Brock, C.A.; Neuman, J.A.; Ryerson, T.B.; et al. Organic aerosol formation in urban and industrial plumes near Houston and Dallas, Texas. J. Geophys. Res. Atmos. 2009, 114, 1-17. 
15. Murphy, B.N.; Donahue, N.M.; Robinson, A.L.; Pandis, S.N. A naming convention for atmospheric organic aerosol. Atmos. Chem. Phys. 2014, 14, 5825-5839.

16. Parrish, D.D.; Allen, D.T.; Bates, T.S.; Estes, M.; Fehsenfeld, F.C.; Feingold, G.; Ferrare, R.; Hardesty, R.M.; Meagher, J.F.; Nielsen-Gammon, J.W.; et al. Overview of the second texas air quality study (TexAQS II) and the Gulf of Mexico atmospheric composition and climate study (GoMACCS). J. Geophys. Res. Atmos. 2009, 114, 1-28.

17. Weber, R.; Sullivan, A.; Peltier, R.; Russell, A.; Yan, B.; Zheng, M.; de Gouw, J.; Warneke, C.; Brock, C.; Holloway, J.; et al. A study of secondary organic aerosol formation in the anthropogenic-influenced southeastern United States. J. Geophys. Res. Atmos. 2007, 112.

18. Xu, L.; Guo, H.; Boyd, C.M.; Bougiatioti, A.; Cerully, K.M.; Hite, J.R.; Isaacman-Vanwertz, G.; Kreisberg, N.M.; Olson, K.; Koss, A.; et al. Effects of anthropogenic emissions on aerosol formation from isoprene and monoterpenes in the southeastern United States. Proc. Natl. Acad. Sci. USA 2015, 112, 37-42.

19. Xu, L.; Suresh, S.; Guo, H.; Weber, R.J.; Ng, N.L. Aerosol characterization over the southeastern United States using high-resolution aerosol mass spectrometry: Spatial and seasonal variation of aerosol composition and sources with a focus on organic nitrates. Atmos. Chem. Phys. 2015, 15, 7307-7336.

20. Boyd, C.M.; Sanchez, J.; Xu, L.; Eugene, A.J.; Nah, T.; Tuet, W.Y.; Guzman, M.I.; Ng, N.L. Secondary organic aerosol formation from the $\beta$-pinene+NO3 system: Effect of humidity and peroxy radical fate. Atmos. Chem. Phys. 2015, 15, 7497-7522.

21. DISCOVER-AQ Home. Available online: http:/ /discover-aq.larc.nasa.gov/ (accessed on 26 February 2016).

22. Texas Air Monitoring Information System (TAMIS) Web Interface. Available online: http://www17.tceq.texas.gov/tamis/ (accessed on 26 February 2016).

23. Kebabian, P.L.; Wood, E.C.; Herndon, S.C.; Freedman, A. A Practical Alternative to Detection of Nitrogen Dioxide: Cavity Attenuated Phase Shift Spectroscopy. Environ. Sci. Technol. 2008, 42, 6040-6045.

24. Ng, N.L.; Herndon, S.C.; Trimborn, A.; Canagaratna, M.R.; Croteau, P.L.; Onasch, T.B.; Sueper, D.; Worsnop, D.R.; Zhang, Q.; Sun, Y.L.; et al. An Aerosol Chemical Speciation Monitor (ACSM) for routine monitoring of the composition and mass concentrations of ambient aerosol. Aerosol Sci. Technol. 2011, 45, 780-794.

25. Bertram, T.H.; Kimmel, J.R.; Crisp, T.A.; Ryder, O.S.; Yatavelli, R.L.N.; Thornton, J.A.; Cubison, M.J.; Gonin, M.; Worsnop, D.R. A field-deployable, chemical ionization time-of-flight mass spectrometer. Atmos. Meas. Tech. 2011, 4, 1471-1479.

26. Yatavelli, R.L.N.; Lopez-Hilfiker, F.; Wargo, J.D.; Kimmel, J.R.; Cubison, M.J.; Bertram, T.H.; Jimenez, J.L.; Gonin, M.; Worsnop, D.R.; Thornton, J.A. A chemical ionization high-resolution time-of-flight mass spectrometer coupled to a Micro Orifice Volatilization Impactor (MOVI-HRToF-CIMS) for analysis of gas and particle-phase organic species. Aerosol Sci. Technol. 2012, 46, 1313-1327. 
27. Lee, B.H.; Lopez-Hilfiker, F.D.; Mohr, C.; Kurtén, T.; Worsnop, D.R.; Thornton, J.A. An iodide-adduct high-resolution time-of-flight chemical-ionization mass spectrometer: Application to atmospheric inorganic and organic compounds. Environ. Sci. Technol. 2014, 48, 6309-6317.

28. Aljawhary, D.; Lee, A.K.Y.; Abbatt, J.P.D. High-resolution chemical ionization mass spectrometry (ToF-CIMS): Application to study SOA composition and processing. Atmos. Meas. Tech. 2013, 6, 3211-3224.

29. Allan, J.D.; Delia, A.E.; Coe, H.; Bower, K.N.; Alfarra, M.R.; Jimenez, J.L.; Middlebrook, A.M.; Drewnick, F.; Onasch, T.B.; Canagaratna, M.R.; et al. A generalised method for the extraction of chemically resolved mass spectra from Aerodyne aerosol mass spectrometer data. J. Aerosol Sci. 2004, 35, 909-922.

30. Leong, Y.J.; Sanchez, N.P.; Wallace, H.W.; Karakurt Cevik, B.; Hernandez, C.S.; Han, Y.; Choi, Y.; Flynn, J.H.; Massoli, P.; Floerchinger, C.; et al. Overview of Surface Measurements and Spatial Characterization of Submicron Particulate Matter during the DISCOVER-AQ 2013 Campaign in Houston, TX, USA, 2016. in preparation.

31. Aiken, A.C.; Decarlo, P.F.; Kroll, J.H.; Worsnop, D.R.; Huffman, J.A.; Docherty, K.S.; Ulbrich, I.M.; Mohr, C.; Kimmel, J.R.; Sueper, D.; et al. O/C and OM/OC Ratios of primary, secondary, and ambient organic aerosols with high-resolution time-of-flight aerosol mass spectrometry. Environ. Sci. Technol. 2008, 42, 4478-4485.

32. Canagaratna, M.R.; Jimenez, J.L.; Kroll, J.H.; Chen, Q.; Kessler, S.H.; Massoli, P.; Hildebrandt Ruiz, L.; Fortner, E.; Williams, L.R.; Wilson, K.R.; et al. Elemental ratio measurements of organic compounds using aerosol mass spectrometry: Characterization, improved calibration, and implications. Atmos. Chem. Phys. 2015, 15, 253-272.

33. Paatero, P.; Tapper, U. Positive matrix factorization: A nonnegative factor model with optimal utilization of error estimates of data values. Environmetrics 1994, 5, 111-126.

34. Hildebrandt, L.; Engelhart, G.J.; Mohr, C.; Kostenidou, E.; Lanz, V.A.; Bougiatioti, A.; DeCarlo, P.F.; Prevot, A.S.H.; Baltensperger, U.; Mihalopoulos, N.; et al. Aged organic aerosol in the eastern Mediterranean: The finokalia aerosol measurement experiment-2008. Atmos. Chem. Phys. 2010, 10, 4167-4186.

35. Hildebrandt, L.; Kostenidou, E.; Lanz, V.A.; Prevot, A.S.H.; Baltensperger, U.; Mihalopoulos, N.; Donahue, N.M.; Pandis, S.N. Sources and atmospheric processing of organic aerosol in the Mediterranean: Insights from aerosol mass spectrometer factor analysis. Atmos. Chem. Phys. 2011, 11, 12499-12515.

36. Lanz, V.A.; Alfarra, M.R.; Baltensperger, U.; Buchmann, B.; Hueglin, C.; Prevot, A.S.H. Source apportionment of submicron organic aerosols at an urban site by factor analytical modelling of aerosol mass spectra. Atmos. Chem. Phys. 2007, 7, 1503-1522.

37. Lanz, V.A.; Prévôt, A.S.H.; Alfarra, M.R.; Weimer, S.; Mohr, C.; DeCarlo, P.F.; Gianini, M.F.D.; Hueglin, C.; Schneider, J.; Favez, O.; et al. Characterization of aerosol chemical composition with aerosol mass spectrometry in Central Europe: An overview. Atmos. Chem. Phys. 2010, 10, 10453-10471. 
38. Ulbrich, I.M.; Canagaratna, M.R.; Zhang, Q.; Worsnop, D.R.; Jimenez, J.L. Interpretation of organic components from Positive Matrix Factorization of aerosol mass spectrometric data. Atmos. Chem. Phys. 2009, 9, 2891-2918.

39. Faxon, C.; Bean, J.; Hildebrandt Ruiz, L. Inland concentrations of CINO2 in Southeast Texas suggest chlorine chemistry significantly contributes to atmospheric reactivity. Atmosphere 2015, 6, 1487-1506.

40. Birch, M.; Cary, R. Elemental carbon-based method for monitoring occupational exposures to particulate diesel exhaust. Aerosol Sci. Technol. 1996, 25, 221-241.

41. Zaveri, R.A.; Shaw, W.J.; Cziczo, D.J.; Schmid, B.; Ferrare, R.A.; Alexander, M.L.; Alexandrov, M.; Alvarez, R.J.; Arnott, W.P.; Atkinson, D.B.; et al. Overview of the 2010 Carbonaceous Aerosols and Radiative Effects Study (CARES). Atmos. Chem. Phys. 2012, 12, 7647-7687.

42. Zotter, P.; El-Haddad, I.; Zhang, Y.; Hayes, P.L.; Zhang, X.; Lin, Y.; Wacker, L.; Schnelle-Kreis, J.; Abbaszade, G.; Zimmermann, R.; et al. Diurnal cycle of fossil and nonfossil carbon using radiocarbon analyses during CalNex. J. Geophys. Res. Atmos. 2014, 119, 6818-6835.

43. Barrett, T.E.; Robinson, E.M.; Usenko, S.; Sheesley, R.J. Source contributions to wintertime elemental and organic carbon in the western arctic based on radiocarbon and tracer apportionment. Environ. Sci. Technol. 2015, 49, 11631-11639.

44. Gustafsson, Ö.; Kruså, M.; Zencak, Z.; Sheesley, R.J.; Granat, L.; Engström, E.; Praveen, P.S.; Rao, P.S.P.; Leck, C.; Rodhe, H. Brown clouds over South Asia: Biomass or fossil fuel combustion? Science 2009, 323, 495-498.

45. Atkinson-Palombo, C.M.; Miller, J.A.; Balling, R.C., Jr. Quantifying the ozone "weekend effect" at various locations in Phoenix, Arizona. Atmos. Environ. 2006, 40, 7644-7658.

46. Wilks, D.S. Statistical Methods in the Atmospheric Science; Academic Press: San Diego, CA, USA, 1995.

47. Ng, N.L.; Canagaratna, M.R.; Jimenez, J.L.; Zhang, Q.; Ulbrich, I.M.; Worsnop, D.R. Real-time methods for estimating organic component mass concentrations from aerosol mass spectrometer data. Environ. Sci. Technol. 2011, 45, 910-916.

48. Rollins, A.W.; Browne, E.C.; Min, K.-E.; Pusede, S.E.; Wooldridge, P.J.; Gentner, D.R.; Goldstein, A.H.; Liu, S.; Day, D.A.; Russell, L.M.; et al. Evidence for NOx control over nighttime SOA formation. Science 2012, 337, 1210-1212.

49. Mylonas, D.T.; Allen, D.T.; Ehrmanf, S.H.; Pratsins, S.E. The sources and size distributions of organonitrates in Los Angeles aerosol. Atmos. Environ. 1991, 25A, 2855-2861.

50. Garnes, L.A.; Allen, D.T. Size distributions of organonitrates in ambient aerosol collected in Houston, Texas. Aerosol Sci. Technol. 2002, 36, 983-992.

51. Laurent, J.-P.; Allen, D.T. Size distributions of organic functional groups in ambient aerosol collected in Houston, Texas. Aerosol Sci. Technol. 2004, 38, 60-67.

52. O'Brien, R.J.; Holmes, J.R.; Bockian, A.H. Formation of photochemical aerosol from hydrocarbons. chemical reactivity and products. Environ. Sci. Technol. 1975, 9, 568-576. 
53. Stein, A.F.; Draxler, R.R.; Rolph, G.D.; Stunder, B.J.B.; Cohen, M.D.; Ngan, F. NOAA'S HYSPLIT atmospheric transport and dispersion modeling system. Am. Meteorol. Soc. 2015, 96, 2059-2077.

54. Pankow, J.F. An absorption model of gas/particle partitioning of organic compounds in the atmosphere. Atmos. Environ. 1994, 28, 185-188.

55. Donahue, N.M.; Robinson, A.L.; Stanier, C.O.; Pandis, S.N. Coupled partitioning, dilution, and chemical aging of semivolatile organics. Environ. Sci. Technol. 2006, 40, 2635-2643.

56. Murphy, B.N.; Pandis, S.N. Exploring summertime organic aerosol formation in the eastern United States using a regional-scale budget approach and ambient measurements. J. Geophys. Res. 2010, 115, D24216.

57. Tucker, S.C.; Banta, R.M.; Langford, A.O.; Senff, C.J.; Brewer, W.A.; Williams, E.J.; Lerner, B.M.; Osthoff, H.D.; Hardesty, R.M. Relationships of coastal nocturnal boundary layer winds and turbulence to Houston ozone concentrations during TexAQS 2006. J. Geophys. Res. 2010, 115, 1-17.

58. Vizuete, W.; Junquera, V.; McDonald-Buller, E.; McGaughey, G.; Yarwood, G.; Allen, D. Effects of temperature and land use on predictions of biogenic emissions in Eastern Texas, USA. Atmos. Environ. 2002, 36, 3321-3337.

59. Lee, B.H.; Mohr, C.; Lopez-Hilfiker, F.D.; Lutz, A.; Hallquist, M.; Lee, L.; Romer, P.; Cohen, R.C.; Iyer, S.; Kurtén, T.; et al. Highly functionalized organic nitrates in the southeast United States: Contribution to secondary organic aerosol and reactive nitrogen budgets. Proc. Natl. Acad. Sci. USA 2016, 113, 1516-1521.

60. Pankow, J.F.; Asher, W.E. SIMPOL.1: A simple group contribution method for predicting vapor pressures and enthalpies of vaporization of multifunctional organic compounds. Atmos. Chem. Phys. 2008, 8, 2773-2796.

61. Ng, N.L.; Chhabra, P.S.; Chan, A.W.H.; Surratt, J.D.; Kroll, J.H.; Kwan, A.J.; McCabe, D.C.; Wennberg, P.O.; Sorooshian, A.; Murphy, S.M.; et al. Effect of NOx level on secondary organic aerosol (SOA) formation from the photooxidation of terpenes. Atmos. Chem. Phys. Discuss. 2007, 7, 10131-10177. 


\title{
Wintertime Residential Biomass Burning in Las Vegas, Nevada; Marker Components and Apportionment Methods
}

\author{
Steven G. Brown, Taehyoung Lee, Paul T. Roberts and Jeffrey L. Collett Jr.
}

Abstract: We characterized residential biomass burning contributions to fine particle concentrations via multiple methods at Fyfe Elementary School in Las Vegas, Nevada, during January 2008: with levoglucosan on quartz fiber filters; with water soluble potassium $\left(\mathrm{K}^{+}\right)$measured using a particle-into-liquid system with ion chromatography (PILS-IC); and with the fragment $\mathrm{C}_{2} \mathrm{H}_{4} \mathrm{O}_{2}{ }^{+}$from an Aerodyne High Resolution Aerosol Mass Spectrometer (HR-AMS). A Magee Scientific Aethalometer was also used to determine aerosol absorption at the UV (370 nm) and black carbon (BC, $880 \mathrm{~nm}$ ) channels, where UV-BC difference is indicative of biomass burning (BB). Levoglucosan and AMS $\mathrm{C}_{2} \mathrm{H}_{4} \mathrm{O}_{2}{ }^{+}$measurements were strongly correlated $\left(r^{2}=0.92\right) ; \mathrm{K}^{+}$correlated well with $\mathrm{C}_{2} \mathrm{H}_{4} \mathrm{O}_{2}{ }^{+}\left(r^{2}=0.86\right)$ during the evening but not during other times. While $\mathrm{K}^{+}$may be an indicator of $\mathrm{BB}$, it is not necessarily a unique tracer, as non-BB sources appear to contribute significantly to $\mathrm{K}^{+}$and can change from day to day. Low correlation was seen between UV-BC difference and other indicators, possibly because of an overwhelming influence of freeway emissions on BC concentrations. Given the sampling location-next to a twelve-lane freeway-urban-scale biomass burning was found to be a surprisingly large source of aerosol: overnight BB organic aerosol contributed between $26 \%$ and $33 \%$ of the organic aerosol mass.

Reprinted from Atmosphere. Cite as: Brown, S.G.; Lee, T.; Roberts, P.T.; Collett, J.L., Jr. Wintertime Residential Biomass Burning in Las Vegas, Nevada; Marker Components and Apportionment Methods. Atmosphere 2016, 7, 58.

\section{Introduction}

\subsection{Residential Wintertime Biomass Burning and Its Fine Particle Tracers}

Biomass burning includes both residential biomass burning for home heating during the wintertime, and smoke transported from wildfires or prescribed burns. In the winter, wildfires and prescribed burns in the Las Vegas area are minimal, so the main biomass burning influence is from residential burning. Understanding the impact of residential biomass burning on aerosol concentrations in urban areas is of particular interest, since emissions are potentially controllable through burn-prevention or fireplace change-out programs [1,2] and because residential 
biomass burning can lead to high concentrations during the evening and overnight, when emissions are trapped in a shallow boundary layer [3,4]. These short, high-concentration events can have acute health impacts [5,6], and specific health effects have also been associated with inhaling biomass burning aerosol [7-10]. Biomass burning emissions include not just black carbon (BC) and organic matter $(\mathrm{OM})$, but also carcinogens such as benzene and polycyclic aromatic hydrocarbons (PAHs) [11].

Biomass burning is typically apportioned using: (1) the organic molecule levoglucosan, either via chemical analysis of filters or semi-continuously via instruments such as the Aerodyne High Resolution Aerosol Mass Spectrometer (HR-AMS); (2) potassium; and (3) multi-channel Aethalometer data. Levoglucosan is an anhydrous sugar produced in the combustion of cellulose [12-16]. It is typically quantified by extracting aerosol collected on quartz fiber filters and analyzing the aerosol by gas chromatograph-mass spectrometer (GC-MS) or other analytical techniques. While levoglucosan is a good tracer for biomass burning, Sullivan et al. and others have found that the relationship of levoglucosan to organic aerosol in biomass burning emissions can vary widely by fuel type and burning conditions [16]. Levoglucosan may not be fully conserved during transport due to atmospheric oxidative processes [17-21], so using levoglucosan observations may not capture the complete impact of primary biomass burning smoke emissions at a receptor. Hennigan et al. [17] in a laboratory study, found that under typical summertime $\mathrm{OH}$ concentrations, levoglucosan is stable for 0.7-2.2 days. Since our study occurred during wintertime, and the main source of levoglucosan is local biomass burning with little transport time or distance, levoglucosan is likely stable enough here to be used as a robust tracer for primary biomass burning emissions. In addition to being quantified by filter collection, levoglucosan and related compounds also emitted by combustion of cellulose or hemi-cellulose can be quantified on a semi-continuous basis by the HR-AMS, where the ion $\mathrm{C}_{2} \mathrm{H}_{4} \mathrm{O}_{2}{ }^{+}$at mass-to-charge ratio $(m / z) 60$ is commonly used to indicate biomass burning; $\mathrm{C}_{2} \mathrm{H}_{4} \mathrm{O}_{2}{ }^{+}$is proportional to the amount of levoglucosan in the sampled aerosol [22-25]. Levoglucosan is not the only source of this ion, since other organic species such as other anhydrosugars (e.g., mannosan and galactosan) and organic acids also contribute to its mass, but levoglucosan and structurally related molecules in biomass burning smoke typically are the dominant source of $\mathrm{C}_{2} \mathrm{H}_{4} \mathrm{O}_{2}{ }^{+}$ion $[17,25]$.

Mohr et al. and Takegawa et al. have found that the additional signal at $m / z 60$ is likely from long chain alkanoic acids or other acid compounds [26,27]. Cubison et al. further demonstrated that without biomass burning influence, ambient aerosol includes a $m / z 60$ background level of $\sim 0.3 \%$ of OM, likely due to acids and other compounds [28]. Lee et al. suggest that increased/decreased levoglucosan yield in biomass burning smoke may be offset to some extent by 
corresponding decreases/increases in other molecules that also yield $\mathrm{C}_{2} \mathrm{H}_{4} \mathrm{O}_{2}{ }^{+}$ions, resulting in a fairly stable $\mathrm{OA} / \mathrm{C}_{2} \mathrm{H}_{4} \mathrm{O}_{2}{ }^{+}$ratio across fuel and burn types [25]. In Spain, Minguillon et al. found that levoglucosan-apportioned biomass burning was less than AMS-apportioned BB, possibly because alkanoic acids contributed to the $m / z 60$ signal. Thus, a combination of filter-based levoglucosan plus higher-time-resolution AMS $\mathrm{C}_{2} \mathrm{H}_{4} \mathrm{O}_{2}{ }^{+}$measurements should effectively bound the contribution of biomass burning to OA [29].

Potassium is also produced from the combustion of wood lignin. Elemental potassium $(\mathrm{K})$ and soluble potassium $\left(\mathrm{K}^{+}\right)$are commonly used as tracers when using data from X-ray fluorescence (XRF) and IC analysis of filter samples [30-33]. Other prevalent sources of potassium, such as dust, sea salt, or cooking aerosol, can confound use of this tracer [34-36]. In experiments of different biomass fuels, Sullivan et al. found poor correlation between emissions of $\mathrm{K}^{+}$and levoglucosan among the fuel types, whereas Lee et al. showed that emissions of $\mathrm{K}^{+}$were higher under flaming conditions compared to smoldering conditions; $\mathrm{AMS}_{2} \mathrm{H}_{4} \mathrm{O}_{2}{ }^{+}$ emissions were comparable between conditions (both $\mathrm{K}^{+}$and $\mathrm{AMS}_{2} \mathrm{H}_{4} \mathrm{O}_{2}{ }^{+}$were reported in terms of ratio to total $\mathrm{PM}$ ) [16,25]. These results are consistent with other studies suggesting that $\mathrm{K}^{+}$may have a modest correlation at best with organic tracers of biomass burning. Zhang et al. found an $r^{2}=0.59$ using 24-h filter data during wintertime in the southeastern U.S., but a much lower correlation in summer; $\mathrm{K}$ had lower spatial variability than levoglucosan did [35]. In Mexico City, Aiken et al. found that levoglucosan had a modest correlation with $\mathrm{PM}_{2.5} \mathrm{~K}$ $\left(r^{2}=0.67\right)$, and that non-biomass burning sources typically accounted for two-thirds of $\mathrm{K}$ concentrations [34]. In source profiles, the ratio between $\mathrm{K}$ and levoglucosan can be quite variable, ranging between 0.03 and 0.16 [11,25,37-39]. In part because of this variability and confounding alternative potassium sources, Minguillon et al. suggested that, based on comparisons of $\mathrm{K}$ from 24-h filter measurements to $\mathrm{K}$ from AMS, levoglucosan, and other measurements, $\mathrm{K}$ was an unreliable tracer for their sites because of the influence of other sources [29]. While $\mathrm{K}$ is nonvolatile and not subject to chemical destruction during plume aging, results from the studies referenced above and others suggest that apportionment using $\mathrm{K}$ can have high uncertainties.

Multi-channel Aethalometers (e.g., Magee Scientific AE22 used here) provide measurements of absorption from sampled aerosol at multiple wavelengths at $880 \mathrm{~nm}$ and at $370 \mathrm{~nm}$. The absorption measurement at $880 \mathrm{~nm}$ defines the concentration of black carbon (BC), while the $370 \mathrm{~nm}$ measurement is the absorption of the aerosol in the UV [40-42]. Aerosols are sampled continuously and impacted on a filter tape, where the absorption measurement is taken. With the Aethalometer, the absorption measurement is then converted to a black carbon concentration using an assumed mass extinction coefficient of $16.6 \mathrm{~m}^{2} / \mathrm{g}$ [40,41]. If measuring only true black carbon, the calculated mass from either channel is the same; when PAHs or other 
"brown carbon" material are present, the response in the UV channel is different than in the BC channel, where this difference in response is defined as UV-BC. The UV-BC difference has been attributed to the presence of wood smoke, meaning that higher UV-BC difference values are indicative of increased wood smoke. Studies in the northeastern U.S. report that there is good agreement between UV-BC and levoglucosan [3,4], and multiple studies have exploited this difference to apportion traffic and wood smoke aerosol $[41,43,44]$. While there is evidence that multi-channel data can be used to indicate or apportion wood smoke, Harrison et al. caution that this method is very dependent on the choice of Angstrom exponent in the calculations, and that apportioning wood smoke via this method in an urban environment is challenging [42]. Here, we report UV-BC difference, and compare trends in BC and UV-BC difference with other wood smoke measures.

\subsection{Study Area: Las Vegas}

Las Vegas, Nevada, in a shallow bowl area with mountains to the west and north, is a relatively isolated, large urban area with a population exceeding 1.9 million in the greater metropolitan area (as of 2010). Unlike areas in the northern and northeastern United States, Las Vegas is not widely recognized as having a tradition of home heating from residential wood combustion; rather, most homes are heated by natural gas or electricity. However, the few studies that have been conducted on Las Vegas aerosol have suggested biomass burning as a moderate source of wintertime aerosol.

A key study, Green et al., focused on approximately 50 24-h filter samples collected in 2000-2001 [45]. The major components of $\mathrm{PM}_{2.5}$ were BC, OM and crustal elements, with carbonaceous material contributing over $50 \%$ of the total mass at an urban site, East Charleston. Ammonium sulfate and nitrate concentrations were generally quite low, about $12 \%$ of the total $\mathrm{PM}_{2.5}$ mass. Though no formal apportionment was completed, extensive data analysis led the authors to surmise that, although gasoline and diesel vehicle emissions are likely an important source, other sources such as residential biomass burning may also be a significant contributor. Another study, the Southern Nevada Air Quality Study (SNAQS), used 10-12 24-h $\mathrm{PM}_{2.5}$ filter samples at four sites in January 2003 to apportion $\mathrm{PM}_{2.5}$ [46]. 80\% of the mass was from carbonaceous aerosol, and $38 \%-49 \%$ of the $\mathrm{PM}_{2.5}$ was attributed to mobile sources. Biomass burning contributed $11 \%-21 \%$ of the mass. Dust, ammonium sulfate, and ammonium nitrate comprised the remainder of the mass. These apportionments were based on a standard suite of filter analyses, including OC and EC by thermal optical reflectance (TOR), sulfate and nitrate by IC, and metals by XRF. No continuous data were used, nor were specific tracers for biomass burning available other than $\mathrm{K}$, which has additional, significant non-BB sources. Without more specific tracers or higher-time-resolution data, the apportionment of OC has a high uncertainty. In addition, the temporal 
pattern of OC could not be examined, since only 24-h filters were collected on a small number of days.

\section{Methodology}

\subsection{Monitoring Location}

Measurements were made next to a classroom and playground in Las Vegas, Nevada, during January 2008 at Fyfe Elementary School, directly adjacent to and 18 meters from the US Highway 95 highway soundwall (Supplementary Materials Figure S1); this monitor is $60 \mathrm{~m}$ from the middle of the first set of lanes, and $90 \mathrm{~m}$ from the middle of the farthest set of lanes. Additional details on monitoring location and the influence of traffic have been reported elsewhere $[47,48]$.

\subsection{Measurement Methods}

Collection of black carbon (BC) and meteorological data are further described in Brown et al. $[47,48]$. Wind speed and direction were measured with an RM Young AQ 5305-L at 10 meters above ground level (AGL). BC data at $880 \mathrm{~nm}$ (BC channel) and $370 \mathrm{~nm}$ (UV channel) were collected using a Magee Scientific Aethalometer model AE-22 with a $\mathrm{PM}_{2.5}$ inlet at $5 \mathrm{~L} / \mathrm{min}$. Time-stamp and filter tape spot saturation corrections were made using the Washington University Air Quality Lab AethDataMasher Version 6.0e (St. Louis, MO, USA). An Aerodyne HR-AMS was used to quantify OM and biomass burning organic aerosol (BBOA) tracers. The HR-AMS is a widely used instrument described in detail elsewhere [49-51]; specifics of its operation in this study are detailed in Brown et al. [47]. Ambient air is drawn through a $\mathrm{PM}_{2.5}$ cyclone and is sampled through a critical orifice into an aerodynamic lens; a narrow particle beam with a 50\% transmission efficiency of $900 \mathrm{~nm}$ diameter particles is thus created so that, essentially, $\mathrm{PM}_{1}$ is measured [52,53]. Particles are sampled through a $\mathrm{PM}_{2.5}$ cyclone, and then accelerated via supersonic expansion of gas molecules into a vacuum at the end of the aerodynamic lens. Particles are collected by inertial impaction onto a heated surface $\left(600{ }^{\circ} \mathrm{C}\right)$, and non-refractory species such as nitrate, sulfate, ammonium, and OM are thermally vaporized. Vaporized gases undergo electron impact ionization, and the charged fragments enter a time-of-flight mass spectrometer (ToF-MS) region, where they are separated by mass-to-charge ratio $(\mathrm{m} / \mathrm{z})$. After correction for interferences from ambient gases such as $\mathrm{N}_{2}$ and $\mathrm{O}_{2}$, mass spectra are analyzed for each 2-min averaged sample. AMS data were processed and analyzed using the standard AMS analysis software, Squirrel version 1.51, implemented with Wavemetric's Igor Pro (version 6.20). Detection limits for individual ions are provided elsewhere [54]; the focus of this work is on $m / z 60$, which has a detection limit of $0.001 \mu \mathrm{g} / \mathrm{m}^{3}$. 
Collection and chemical analysis of quartz fiber filters are detailed elsewhere [55]. Briefly, $8^{\prime \prime} \times 10^{\prime \prime}$ filters in Tisch $231 \mathrm{PM}_{2.5}$ plates were used in hi-volume samplers (nominal flow rate $68 \mathrm{~m}^{3} / \mathrm{h}$ ) to collect aerosol at multiple times of day: 0500-0900 LST, 0900-1100 LST, 1100-1700 LST, and 1700-0500 LST. Filters were pre-baked, individually wrapped in aluminum foil, and kept in a freezer before and after sampling. Flow checks were done in the morning and evening (e.g., prior to 0900 and prior to 1700). Only a limited number of samples could be analyzed, so 12 overnight samples were selected, since this is the period of highest $\mathrm{OM}$ concentrations. Chemical analysis was done by GC-MS for levoglucosan and more than 20 PAHs, the latter reported in Olson et al. [55].

Semi-continuous measurements of $\mathrm{PM}_{2.5}, \mathrm{~K}^{+}$, sulfate, nitrate, ammonium, and other major ions were made using a Particle Into Liquid Sampler (PILS) coupled to two ion chromatographs (IC). The detailed design and operation of the PILS is described elsewhere [56-59] and is briefly summarized here. The PILS nucleates aerosol particles to form water droplets by mixing a denuded aerosol stream with supersaturated steam. The nucleated droplets are collected into a flowing liquid stream by inertial impaction. The liquid stream, containing an internal $\mathrm{LiBr}$ standard to determine dilution by condensed water vapor, is split into two streams which are injected every $15 \mathrm{~min}$ to two ion chromatographs (Dionex, DX-500) for measurement of major inorganic ion $\left(\mathrm{NO}_{3}{ }^{-}, \mathrm{SO}_{4}{ }^{2-}, \mathrm{NH}_{4}{ }^{+}, \mathrm{Cl}^{-}, \mathrm{Na}^{+}, \mathrm{K}^{+}, \mathrm{Ca}^{2+}\right.$ and $\mathrm{Mg}^{2+}$ ) concentrations. $\mathrm{K}^{+}$, the focus of our analysis, has a detection limit of $0.06 \mu \mathrm{g} / \mathrm{m}^{3}[60]$.

A PM 2.5 cyclone (16.7 LPM, URG-2000-30EH) and two URG annular denuders (URG-2000-30X242-3CSS) were used upstream of the PILS/IC. The first denuder was coated with $\mathrm{Na}_{2} \mathrm{CO}_{3}$ for removal of acidic gases, and the second denuder was coated with phosphorous acid to remove basic gases. Denuders were exchanged every 5-6 days after calibration and blank checks. Blanks were taken by sampling particle-free air, drawn through a High Efficiency Particulate-Free Air (HEPA) capsule filter (Pall Corporation, New York, NY, USA), through the PILS/IC system after a calibration check standard $\left(\mathrm{NO}_{3}{ }^{-}, \mathrm{SO}_{4}{ }^{2-}\right.$, and $\mathrm{NH}_{4}{ }^{+}$concentrations of $20 \mu \mathrm{N}$ and $\mathrm{Cl}^{-}, \mathrm{Na}^{+}, \mathrm{K}^{+}, \mathrm{Ca}^{2+}$, and $\mathrm{Mg}^{2+}$ concentrations of $10 \mu \mathrm{N}$ ) was injected. Approximately every 10 days, the PILS was cleaned and the ion chromatographs recalibrated. A sample flow rate of $16.7 \mathrm{~L} / \mathrm{min}$ for the PILS/IC was controlled by a critical orifice with a vacuum regulator. 20-min data were aggregated into hourly concentrations, where all three 20-min measurements within an hour were required to accept an hourly average.

\subsection{Source Apportionment Methods}

EPA's Positive Matrix Factorization (PMF) tool, EPA PMF [61], was used to apportion organic matter (OM) as measured by the HR-AMS, and is further 
described elsewhere $[47,62]$. Briefly, four factors were found with the PMF analysis: hydrocarbon-like organic aerosol (HOA), low-volatility oxygenated organic aerosol (LV-OOA), biomass burning organic aerosol (BBOA), and semi-volatile oxygenated organic aerosol (SV-OOA). These factors are typical of PMF deconvolution of HR-AMS data, and represent a spectrum of OA [51,63]. On average in this study, HOA made up $26 \%$ of the OM, while LV-OOA was highest in the afternoon and accounted for $26 \%$ of the OM. PMF-derived BBOA (PMF-BBOA) occurred in the evening hours, was transported predominantly from the residential area to the north, and on average constituted $12 \%$ of the OM; SV-OOA accounted for the remaining one-third of the OM.

\section{Results}

\subsection{Ambient Concentrations and Temporal Variability of Biomass Burning Markers}

Concentrations of organic matter, black carbon, and biomass burning indicators (levoglucosan, $\mathrm{C}_{2} \mathrm{H}_{4} \mathrm{O}_{2}{ }^{+}, \mathrm{K}^{+}$, and UV-BC difference) varied widely during January 2008, typically reaching a peak in the early evening (i.e., 1900 through 2100 LST). Figure 1 shows a time series for these species. OM at our roadside site was $3.3 \mu \mathrm{g} / \mathrm{m}^{3}$ on average, while BC was $1.8 \mu \mathrm{g} / \mathrm{m}^{3}$. Other aerosol and gaseous species were also measured and are summarized elsewhere [47]; in January 2008, OM and BC comprised $74 \%$ of the $\mathrm{PM}_{1}$ mass measured via the AMS and Aethalometer (excluding metals and crustal material which were not measured). $\mathrm{C}_{2} \mathrm{H}_{4} \mathrm{O}_{2}{ }^{+}$concentrations averaged $0.018 \mu \mathrm{g} / \mathrm{m}^{3}$, and between 1800 and 0000 LST were nearly three times higher at $0.040 \mu \mathrm{g} / \mathrm{m}^{3}$. PILS $\mathrm{K}^{+}$concentrations averaged $0.033 \mu \mathrm{g} / \mathrm{m}^{3}$ across the month of measurements, while levoglucosan concentrations during the 12-h overnight samples averaged $0.14 \mu \mathrm{g} / \mathrm{m}^{3}$. For comparison, the concentrations of elemental potassium at the Chemical Speciation Network (CSN) site in Las Vegas were $0.03 \mu \mathrm{g} / \mathrm{m}^{3}$ across five measurement days that fell within our study period.

Figure 2 summarizes the typical diurnal pattern of the semi-continuous measurements. $\mathrm{BC}$ concentrations were similar in the morning and evening, during the rush hour commute times. OM showed a minor peak in the morning, and was on average three times higher in the evening than in the morning. See Supplementary Materials Figures S1 and S2 for diurnal box plots of $\mathrm{OM}$ and $\mathrm{BC} . \mathrm{C}_{2} \mathrm{H}_{4} \mathrm{O}_{2}{ }^{+}, \mathrm{K}^{+}$, and UV-BC difference all show a similar average diurnal pattern with a concentration peak extending from early evening through late night. $\mathrm{K}^{+}$concentrations decrease more slowly than $\mathrm{C}_{2} \mathrm{H}_{4} \mathrm{O}_{2}{ }^{+}$after midnight, possibly suggesting that $\mathrm{C}_{2} \mathrm{H}_{4} \mathrm{O}_{2}{ }^{+}$is being lost via other mechanisms (such as partitioning from particle to gas phase or atmospheric reactions) than those affecting the nonvolatile and non-reactive species $\mathrm{K}^{+} . \mathrm{K}^{+}, \mathrm{C}_{2} \mathrm{H}_{4} \mathrm{O}_{2}{ }^{+}$, and UV-BC difference are all lowest in the midday, when emissions 
of residential biomass burning are low, wind speeds and dispersion are higher, and $\mathrm{OM}$ is lower.

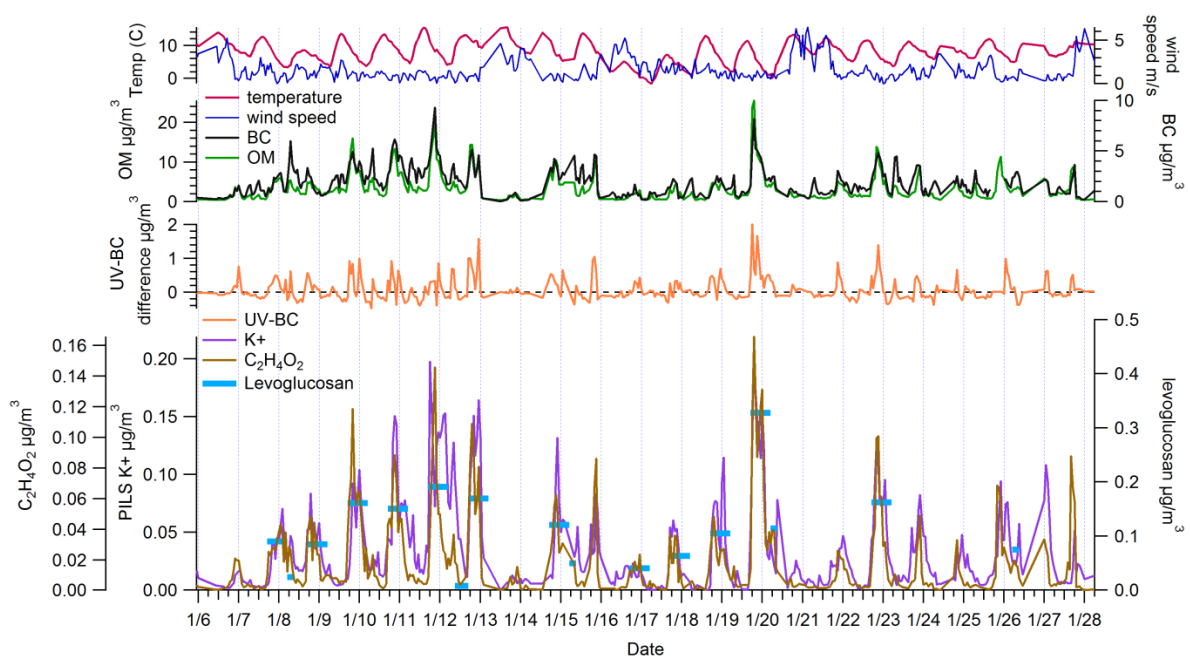

Figure 1. Time series of temperature, wind speed, Aethalometer black carbon (BC), Aerosol Mass Spectrometer (AMS) organic matter (OM), Aethalometer UV-BC difference, PILS K ${ }^{+}$, AMS $\mathrm{C}_{2} \mathrm{H}_{4} \mathrm{O}_{2}{ }^{+}$, and levoglucosan from quartz fiber filters at Fyfe during January 2008 (all units in $\mu \mathrm{g} / \mathrm{m}^{3}$ except temperature in degrees $\mathrm{C}$ and wind speed in $\mathrm{m} / \mathrm{s}$ ).
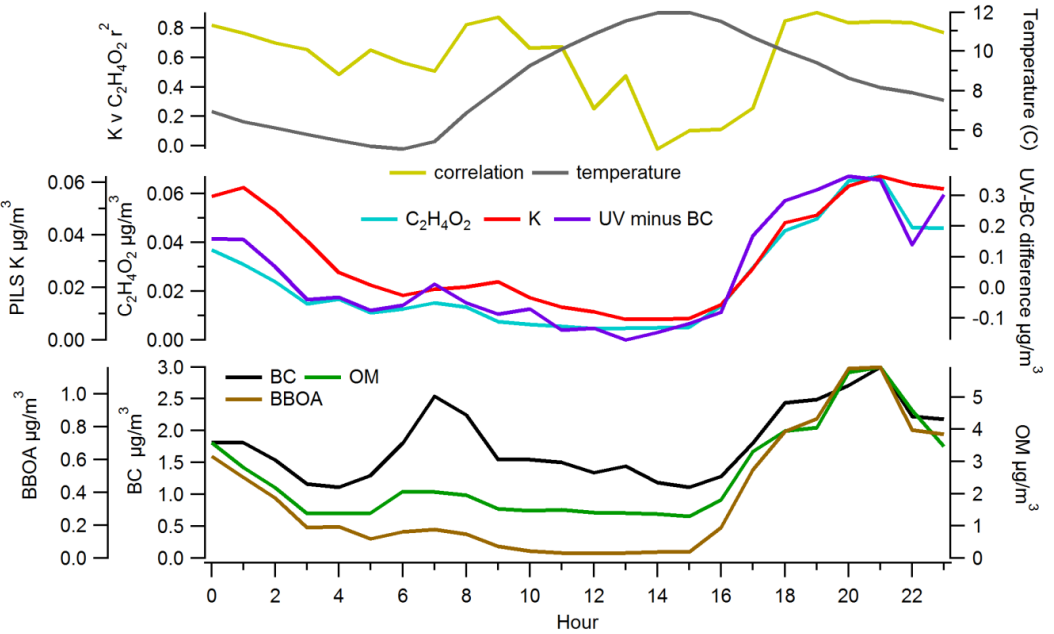

Figure 2. Average concentration by hour (LST) for Aethalometer BC, AMS OM, PMF-BBOA, UV-BC difference, PILS K ${ }^{+}$, and AMS $\mathrm{C}_{2} \mathrm{H}_{4} \mathrm{O}_{2}{ }^{+}$(all units $\mu \mathrm{g} / \mathrm{m}^{3}$ ), plus correlation $\left(r^{2}\right)$ by hour of PILS $\mathrm{K}^{+}$vs. AMS $\mathrm{C}_{2} \mathrm{H}_{4} \mathrm{O}_{2}{ }^{+}$and temperature (degrees C). 
OM has a similar pattern as these BB indicators, while BC has a different pattern; concentrations of $\mathrm{BC}$ reach comparable average maxima in the morning and evening. The diurnal pattern of $\mathrm{BC}$ indicates that mobile source emissions related to rush hour traffic are likely the most important source of BC. The diurnal OM pattern-low concentrations in the midday and a steep rise in concentrations in the evening-is likely due to a mix of fresh emissions in the morning and evening with the rush hour and other activities, plus an additional evening source of biomass burning. This was further demonstrated with PMF analyses on the AMS data [47], which showed that fresh, hydrocarbon-like organic aerosol (HOA) was present in the morning and evening, and that additional semi-volatile oxidized organic aerosol (SV-OOA) and BBOA were evident during the evening peak.

\subsection{Comparison among Biomass Burning Markers}

\subsubsection{Comparisons with Levoglucosan}

There was a range in how well the potential biomass burning indicators correlated with each other. Filter-based levoglucosan was available only for a subset of times during the study, at varying intervals. Correlations of filter-based levoglucosan with other measurements are summarized in Figure 3, while correlation among semi-continuous measurements from other instruments is discussed in the next section.

Levoglucosan concentrations measured from filters had high correlations with AMS $\mathrm{C}_{2} \mathrm{H}_{4} \mathrm{O}_{2}{ }^{+}\left(r^{2}=0.92\right)$. This is expected, since $\mathrm{C}_{2} \mathrm{H}_{4} \mathrm{O}_{2}{ }^{+}$is a fragment from levoglucosan and other co-emitted anhydrous sugars; pure levoglucosan introduced into an AMS yields a suite of ions that has $\mathrm{C}_{2} \mathrm{H}_{4} \mathrm{O}_{2}{ }^{+}$as $13 \%-14 \%$ of the total ion fragment pattern [25]. In contrast, there was only a moderate correlation of PILS $\mathrm{K}^{+}\left(r^{2}=0.66\right)$ or UV-BC difference $\left(r^{2}=0.53\right)$ with levoglucosan; no correlation was seen between levoglucosan and $\mathrm{BC}\left(r^{2}=0.16\right)$. The lower correlations are perhaps not surprising, as both $\mathrm{BC}$ and $\mathrm{K}^{+}$have other non-biomass burning sources; further, levoglucosan may be depleted during the 12-h sampling period via atmospheric reactions or phase partitioning to the gas phase, while $\mathrm{BC}$ and $\mathrm{K}^{+}$would not undergo similar processes. $\mathrm{BC}$ and $\mathrm{K}^{+}$are emitted primarily during flaming combustion, while levoglucosan is emitted more during smoldering combustion [25], which may also cause the lower correlation. The very low correlation with BC is likely because $\mathrm{BC}$ next to a roadway is predominantly from mobile sources, rather than from biomass burning. The modest correlation of levoglucosan with UV-BC difference, in the context of no correlation with $\mathrm{BC}$, indicates that the UV-BC difference can be indicative of biomass burning aerosol, even when total $\mathrm{BC}$ is overwhelmingly from traffic-related sources. 


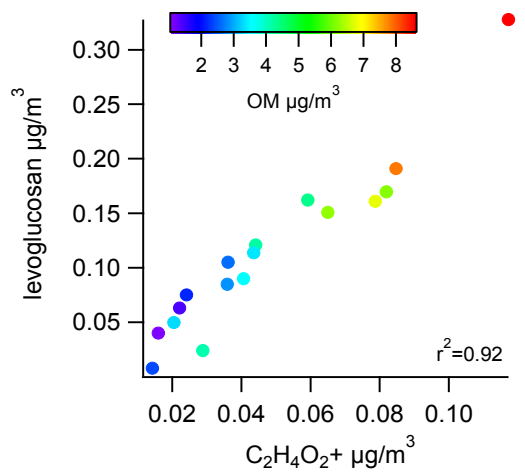

(a)

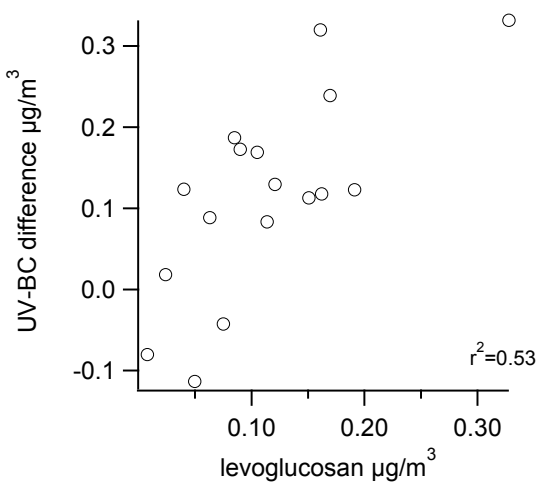

(c)

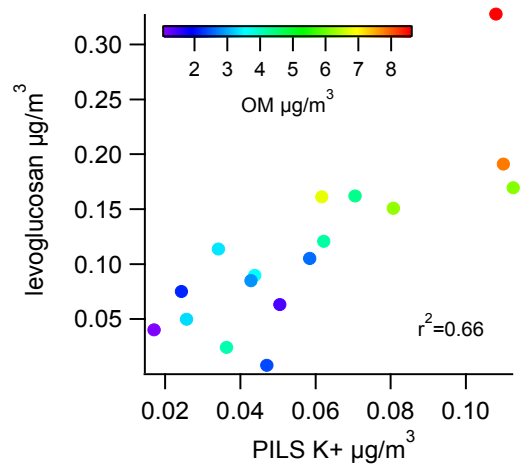

(b)

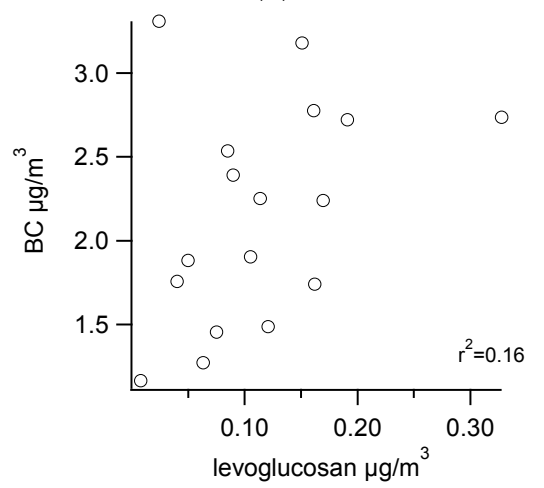

(d)

Figure 3. Scatter plots of levoglucosan concentrations $\left(\mu \mathrm{g} / \mathrm{m}^{3}\right)$ correlated with (a) AMS $\mathrm{C}_{2} \mathrm{H}_{4} \mathrm{O}_{2}{ }^{+}\left(\mu \mathrm{g} / \mathrm{m}^{3}\right)$; (b) PILS K ${ }^{+}\left(\mu \mathrm{g} / \mathrm{m}^{3}\right)$; (c) UV-BC difference $\left(\mu \mathrm{g} / \mathrm{m}^{3}\right)$; and $(\mathbf{d}) \mathrm{BC}\left(\mu \mathrm{g} / \mathrm{m}^{3}\right)$.

\subsubsection{Comparisons among Semi-Continuous Biomass Burning Markers}

While there are a limited number of multi-hour samples of levoglucosan, the high correlation between levoglucosan and $\mathrm{C}_{2} \mathrm{H}_{4} \mathrm{O}_{2}{ }^{+}$confirms that $\mathrm{C}_{2} \mathrm{H}_{4} \mathrm{O}_{2}{ }^{+}$is an excellent tracer for levoglucosan and biomass burning emissions. We next examined correlations of hourly averaged $\mathrm{C}_{2} \mathrm{H}_{4} \mathrm{O}_{2}{ }^{+}$concentrations with $\mathrm{K}^{+}$, UV-BC difference values, and BC. Scatter plots of semi-continuous measurements are provided in Supplementary Materials Figure S2. As indicated by similar diurnal patterns, the measurements of biomass burning indicators were somewhat correlated, with some differences between species and time of day. The overall correlation coefficient $\left(r^{2}\right)$ between $\mathrm{K}^{+}$and $\mathrm{C}_{2} \mathrm{H}_{4} \mathrm{O}_{2}{ }^{+}$was 0.56 , but if the correlations are examined by time of day, there is a large range in this correlation coefficient (Figure 2). Between 1800 and 0000 LST, when fresh biomass burning emissions are most likely, the correlation coefficient between $\mathrm{K}^{+}$and $\mathrm{C}_{2} \mathrm{H}_{4} \mathrm{O}_{2}{ }^{+}$was 0.84 ; it slowly decreased through the 
morning until 1200 through 1600 LST, when the correlation coefficient was 0.19. Midday, when the correlation is lowest, is also when concentrations are lowest and approaching the detection limit; the lower correlations may simply be due to increased measurement noise closer to the detection limits.

UV-BC difference had only a modest correlation with $\mathrm{C}_{2} \mathrm{H}_{4} \mathrm{O}_{2}{ }^{+}\left(r^{2}=0.43\right)$, similar to the correlation between UV-BC difference and levoglucosan $\left(r^{2}=0.53\right)$. $\mathrm{BC}$ and $\mathrm{C}_{2} \mathrm{H}_{4} \mathrm{O}_{2}{ }^{+}$have a good correlation during the evening $\left(r^{2}=0.80\right)$ during the period of strong residential wood combustion, but only a modest correlation in the morning $\left(r^{2}=0.35\right)$. $\mathrm{K}^{+}$correlated poorly with both $\mathrm{BC}$ and UV-BC difference.

Overall, these results suggest that $\mathrm{K}^{+}$and UV-BC difference are only modestly good indicators of biomass burning in Las Vegas next to a roadway, probably at least in part because there are other sources of $\mathrm{K}^{+}$and $\mathrm{BC}$ at the monitoring site. It is clearly plausible that the majority of $\mathrm{BC}$ is from traffic-related emissions, which may complicate the relationship between UV-BC difference and levoglucosan or $\mathrm{C}_{2} \mathrm{H}_{4} \mathrm{O}_{2}{ }^{+}$. For $\mathrm{K}^{+}$, the modest correlation with levoglucosan or $\mathrm{C}_{2} \mathrm{H}_{4} \mathrm{O}_{2}{ }^{+}$may be due to differences in emissions of these species during flaming and smoldering processes, or to minor sources of $\mathrm{K}^{+}$confounding the relationship.

\subsubsection{Urban Background Levels of $\mathrm{C}_{2} \mathrm{H}_{4} \mathrm{O}_{2}{ }^{+}$}

There is a clear, strong relationship of levoglucosan with $\mathrm{C}_{2} \mathrm{H}_{4} \mathrm{O}_{2}{ }^{+}$in the data here and in prior studies [25]. However, non-biomass burning sources, including organic acids, also can contribute to $\mathrm{C}_{2} \mathrm{H}_{4} \mathrm{O}_{2}{ }^{+}$[28]. Lee et al. suggested that there is a background level of $\mathrm{C}_{2} \mathrm{H}_{4} \mathrm{O}_{2}{ }^{+}$, so that even when biomass burning is null, there is still some small concentration of $\mathrm{C}_{2} \mathrm{H}_{4} \mathrm{O}_{2}{ }^{+}$, approximately $0.3 \%$ of $\mathrm{OA}$. This background $\mathrm{C}_{2} \mathrm{H}_{4} \mathrm{O}_{2}{ }^{+}$can be seen in Figure 4 , which shows the fraction of OM from $\mathrm{C}_{2} \mathrm{H}_{4} \mathrm{O}_{2}{ }^{+}$ $\left(\mathrm{fC}_{2} \mathrm{H}_{4} \mathrm{O}_{2}{ }^{+}\right)$vs. the fraction from $\mathrm{m} / z 44$ (f44). During the morning and midday hours, a background of $\mathrm{C}_{2} \mathrm{H}_{4} \mathrm{O}_{2}{ }^{+}$is evident of approximately $0.25 \%$ of the OM; during the evening, the fraction of mass from $m / z 44$ is much lower and the fraction from $\mathrm{C}_{2} \mathrm{H}_{4} \mathrm{O}_{2}{ }^{+}$is much higher. Figure $4 \mathrm{~b}$ shows how the relationship between $m / z 44$ and $\mathrm{C}_{2} \mathrm{H}_{4} \mathrm{O}_{2}{ }^{+}$progresses, with a low $\mathrm{m} / z 44$ fraction and $\mathrm{C}_{2} \mathrm{H}_{4} \mathrm{O}_{2}{ }^{+}$fraction in the morning, followed by a midday increase in $m / z 44$ fraction, and an evening increase in $\mathrm{C}_{2} \mathrm{H}_{4} \mathrm{O}_{2}{ }^{+}$fraction and decrease of $\mathrm{m} / z 44$ fraction. This further shows the important contribution of biomass burning during the evening only, while other primary and secondary sources contribute to OM throughout the day. 


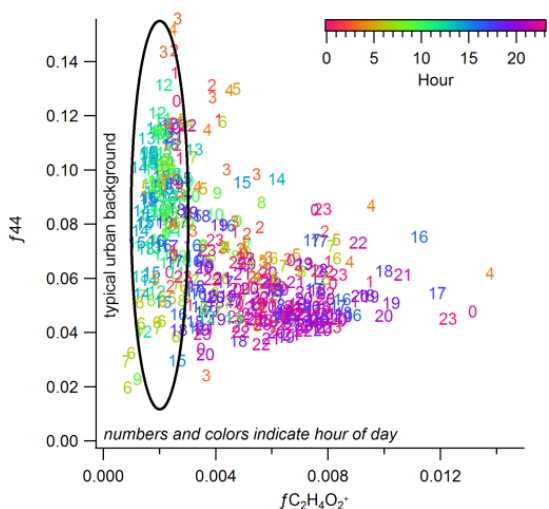

(a)

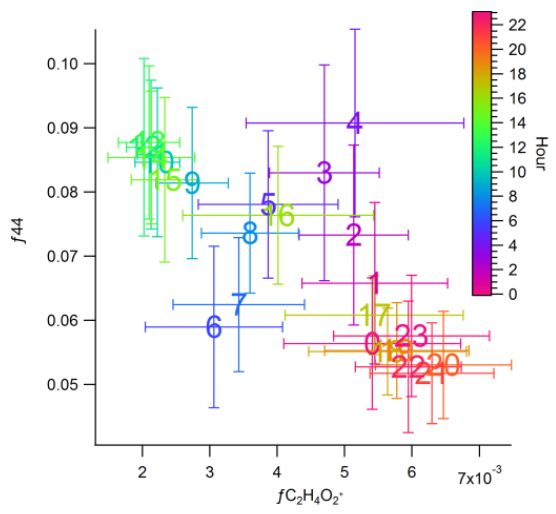

(b)

Figure 4. Scatter plot of the fraction of $\mathrm{OM}$ from $m / z 44$ and $\mathrm{C}_{2} \mathrm{H}_{4} \mathrm{O}_{2}{ }^{+}$, with color and numbers indicating hour of the day, for: (a) all data (hourly averages); and (b) data averaged by hour during the study.

\subsection{Apportioning Biomass Burning via Multiple Methods}

With the suite of biomass burning tracers observed here, multiple methods are available to apportion the contribution of biomass burning to OM: (1) use PMF-AMS, applying PMF to the AMS data to determine contributing factors, including BBOA [63,64], and comparing to the $\left(\mathrm{C}_{2} \mathrm{H}_{4} \mathrm{O}_{2}{ }^{+} \times \mathrm{OM}\right)^{-1}$ ratio reported in laboratory source experiments for biomass burning fuels [25]; (2) use a (levoglucosan/OC) ${ }^{-1}$ ratio as reported in filter-based source profiles, estimating the amount of OC from the levoglucosan concentrations and using an assumed $\mathrm{OM} / \mathrm{OC}$ ratio to estimate BBOA contributions to OM; and (3) use the same process as for Method 2, but using potassium from PILS and source profiles. Since Methods 2 and 3 rely on source profiles, these methods should estimate primary emissions, if the source profiles represent only primary emissions. The PMF factor approach in Method 1 may include primary and some secondary aerosol formation associated with BBOA. However, the PMF method could underestimate secondary OA from biomass burning in the obtained BBOA factor if the secondary OA is chemically more similar to SV-OOA than to primary BBOA. Since SV-OOA concentrations observed here are typically concurrent with and higher than BBOA, secondary OA associated with biomass burning emissions may not be fully captured in the BBOA factor. With only three PMF factors, i.e., with no SV-OOA factor, BBOA is higher than when four factors are used; it may be that with three factors, more of the secondary OA associated with biomass burning is contained in the BBOA factor. Table 1 summarizes the fraction of OM apportioned via each method. Brown et al. report the results from the PMF-AMS method where, using unit mass resolution AMS data and the EPA PMF program, 
on average $12 \%$ of the OM was attributable to biomass burning organic aerosol (BBOA) [47]. During overnight periods, BBOA was on average $26 \%$ of the OM.

Table 1. Fraction and standard deviation of OM (fOM) apportioned during 12 overnight (1700-0500 LST) periods, January evenings, and over all hours, via PMF-AMS, levoglucosan, and $\mathrm{K}^{+}$. Apportionment by levoglucosan is available only for the 12 overnight filter sample periods.

\begin{tabular}{cccc}
\hline Sample Range & $\begin{array}{c}\text { \% OM from BB } \\
\text { via Levoglucosan }\end{array}$ & $\begin{array}{c}\text { \% OM from BB } \\
\text { via PMF-AMS } \\
\text { (BBOA) }\end{array}$ & \% OM via K \\
\hline 12 12-h overnight periods & $33 \%+/-7 \%$ & $26 \%+/-9 \%$ & $44 \%+/-18 \%$ \\
All evenings (1800-2300 & $\mathrm{n} / \mathrm{a}$ & $15 \%+/-9 \%$ & $26 \%+/-24 \%$ \\
LST) & $\mathrm{n} / \mathrm{a}$ & $9 \%+/-8 \%$ & $25 \%+/-25 \%$ \\
\hline All hours & &
\end{tabular}

A number of studies have reported a range of $\mathrm{OM} / \mathrm{C}_{2} \mathrm{H}_{4} \mathrm{O}_{2}{ }^{+}$ratios from source experiments. Lee et al. report a value of 34.5 for the $\mathrm{OM} / \mathrm{C}_{2} \mathrm{H}_{4} \mathrm{O}_{2}{ }^{+}$ratio generated in biomass burning experiments [25]. Alfarra et al. used a combination of PMF and ${ }^{14} \mathrm{C}$ analyses to determine a similar ratio for $\mathrm{OM}$ to $m / z$ 60, equal to 36 , for wintertime wood combustion in Zurich, and suggested this ratio as a conservative estimate for apportioning BBOA [22]. The ratio of 34.5 is very close to the $\mathrm{OM} / \mathrm{C}_{2} \mathrm{H}_{4} \mathrm{O}_{2}{ }^{+}$ratio in the BBOA factor found here, which is 34.1, indicating that the BBOA factor is consistent with BBOA found in specific experiments where biomass burning is the main source of OA. In our PMF-AMS results, when using just three PMF factors, BBOA also comprises an average of $15 \%$ of the OM.

Fine et al. report an OC/levoglucosan ratio of 7.35 and an $\mathrm{OC} / \mathrm{K}$ ratio of 20.83 for residential biomass burning emissions, used here to apportion $\mathrm{BB}$ OC based on our filter levoglucosan and PILS potassium measurements [38]. Recent studies have reported a wider range of levoglucosan/OC and K/OC emission ratios depending on biomass fuel type and burn conditions $[16,29,65]$. The 7.35 value for OC/levoglucosan is representative of fireplace combustion of hardwoods, which is likely appropriate for the Las Vegas area. Schmidl et al. developed a similar factor for Austrian fuels of 7.1 based on test burns in a tiled stove [66]. Puxbaum et al. [65] suggest an OM/OC conversion factor of 1.4 based on their calculations from the data reported in Fine et al. [11]. During the wintertime evening in Las Vegas, when biomass burning is most prevalent, the average OM/OC ratio is 1.46 [67], so a value of 1.4 for biomass burning appears reasonable. This yields a conversion of biomass burning OM equal to levoglucosan $\times 7.35 \times 1.4$. For potassium, biomass burning $\mathrm{OM}$ is calculated as $\mathrm{K}^{+} \times 20.83 \times 1.4$. 
Figure 5 shows the fraction of $\mathrm{OM}$ by each method for periods when levoglucosan data are available. Figure 6 compares PMF-BBOA with levoglucosan measurements and levoglucosan-BBOA apportionment. Using conversions from levoglucosan, $33 \%$ of the $\mathrm{OM}$ is from biomass burning during the overnight periods. This range is slightly higher than the $26 \%$ apportioned via 4 -factor PMF-AMS. Estimates of $\mathrm{K}$-based BBOA are higher, with $44 \%$ of the OM apportioned to BBOA during the 12-h overnight periods with levoglucosan data, and $26 \%$ on all evenings. All but the highest levoglucosan concentration data points fall about the 1:1 line between PMF-BBOA and levoglucosan-BBOA in Figure 6, and on most evenings the PMF and levoglucosan apportionment methods yield a similar result. Apportionment via $\mathrm{K}^{+}$is consistently higher than all other methods. Each of the methods used has underlying uncertainties, in particular the selection of source profiles, since emissions of levoglucosan, $\mathrm{K}^{+}$, and $\mathrm{OM}$ vary by wood type, flaming vs. smoldering etc. Results in Table 1 capture some of this uncertainty, showing that the $\mathrm{K}^{+}$method is the most uncertain compared to levoglucosan and AMS PMF.

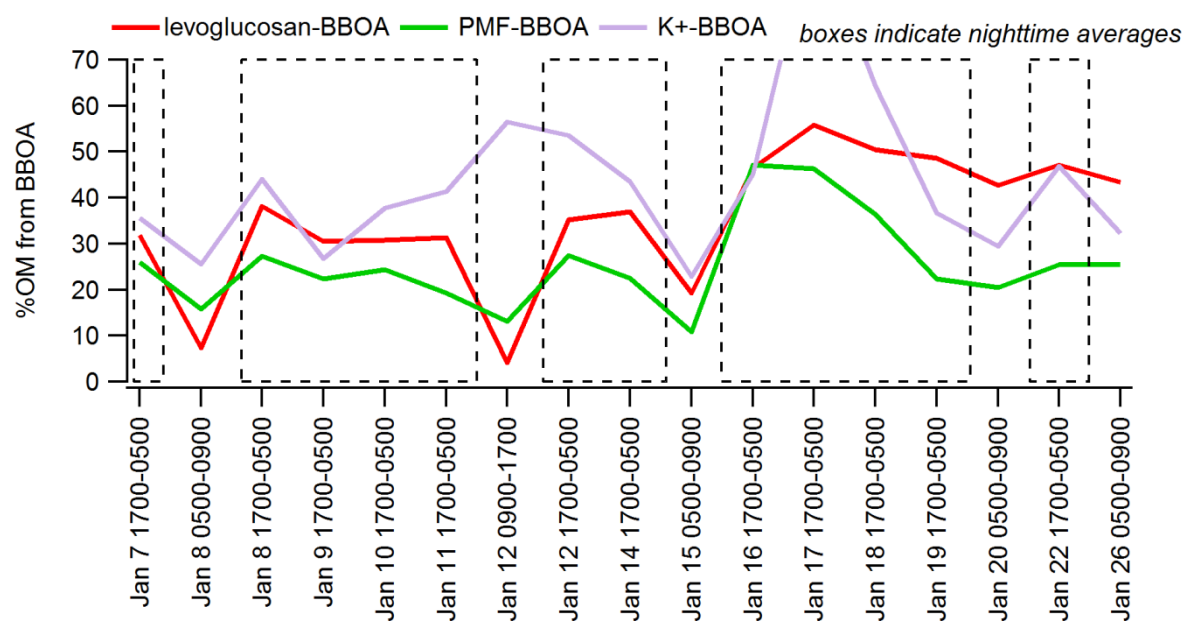

Figure 5. Percentage of OM apportioned by four methods for each time period where levoglucosan was quantified; boxes indicate nighttime averages (1700-0500 LST). Not shown is K-BBOA value of $100 \%$ apportioned OM on 17 January 1700-0500.

One difficulty with comparing 12-h average apportionments via levoglucosan and $\mathrm{K}^{+}$is that they may be lost at different rates by atmospheric processes [28], or emitted at varying rates as burning goes from flaming to smoldering [25]. In addition, as emissions age, gas/particle partitioning of semivolatile material may mean that the relationship of levoglucosan to OM emitted changes over time, as organic material is either condensed into the particle phase or partitioned in the vapor phase [17, 
28,68]. We examined the hourly average ratio and correlation between $\mathrm{K}^{+}$and $\mathrm{C}_{2} \mathrm{H}_{4} \mathrm{O}_{2}{ }^{+}$to understand how the relationship varies during the night (Figure 2). Between 1900 and $2300 \mathrm{LST}$, the ratio $(0.625)$ and correlation $\left(r^{2}=0.80\right)$ between $\mathrm{K}^{+}$ and $\mathrm{C}_{2} \mathrm{H}_{4} \mathrm{O}_{2}{ }^{+}$is consistent, but it degrades after $0000 \mathrm{LST}$, which is likely around the time that emissions have nearly stopped and levoglucosan may be lost via atmospheric reactions.

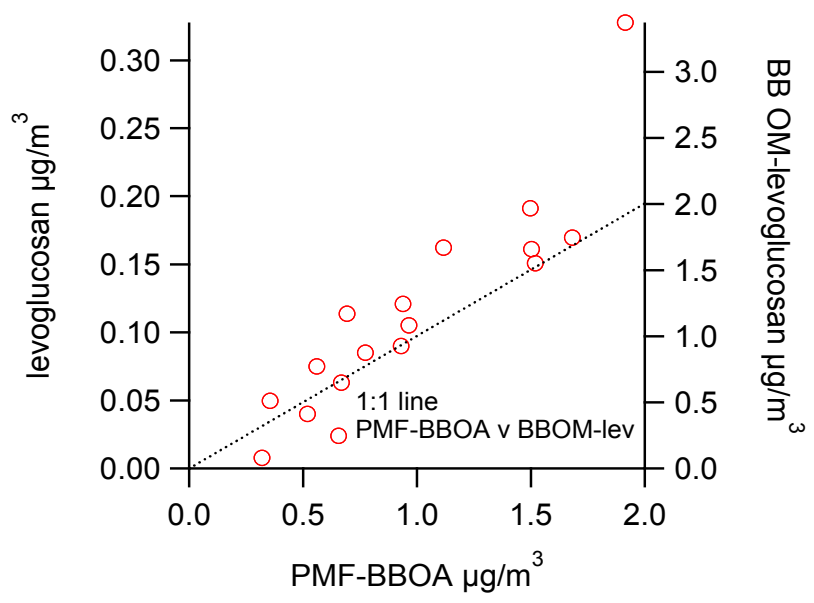

Figure 6. Comparison of PMF-BBOA concentrations vs. levoglucosan (primary $y$-axis) and BB OM by levoglucosan (secondary $y$-axis); all units are $\mu \mathrm{g} / \mathrm{m}^{3}$.

The sample with the highest disagreement between methods was the night of 19 January, when levoglucosan-BBOA and K-BBOA are similar (37\%-39\% of the OM) but are 1.6 times higher than PMF-BBOA. As seen in Figure 1, this was not only the evening of the highest levoglucosan and $\mathrm{C}_{2} \mathrm{H}_{4} \mathrm{O}_{2}{ }^{+}$concentrations but also highest $\mathrm{OM}$. It may be that PMF is under-predicting the amount of $\mathrm{BBOA}$, since the $\mathrm{OM}$ concentration and possibly composition is quickly changing. The $Q / Q_{\text {expected }}$ ratio and scaled residuals from PMF during this evening are low, indicating a good fit, but SV-OOA is also very high during this evening, so it is likely that some mass assigned by PMF as SV-OOA is actually BBOA. Since a constant profile is needed in PMF, differences in the BBOA composition between evenings mean that a "typical" or average profile is found; deviations from this profile suggest that mass appears to be apportioned to SV-OOA. However, as the results are consistent for all the other data points, our conclusion is that the three BBOA methods using levoglucosan and AMS data compare rather well most of the time. As there are other non-biomass burning sources of $\mathrm{K}^{+}$in the area, and the amount of $\mathrm{K}^{+}$emitted depends on the amount of flaming $v s$. smoldering emissions, assuming all the $\mathrm{K}^{+}$is from biomass burning 
yields an upper limit of BBOA that is likely less accurate than the other methods used here.

\section{Conclusions}

Urban-scale biomass burning was found to be a surprising source of aerosol at Fyfe Elementary School in Las Vegas, even though the monitoring site was located next to a major freeway in a city with no tradition of home heating from wood stoves or fireplaces. Multiple methods of estimating the contribution of this source to fine PM were compared; HR-AMS measurements correlated with levoglucosan measurements, and both yielded similar estimates of total biomass burning organic aerosol (BBOA). Water-soluble potassium correlated with AMS $\mathrm{C}_{2} \mathrm{H}_{4} \mathrm{O}_{2}{ }^{+}$only during evening hours, when biomass burning was relatively high; during other hours, there was little correlation, indicating that although $\mathrm{K}^{+}$can be a useful biomass burning indicator when biomass burning is high, other sources tend to overwhelm the $\mathrm{K}^{+}$concentrations during other hours. On average, BBOA comprised $9 \%-14 \%$ of the organic matter (OM), but was only significant during the evening hours, when OM was highest. During the overnight period between 1700 and 0500 LST, BBOA contributed between $26 \%$ and $33 \%$ of the OM (range derived from different analysis/measurement techniques). Thus, residential biomass burning is an unexpected, but relatively important, source of $\mathrm{PM}_{2.5}$ in Las Vegas.

Supplementary Materials: The following are available online at www.mdpi.com/20734433/7/4/58/s1, Figure S1: Diurnal box plot of HR-AMS OM $\left(\mu \mathrm{g} / \mathrm{m}^{3}\right)$; Figure S2: Diurnal box plot of Aethalometer BC $\left(\mu \mathrm{g} / \mathrm{m}^{3}\right)$.

Acknowledgments: Gary Norris and David Olson at EPA's Office of Research and Development provided the chemical analysis of levoglucosan. Funding for the core measurements, including BC and meteorology, as well as for site operations, was provided by Nevada Department of Transportation. Sonoma Technology, Inc. (Petaluma, CA, USA), provided supplemental internal funding for the HR-AMS measurements. Lastly, we appreciate the review and comments from Steven G. Brown's PhD committee on this work, including Sonia Kreidenweis, Colette Heald, and Anthony Marchese.

Author Contributions: Steven Brown, Paul Roberts, and Jeffrey Collett conceived and designed the experiments; Taehyoung Lee and Steven Brown performed the experiments; Steven Brown analyzed the data; Taehyoung Lee contributed analysis tools; Steven Brown wrote the paper.

Conflicts of Interest: The authors declare no conflict of interest. The funding sponsors had no role in the design of the study; in the collection, analyses, or interpretation of the data; in the writing of the manuscript; and in the decision to publish the results.

\section{References}

1. Bergauff, M.A.; Ward, T.J.; Noonan, C.W.; Palmer, C.P. The effect of a woodstove changeout on ambient levels of $\mathrm{PM}_{2.5}$ and chemical tracers for woodsmoke in Libby, Montana. Atmos Environ. 2009, 43, 2938-2943. 
2. Ward, T.; Noonan, C. Results of a residential indoor $\mathrm{PM}_{2.5}$ sampling program before and after a woodstove changeout. Indoor Air 2008, 18, 408-415.

3. Allen, G.A.; Miller, P.J.; Rector, L.J.; Brauer, M.; Su, J.G. Characterization of valley winter woodsmoke concentrations in Northern NY using highly time-resolved measurements. Aerosol Air Qual. Res. 2011, 11, 519-530.

4. Wang, Y.; Hopke, P.K.; Utell, M.J. Urban-scale spatial-temporal variability of black carbon and winter residential wood combustion particles. Aerosol Air Qual. Res. 2011, 11, 473-481.

5. Lighty, J.S.; Veranth, J.M.; Sarofim, A.F. Combustion aerosols: Factors governing their size and composition and implications to human health. J. Air Waste Manag. Assoc. 2000, 50, 1565-1618.

6. Barregard, L.; Sallsten, G.; Andersson, L.; Almstrand, A.-C.; Gustafson, P.; Andersson, M.; Olin, A.-C. Experimental exposure to wood smoke: Effects on airway inflammation and oxidative stress. Occup. Environ. Med. 2007, 65, 319-324.

7. Freeman, L.; Stiefer, P.S.; Weir, B.R. Carcinogenic Risk and Residential Wood Smoke; Systems Applications International: San Rafael, CA, USA, 1992.

8. Seagrave, J.; McDonald, J.D.; Bedrick, E.; Edgerton, E.S.; Gigliotti, A.P.; Jansen, J.J.; Ke, L.; Naeher, L.P.; Seilkop, S.K.; Zheng, M.; et al. Lung toxicity of ambient particulate matter from southeastern U.S. sites with different contributing sources: Relationships between composition and effects. Environ. Health Perspect. 2006, 114, 1387-1393.

9. Travis, C.C.; Etnier, E.L.; Meyer, H.R. Health risks of residential wood heat. Environ. Manag. 1985, 9, 209-215.

10. Naeher, L.P.; Brauer, M.; Lipsett, M.; Zelikoff, J.T.; Simpson, C.D.; Koenig, J.Q.; Smith, K.R. Woodsmoke health effects: A review. Inhal. Toxicol. 2007, 19, 67-106.

11. Fine, P.M.; Cass, G.R.; Simoneit, B.R.T. Chemical characterization of fine particle emissions from the fireplace combustion of wood types grown in the Midwestern and Western United States. Environ. Eng. Sci. 2004, 21, 387-409.

12. Simoneit, B.R.T.; Schauer, J.J.; Nolte, C.G.; Oros, D.R.; Elias, V.O.; Fraser, M.P.; Rogge, W.F.; Cass, G.R. Levoglucosan, a tracer for cellulose in biomass burning and atmospheric particles. Atmos. Environ. 1999, 33, 173-182.

13. Simoneit, B.R.T. Biomass burning-A review of organic tracers for smoke from incomplete combustion. Appl. Geochem. 2002, 17, 129-162.

14. Engling, G.; Herckes, P.; Kreidenweis, S.M.; Malm, W.C.; Collett, J.L. Composition of the fine organic aerosol in Yosemite National Park during the 2002 Yosemite Aerosol Characterization Study. Atmos. Environ. 2006, 40, 2959-2972.

15. Schauer, J.J.; Kleeman, M.J.; Cass, G.R.; Simoneit, B.R.T. Measurement of emissions from air pollution sources. 3. $\mathrm{C}_{1}$ through $\mathrm{C}_{29}$ organic compounds from fireplace combustion of wood. Environ. Sci. Technol. 2001, 35, 1716-1728. 
16. Sullivan, A.P.; Holden, A.S.; Patterson, L.A.; McMeeking, G.R.; Kreidenweis, S.M.; Malm, W.C.; Hao, W.M.; Wold, C.E.; Collett, J.L., Jr. A method for smoke marker measurements and its potential application for determining the contribution of biomass burning from wildfires and prescribed fires to ambient $\mathrm{PM}_{2.5}$ organic carbon. J. Geophys. Res. 2008.

17. Hennigan, C.J.; Miracolo, M.A.; Engelhart, G.J.; May, A.A.; Presto, A.A.; Lee, T.; Sullivan, A.P.; McMeeking, G.R.; Coe, H.; Wold, C.E.; et al. Chemical and physical transformations of organic aerosol from the photo-oxidation of open biomass burning emissions in an environmental chamber. Atmos. Chem. Phys. 2011, 11, 7669-7686.

18. Hoffmann, D.; Tilgner, A.; Iinuma, Y.; Herrmann, H. Atmospheric stability of levoglucosan: A detailed laboratory and modeling study. Environ. Sci. Technol. 2010, 44, 694-699.

19. Slade, J.H.; Knopf, D.A. Multiphase $\mathrm{OH}$ oxidation kinetics of organic aerosol: The role of particle phase state and relative humidity. Geophys. Res. Lett. 2014, 41, 5297-5306.

20. Kessler, S.H.; Smith, J.D.; Che, D.L.; Worsnop, D.R.; Wilson, K.R.; Kroll, J.H. Chemical sinks of organic aerosol: Kinetics and products of the heterogeneous oxidation of erythritol and levoglucosan. Environ. Sci. Technol. 2010, 44, 7005-7010.

21. Slade, J.H.; Knopf, D.A. Heterogeneous OH oxidation of biomass burning organic aerosol surrogate compounds: Assessment of volatilisation products and the role of $\mathrm{OH}$ concentration on the reactive uptake kinetics. Phys. Chem. Chem. Phys. 2013, 15, 5898-5915.

22. Alfarra, M.R.; Prévôt, A.S.H.; Szidat, S.; Sandradewi, J.; Weimer, S.; Lanz, V.A.; Schreiber, D.; Mohr, M.; Baltensperger, U. Identification of the mass spectral signature of organic aerosols from wood burning emissions. Environ. Sci. Technol. 2007, 41, 5770-5777.

23. Weimer, S.; Alfarra, M.R.; Schreiber, D.; Mohr, M.; Prévôt, A.S.H.; Baltensperger, U. Organic aerosol mass spectral signatures from wood-burning emissions: Influence of burning conditions and wood type. J. Geophys. Res. Atmos. 2008.

24. Schneider, J.; Weimer, S.; Drewnick, F.; Borrmann, S.; Helas, G.; Gwaze, P.; Schmid, O.; Andreae, M.O.; Kirchner, U. Mass spectrometric analysis and aerodynamic properties of various types of combustion-related aerosol particles. Int. J. Mass Spec. 2006, 258, 37-49.

25. Lee, T.; Sullivan, A.P.; Mack, L.; Jimenez, J.L.; Kreidenweis, S.M.; Onasch, T.B.; Worsnop, D.R.; Malm, W.; Wold, C.E.; Hao, W.M.; et al. Chemical smoke marker emissions during flaming and smoldering phases of laboratory open burning of wildland fuels. Aerosol Sci. Technol. 2010.

26. Mohr, C.; Huffman, J.A.; Cubison, M.; Aiken, A.C.; Docherty, K.S.; Kimmel, J.R.; Ulbrich, I.M.; Hannigan, M.; Jimenez, J.L. Characterization of primary organic aerosol emissions from meat cooking, trash burning, and motor vehicles with high-resolution aerosol mass spectrometry and comparison with ambient and chamber observations. Environ. Sci. Technol. 2009, 43, 2443-2449. 
27. Takegawa, N.; Miyakawa, T.; Kawamura, K.; Kondo, Y. Contribution of selected dicarboxylic and omega-oxocarboxylic acids in ambient aerosol to the $m / z 44$ signal of an aerodyne aerosol mass spectrometer. Aerosol Sci. Technol. 2007, 41, 418-437.

28. Cubison, M.J.; Ortega, A.M.; Hayes, P.L.; Farmer, D.K.; Day, D.; Lechner, M.J.; Brune, W.H.; Apel, E.; Diskin, G.S.; Fisher, J.A.; et al. Effects of aging on organic aerosol from open biomass burning smoke in aircraft and laboratory studies. Atmos. Chem. Phys. 2011, 11, 12049-12064.

29. Minguillon, M.C.; Perron, N.; Querol, X.; Szidat, S.; Fahrni, S.M.; Alastuey, A.; Jimenez, J.L.; Mohr, C.; Ortega, A.M.; Day, D.A.; et al. Fossil versus contemporary sources of fine elemental and organic carbonaceous particulate matter during the DAURE campaign in Northeast Spain. Atmos. Chem. Phys. 2011, 11, 12067-12084.

30. Kim, E.; Larson, T.V.; Hopke, P.K.; Slaughter, C.; Sheppard, L.E.; Claiborn, C. Source identification of $\mathrm{PM}_{2.5}$ in an arid northwest U.S. city by positive matrix factorization. Atmos. Res. 2003, 66, 291-305.

31. Poirot, R. Tracers of Opportunity: Potassium. Available online: http://capita. wustl.edu/PMFine/ Workgroup/SourceAttribution/Reports/In-progress/potass/ Kcover.htm (accessed on 12 April 2016).

32. Liu, W.; Wang, Y.; Russell, A.; Edgerton, E.S. Atmospheric aerosol over two urban-rural pairs in the southeastern United States: Chemical composition and possible sources. Atmos. Environ. 2005, 39, 4453-4470.

33. Brown, S.G.; Frankel, A.; Raffuse, S.M.; Roberts, P.T.; Hafner, H.R.; Anderson, D.J. Source apportionment of fine particulate matter in Phoenix, Arizona, using positive matrix factorization. J. Air Waste Manag. Assoc. 2007, 57, 741-752.

34. Aiken, A.C.; de Foy, B.; Wiedinmyer, C.; DeCarlo, P.F.; Ulbrich, I.M.; Wehrli, M.N.; Szidat, S.; Prévôt, A.S.H.; Noda, J.; Wacker, L.; et al. Mexico City aerosol analysis during MILAGRO using high resolution aerosol mass spectrometry at the urban supersite (T0). Part 2: Analysis of the biomass burning contribution and the non-fossil carbon fraction. Atmos. Chem. Phys. 2010, 10, 5315-5341.

35. Zhang, X.; Hecobian, A.; Zheng, M.; Frank, N.H.; Weber, R.J. Biomass burning impact on $\mathrm{PM}_{2.5}$ over the southeastern US during 2007: Integrating chemically speciated FRM filter measurements, MODIS fire counts and PMF analysis. Atmos. Chem. Phys. 2010, 10, 6839-6853.

36. Schauer, J.J.; Kleeman, M.J.; Cass, G.R.; Simoneit, B.R.T. Measurement of emissions from air pollution sources. $1 . \mathrm{C}_{1}$ through $\mathrm{C}_{29}$ organic compounds from meat charbroiling. Environ. Sci. Technol. 1999, 33, 1566-1577.

37. Fine, P.M.; Cass, G.R.; Simoneit, B.R.T. Chemical characterization of fine particle emissions from the fireplace combustion of woods grown in the southern United States. Environ. Sci. Technol. 2002, 36, 1442-1451.

38. Fine, P.M.; Cass, G.R.; Simoneit, B.R.T. Organic compounds in biomass smoke from residential wood combustion: Emissions characterization at a continental scale. J. Geophys. Res. Atmos. 2002. 
39. Fine, P.M.; Cass, G.R.; Simoneit, B.R.T. Chemical characterization of fine particle emissions from fireplace combustion of woods grown in the northeastern United States. Environ. Sci. Technol. 2001, 35, 2665-2675.

40. Allen, G.A.; Lawrence, J.; Koutrakis, P. Field validation of a semi-continuous method for aerosol black carbon (Aethalometer) and termporal patterns of summertime hourly black carbon measurements in Southwestern Pennsylvania. Atmos. Environ. 1999, 33, 817-823.

41. Sandradewi, J.; Prévôt, A.S.H.; Weingartner, E.; Schmidhauser, R.; Gysel, M.; Baltensperger, U. A study of wood burning and traffic aerosols in an Alpine valley using a multi-wavelength Aethalometer. Atmos. Environ. 2008, 42, 101-112.

42. Harrison, R.M.; Beddowsa, D.C.S.; Jones, A.M.; Calvo, A.; Alves, C.; Pio, C. An evaluation of some issues regarding the use of aethalometers to measure woodsmoke concentrations. Atmos. Environ. 2013, 80, 540-548.

43. Sandradewi, J.; Prévôt, A.S.H.; Alfarra, M.R.; Szidat, S.; Wehrli, M.N.; Ruff, M.; Weimer, S.; Lanz, V.A.; Weingartner, E.; Perron, N.; et al. Comparison of several wood smoke markers and source apportionment methods for wood burning particulate mass. Atmos. Chem. Phys. Discuss. 2008, 8, 8091-8118.

44. Favez, O.; El Haddad, I.; Piot, C.; Boréave, A.; Abidi, E.; Marchand, N.; Jaffrezo, J.-L.; Besombes, J.-L.; Personnaz, M.-B.; Sciare, J.; et al. Inter-comparison of source apportionment models for the estimation of wood burning aerosols during wintertime in an Alpine city (Grenoble, France). Atmos. Chem. Phys. 2010, 10, 5295-5314.

45. Green, M.C.; Chow, J.C.; Hecobian, A.; Etyemezian, V.; Kuhns, H.; Watson, J.G. Las Vegas Valley Visibility and PM 2.5 Study; Final Report Prepared for the Clark County Department of Air Quality Management, Las Vegas, NV; Desert Research Institute: Las Vegas, NV, USA, 2002.

46. Watson, J.G.; Barber, P.W.; Chang, M.C.O.; Chow, J.C.; Etyemezian, V.R.; Green, M.C.; Keislar, R.E.; Kuhns, H.D.; Mazzoleni, C.; Moosmüller, H.; et al. Southern Nevada Air Quality Study; Final Report Prepared for the U.S. Department of Transportation, Washington, DC; Desert Research Institute: Reno, NV, USA, 2007.

47. Brown, S.G.; Lee, T.; Norris, G.A.; Roberts, P.T.; Collett, J.L., Jr.; Paatero, P.; Worsnop, D.R. Receptor modeling of near-roadway aerosol mass spectrometer data in Las Vegas, Nevada, with EPA PMF. Atmos. Chem. Phys. 2012, 12, 309-325.

48. Brown, S.G.; McCarthy, M.C.; DeWinter, J.L.; Vaughn, D.L.; Roberts, P.T. Changes in air quality at near-roadway schools after a major freeway expansion in Las Vegas, Nevada. J. Air Waste Manag. Assoc. 2014, 64, 1002-1012.

49. DeCarlo, P.; Kimmel, J.R.; Trimborn, A.; Northway, M.; Jayne, J.T.; Aiken, A.C.; Gonin, M.; Fuhrer, K.; Horvath, T.; Docherty, K.S.; et al. Field-deployable, high-resolution, time-of-flight aerosol mass spectrometer. Anal. Chem. 2006, 78, 8281-8289.

50. Jimenez, J.L.; Jayne, J.T.; Shi, Q.; Kolb, C.E.; Worsnop, D.R.; Yourshaw, I.; Seinfeld, J.H.; Flagan, R.C.; Zhang, X.F.; Smith, K.A.; et al. Ambient aerosol sampling using the Aerodyne Aerosol Mass Spectrometer. J. Geophys. Res. Atmos. 2003. 
51. Zhang, Q.; Jimenez, J.L.; Canagaratna, M.R.; Ulbrich, I.M.; Ng, N.L.; Worsnop, D.R.; Sun, Y. Understanding atmospheric organic aerosols via factor analysis of aerosol mass spectrometry: A review. Anal. Bioanal. Chem. 2011, 401, 3045-3067.

52. Sun, Y.; Zhang, Q.; MacDonald, A.M.; Hayden, K.; Li, S.M.; Liggio, J.; Liu, P.S.K.; Anlauf, K.G.; Leaitch, W.R.; Steffen, A.; et al. Size-resolved aerosol chemistry on Whistler Mountain, Canada with a high-resolution aerosol mass spectrometer during INTEX-B. Atmos. Chem. Phys. 2009, 9, 3095-3111.

53. Canagaratna, M.R.; Jayne, J.T.; Jimenez, J.L.; Allan, J.D.; Alfarra, M.R.; Zhang, Q.; Onasch, T.B.; Drewnick, F.; Coe, H.; Middlebrook, A.; et al. Chemical and microphysical characterization of ambient aerosols with the aerodyne aerosol mass spectrometer. Mass Spectrom. Rev. 2007, 26, 185-222.

54. Drewnick, F.; Hings, S.S.; Alfarra, M.R.; Prevot, A.S.H.; Borrmann, S. Aerosol quantification with the Aerodyne Aerosol Mass Spectrometer: Detection limits and ionizer background effects. Atmos. Measure. Tech. 2009, 2, 33-46.

55. Olson, D.A.; Vedantham, R.; Norris, G.A.; Brown, S.G.; Roberts, P. Determining source impacts near roadways using wind regression and organic source markers. Atmos. Environ. 2012, 47, 261-268.

56. Orsini, D.A.; Ma, Y.L.; Sullivan, A.; Sierau, B.; Baumann, K.; Weber, R.J. Refinements to the particle-into-liquid sampler (PILS) for ground and airborne measurements of water soluble aerosol composition. Atmos. Environ. 2003, 37, 1243-1259.

57. Weber, R.J.; Orsini, D.; Daun, Y.; Lee, Y.N.; Klotz, P.J.; Brechtel, F. A particle-into-liquid collector for rapid measurement of aerosol bulk chemical composition. Aerosol Sci. Technol. 2001, 35, 718-727.

58. Weber, R.; Orsini, D.; Duan, Y.; Baumann, K.; Kiang, C.S.; Chameides, W.; Lee, Y.N.; Brechtel, F.; Klotz, P.; Jongejan, P.; et al. Intercomparison of near real time monitors of $\mathrm{PM}_{2.5}$ nitrate and sulfate at the U.S. Environmental Protection Agency Atlanta Supersite. J. Geophys. Res. Atmos. 2003.

59. Sorooshian, A.; Brechtel, F.J.; Ma, Y.L.; Weber, R.J.; Corless, A.; Flagan, R.C.; Seinfeld, J.H. Modeling and characterization of a particle-into-liquid sampler (PILS). Aerosol Sci. Technol. 2006, 40, 396-409.

60. Lee, T.; Yu, X.-Y.; Kreidenweis, S.M.; Malm, W.C.; Collett, J.L. Semi-continuous measurement of $\mathrm{PM}_{2.5}$ ionic composition at several rural locations in the United States. Atmos. Environ. 2008, 42, 6655-6669.

61. Norris, G.; Duvall, R.; Brown, S.; Bai, S. EPA Positive Matrix Factorization (PMF) 5.0 Fundamentals and User Guide; Prepared for the U.S. Environmental Protection Agency Office of Research and Development: Washington, DC, USA, 2014.

62. Brown, S.G.; Eberly, S.; Paatero, P.; Norris, G.A. Methods for estimating uncertainty in PMF solutions: Examples with ambient air and water quality data and guidance on reporting PMF results. Sci. Total Environ. 2015, 518, 626-635.

63. Ulbrich, I.M.; Canagaratna, M.R.; Zhang, Q.; Worsnop, D.R.; Jimenez, J.L. Interpretation of organic components from Positive Matrix Factorization of aerosol mass spectrometric data. Atmos. Chem. Phys. 2009, 9, 2891-2918. 
64. Lanz, V.A.; Alfarra, M.R.; Baltensperger, U.; Buchmann, B.; Hueglin, C.; Prévôt, A.S.H. Source apportionment of submicron organic aerosols at an urban site by factor analytical modelling of aerosol mass spectra. Atmos. Chem. Phys. 2007, 7, 1503-1522.

65. Puxbaum, H.; Caseiro, A.; Sanchez-Ochoa, A.; Kasper-Giebl, A.; Claeys, M.; Gelencser, A.; Legrand, M.; Preunkert, S.; Pio, C. Levoglucosan levels at background sites in Europe for assessing the impact of biomass combustion on the European aerosol background. J. Geophys. Res. 2007.

66. Schmidl, C.; Marr, I.L.; Caseiro, A.; Kotianova, P.; Berner, A.; Bauer, H.; Kasper-Giebl, A.; Puxbaum, H. Chemical characterisation of fine particle emissions from wood stove combustion of common woods growing in mid-European Alpine regions. Atmos. Environ. 2008, 42, 126-141.

67. Brown, S.G.; Lee, T.; Roberts, P.T.; Collett, J.L., Jr. Variations in the OM/OC ratio of urban organic aerosol next to a major roadway. J. Air Waste Manag. Assoc. 2013, 63, 1422-1433.

68. Oja, V.; Suuberg, E.M. Vapor pressures and enthalpies of sublimation of D-glucose, D-xylose, cellobiose, and levoglucosan. J. Chem. Eng. Data 1999, 44, $26-29$. 


\title{
Detailed Source-Specific Molecular Composition of Ambient Aerosol Organic Matter Using Ultrahigh Resolution Mass Spectrometry and ${ }^{1} \mathrm{H}$ NMR
}

\author{
Amanda S. Willoughby, Andrew S. Wozniak and Patrick G. Hatcher
}

\begin{abstract}
Organic aerosols (OA) are universally regarded as an important component of the atmosphere that have far-ranging impacts on climate forcing and human health. Many of these impacts are related to OA molecular characteristics. Despite the acknowledged importance, current uncertainties related to the source apportionment of molecular properties and environmental impacts make it difficult to confidently predict the net impacts of OA. Here we evaluate the specific molecular compounds as well as bulk structural properties of total suspended particulates in ambient OA collected from key emission sources (marine, biomass burning, and urban) using ultrahigh resolution mass spectrometry (UHR-MS) and proton nuclear magnetic resonance spectroscopy $\left({ }^{1} \mathrm{H}\right.$ NMR). UHR-MS and ${ }^{1} \mathrm{H}$ NMR show that OA within each source is structurally diverse, and the molecular characteristics are described in detail. Principal component analysis (PCA) revealed that (1) aromatic nitrogen species are distinguishing components for these biomass burning aerosols; (2) these urban aerosols are distinguished by having formulas with high $\mathrm{O} / \mathrm{C}$ ratios and lesser aromatic and condensed aromatic formulas; and (3) these marine aerosols are distinguished by lipid-like compounds of likely marine biological origin. This study provides a unique qualitative approach for enhancing the chemical characterization of OA necessary for molecular source apportionment.
\end{abstract}

Reprinted from Atmosphere. Cite as: Willoughby, A.S.; Wozniak, A.S.; Hatcher, P.G. Detailed Source-Specific Molecular Composition of Ambient Aerosol Organic Matter Using Ultrahigh Resolution Mass Spectrometry and ${ }^{1} \mathrm{H}$ NMR. Atmosphere 2016, 7, 79.

\section{Introduction}

Organic matter (OM) comprises a significant portion of total aerosol mass, as much as $90 \%$ in certain areas [1,2], and is generated by a number of anthropogenic and biogenic emission sources. Organic aerosol (OA) compounds, once emitted into the atmosphere as primary OA or formed in situ as secondary OA (SOA) from gas-phase precursors, can undergo a myriad of atmospheric reactions forming new compounds that have different chemical structures and associated physical properties. The immense complexity of OA contributes to the difficulty in 
understanding the net impacts OA has on human health, biogeochemical cycling, and net radiative forcing.

The composition and relative concentrations of OA are expected to vary spatially and temporally due to differences in emission inputs and in the extent to which OA are transformed in the atmosphere by secondary aging processes [1]. The molecular composition of OA resulting from these emissions and aging processes will, in part, determine its impacts on e.g., aerosol hygroscopicity [3,4], light absorption [5], and biogeochemical cycling upon deposition [6,7]. The ability to apportion molecular compositions and impacts to specific aerosol emission sources and aging processes is therefore an important goal of the atmospheric community. Many studies have addressed similarities and differences of OA molecular composition among various aerosol sources, as well as seasonal and diurnal variability [6,8-12], but considerable work remains for a full understanding of this complex problem.

Fortunately, the adoption of new powerful analytical techniques such as nuclear magnetic resonance spectroscopy (NMR) and ultrahigh resolution mass spectrometry (UHR-MS) have enabled the characterization of important OA molecular and structural details. Solution-state proton NMR ( ${ }^{1} \mathrm{H}$ NMR) enables the characterization of soluble extracts of OA without extensive sample preparation and has been thoroughly reviewed $[13,14]$. A ${ }^{1} \mathrm{H}$ NMR spectrum can be analyzed to determine the relative contributions of major proton groups (e.g., alkyl protons) within OA, and also to identify specific compounds such as acetate, methanesulfonic acid, and levoglucosan that feature as sharp peaks in a spectrum [6,15-18]. Where NMR succeeds in providing these general structural details, it is unable to provide specific molecular details due to the overlapping signals from hydrogens associated with atmospherically relevant functional groups, and spectral interpretations must be simplified.

Pairing NMR with UHR-MS, which provides detailed molecular composition but only limited structural information, is therefore an attractive approach. UHR-MS, particularly Fourier transform ion cyclotron resonance mass spectrometry (FTICR-MS), allows for the determination of molecular formulas for thousands of high-molecular weight (>200 Da) compounds present within a single sample providing important chemical properties of OA. Its ultrahigh resolution $(\sim 500,000$ over $m / z$ 200-800) and mass accuracy (<1 ppm) can be used to obtain vital fingerprints, in the form of specific related molecular compound classes, that may be diagnostic for OA from specific emission sources and/or that have undergone molecular transformations. Numerous studies have used UHR-MS to reveal the molecular details of atmospheric OM [17,19-33]. UHR-MS techniques are generally regarded as non-quantitative, and structure can only be inferred from the molecular formula information, but when used in tandem with NMR extensive molecular and structural information can be achieved with minimal sample preparation. Such a 
pairing can provide fingerprints for the qualitative apportionment of OA molecular features that determine OA impact in the atmosphere and depositional environments.

The work presented here pairs these two powerful techniques (UHR-MS and ${ }^{1} \mathrm{H}$ NMR) to provide source-specific molecular characteristics for ambient aerosol samples from key anthropogenic and biogenic emission sources that can be used to aid more traditional source apportionment studies. The emission sources chosen here (marine, mixed source, biomass burning, urban) have significant regional and global quantitative importance on atmospheric aerosol loadings. Water-soluble and pyridine-soluble extracts for multiple samples from each source were evaluated for molecular characteristics using FTICR-MS and ${ }^{1} \mathrm{H}$ NMR. Compositional differences were elucidated using the chemometric approach, principal component analysis (PCA), to identify characteristic molecular features for each source type. Though qualitative in nature, this study sheds light on the sources of OA present in the ambient atmosphere and will be valuable for assessing the source-specific environmental impacts of OA as relationships between molecular characteristics and environmental impacts are strengthened.

\section{Experiments}

\subsection{Aerosol Sample Collection}

Ambient aerosol total suspended particulates (TSP, $n=14$ ) were collected from four different locations to represent different emission source types. Air was drawn through pre-combusted $\left(4 \mathrm{~h}, 475^{\circ} \mathrm{C}\right)$ quartz microfiber filters (Whatman QM/A, $20.3 \times 25.4 \mathrm{~cm}, 419 \mathrm{~cm}^{2}$ exposed area, $0.6 \mu \mathrm{m}$ effective pore size) using a TSP high-volume air sampler (model GS2310, Thermo Andersen, Smyrna, GA, USA) at flow rates ranging between 0.7 and $0.9 \mathrm{~m}^{3} \cdot \mathrm{min}^{-1}$. Air particles were collected for 8-29 $\mathrm{h}$ with total air volumes ranging between 410 and $1170 \mathrm{~m}^{3}$. The filters were transferred to combusted foil pouches immediately after collection and stored at $8{ }^{\circ} \mathrm{C}$ until analysis. Exact sampling dates and locations can be found in the supplemental methods. Briefly, marine TSP $(n=4)$ were collected aboard the R/V Knorr (Woods Hole, MA, USA) as part of the 2011 US GEOTRACES program cruise (GA03) [34] and as part of the 2014 second Western Atlantic Climate Study [35]. The US GEOTRACES samples $(n=3)$ are a subset of samples described in Wozniak et al. [7,31] where their WSOM FTICR-MS (negative ionization) and ${ }^{1} \mathrm{H}$ NMR characteristics were described. Mixed source TSP samples $(n=3)$ were collected at sea level at the Virginia Institute of Marine Science in Gloucester Point, Virginia, USA. Data for these mixed source samples are also presented in Willoughby et al. [30], a study demonstrating the utility of pyridine as a method for extracting and analyzing water-insoluble aerosol OM. Biomass burning TSP samples $(n=2)$ were collected at sea level in Suffolk, VA downwind of heavy smoke pollution from a fire burning at the Great Dismal 
Swamp. Urban TSP samples $(n=5)$ were collected $\sim 60 \mathrm{~m}$ above sea level on the roof of an academic building at Drexel University in downtown Philadelphia, PA, USA. A storage or field blank filter was analyzed for each respective aerosol sample.

\subsection{Aerosol Mass and Carbon Measurements}

The QM / A filters were weighed before and after sampling to determine the TSP mass loadings (Table 1). A portion of each aerosol filter was analyzed in triplicate for total carbon (TC) using a FlashEA 1112 elemental analyzer (Thermo Scientific, Waltham, Massachusetts, USA). Black carbon (BC) amounts were determined using the chemothermal oxidation at $375{ }^{\circ} \mathrm{C}$ method (CTO-375) [36] and measured on the same elemental analyzer. Solvent extracts of the aerosols and respective filter blanks were obtained by combining aerosol filter plugs of known OC masses with ultrapure water (Millipore Synergy Ultrapure Water System, Darmstadt, Germany) or pyridine (Sigma-Aldrich, St. Louis, Missouri, USA, $\geqslant 99.9 \%$ ), and insoluble particles were removed using a syringe with a $0.45 \mu \mathrm{m}$ PTFE filter cartridge. Percent water-soluble organic carbon (WSOC) for each water filtrate was determined by evaluating the non-purgeable organic carbon using a Shimadzu (Kyoto, Japan) TOC-VCPH analyzer. The pyridine-soluble organic carbon percentage (\%PSOC) was determined by dissolving each of the aerosol samples into pyridine- $\mathrm{D}_{5}$ and comparing spectral signals determined by ${ }^{1} \mathrm{H}$ NMR to that of a glucose standard [30]. These methods are described in greater detail in the supplementary methods. Due to limited sample availability, the marine aerosols were only measured for TC and WSOC.

Table 1. Average total suspended particulates (TSP) and total carbon (TC) concentrations and carbon percentages (relative to TC) for each aerosol source type.

\begin{tabular}{|c|c|c|c|c|c|c|}
\hline Aerosol Source & $n$ & $\begin{array}{c}\text { TSP } \\
\left(\mu \mathrm{g} \cdot \mathrm{m}^{-3}\right)\end{array}$ & $\begin{array}{c}\mathrm{TC} \\
\left(\mu \mathrm{g} \cdot \mathrm{m}^{-3}\right)\end{array}$ & $\% \mathrm{BC}$ & \%WSOC & \%PSOC \\
\hline * Marine & 4 & - & $0.5 \pm 0.7$ & - & $39.6 \pm 25.1$ & - \\
\hline $\begin{array}{l}\text { Biomass } \\
\text { burning }\end{array}$ & 2 & $73.2 \pm 5.3$ & $24.8 \pm 4.4$ & $6.5 \pm 0.7$ & $33.6 \pm 2.6$ & $66 \pm 20$ \\
\hline Urban & 5 & $47.1 \pm 11.0$ & $6.3 \pm 1.3$ & $3.4 \pm 3.2$ & $40.8 \pm 5.5$ & $44 \pm 6$ \\
\hline Mixed source & 3 & $24.1 \pm 2.9$ & $5.7 \pm 0.7$ & $1.9 \pm 2.5$ & $50.5 \pm 10.6$ & $45 \pm 13$ \\
\hline
\end{tabular}

* Some parameters for the marine aerosols could not be evaluated due to limited sample availability.

\subsection{FTICR-MS Analysis}

For FTICR-MS analyses, the water extracts were desalted using an established procedure for Agilent PPL solid-phase extraction cartridges [37]. The desalted sample was eluted in methanol (Acros Organics, Geel, Belgium, 99.9\%), and will be referred to as $\mathrm{WSOM}_{\mathrm{PPL}}$ to differentiate it from WSOM. All WSOMPPL samples were 
analyzed in both positive and negative electrospray ionization (ESI) mode (WSOM+ and WSOM-, respectively), and PSOM samples were analyzed in negative mode (PSOM-) only due to poor signal observed in the positive mode. A respective field blank extract was prepared identically and analyzed immediately prior to each of the sample extracts to obtain a representative experimental blank spectrum. Each of the samples was analyzed on a Bruker Daltonics (Bremen, Germany) 12 Tesla Apex Qe FTICR-MS with an Apollo II ESI source housed at the College of Sciences Major Instrumentation Cluster at Old Dominion University. Samples were infused to the ESI source at $120 \mathrm{~nL} \cdot \mathrm{min}^{-1}$, and spray voltages were optimized for each sample. Ions were accumulated in the hexapole for $0.5-2.0 \mathrm{~s}$ before transfer into the ICR cell, where exactly 300 transients were co-added. The instrument was externally calibrated daily using a polyethylene glycol standard. Each spectrum was internally calibrated using the naturally occurring molecules including fatty acids and other homologous series of compounds containing only carbon, hydrogen and oxygen [38]. Peaks consistent with salts (mass defect $0.4-0.98$ for $m / z<400$, and mass defect $0.6-0.97$ for $m / z>400$ ), blank peaks (those found in the respective filter blank), and ${ }^{13} \mathrm{C}$ isotopologue peaks were subtracted from the mass list and not considered for formula assignments.

\subsection{Molecular Formula Assignments}

A unique molecular formula was assigned to a majority $(82 \% \pm 9 \%)$ of the measured peaks having a $S / N$ ratio of at least 3 using an in-house generated MatLab (The MathWorks Inc., Natick, MA, USA) code according to the criteria ${ }^{12} \mathrm{C}_{5-80}{ }^{1} \mathrm{H}_{5-200}{ }^{16} \mathrm{O}_{1-30}{ }^{14} \mathrm{~N}_{0-5}{ }^{32} \mathrm{~S}_{0-2}{ }^{34} \mathrm{P}_{0-2}$ for negative ESI and ${ }^{12} \mathrm{C}_{5-80}$ ${ }^{1} \mathrm{H}_{5-200}{ }^{16} \mathrm{O}_{1-30}{ }^{14} \mathrm{~N}_{0-5}{ }^{32} \mathrm{~S}_{0-2}{ }^{23} \mathrm{Na}_{0-1}$ for positive ESI, where the subscripts indicate the range of atoms allowed in a single formula. The assigned formulas were screened to remove any chemically unreasonable formulas for natural OM molecules according to previously published criteria (e.g., studies by Stubbins et al. [39] and Wozniak et al. [20]), and Kendrick mass defect homologous series $\left(\mathrm{CH}_{2}, \mathrm{H}_{2}\right.$, and $\mathrm{CO}_{2}$ ) were used to verify ambiguous assignments. Each of the assigned formulas has a calculated mass within 1 ppm agreement with the measured $m / z$, where a large majority of the formulas $(88 \% \pm 7 \%)$ have less than 0.5 ppm error.

\section{5. ${ }^{1}$ H NMR Spectroscopy}

Each WSOM extract was diluted immediately before ${ }^{1} \mathrm{H}$ NMR analysis using $\mathrm{D}_{2} \mathrm{O}\left(100 \%\right.$ atom $\mathrm{D}$, Acros Organics) at a ratio of 90:10 WSOM: $\mathrm{D}_{2} \mathrm{O}$. The deuterated WSOM solutions were analyzed via ${ }^{1} \mathrm{H}$ NMR spectroscopy using a Bruker Daltonics $400 \mathrm{MHz}$ NMR with a BBI probe. Each sample was scanned 4000 (mixed source, biomass burning, and urban WSOM) or 8000 times (marine WSOM) using a standard Bruker water-suppression pulse program, where the $90^{\circ}$ pulse and the transmitter offset were optimized individually for each sample. The signals obtained from 
${ }^{1} \mathrm{H}$ NMR spectra were integrated over the entire spectral range to obtain the total signal response, and were also integrated over four specific chemical shift ranges to determine contributions from major proton types $[16,18]$. The signal response was normalized to the total signal in these regions (i.e., total signal $=$ Area $_{0.6-4.4} \mathrm{ppm}+$ Area $6.0-9.0 \mathrm{ppm}$ ) to determine the average relative contributions for each region. The regions are defined based on the chemical environment of protons exhibiting signal at those chemical shifts: (1) aliphatic hydrogen (H-C, 0.6-1.8 ppm); (2) unsaturated alkyl hydrogen (H-C-C $=, 1.8-3.2 \mathrm{ppm}$ ); (3) oxygenated aliphatic hydrogen (H-C-O, 3.2-4.4 ppm), and aromatic hydrogen (Ar- $\mathrm{H}, 6.0-9.0 \mathrm{ppm})$. Aldehyde and carboxylic acid hydrogen $(\mathrm{H}-\mathrm{C}=\mathrm{O}$, and $\mathrm{HO}-\mathrm{C}=\mathrm{O})$ would appear downfield of the aromatic protons (i.e., $>9 \mathrm{ppm}$ ), but were not detected because these protons readily exchange with the deuterium in the $\mathrm{D}_{2} \mathrm{O}$ required for analysis.

\subsection{Principal Component Analysis}

Principal component analysis was applied separately to the molecular formulas assigned to FTICR mass spectra and peaks present in the ${ }^{1} \mathrm{H}$ NMR spectra in order to reveal the components that describe the greatest amount of variance between the source types. The PCA was performed using an in-house MatLab script. The first PC (PC1) explains the most amount of variance, and the second PC (PC2) is orthogonal to PC1 and explains the second largest portion of the variance. Each successive PC explains less variance until a point of diminishing returns is reached (i.e., $<1 \%$ variance explained).

\subsubsection{FTICR-MS PCA}

Similar to positive matrix factorization, PCA is a factor analysis technique for explaining the observed composition in complex mixtures. It uses an eigenvector analysis of a correlation matrix to calculate principal components and variable loadings. The molecular formulas from each FTICR mass spectrum for the WSOM-, WSOM+, and PSOM- were compiled into a master formula list containing the formulas present in $2-13$ of the 14 samples (14,808 formulas). Formulas present in only one sample, and formulas present in all 14 samples were removed to avoid biasing the PCA toward rare formulas and to eliminate formulas that do not contribute to the sample variance, respectively [31,40,41]. A 14,808 $\times 14$ matrix was created by using an input value of 1 if a formula is present and an input value of 0 for a formula not present within a given sample.

\subsection{2. ${ }^{1} \mathrm{H}$ NMR PCA}

The ${ }^{1} \mathrm{H}$ NMR spectra were analyzed in a PCA following previous studies $[6,7]$. Briefly, all of the peaks in the ${ }^{1} \mathrm{H}$ NMR spectrum for each of the aerosol WSOM extracts between 0.0 and $11.0 \mathrm{ppm}$ were binned to a resolution of 1 data point per 
$0.005 \mathrm{ppm}$ from an initial resolution of $0.0008 \mathrm{ppm}$ between data points. The discrete signal (peak area) at each chemical shift was normalized to the total area in the given spectrum, and the normalized area was used as the data input variables $(n=2769)$ for the PCA. The ${ }^{1} \mathrm{H}$ NMR spectra were evaluated initially using all of the aerosol samples $(n=14)$, and a second time after omitting the marine aerosols $(n=10)$.

\section{Results and Discussion}

\subsection{Aerosol Loadings}

The aerosol samples from each of the emission sources show OM characteristics that distinguish the sources from one another. TSP and TC concentrations and BC, WSOC and PSOC percentages (relative to TC) were determined for each of the aerosol samples (Table 1). TSP, \%BC, and \%PSOC were not determined for the marine samples as discussed in the methods section. TSP loadings were highest for the biomass burning samples $\left(73.2 \mu \mathrm{g} \cdot \mathrm{m}^{-3}\right)$ followed by the urban $\left(47.1 \mu \mathrm{g} \cdot \mathrm{m}^{-3}\right)$ and mixed source $\left(24.1 \mu \mathrm{g} \cdot \mathrm{m}^{-3}\right)$ samples. The marine samples show TC loadings $\left(0.5 \mu \mathrm{g} \cdot \mathrm{m}^{-3}\right)$ one order of magnitude lower than the mixed source $\left(5.7 \mu \mathrm{g} \cdot \mathrm{m}^{-3}\right)$ and urban $\left(6.3 \mu \mathrm{g} \cdot \mathrm{m}^{-3}\right)$ samples and two orders of magnitude lower than the biomass burning samples $\left(24.8 \mu \mathrm{g} \cdot \mathrm{m}^{-3}\right)$ as one would expect for samples collected over the middle of the ocean far from major terrestrial and anthropogenic sources. In spite of the urban samples having TSP loadings that are approximately twice that of the mixed source samples, they show similar TC concentrations indicating that the urban samples contain high amounts of inorganic materials. The biomass burning samples showed the highest \%BC (6.5\%) and lowest \%WSOC (33.6\%) values of the samples which is expected for samples collected in proximity $(<30 \mathrm{~km})$ to biomass combustion processes that produce $\mathrm{BC}$ and have not been exposed to aging processes known to increase water solubility. The marine samples show low but variable \%WSOC values $(39.6 \pm 25.1 \%)$. The urban aerosol samples contained a higher $\% \mathrm{BC}(3.4 \%)$ and lower $\%$ WSOC $(40.8 \%)$ than the mixed source aerosol $(\% \mathrm{BC}=1.9, \%$ WSOC $=50.5)$ samples. Like all elemental and BC measurements, the CTO-375 method used here is subject to artifacts; it is thought to be selective for highly condensed soot BC and is susceptible to potential positive bias from the charring of melanoidin-like species [42], and the $\mathrm{BC}$ results should be viewed with this in mind. In a multi-laboratory comparison study, CTO-375 of aerosol particulate materials yielded lower \%BC $(3.7 \%-14.3 \%)$ relative to elemental carbon measured using thermal optical reflectance and thermal optical transmittance methods (16\%-50\%) frequently used in atmospheric studies likely due to the latter two methods inclusion of a portion of OC and the CTO-375 method's selectivity for highly condensed soot BC [42].

The \%PSOC amounts were calculated from ${ }^{1} \mathrm{H}$ NMR data (Supplemental Table S1) after Willoughby et al. [30] and are useful for understanding the amount of material 
analyzed in PSOM extracts for FTICR-MS analyses of water-insoluble OM. Because the pyridine extractions were conducted in parallel to the water extractions and some carbon compounds are soluble in both solvents and others are soluble in neither, the sum of these two percentages ( $\%$ WSOC $+\%$ PSOC) may be more or less than $100 \%$. The biomass burning samples can be expected to contain significant amounts of water-insoluble primary OA, and this is reflected in the high \%PSOC and low \%WSOC values. The calculation for PSOC percentage by the ${ }^{1} \mathrm{H}$ NMR technique omits aromatic peaks due to interference by the exchanged pyridine protons. Because the biomass burning samples are expected to have high aromatic contributions, as indicated by the high \%BC and increased signal in aromatic region of the ${ }^{1} \mathrm{H}$ NMR spectrum for the WSOM (discussed in Section 3.4), this \%PSOC value may be considered a low estimation. The urban and mixed source aerosols have considerably lower \%PSOC (urban $=44 \%$; mixed $=45 \%$ ) reflecting their higher water solubility and suggesting that these two sample types have more influence from secondary and aging reactions that produce OA insoluble in pyridine.

\subsection{Mass Spectra and Average Source Molecular Characteristics}

Averaged values calculated for properties determined using FTICR-MS molecular formulas for each of the sample types demonstrate some source-specific characteristics that differentiate them from one another. Each of the ESI-FTICR mass spectra for the ambient aerosol extracts average thousands of peaks across a broad range of 200-800 m/z (Figure 1). The average number of formulas found in each sample's master formula list (i.e., WSOM-, WSOM+, and PSOM- combined) followed the same trend as was observed for the TSP and TC concentrations (Table 2). The biomass burning aerosols showed the highest TC loads and averaged 6579 $( \pm 173)$ formulas assigned to each sample and a total of 7891 formulas. The urban aerosols were the next most molecularly abundant sample type averaging $6527( \pm 173)$ formulas per sample and a total of 10,701 formulas in all samples. An average of $4104( \pm 467)$ formulas were assigned to each mixed source sample, and a total of 6134 formulas were identified. To go along with their lowest TC load (Table 1), the marine aerosol samples totaled just 4570 formulas, averaging 2569 ( \pm 736$)$ formulas per aerosol sample. Higher quantities of organic carbon increase the overall number of compounds and the probability of a more diverse suite of compounds, and the similar trends in molecular formula abundances and TC loads are thus logical and likely related. 


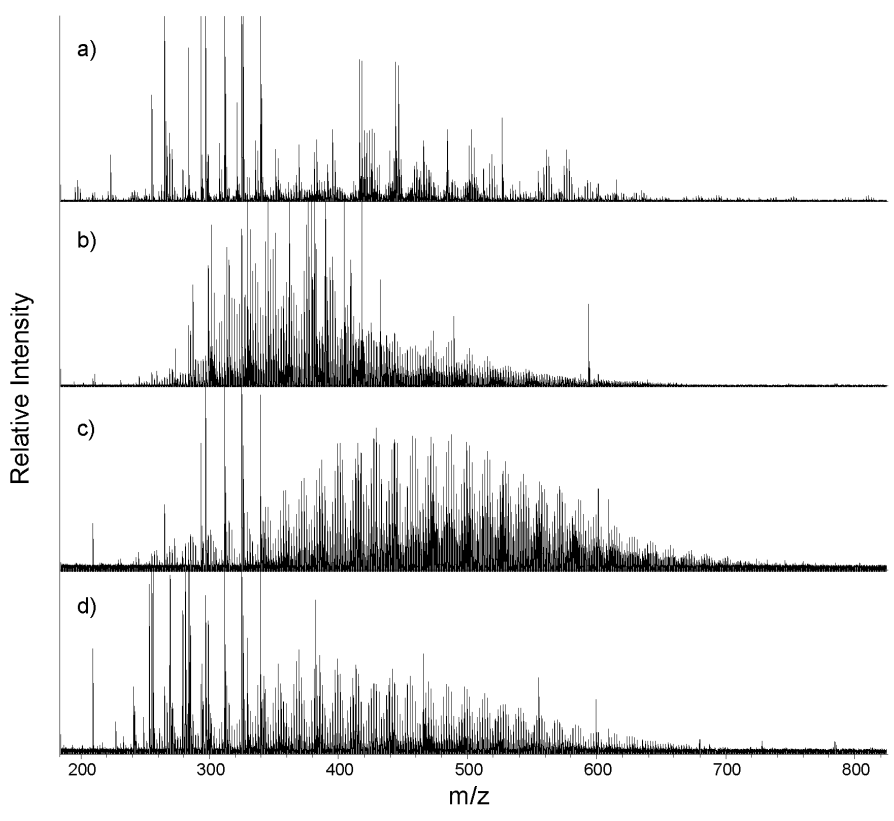

Figure 1. Representative full ESI(-) FTICR mass spectra for WSOMPPL extracts of (a) marine; (b) biomass burning; (c) urban; and (d) mixed source aerosols between 200 and $800 \mathrm{~m} / \mathrm{z}$. Some intense peaks are shown off scale.

Table 2. Total formulas and average elemental properties for aerosol WSOM $\mathrm{WPL}_{\mathrm{P}}$ and PSOM from each emission source determined using FTICR mass spectra.

\begin{tabular}{ccccc}
\hline & $\begin{array}{c}\text { Marine } \\
\text { Aerosols } \\
\boldsymbol{n = 4}\end{array}$ & $\begin{array}{c}\text { Biomass } \\
\text { Burning } \\
\text { Aerosols } \\
\boldsymbol{n = 2}\end{array}$ & $\begin{array}{c}\text { Urban } \\
\text { Aerosols } \\
\boldsymbol{n}=\mathbf{5}\end{array}$ & $\begin{array}{c}\text { Mixed Source } \\
\text { Aerosols } \\
\boldsymbol{n}=\mathbf{3}\end{array}$ \\
\hline $\begin{array}{c}\text { Average } \\
\text { formulas }\end{array}$ & $2569 \pm 736$ & $\mathbf{6 5 7 9} \pm 173$ & $6527 \pm 173$ & $4104 \pm 467$ \\
Total formulas & 4570 & 7891 & 10,701 & 6134 \\
Average O/C & $0.32 \pm 0.19$ & $0.32 \pm 0.19$ & $0.45 \pm 0.23$ & $0.44 \pm 0.23$ \\
Average H/C & $1.56 \pm 0.39$ & $1.35 \pm 0.39$ & $1.44 \pm 0.37$ & $1.46 \pm 0.35$ \\
Average AI $\mathrm{mod}$ & $0.18 \pm 0.26$ & $0.29 \pm 0.27$ & $0.18 \pm 0.24$ & $0.18 \pm 0.23$ \\
\hline
\end{tabular}

The marine aerosols share the lowest average $\mathrm{O} / \mathrm{C}$ ratio $(0.32 \pm 0.19$; Table 2$)$ with the biomass burning aerosols, differentiating them from the urban and mixed source aerosols which had considerably higher average $\mathrm{O} / \mathrm{C}$ ratios $(0.45 \pm 0.23$ and $0.44 \pm 0.23$, respectively). The lower average $\mathrm{O} / \mathrm{C}$ values for the biomass burning and marine aerosol samples suggest they are less oxidized than the mixed source and urban aerosols due to less post-emission atmospheric processing and/or 
lower characteristic $\mathrm{O} / \mathrm{C} \mathrm{OM}$ at emission. Atmospheric aging processes are known to increase the average $\mathrm{O} / \mathrm{C}$ ratio of aerosol $\mathrm{OM}[43,44]$. The average $\mathrm{O} / \mathrm{C}$ ratio $(0.45 \pm 0.23)$ for the urban aerosols is the highest of all the samples, supporting previous work showing highly oxidized OM near urban regions due to active photochemistry and abundant inorganic oxidants $[45,46]$ in spite of proximity to primary OA sources including vehicle exhausts that are expected to have a hydrocarbon-like (low $\mathrm{O} / \mathrm{C}$ ) profile. The similarly high average $\mathrm{O} / \mathrm{C}$ ratio measured for the mixed source samples, however, demonstrates that the high $\mathrm{O} / \mathrm{C}$ ratios and presumed high extent of atmospheric oxidation are not unique to urban environments.

The marine aerosols have the highest average $\mathrm{H} / \mathrm{C}$ ratio $(1.56 \pm 0.39)$. The modified aromaticity index $\left(\mathrm{AI}_{\text {mod }}\right)$ was calculated for each molecular formula according to the formula proposed by Koch and Dittmar [47]. The average $\mathrm{AI}_{\text {mod }}$ for the marine aerosols $(0.18)$ is equal to the mixed source and urban aerosols and indicative of the prevalence of olefinic/alicyclic $\left(0<\mathrm{AI}_{\bmod }<0.5\right)$ compounds. These ratios differentiate the marine aerosols from the biomass burning aerosols where the $\mathrm{O} / \mathrm{C}$ ratios did not. The average $\mathrm{H} / \mathrm{C}$ ratios for the biomass burning samples are the lowest $(1.35 \pm 0.39)$ of any of the aerosol sources indicating a large number of unsaturated molecules, and this is verified by its average $\mathrm{AI}_{\text {mod }}$ $(0.29 \pm 0.27)$, which is much higher than those of the other three types of samples. As was the case for the $\mathrm{O} / \mathrm{C}$ ratios, the average $\mathrm{H} / \mathrm{C}$ ratio $(1.46 \pm 0.35)$, and $\mathrm{AI}_{\text {mod }}$ $(0.18 \pm 0.23)$ of the mixed source aerosols are very similar to those calculated for the urban samples $\left(\mathrm{H} / \mathrm{C}\right.$ ratio $\left.=1.44 \pm 0.37, \mathrm{AI}_{\text {mod }}=0.18 \pm 0.24\right)$ making them almost indistinguishable based on these properties alone (Table 2). The biomass burning aerosols have substantially more aromatic $\left(0.5 \leqslant \mathrm{AI}_{\text {mod }}<0.67,16.7 \%, 1318\right.$ formulas $)$ and condensed aromatic $\left(\mathrm{AI}_{\text {mod }} \geqslant 0.67,6.6 \%, 523\right.$ formulas), and fewer aliphatic $\left(\mathrm{AI}_{\mathrm{mod}}=0,23.6 \%, 1864\right.$ formulas) formulas than any of the other emission sources but a similar amount of olefinic/alicyclic formulas (53.0\%; Supplemental Table S2). The urban, marine, and mixed source aerosols all showed similar distributions with regard to $\mathrm{AI}_{\text {mod }}$ classifications.

The averaged contributions of elemental formula combinations to each master formula list also present a broad brush method for distinguishing among the four sample types. Details regarding the properties for each ionization source can be found in the supplementary information (Supplemental Table S3), but will not be discussed. $\mathrm{CHO}$ formulas were always the most abundant (marine, mixed source) or second most abundant (biomass burning, urban) formula type for each group (Supplemental Table S2). The relative distribution of CHOS and CHONS formulas are similar among all the sources $(\mathrm{CHOS}=17.8 \%-20.9 \%, \mathrm{CHONS}=12.2 \%-15.4 \%$ ) with the mixed source aerosols having the highest contributions from both formula types. The marine aerosols show the largest relative contributions from P-containing 
molecular formulas. The van Krevelen diagram enables a representation of all of the molecular formulas assigned to the samples including the variation of $\mathrm{H} / \mathrm{C}$ and $\mathrm{O} / \mathrm{C}$ ratios as well as a visualization of some of the differences and commonalities described by the averaged ratio values (Supplemental Figure S1), and can be used to characterize differences among the four sample types. However, any of several molecular formulas can plot at the same $\mathrm{H} / \mathrm{C}$ and $\mathrm{O} / \mathrm{C}$ ratios, and it is laborious and inefficient to evaluate similarities and differences among samples by looking at tens of van Krevelen diagrams. It is more efficient and statistically valid to identify the defining features among several samples with large molecular formula datasets using a factor analysis such as PCA.

\subsection{FTICR-MS PCA}

The majority of the variance $(66.0 \%)$ in the FTICR-MS formula identifications among the four aerosol sample types is explained by the first three principal components (PC1, 32.5\%; PC2, 22.4\%; PC3, 11.1\%; Figure 2). The aerosol samples show distinctive PC1-PC3 values based on their source characterization. Each of the marine samples have a negative PC1 score, a positive PC2 score, and a positive PC3 score. The mixed source samples have a positive PC1, a positive PC2, and a negative PC3 score. The biomass burning samples have a negative PC1, a negative PC2, and a positive PC3. The urban samples have a positive PC1, a negative PC2, and a positive PC3. These PC score classifications were used to identify the loadings (the molecular formulas used as PCA input variables; Supplemental Figure S2) diagnostic for each source. For example, if a molecular formula has negative PC1 loadings, and positive PC2 and PC3 loadings, it is classified as a formula characteristic of marine sources. This resulted in the identification of 1078 formulas characteristic for marine aerosols, 693 formulas for mixed source aerosols, 4174 formulas for biomass burning aerosols, and 3484 formulas for urban aerosols. The remaining 5379 formulas contain characteristics that are represented by multiple sources indicating that they are not diagnostic of a particular source and may be ubiquitous in aerosol OM or inconsistently present in a given source.

\subsubsection{Marine Aerosols}

In contrast with the average $\mathrm{CHO}$ contributions for the master formula list $(41.1 \%)$, the PCA-identified formulas for the marine aerosols showed the lowest contributions from $\mathrm{CHO}$ formulas (31.6\%, Table 3$)$ of all the sample types. $\mathrm{CHO}$ formulas are still the most abundant formula type of the PC loadings associated with the marine aerosols, and the majority of these formulas are present at high $\mathrm{H} / \mathrm{C}$ and low $\mathrm{O} / \mathrm{C}$ ratios (Figure 3a). In fact, most of the formulas identified as specific to marine sources by PCA are localized to the upper-left region of the van Krevelen diagram $(\mathrm{O} / \mathrm{C} \leqslant 0.6, \mathrm{H} / \mathrm{C} \geqslant 1.5)$, a region where many 
biologically-relevant compounds (lipids, fatty acids, proteins), suggesting that biological activity is an important source for marine aerosols (Figure 3a).

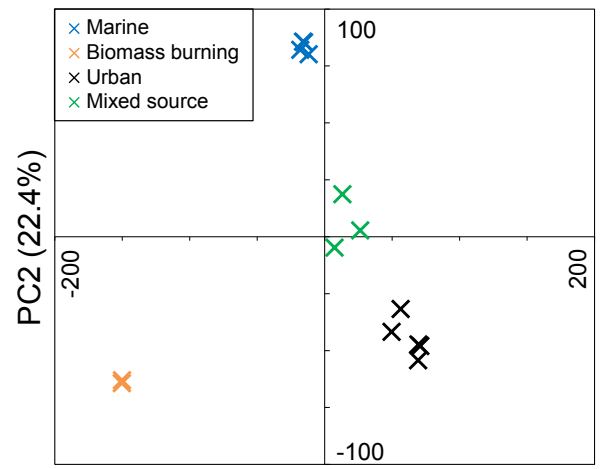

PC1 (32.5\%)

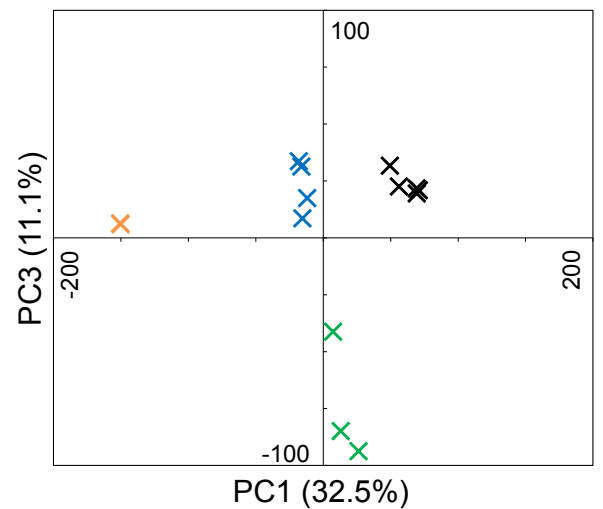

Figure 2. PCA score plots for PC2 versus PC1 (left) and PC3 versus PC1 (right). PCA was performed using molecular formulas identified in FTICR mass spectra for aerosol OM extracts from marine, biomass burning, urban, and mixed source areas.

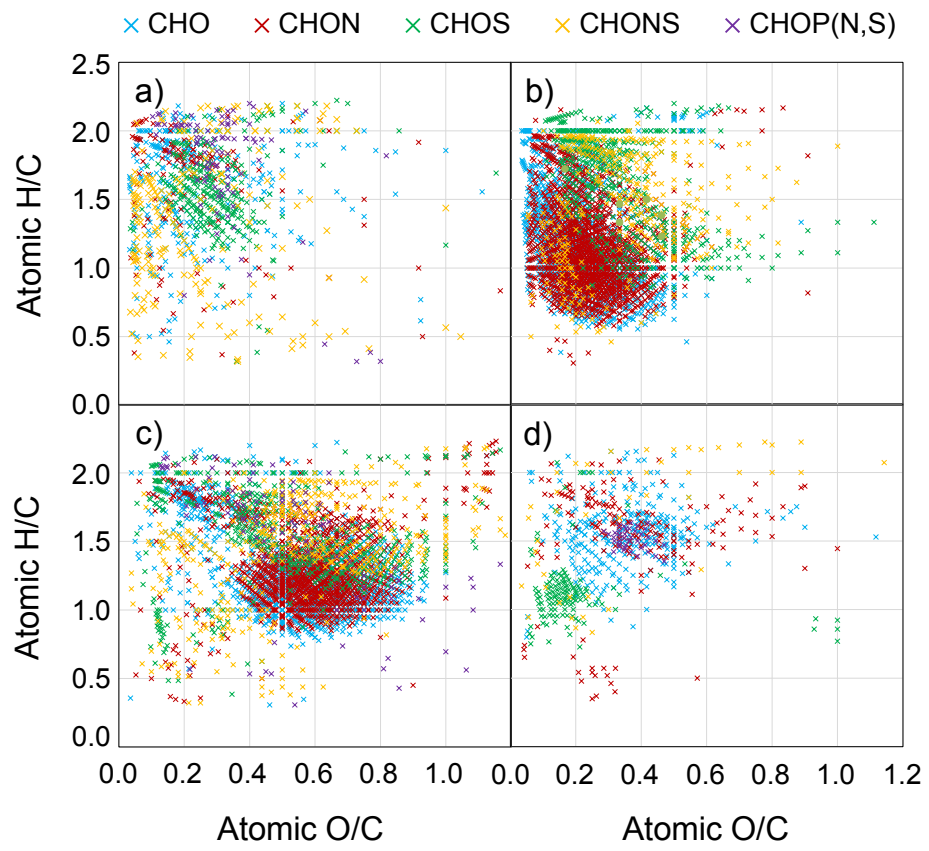

Figure 3. Van Krevelen diagrams for molecular formulas identified by PCA for (a) marine; (b) biomass burning; (c) urban; and (d) mixed source aerosols. Each data point is colored according to the atomic content of the molecular formula. 
Table 3. Total formulas and average elemental properties for molecular formulas identified by PCA. Distributions of formulas based on atomic content and $\mathrm{AI}_{\text {mod }}$ structure type are listed as percentage of total formulas.

\begin{tabular}{ccccc}
\hline & $\begin{array}{c}\text { Marine } \\
\text { Aerosols }\end{array}$ & $\begin{array}{c}\text { Biomass } \\
\text { Burning } \\
\text { Aerosols }\end{array}$ & $\begin{array}{c}\text { Urban } \\
\text { Aerosols }\end{array}$ & $\begin{array}{c}\text { Mixed Source } \\
\text { Aerosols }\end{array}$ \\
\hline Total formulas & 1078 & 4174 & 3484 & 693 \\
\hline Average O/C & $0.27 \pm 0.17$ & $0.26 \pm 0.13$ & $0.55 \pm 0.21$ & $0.33 \pm 0.18$ \\
Average H/C & $1.55 \pm 0.41$ & $1.24 \pm 0.37$ & $1.36 \pm 0.34$ & $1.48 \pm 0.34$ \\
Average AI mod & $0.20 \pm 0.25$ & $0.37 \pm 0.23$ & $0.18 \pm 0.22$ & $0.20 \pm 0.21$ \\
\hline Atomic Content $(\%)$ & & & & \\
\hline CHO & 31.6 & 34.7 & 33.4 & 45.0 \\
CHON & 13.4 & 45.4 & 38.0 & 24.4 \\
CHOS & 27.4 & 12.0 & 13.3 & 18.3 \\
CHONS & 19.0 & 7.8 & 12.5 & 6.6 \\
CHOP(N,S) & 8.6 & 0.1 & 2.8 & 5.6 \\
\hline Structure Type (\%) & & & & \\
\hline Aliphatic & 31.4 & 12.0 & 34.1 & 24.0 \\
Olefinic/alicyclic & 56.6 & 55.6 & 60.6 & 67.8 \\
Aromatic & 5.5 & 26.8 & 3.1 & 4.9 \\
Condensed aromatic & 6.6 & 5.6 & 2.3 & 3.3 \\
\hline
\end{tabular}

The PC loadings for the marine aerosols have the largest fraction of CHOS $(27.4 \%)$, CHONS $(19.0 \%)$, and CHOP $(\mathrm{N}, \mathrm{S})(8.6 \%)$ formulas of all the samples (Table 3). It appears thus, that the heteroatom containing formulas that are present in marine aerosols are very distinctive. The abundance of P-containing formulas in this region of the van Krevelen diagram is consistent with inputs of biologically-derived phospholipids as has been observed previously for marine aerosols [31]. Membrane phospholipids have characteristic fatty acid tails with hydrophobic alkyl chains and hydrophilic phosphate heads that can impart amphipathic characteristics, and these P-containing formulas are found in both the PSOM- and WSOM- (Supplemental Table S4; Figure S3) in agreement with this partial solubility. The large number of CHOS and CHONS formulas plotting in these regions have $\mathrm{O} / \mathrm{S}$ ratios $>4$ and are suggestive of organosulfate compounds which have also been observed in marine aerosols $[31,48,49]$. Organosulfates are formed via photochemical aging reactions with the acid-catalyzed ring opening reactions of precursor molecules being the most kinetically favorable reaction mechanism [50-52]. In this instance, the sulfate available for reaction is likely to be marine-derived from biological emissions of dimethyl sulfide that is oxidized in the atmosphere or from sea salt sulfates emitted with sea spray. The low $\mathrm{O} / \mathrm{C}$ ratios of the marine $\mathrm{CHOS}$ and $\mathrm{CHONS}$ molecular 
formulas suggest that any precursor organic compounds were lipid-like in nature and also had low $\mathrm{O} / \mathrm{C}$ ratios.

Many studies have demonstrated the influence of biological activity on marine aerosols citing the importance of carbohydrate-like and amino-acid-like compounds, for example [53-55]. Carbohydrates are not strongly ionizable compounds under electrospray and are not observed in these samples, and it is important to note that these characteristics represent only the polar, ionizable fraction of marine aerosols. The high $\mathrm{H} / \mathrm{C}$ and low $\mathrm{O} / \mathrm{C} \mathrm{CHO}, \mathrm{CHOP}(\mathrm{N}, \mathrm{S}), \mathrm{CHOS}$, and CHONS molecular formulas are characteristic of that polar, ionizable fraction, and studies apportioning the sources of OA to a coastal site, for example, can use them as evidence for a marine input to coastal OA. Likewise, studies apportioning sources to OA collected in the marine environment can take large contributions from aromatic or highly oxygenated compounds $(\mathrm{O} / \mathrm{C}>0.6)$ as evidence for terrestrial sources.

\subsubsection{Biomass Burning Aerosols}

The biomass burning aerosol PC loadings are characterized by having the lowest average $\mathrm{O} / \mathrm{C}$ and $\mathrm{H} / \mathrm{C}$ values, and the highest $\mathrm{AI}_{\text {mod }}$ values (Table 3 ). These average ratios are consistent with the bulk properties discussed in Section 3.2 (Supplemental Table S2) but exaggerate the extreme ratios in the biomass burning aerosols to even lower $\mathrm{H} / \mathrm{C}(1.24$ vs. 1.35$)$ and $\mathrm{O} / \mathrm{C}(0.26$ vs. 0.32$)$ ratios and a higher $\mathrm{AI}_{\mathrm{mod}}$ ( 0.37 vs. 0.29). The PC loadings that define the biomass burning aerosols thus have low $\mathrm{O} / \mathrm{C}$ and $\mathrm{H} / \mathrm{C}$ and high $\mathrm{AI}_{\text {mod }}$ and show the largest fraction of aromatic and condensed aromatic formulas (32.4\%) of all the sample types (Table 3). Additionally, more than $80 \%$ of the biomass burning PC loading formulas are CHON $(45.4 \%)$ and $\mathrm{CHO}(34.7 \%)$, suggesting that these two elemental formula groups are most responsible for distinguishing biomass burning aerosols from the other sample groups. Interestingly, the CHOS and CHONS formulas for the biomass burning aerosols master list of formulas made up nearly $20 \%$ and $12 \%$ of all assigned formulas and spanned a very wide $\mathrm{O} / \mathrm{C}(0.10-1.20)$ and $\mathrm{H} / \mathrm{C}(1-2)$ range (Figure 2). However, CHOS and CHONS formulas accounted for just $12 \%$ and $7.8 \%$ of the PC loadings associated with the biomass burning aerosols and plot in two clusters of the $\mathrm{vK}$ diagram (1) at $\mathrm{H} / \mathrm{C}$ between 1.5 and 2.0 and $\mathrm{O} / \mathrm{C}$ between 0.1 and 0.5 ; and (2) at $\mathrm{H} / \mathrm{C}$ between 1.0 and 1.5 and $\mathrm{O} / \mathrm{C}$ between 0.3 and 0.6 . The much lower contributions of S-containing formulas attributable to biomass burning in the PC loadings suggests that the majority of the CHOS and CHONS formulas in the biomass burning samples (at high $\mathrm{H} / \mathrm{C}$ and high $\mathrm{O} / \mathrm{C}$ ) are found in multiple sample types, and those particular CHOS and CHONS formulas may not be particularly useful as diagnostic of any one sample type. Studies of S-containing OA demonstrate the ability of existing OA and VOCs to form organosulfates via atmospheric oxidation reactions [17,56-58]. Emissions of inorganic sulfur are commonly associated with anthropogenic (e.g., 
fossil fuel emissions) $[59,60]$ and marine sources (e.g., gas and aerosol-phase marine emissions) [61], but the abundance of CHOS and CHONS formulas in the mixed source and biomass burning aerosols demonstrates the ubiquity of organosulfur compounds in and beyond those environments.

The van Krevelen diagram shows the $\mathrm{CHON}$ and $\mathrm{CHO}$ formulas to make up a large portion of the aromatic and condensed aromatic PC loading formulas for the biomass burning aerosols, as indicated by their presence in the low $\mathrm{O} / \mathrm{C}$ and low $\mathrm{H} / \mathrm{C}$ regions (Figure $3 \mathrm{~b}$ ). Aromatic and condensed aromatic compounds have higher potential for absorbing light than more saturated molecules [5] and make up portions of the $\mathrm{BC}$ and brown carbon pools. The definitions of these two carbon pools are, by necessity, operational and remain a topic of debate $[5,42,62]$. Traditional definitions of BC assume it to be insoluble in water, but this has been challenged, and BC is recognized to exist on a continuum of solubility. Recent studies have shown that BC can become soluble upon oxidation $[63,64]$ and have detected dissolved forms of BC in aerosols [20] and aquatic dissolved OM [65]. The definitive study relating dissolved BC determined by chemical techniques to thermal optically-defined BC has not to our knowledge been performed. However, the polyaromatic structures that are required for formulas defined as condensed aromatic using the $\mathrm{AI}_{\text {mod }}$ classification system [47] are consistent with structures proposed for BC [66]. The biomass burning PC loadings are distributed relatively evenly among the three extract-ionization pairings (Supplemental Figure S3). Interestingly, however, the majority of the aromatic and condensed aromatic formulas assigned as important to the biomass burning samples by the PCA were detected in the WSOMand WSOM+ analyses (Supplemental Table S4). This may result because pyridine does not efficiently extract $\mathrm{BC}$ or because less oxygenated $\mathrm{BC}$ that is extracted into PSOM does not ionize efficiently in ESI, and it is unclear what fraction of the biomass burning $\mathrm{BC}$ is soluble.

A great many $\mathrm{CHON}$ formulas have very low $\mathrm{O} / \mathrm{C}(0.05-0.40)$ and $\mathrm{H} / \mathrm{C}(<1.0)$ ratios, indicating that they may contain reduced nitrogen functional groups (e.g., amines) or have heterocyclic rings. A subset of these compounds contributes to the black nitrogen (heterocyclic aromatic nitrogen produced during biomass combustion or derivatives of $\mathrm{BC}$ that have undergone reactions with inorganic nitrogen) compounds that have recently suggested to be important components of the nitrogen and carbon cycles in aquatic systems [65]. Indeed, the WSOM from these biomass burning aerosols do contain fluorophoric compounds, and the fluorescence intensity is substantially higher than the mixed source and urban aerosols (Willoughby et al., unpublished data). The brown color of the sample filters suggests that these samples do contain significant amounts of brown carbon which, like BC, has no unequivocal chemical definition [5]. Brown carbon is formed alongside $\mathrm{BC}$ in combustion processes [5], and has also been formed 
through model reactions of aqueous SOA with $\mathrm{NH}_{3}[67,68]$. Though the global importance of brown carbon is still a topic of debate, it has recently been suggested that biomass burning is the predominant source of brown carbon to the world's atmosphere [69], and the results presented here and elsewhere [70,71] suggest that aromatic N-containing compounds are major components of that brown carbon and diagnostic of biomass burning.

\subsubsection{Urban Aerosols}

The molecular formulas with PC loadings that identify them as important to the urban aerosols are also characterized by a large number of $\mathrm{CHON}(38.0 \%)$ and $\mathrm{CHO}(33.4 \%)$ formulas. The majority of these PC loadings are found in WSOMmeasurements (Supplemental Figure S3) and have significantly higher O/C ratios than those found in the biomass burning aerosols (Figure 3c). The average $\mathrm{O} / \mathrm{C}$ $(0.55 \pm 0.21)$ is double and the average $\mathrm{AI}_{\bmod }(0.18 \pm 0.22)$ is half that of the biomass burning aerosols. The average $\mathrm{O} / \mathrm{C}$ value for the urban aerosol PC loadings is much higher than the average value for the entire urban aerosol master list $(0.45$, Table 2$)$ highlighting the distinguishing nature of those high $\mathrm{O} / \mathrm{C}$ components. Many of the $\mathrm{CHO}$ and $\mathrm{CHON}$ formulas that the PCA associates as important to the urban aerosols have $\mathrm{O} / \mathrm{C}$ ratios between 0.35 and 0.85 and $\mathrm{H} / \mathrm{C}$ ratios between 0.8 and 1.8 , an area of the van Krevelen diagram that overlaps with regions previously described for lignin-like or carboxyl-rich alicyclic molecules (CRAM) in the soil and aquatic literature (Figure 3c) [72,73]. In the atmosphere, formulas in this region are likely to be the result of atmospheric aging reactions which tend to increase the oxidation state of carbon [44] and transform OA compounds into new compounds that plot downwards and to the right on a van Krevelen diagram [43].

Aliphatic CHOS and CHONS molecular formulas plotting at $\mathrm{O} / \mathrm{C}$ between 0.3 and 1.2 and $\mathrm{H} / \mathrm{C}$ between 1.3 and 2.0 were also abundant among the PC loadings for the urban aerosols. Fossil fuel combustion and biological emissions are major sources for aliphatic compounds in the atmosphere [11,74], and the presence of heavy traffic and heavy industrial activity in short and long range proximity of the urban sampling site suggests that fossil fuel combustion as strong candidates for these compounds. The high $\mathrm{O}$ content in these formulas is suggestive of organosulfate $(\mathrm{O} / \mathrm{S}>4)$ and nitrooxyorganosulfate $(\mathrm{O} / \mathrm{S}>7$, contains $\mathrm{N})$ compounds as potential identities. The abundance of oxidized inorganic nitrogen and sulfur emitted in urban areas combined with emissions of aliphatic biological and anthropogenic compounds make for an excellent environment for organosulfate and nitrooxyorganosulfate compound formation [75,76].

Those two major distinguishing features $(\mathrm{CHO}$ and $\mathrm{CHON}$ formulas at $0.35<\mathrm{O} / \mathrm{C}<0.85$ and $\mathrm{CHOS}$ and $\mathrm{CHONS}$ formulas at $0.8<\mathrm{O} / \mathrm{C}<1.8$ ) can be used to apportion $\mathrm{OA}$ as anthropogenically-influenced urban aerosols. In fact, they 
have been used in a study of OA collected on a transect in the North Atlantic Ocean to apportion OA to North American terrestrial air mass influences [31]. The CHON, CHONS, and CHOS formulas identified as important to the urban OA have distinct characteristics from those identified as important to the marine and biomass burning aerosols. The carbon backbones to which $\mathrm{N}$ and $\mathrm{S}$ functional groups are bound (or incorporated) are very different, and the PCA has made this clear.

\subsubsection{Mixed Source Aerosols}

The mixed source aerosols contain the fewest formulas identified by PCA, indicating those samples have few compounds specific to a unique source and share many molecular features with the other aerosols. Given the potential influences to these aerosols, the lack of an abundance of truly defining features is perhaps expected. Nonetheless, the PCA did identify a few OA components specific to the mixed source aerosols. Like the urban aerosols, the majority of the PC loadings important to the mixed source samples were water-soluble. Unlike the urban aerosols, many of these PC loadings were in the WSOM+ measurements suggesting relatively higher amounts of compounds with basic functional groups in the mixed source environment (Supplementary Table S4, Figure S3).

A cluster of $\mathrm{CHOS}$ formulas at low $\mathrm{O} / \mathrm{C}$ and $\mathrm{H} / \mathrm{C}$ ratios $(\mathrm{O} / \mathrm{C}<0.4, \mathrm{H} / \mathrm{C}$ $<1.2$ ) is evident in the PC loadings (Figure $3 \mathrm{~d}$ ). Most of these formulas do not contain sufficient oxygen to be organosulfates, and therefore must represent more reduced forms of organic sulfur (e.g., thiols). Examination of the master list van Krevelen diagram shows that these types of compounds are also present in the urban and biomass burning aerosols but not nearly to the extent of the mixed source OA (Figure S1). Sulfonates are a common anthropogenic pollutant and are ubiquitous in personal care products, and have been previously identified in aerosol OM [75]. Non-sulfate aromatic S-containing compounds have been identified in fossil fuels $[77,78]$. The presence of these reduced sulfur compounds in North American continental relative to marine aerosols lends support to the idea that this group of compounds may be anthropogenically-derived. A tight cluster of P-containing formulas $(0.35<\mathrm{O} / \mathrm{C}<0.45,1.45<\mathrm{H} / \mathrm{C}<1.55$; Figure $3 \mathrm{~d})$ is also evident in the mixed source aerosols. OA compounds containing $\mathrm{P}$ have been attributed to biological sources [31,79], and a distinct local biological source is speculated for these formulas in the mixed source OA. The remaining $\mathrm{CHO}, \mathrm{CHON}$, and $\mathrm{CHOS}$ formulas with $\mathrm{PC}$ loadings assigned to the mixed source $\mathrm{OA}$ are scattered at $\mathrm{O} / \mathrm{C}<0.6$ and $\mathrm{H} / \mathrm{C}>1.0$, less oxygenated than the urban aerosol PC loadings and less aromatic than the biomass burning aerosols. The defining features for the mixed source aerosols are, as expected, indicative of the multiple potential sources to the sampling site.

As was found for each of the other sources, a portion of the mixed source PC loading formulas can be defined as condensed aromatic. The presence of condensed 
aromatic species, which may also be characterized as BC and functionalized derivatives of $\mathrm{BC}$, in all of these samples reflects their ubiquity in the atmosphere even over the North Atlantic Ocean. BC is traditionally regarded as a product of combustion, as in the combustion of fossil fuel or biomass. Numerous pyrogenic sources exist on the east coast of the US (vehicular exhaust, shipping, biomass burning, and long-range transport from various anthropogenic activities), and are probably contributors to $\mathrm{BC}$ even in the rural environment where the mixed source aerosols were sampled and over the marine environment. It has been recently shown that BC-like compounds can also be produced from non-pyrogenic sources [80,81], but the prevalence of this mechanism has yet to be established for atmospheric systems. Regardless of origin, these aromatic and condensed aromatic species are capable of absorbing ultraviolet radiation resulting in a positive radiative forcing (i.e., climate warming) [5]. While ESI-FTICR-MS provides an immense amount of molecular information regarding complex OM mixtures, the limitations are well-established. The ability of a compound to be analyzed is highly dependent on its ability to ionize, and non-polar and non-ionizable compounds (e.g., hydrocarbons and carbohydrates) are largely omitted from this analysis. Additionally, this analysis is necessarily qualitative because a combination of charge competition, concentration, and ionization efficiency drive the peak intensities. However, ${ }^{1} \mathrm{H}$ NMR does not have the same bias for the detection of OM, and provides a complementary set of information regarding the chemical makeup of these complex samples.

\section{4. ${ }^{1}$ H NMR Analysis}

The WSOM for each of the aerosols display an array of proton types spanning the spectral region between 0 and 11 ppm (Figure 4). The observed chemical shifts are related to the chemical environment of each proton, and provides clues to the structural connectivity of the atoms within each sample. The region between 0 and 4.4 ppm contains at least $90 \%$ of the signal in each of the spectra. Most of the spectra contain broad peaks indicating similar proton types attached to varying carbon chain lengths or located in varying proximity to polar functional groups. These broad peaks exemplify the complexity of aerosol WSOM, and make it difficult to identify individual compounds. However, the region in which a proton signal is detected can indicate the general class of compounds to which that proton belongs. For example, the most intense peak in each spectrum is located at $1.2 \mathrm{ppm}$ and is indicative of protons that are part of a $\mathrm{CH}_{2}$ group, which represent those that are part of an alkyl chain. This peak is broadest in the urban aerosols, suggesting the alkyl chains are longer, and the $\mathrm{CH}_{2}$ protons in these aerosols are attached to the widest variety of structural entities. Conversely, the narrower $\mathrm{CH}_{2}$ peak in the marine, mixed source, and biomass burning aerosols suggests shorter chain lengths and less diversity regarding chemical environments among $\mathrm{CH}_{2}$ groups. Smaller chain lengths could 
indicate decomposition of larger molecules by photochemical degradation, or suggest that the molecules have not undergone substantial oligomerization reactions, such as those that add small volatile species like isoprene.

Dividing the spectrum into key proton regions and evaluating the relative contributions of the total spectral intensity can reveal important differences among the different sources (Table 4). The region where signal from aromatic protons are found (6-9 ppm) is the most variable among the sources. A broad signal is observed in the aromatic region of the biomass burning aerosols spectra (Figure $4 \mathrm{~b}$ inset) and it makes up $9.2 \%$ of the total intensity, a percentage more than 4 times greater than the other sources (Table 4). Protons in this region are attached to aromatic or condensed aromatic rings, and the broadness of the peak indicates a high degree of structural diversity among the aromatic protons in these aerosols. There is little signal in the aromatic region in the urban and mixed source aerosols, and essentially no signal in the marine aerosols, indicating there are either very few aromatic compounds in these aerosols or that only water-insoluble aromatic species are present. The observation of a much larger intensity in the aromatic region of the biomass burning aerosols supports the detection of more aromatic and condensed aromatic formulas in the FTICR mass spectra as well as the higher concentration of $B C$, and suggests that the biomass burning aerosols contain a larger quantity of chromophoric OM than the other aerosol sources investigated here.

As previously mentioned, the majority of the signal in each NMR spectrum falls in the region between 0.6 and $4.4 \mathrm{ppm}$, and the relative signal in each of the major proton regions does not vary greatly between the sources. At least $50 \%$ of the signal falls in the $\mathrm{H}-\mathrm{C}$ region (0.6-1.8 ppm) in all cases, indicating that a majority of the protons are part of alkyl groups. The larger $\mathrm{H}-\mathrm{C}$ fractions observed in the urban and mixed source aerosols suggest that OM contains larger carbon backbones (linear or branched). Carbon can be added to existing OM via oligomerization reactions, and the larger carbon chains present in the mixed and urban aerosols suggests that they have undergone oligomerization reactions more extensively than the marine and biomass burning aerosols. Protons that are more downfield in this region (1.4-1.8 ppm) are often attributed to an $\mathrm{H}-\mathrm{C}$ group that is $\beta$ to a carbon attached to heteroatoms (H-C-C-C-X, where $X=N, S$, or O) [14]. The presence of a large number of heteroatomic compounds identified in each of the mass spectra $(\mathrm{CHON}, \mathrm{CHOS}$, and $\mathrm{CHONS}$ ) indicates some portion of the signal in this region represents these species as can be expected for OA and was noted previously (Section 3.2). 

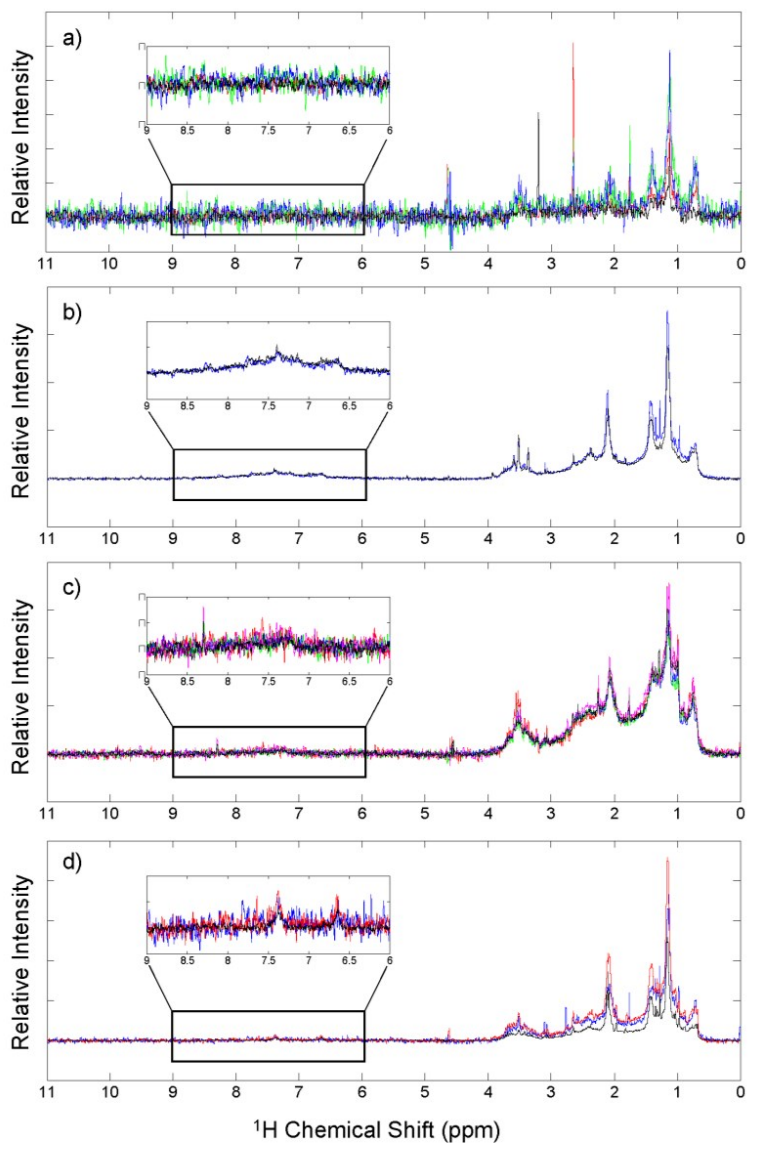

Figure 4. ${ }^{1} \mathrm{H}$ NMR spectra for WSOM of (a) marine; (b) biomass burning; (c) urban; and (d) mixed source aerosols, where each colored line represents a different sample spectrum. The region between 6 and 9 ppm represents aromatic protons, and is expanded in the inset of each spectrum.

Table 4. Average relative contributions of total spectral intensity for integrations of major proton regions in ${ }^{1} \mathrm{H}$ NMR spectra for each of the aerosol sources. Standard deviations of the relative signal in each region among aerosols from the same source are provided.

\begin{tabular}{ccccc}
\hline Aerosol Source & $\begin{array}{c}\text { H-C } \\
(\mathbf{0 . 6}-\mathbf{1 . 8} \mathbf{~ p m})\end{array}$ & $\begin{array}{c}\text { H-C-C }= \\
\mathbf{( 1 . 8 - 3 . 2} \mathbf{~ p p m})\end{array}$ & $\begin{array}{c}\text { H-C-O-R } \\
(\mathbf{3 . 2}-\mathbf{4 . 4} \mathbf{~ p p m})\end{array}$ & $\begin{array}{c}\text { Ar-H } \\
\mathbf{( 6 . 0 - 9 . 0 ~} \mathbf{~ p p m})\end{array}$ \\
\hline Marine & $50.3 \pm 5.5$ & $34.2 \pm 3.9$ & $14.5 \pm 3.6$ & $1.0 \pm 0.3$ \\
Biomass burning & $50.9 \pm 3.4$ & $31.1 \pm 0.6$ & $9.4 \pm 0.9$ & $9.2 \pm 1.9$ \\
Urban & $53.2 \pm 1.5$ & $35.0 \pm 2.0$ & $9.4 \pm 1.1$ & $2.4 \pm 0.6$ \\
Mixed source & $57.0 \pm 1.3$ & $32.9 \pm 0.4$ & $8.4 \pm 0.8$ & $1.7 \pm 0.3$ \\
\hline
\end{tabular}


Approximately one-third of the signal intensity falls in the unsaturated alkyl region (H-C-C=; 1.8-3.2 ppm), which includes carbonyl, carboxyl, alkenes, and also hydrogen attached to carbons adjacent to a nitrogen or sulfur (i.e., amines, thiols, etc.). The marine and urban aerosols have the highest relative percentage of proton signal in this region, but are also the most variable. On average, approximately $9 \%$ of the proton signals are found in the oxygenated aliphatic region (3.2-4.4 ppm) for the aerosols collected over terrestrial environments and a much higher percentage is observed in the marine aerosols (14.5\%). The greater signal intensity in this region of the marine aerosols is surprising given the low $\mathrm{O} / \mathrm{C}$ ratios of the molecules identified in the FTICR mass spectra, but this could be due to the presence of oxygenated species that are outside of the ESI-FTICR-MS analytical window (i.e., nonionizable compounds, compounds $<200 \mathrm{~m} / \mathrm{z}$ ) as suggested by the presence of a sharp, intense peak in this region. This region includes protons attached to carbons that are singly bound to an oxygen atom such as ethers, esters, alcohols, and carbohydrates. Carbohydrates are thought to be important components of aerosols produced via bubble bursting [54] but do not ionize efficiently via electrospray ionization. The complexity of aerosol OM limits the ability to identify each of the individual components within the mixture, but ${ }^{1} \mathrm{H}$ NMR provides valuable information regarding the connectivity of the compounds present and because of its complementarity to FTICR-MS we can gather complementary chemical features contained within these complex mixtures. The important and distinguishing features can be observed more clearly with the help of PCA.

\section{5. ${ }^{1} H$ NMR PCA}

PCA was performed on the whole ${ }^{1} \mathrm{H}$ NMR spectra for each of the aerosol WSOM extracts, similar to previous studies $[6,7,82]$. The initial PCA results indicate that the marine aerosols are significantly different than the mixed source, biomass burning, and urban aerosols and inclusion of the marine aerosols does not adequately explain the variance between the three terrestrial sources (Figure 5a). The main differences include the fact that the marine aerosols contain a few sharp peaks (e.g., methanesulfonic acid at $2.7 \mathrm{ppm}$, and acetate at $1.8 \mathrm{ppm}$ ), and the other aerosols contain multiple broad signals throughout each spectrum. The PCA was evaluated a second time using only the mixed source, biomass burning, and urban aerosols, and key differences among those sources are discussed further. The key features of marine aerosol WSOM that distinguish them from continentally-influenced air masses have been discussed at length in previous studies [6,7]. Briefly, the marine aerosols differ from those influenced by the North American continent in that the marine aerosols have more saturated aliphatic chains and are less structurally diverse. 
a)

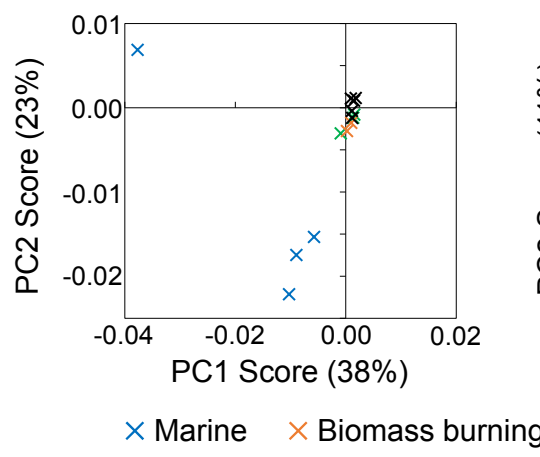

b)

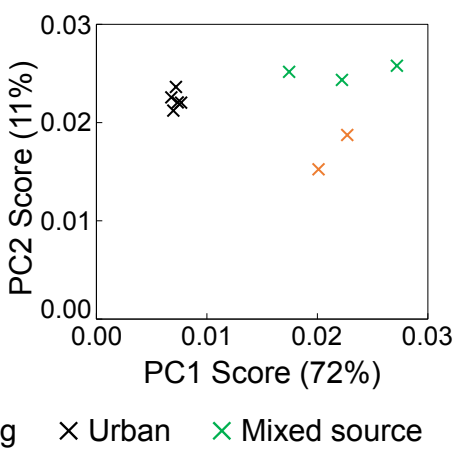

Figure 5. Aerosol WSOM (a) PC1 and PC2 scores for PCA of full ${ }^{1} \mathrm{H}$ NMR spectra of marine, mixed source, biomass burning, and urban aerosols and (b) PC1 and PC2 scores for PCA omitting marine aerosols. The amount of variation explained by each PC is indicated in parentheses on each axis.

The first two principal components (PC1 and PC2) explain more than $80 \%$ of the variance between the mixed source, biomass burning, and urban aerosol WSOM (Figure $5 b$ ). The urban aerosols have lower PC1 scores than the mixed source and biomass burning aerosols, the biomass burning aerosols have lower PC2 scores than the urban and mixed source aerosols, and the mixed source aerosols do not have unique PC values (Figure 5b). Thus, PC1 shows the spectral characteristics that differentiate the urban aerosols from the biomass burning and mixed source aerosols, and PC2 shows the spectral characteristics that differentiate the biomass burning aerosols from the other aerosols.

The most intense peak in the variable loadings plot for PC1 (Figure 6a) is positive and represents a $\mathrm{CH}_{2}$ group (1.2 ppm), suggesting that alkyl chain length is important in distinguishing aerosol emission sources. The $\mathrm{CH}_{2}$ peak in the mixed source and biomass burning aerosols is more narrow than in the urban aerosols, so the positive peak in the PC1 loadings may be indicative of shorter alkyl chains (i.e., less variability). A splitting of the $\mathrm{CH}_{3}$ peak $(0.9 \mathrm{ppm})$ is observed, and the negative peak is more downfield than the positive peak. This splitting suggests that the urban aerosols (represented by negative PC1 variable loadings) contain terminal methyl groups in closer proximity to polar functional groups, which is supported by the presence of broad peaks in the region where polar functional groups appear $(1.8-3.2 \mathrm{ppm})$. Another intense positive peak is found around $2.1 \mathrm{ppm}$, which can represent hydrogen bound to a carbon $\alpha$ to a carbonyl group (Figure 6a). There is an intense peak in this area in each of the whole sample spectra, but the width of the peaks vary (Figure 4) indicating varying structural diversity of similar functional groups. This peak is sharper in the mixed source and biomass burning aerosols, and 
broad in the urban aerosols. In fact, the edges of the peak at $2.1 \mathrm{ppm}$ can be found as negative peaks in PC1 indicating that the broadness of that peak is characteristic of the urban aerosols. While protons bound to carbon adjacent to a carbonyl group are widespread among the aerosols as indicated by a strong signal around $2.1 \mathrm{ppm}$ in each ${ }^{1} \mathrm{H}$ NMR spectrum, the urban aerosols contain protons that are in more diverse chemical environments.

a)

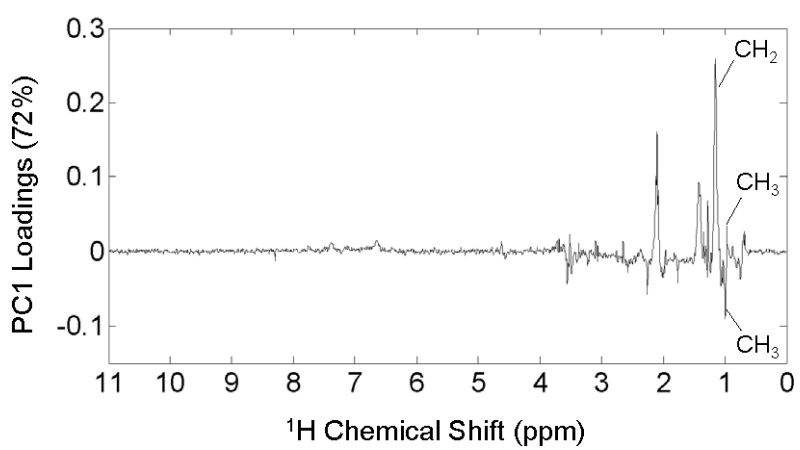

b)

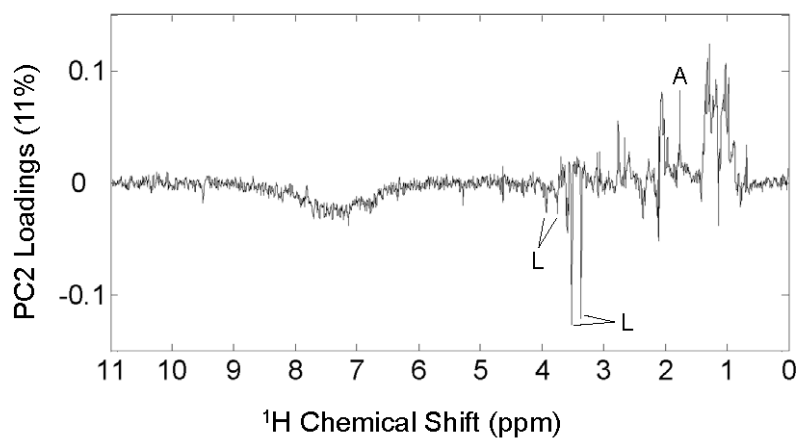

Figure 6. Variable loadings plots for (a) PC1 and (b) PC2 resulting from PCA using full ${ }^{1} \mathrm{H}$ NMR spectra of mixed source, biomass burning, and urban aerosol WSOM. Some peaks are labeled with the functional group region and some peaks labeled with a single letter to indicate a specific compound, where $\mathrm{A}=$ acetic acid or acetate and $\mathrm{L}=$ levoglucosan.

The variable loadings plot for PC2 (Figure 6b) shows the spectral characteristics important to the biomass burning aerosols. A broad negative peak in the aromatic region (6-9 ppm) is apparent, and is equivalent to the aromatic signal observed in the individual spectra of the biomass burning aerosols. Peaks consistent with levoglucosan $(3.36,3.52,3.75$, and $3.93 \mathrm{ppm})$ [15] are identified in the negative PC2 loadings, indicating that they are important in distinguishing the biomass burning aerosols from the other source. Levoglucosan is a common product of the combustion of cellulose material and is widely used as a tracer compound for biomass burning 
aerosols [83]. Levoglucosan does produce additional ${ }^{1} \mathrm{H}$ NMR peaks, but they are obscured by the water-suppression pulse program due to their proximity to the peak generated by water ( 4.7 ppm). A slight negative peak at $2.3 \mathrm{ppm}$ is consistent with hydrogen attached to nitrogen. The peak is broad indicating that there are many compounds with the same functional group attached to varying carbon structures. Without standards, it cannot be confirmed that this peak represents amino groups, but the large number of $\mathrm{CHON}$ formulas identified in the FTICR mass spectra supports the presence of a diverse suite of $\mathrm{N}$-containing $\mathrm{OM}$ in the biomass burning aerosols. Positive peaks in the aliphatic region (0.8-1.5 ppm) and at $1.8 \mathrm{ppm}$ representing acetate or acetic acid demonstrate that the higher PC2 scores for the urban and mixed source aerosols have a more oxygenated and aliphatic WSOM composition.

Overall, there is good consistency and complementarity between the ${ }^{1} \mathrm{H}$ NMR and FTICR-MS techniques. Both techniques identify aromatic compounds and nitrogen-containing compounds that are not extensively oxidized as important for distinguishing the OM from biomass burning aerosols from the other sources. The lower degree of oxidation in the OM found in the biomass burning and also the marine aerosols suggests that these aerosols are collected close to their source and/or have not been exposed to conditions that promote extensive oxidative or oligomeric transformations. The urban aerosols are characteristically more polar as indicated by ${ }^{1} \mathrm{H}$ NMR peaks that are shifted more slightly downfield than in the other aerosols and also the higher $\mathrm{O} / \mathrm{C}$ ratios of the formulas, with more structurally diverse carbon chains. This structural diversity may be represented by longer and/or more branched carbon chains indicative of more oligomeric or other chain elongation reactions. While some of these features were readily apparent, the PCA was able to highlight and confirm some of these variations.

The combination of ${ }^{1} \mathrm{H}$ NMR and FTICR-MS provides an incredible amount of molecular-level information regarding the chemical composition of aerosol OM. While ${ }^{1} \mathrm{H}$ NMR overcomes some of the bias introduced by ESI-FTICR-MS, it comes with its own limitations. The ${ }^{1} \mathrm{H}$ NMR analysis used here requires a liquid sample, so the water-insoluble OM is not analyzed by this method. Solid-state NMR techniques that analyze a whole solid sample do exist but require very large samples that require extremely large sample volumes which typically can only be obtained over weeks of sampling. Additionally, the water-suppression removes all signal in the region of $4.7 \mathrm{ppm}$ and may reduce the signal in the region within $\pm 0.5 \mathrm{ppm}$ including protons directly attached to carbon-carbon double bonds $(\mathrm{H}-\mathrm{C}=\mathrm{C})$ which are typically found around $5 \mathrm{ppm}$.

\section{Conclusions}

The ${ }^{1} \mathrm{H}$ NMR and FTICR-MS results described here, while not fully quantitative in nature, provide detailed, source-specific distinguishing characteristics of the water- 
and pyridine- extractable and ionizable components of marine, urban, biomass burning, and mixed source OA. PCA efficiently highlights the molecular formulas and ${ }^{1} \mathrm{H}$ NMR structural components that distinguish the OM contained within aerosols from each of these sources. Marine aerosols contain molecules consistent with biological inputs including lipid- and phospholipid-like compounds as well as a large fraction of low $\mathrm{O} / \mathrm{C}$ ratio organosulfur compounds, likely derived from reactions with sulfate derived from biological dimethyl sulfide emissions. The carbon backbones of these molecules are more aliphatic and less diverse than terrestrial $\mathrm{OA}$, and the $\mathrm{OM}$ is overall less oxidized. The OM in biomass burning aerosols has more aromatic character and less oxygen content than the other OA groups. Aromatic, nitrogen containing compounds are a defining feature of biomass burning aerosols, and nitrogen-incorporation reactions play a major role in the formation or transformation of these aerosols. The urban aerosols are also characteristically more oxygenated and more structurally complex, suggesting they have been subject to more extensive atmospheric aging. Nitrogen-containing formulas of lesser aromaticity than described for the biomass burning OA are an important feature of urban aerosols. These compounds likely reflect the prevalence of OA transformations that incorporate inorganic NOx, either through NOx additions to aliphatic/olefinic compounds or ring-opening reactions of biomass burning OA. The combined results of the FTICR-MS and ${ }^{1} \mathrm{H}$ NMR PCAs show the mixed source OA to be very similar to but less chemically diverse than the urban aerosols.

These defining OA molecular features can be used in future work to provide clues to the primary inputs and degree of atmospheric transformation. In environments impacted by multiple emission sources, these molecular features can help identify key sources. Further, as the relationships between molecular composition and atmospheric impacts (e.g., hygroscopicity, ice and cloud condensation formation, light absorption) and environmental fates (e.g., photochemical and microbial lability, metal complexing ability) are strengthened, these source-specific molecular characteristics can be used to partition the relative importance of each of these emission sources to these impacts and fates. The highly aliphatic nature of and biological source for the marine aerosols suggests them to be highly susceptible to microbial components, while the aromatic nature of biomass burning OA are likely to be less microbially labile and more susceptible to photodegradation. Though the exact relationship is yet to be fully understood, the extent of oxidation is associated with hygroscopicity and the ability of aerosols to act as cloud condensation nuclei, and the high $\mathrm{O} / \mathrm{C}$ content of urban and mixed source aerosols present them as high hygroscopic candidates. The additional molecular formula and structural details provided here may help understand deviations from the expected $\mathrm{O} / \mathrm{C}$ ratio-hygroscopic behavior relationship. The highly aromatic, nitrogen compounds are likely an important component of atmospheric brown carbon, which makes a 
significant contribution to light-absorbing carbon in the atmosphere. Any extensive light absorption found for other source components may be due to higher amounts of inorganic components or olefinic or non-ionizable OA.

Aerosol FTICR-MS and ${ }^{1} \mathrm{H}$ NMR analyses provide a complementary set of information regarding OA chemical composition, and PCA provides a useful tool for deconstructing the important components that define each of the aerosol sources. While this study presents several aerosols from some key sources, application of this method to a larger number of samples from more emission sources are needed for a more comprehensive inventory of atmospherically-relevant OA. Additionally, pairing these analysis with highly time-resolved methods, such as aerosol mass spectrometry, would provide an excellent accounting of the inorganic ions and volatile OM that influence aerosol atmospheric and environmental impacts and fates.

Supplementary Materials: The following are available online at http:/ /www.mdpi.com/ 2073-4433/7/6/79/s1,

Supplementary methods.

Table S1: Percent area contributions from the major proton regions and calculated $\mathrm{H} / \mathrm{C}$ ratios in ${ }^{1} \mathrm{H}$ NMR spectra for aerosol PSOM.

Table S2: Total formulas and average elemental properties for aerosol $\mathrm{WSOM}_{\mathrm{PPL}}$ and PSOM from each emission source determined using FTICR mass spectra. The distribution of molecular formulas based on atomic content and $\mathrm{AI}_{\text {mod }}$ structure type are listed as number of formulas with the percentage of total formulas in parentheses directly below.

Table S3: Total formulas and average elemental properties for aerosol WSOM-, WSOM+, and PSOM - from each emission source determined using FTICR-MS. Atomic content and structure type values are expressed as the number of formulas. The values in parentheses are the percentage of total molecular formulas in each sample, an average for each source.

Table S4: Total formulas and average elemental properties for aerosol WSOM-, WSOM+, and PSOM from each emission source identified by PCA. Distributions of formulas based on atomic content and $\mathrm{AI}_{\text {mod }}$ structure type are listed as percentage of total formulas.

Figure S1: Van Krevelen diagrams for molecular formulas identified in the FTICR mass spectra for the marine, biomass burning, urban, and mixed source aerosols. Each row represents a different source, and each column represents only those formulas with a specific elemental makeup ( $\mathrm{CHO}, \mathrm{CHON}$, or $\mathrm{CHOS})$. Each " $x$ " represents one or more molecular formulas.

Figure S2: The loadings for (a) PC1 and PC2 and (b) PC1 and PC3 from the PCA analysis of the FTICR-MS molecular formulas.

Figure S3: Venn diagrams showing the relative distribution of PCA molecular formulas present in any of the three solvent/ionization methods (WSOM-, WSOM+, and PSOM) for each aerosol source. Areas of overlap represent percentages of molecular formulas that appear in two or more of those samples. Areas with no overlap represent the percentage of molecular formulas unique to that individual solvent/ionization method.

Acknowledgments: This work was funded by the Frank Batten Endowment to Patrick Hatcher. Amanda Willoughby was supported by a US EPA STAR graduate fellowship program (Grant: 
FP 91736001). The EPA has not officially endorsed this publication and the views expressed herein may not reflect the views of the EPA. The authors thank Peter DeCarlo and Anita Johnson at Drexel University for assistance in the collection of the urban aerosol samples, Siddhartha Mitra for BC analyses, and Susan Hatcher and Jared Callan of the COSMIC facility at Old Dominion University for assistance with the FTICR-MS. We thank the crew of the $\mathrm{R} / \mathrm{V}$ Knorr for assistance in collecting the marine samples and William Landing for sharing the GEOTRACES marine samples collected as part of NSF grants OCE-0752351, 0929919, and 1132766. Any opinions, findings, and conclusions or recommendations expressed in this material are those of the authors and do not necessarily reflect the views of the National Science Foundation. Finally, we thank two anonymous reviewers for their valuable suggestions that have improved this manuscript.

Author Contributions: All authors conceived and designed the experiments; Amanda Willoughby performed the experiments; Amanda Willoughby and Andrew Wozniak analyzed the data; Patrick Hatcher contributed reagents/materials/analysis tools; Amanda Willoughby and Andrew Wozniak wrote the paper.

Conflicts of Interest: The authors declare no conflict of interest.

\section{Abbreviations}

The following abbreviations are used in this manuscript:

$\begin{array}{ll}\mathrm{AI}_{\text {mod }} & \text { modified aromaticity index } \\ \text { BC } & \text { black carbon } \\ \text { CTO-375 } & \text { chemothermal oxidation at } 375{ }^{\circ} \mathrm{C} \\ \text { ESI } & \text { electrospray ionization } \\ \text { FTICR-MS } & \text { Fourier transform ion cyclotron resonance mass spectrometry } \\ \text { H/C } & \text { hydrogen-to-carbon atomic ratio } \\ { }^{1} \text { H NMR } & \text { proton nuclear magnetic resonance spectroscopy } \\ \text { NMR } & \text { nuclear magnetic resonance spectroscopy } \\ \text { O/C } & \text { oxygen-to-carbon atomic ratio } \\ \text { OA } & \text { organic aerosols } \\ \text { OM } & \text { organic matter } \\ \text { PC } & \text { principal component } \\ \text { PCA } & \text { principal component analysis } \\ \text { PPL } & \text { solid phase extraction medium } \\ \text { PSOC } & \text { pyridine-soluble organic carbon } \\ \text { PSOM } & \text { pyridine-soluble organic matter } \\ \text { SOA } & \text { secondary organic aerosol } \\ \text { TC } & \text { total carbon } \\ \text { TSP } & \text { total suspended particulates } \\ \text { UHR-MS } & \text { ultrahigh resolution mass spectrometry } \\ \text { WSOC } & \text { water-soluble organic carbon } \\ \text { WSOM } & \text { water-soluble organic matter } \\ \text { WSOM } & \text { PPL-extracted water-soluble organic matter } \\ & \end{array}$




\section{References}

1. Jimenez, J.L.; Canagaratna, M.R.; Donahue, N.M.; Prevot, A.S.H.; Zhang, Q.; Kroll, J.H.; DeCarlo, P.F.; Allan, J.D.; Coe, H.; Ng, N.L.; et al. Evolution of organic aerosols in the atmosphere. Science 2009, 326, 1525-1529.

2. Kanakidou, M.; Seinfeld, J.; Pandis, S.; Barnes, I.; Dentener, F.; Facchini, M.; Van Dingenen, R.; Ervens, B.; Nenes, A.; Nielsen, C.; et al. Organic aerosol and global climate modelling: A review. Atmos. Chem. Phys. 2005, 5, 1053-1123.

3. Chan, M.N.; Choi, M.Y.; Ng, N.L.; Chan, C.K. Hygroscopicity of water-soluble organic compounds in atmospheric aerosols: Amino acids and biomass burning derived organic species. Environ. Sci. Technol. 2005, 39, 1555-1562.

4. Cerully, K.; Bougiatioti, A.; Hite, J., Jr.; Guo, H.; Xu, L.; Ng, N.; Weber, R.; Nenes, A. On the link between hygroscopicity, volatility, and oxidation state of ambient and water-soluble aerosols in the southeastern united states. Atmos. Chem. Phys. 2015, 15, 8679-8694.

5. Andreae, M.O.; Gelencsér, A. Black carbon or brown carbon? The nature of light-absorbing carbonaceous aerosols. Atmos. Chem. Phys. 2006, 6, 3131-3148.

6. Wozniak, A.S.; Shelley, R.U.; Sleighter, R.L.; Abdulla, H.A.; Morton, P.L.; Landing, W.M.; Hatcher, P.G. Relationships among aerosol water soluble organic matter, iron and aluminum in European, North African, and marine air masses from the 2010 US GEOTRACES cruise. Mar. Chem. 2013, 54, 557-898.

7. Wozniak, A.S.; Shelley, R.U.; McElhenie, S.D.; Landing, W.M.; Hatcher, P.G. Aerosol water soluble organic matter characteristics over the North Atlantic Ocean: Implications for iron-binding ligands and iron solubility. Mar. Chem. 2015, 173, 162-172.

8. Samburova, V.; Szidat, S.; Hueglin, C.; Fisseha, R.; Baltensperger, U.; Zenobi, R.; Kalberer, M. Seasonal variation of high-molecular-weight compounds in the water-soluble fraction of organic urban aerosols. J. Geophys. Res. Atmos. 2005, 110.

9. Takegawa, N.; Miyakawa, T.; Kondo, Y.; Jimenez, J.L.; Zhang, Q.; Worsnop, D.R.; Fukuda, M. Seasonal and diurnal variations of submicron organic aerosol in Tokyo observed using the Aerodyne aerosol mass spectrometer. J. Geophys. Res. Atmos. 2006, 111.

10. Baduel, C.; Voisin, D.; Jaffrezo, J. Seasonal variations of concentrations and optical properties of water soluble HULIS collected in urban environments. Atmos. Chem. Phys. 2010, 10, 4085-4095.

11. Alves, C.; Vicente, A.; Pio, C.; Kiss, G.; Hoffer, A.; Decesari, S.; Prevôt, A.S.H.; Cruz Minguillón, M.; Querol, X.; Hillamo, R. Organic compounds in aerosols from selected European sites-Biogenic versus anthropogenic sources. Atmos. Environ. 2012, 59, 243-255.

12. Kieber, R.J.; Adams, M.B.; Willey, J.D.; Whitehead, R.F.; Avery, G.B.; Mullaugh, K.M.; Mead, R.N. Short term temporal variability in the photochemically mediated alteration of chromophoric dissolved organic matter (CDOM) in rainwater. Atmos. Environ. 2012, 50, 112-119.

13. Chalbot, M.G.; Kavouras, I.G. Nuclear magnetic resonance spectroscopy for determining the functional content of organic aerosols: A review. Environ. Pollut. 2014, 191, 232-249. 
14. Duarte, R.M.; Freire, S.M.; Duarte, A.C. Investigating the water-soluble organic functionality of urban aerosols using two-dimensional correlation of solid-state ${ }^{13} \mathrm{C}$ NMR and FTIR spectral data. Atmos. Environ. 2015, 116, 245-252.

15. Decesari, S.; Facchini, M.; Matta, E.; Lettini, F.; Mircea, M.; Fuzzi, S.; Tagliavini, E.; Putaud, J. Chemical features and seasonal variation of fine aerosol water-soluble organic compounds in the Po Valley, Italy. Atmos. Environ. 2001, 35, 3691-3699.

16. Moretti, F.; Tagliavini, E.; Decesari, S.; Facchini, M.; Rinaldi, M.; Fuzzi, S. NMR determination of total carbonyls and carboxyls: A tool for tracing the evolution of atmospheric oxidized organic aerosols. Environ. Sci. Technol. 2008, 42, 4844-4849.

17. Schmitt-Kopplin, P.; Gelencser, A.; Dabek-Zlotorzynska, E.; Kiss, G.; Hertkorn, N.; Harir, M.; Hong, Y.; Gebefugi, I. Analysis of the unresolved organic fraction in atmospheric aerosols with ultrahigh-resolution mass spectrometry and nuclear magnetic resonance spectroscopy: Organosulfates as photochemical smog constituents. Anal. Chem. 2010, 82, 8017-8026.

18. Shakya, K.M.; Place, P.F.; Griffin, R.J.; Talbot, R.W. Carbonaceous content and water-soluble organic functionality of atmospheric aerosols at a semi-rural New England location. J. Geophys. Res. Atmos. 2012, 117, D03301.

19. Altieri, K.E.; Seitzinger, S.P.; Carlton, A.G.; Turpin, B.J.; Klein, G.C.; Marshall, A.G. Oligomers formed through in-cloud methylglyoxal reactions: Chemical composition, properties, and mechanisms investigated by ultra-high resolution FT-ICR mass spectrometry. Atmos. Environ. 2008, 42, 1476-1490.

20. Wozniak, A.; Bauer, J.; Sleighter, R.; Dickhut, R.; Hatcher, P. Technical note: Molecular characterization of aerosol-derived water soluble organic carbon using ultrahigh resolution electrospray ionization fourier transform ion cyclotron resonance mass spectrometry. Atmos. Chem. Phys. 2008, 8, 5099-5111.

21. Heaton, K.J.; Sleighter, R.L.; Hatcher, P.G.; Hall, W.A., IV; Johnston, M.V. Composition domains in monoterpene secondary organic aerosol. Environ. Sci. Technol. 2009, 43, 6950-6955.

22. Laskin, J.; Laskin, A.; Roach, P.; Slysz, G.; Anderson, G.; Nizkorodov, S.; Bones, D.; Nguyen, L. High-resolution desorption electrospray ionization mass spectrometry for chemical characterization of organic aerosols. Anal. Chem. 2010, 82, 2048-2058.

23. Mazzoleni, L.; Ehrmann, B.; Shen, X.; Marshall, A.; Collett, J., Jr. Water-soluble atmospheric organic matter in fog: Exact masses and chemical formula identification by ultrahigh-resolution Fourier transform ion cyclotron resonance mass spectrometry. Environ. Sci. Technol. 2010, 44, 3690-3697.

24. Nguyen, T.; Bateman, A.; Bones, D.; Nizkorodov, S.; Laskin, J.; Laskin, A. High-resolution mass spectrometry analysis of secondary organic aerosol generated by ozonolysis of isoprene. Atmos. Environ. 2010, 44, 1032-1042.

25. LeClair, J.P.; Collett, J.L.; Mazzoleni, L.R. Fragmentation analysis of water-soluble atmospheric organic matter using ultrahigh-resolution FT-ICR mass spectrometry. Environ. Sci. Technol. 2012, 46, 4312-4322. 
26. Mazzoleni, L.R.; Saranjampour, P.; Dalbec, M.M.; Samburova, V.; Hallar, A.G.; Zielinska, B.; Lowenthal, D.H.; Kohl, S. Identification of water-soluble organic carbon in non-urban aerosols using ultrahigh-resolution FT-ICR mass spectrometry: Organic anions. Environ. Chem. 2012, 9, 285-297.

27. Mead, R.; Mullaugh, K.; Brooks Avery, G.; Kieber, R.; Willey, J.; Podgorski, D. Insights into dissolved organic matter complexity in rainwater from continental and coastal storms by ultrahigh resolution Fourier transform ion cyclotron resonance mass spectrometry. Atmos. Chem. Phys. 2013, 13, 4829-4838.

28. Mitra, S.; Wozniak, A.S.; Miller, R.; Hatcher, P.G.; Buonassissi, C.; Brown, M. Multiproxy probing of rainwater dissolved organic matter (DOM) composition in coastal storms as a function of trajectory. Mar. Chem. 2013, 154, 67-76.

29. Kourtchev, I.; Fuller, S.J.; Giorio, C.; Healy, R.M.; Wilson, E.; O'Connor, I.; Wenger, J.C.; McLeod, M.; Aalto, J.; Ruuskanen, T.M. Molecular composition of biogenic secondary organic aerosols using ultrahigh-resolution mass spectrometry: Comparing laboratory and field studies. Atmos. Chem. Phys. 2014, 14, 2155-2167.

30. Willoughby, A.S.; Wozniak, A.S.; Hatcher, P.G. A molecular-level approach for characterizing water-insoluble components of ambient organic aerosol particulates using ultrahigh-resolution mass spectrometry. Atmos. Chem. Phys. 2014, 14, 10299-10314.

31. Wozniak, A.S.; Willoughby, A.S.; Gurganus, S.C.; Hatcher, P.G. Distinguishing molecular characteristics of aerosol water soluble organic matter from the 2011 Trans-North Atlantic US GEOTRACES cruise. Atmos. Chem. Phys. 2014, 14, 8419-8434.

32. Kourtchev, I.; Doussin, J.-F.; Giorio, C.; Mahon, B.; Wilson, E.; Maurin, N.; Pangui, E.; Venables, D.; Wenger, J.; Kalberer, M. Molecular composition of fresh and aged secondary organic aerosol from a mixture of biogenic volatile compounds: A high-resolution mass spectrometry study. Atmos. Chem. Phys. 2015, 15, 5683-5695.

33. Reinhardt, A.; Emmenegger, C.; Gerrits, B.; Panse, C.; Dommen, J.; Baltensperger, U.; Zenobi, R.; Kalberer, M. Ultrahigh mass resolution and accurate mass measurements as a tool to characterize oligomers in secondary organic aerosols. Anal. Chem. 2007, 79, 4074-4082.

34. Geotraces: An international study of the marine biogeochemical cycles of trace elements and their isotopes. Available online: http://www.geotraces.org/ (accessed on 1 June 2016).

35. National Oceanic and Atmospheric Administration: Pacific Marine Environmental Laboratory. WACS2 (2014) Western Atlantic Climate Study. Available online: http://saga.pmel.noaa.gov/ field_WACS2 (accessed on 1 June 2016).

36. Gustafsson, Ö.; Haghseta, F.; Chan, C.; MacFarlane, J.; Gschwend, P. Quantification of the dilute sedimentary soot phase: Implications for pah speciation and bioavailability. Environ. Sci. Technol. 1997, 31, 203-209.

37. Dittmar, T.; Koch, B.; Hertkorn, N.; Kattner, G. A simple and efficient method for the solid-phase extraction of dissolved organic matter (SPE-DOM) from seawater. Limnol. Oceanogr. Methods 2008, 6, 230-235. 
38. Sleighter, R.; McKee, G.; Liu, Z.; Hatcher, P. Naturally present fatty acids as internal calibrants for Fourier transform mass spectra of dissolved organic matter. Limnol. Oceanogr. Methods 2008, 6, 246-253.

39. Stubbins, A.; Spencer, R.G.M.; Chen, H.; Hatcher, P.G.; Mopper, K.; Hernes, P.J.; Mwamba, V.L.; Mangangu, A.M.; Wabakanghanzi, J.N.; Six, J. Illuminated darkness: Molecular signatures of Congo River dissolved organic matter and its photochemical alteration as revealed by ultrahigh precision mass spectrometry. Limnol. Oceanogr. 2010, $55,1467-1477$.

40. Sleighter, R.; Liu, Z.; Xue, J.; Hatcher, P. Multivariate statistical approaches for the characterization of dissolved organic matter analyzed by ultrahigh resolution mass spectrometry. Environ. Sci. Technol. 2010, 44, 7576-7582.

41. Gurganus, S.C.; Wozniak, A.S.; Hatcher, P.G. Molecular characteristics of the water soluble organic matter in size-fractionated aerosols collected over the North Atlantic Ocean. Mar. Chem. 2015, 170, 37-48.

42. Hammes, K.; Schmidt, M.W.; Smernik, R.J.; Currie, L.A.; Ball, W.P.; Nguyen, T.H.; Louchouarn, P.; Houel, S.; Gustafsson, Ö.; Elmquist, M. Comparison of quantification methods to measure fire-derived (black/elemental) carbon in soils and sediments using reference materials from soil, water, sediment and the atmosphere. Glob. Biogeochem. Cycles 2007, 21.

43. Heald, C.; Kroll, J.; Jimenez, J.; Docherty, K.; DeCarlo, P.; Aiken, A.; Chen, Q.; Martin, S.; Farmer, D.; Artaxo, P. A simplified description of the evolution of organic aerosol composition in the atmosphere. Geophys. Res. Lett. 2010, 37.

44. Kroll, J.H.; Donahue, N.M.; Jimenez, J.L.; Kessler, S.H.; Canagaratna, M.R.; Wilson, K.R.; Altieri, K.E.; Mazzoleni, L.R.; Wozniak, A.S.; Bluhm, H. Carbon oxidation state as a metric for describing the chemistry of atmospheric organic aerosol. Nat. Chem. 2011, 3, 133-139.

45. Zhang, Q.; Alfarra, M.R.; Worsnop, D.R.; Allan, J.D.; Coe, H.; Canagaratna, M.R.; Jimenez, J.L. Deconvolution and quantification of hydrocarbon-like and oxygenated organic aerosols based on aerosol mass spectrometry. Environ. Sci. Technol. 2005, 39, 4938-4952.

46. Aiken, A.C.; Decarlo, P.F.; Kroll, J.H.; Worsnop, D.R.; Huffman, J.A.; Docherty, K.S.; Ulbrich, I.M.; Mohr, C.; Kimmel, J.R.; Sueper, D. O/C and OM/OC ratios of primary, secondary, and ambient organic aerosols with high-resolution time-of-flight aerosol mass spectrometry. Environ. Sci. Technol. 2008, 42, 4478-4485.

47. Koch, B.; Dittmar, T. From mass to structure: An aromaticity index for high-resolution mass data of natural organic matter. Rapid Commun. Mass Spectrom. 2006, 20, 926-932.

48. Claeys, M.; Wang, W.; Vermeylen, R.; Kourtchev, I.; Chi, X.; Farhat, Y.; Surratt, J.D.; Gómez-González, Y.; Sciare, J.; Maenhaut, W. Chemical characterisation of marine aerosol at Amsterdam Island during the austral summer of 2006-2007. J. Aerosol Sci. 2010, $41,13-22$. 
49. Hawkins, L.; Russell, L.; Covert, D.; Quinn, P.; Bates, T. Carboxylic acids, sulfates, and organosulfates in processed continental organic aerosol over the southeast Pacific Ocean during VOCALS-REX 2008. J. Geophys. Res. 2010, 115.

50. Iinuma, Y.; Müller, C.; Berndt, T.; Böge, O.; Claeys, M.; Herrmann, H. Evidence for the existence of organosulfates from $\beta$-pinene ozonolysis in ambient secondary organic aerosol. Environ. Sci. Technol. 2007, 41, 6678-6683.

51. Minerath, E.C.; Casale, M.T.; Elrod, M.J. Kinetics feasibility study of alcohol sulfate esterification reactions in tropospheric aerosols. Environ. Sci. Technol. 2008, 42, 4410-4415.

52. Minerath, E.C.; Elrod, M.J. Assessing the potential for diol and hydroxy sulfate ester formation from the reaction of epoxides in tropospheric aerosols. Environ. Sci. Technol. 2009, 43, 1386-1392.

53. Kuznetsova, M.; Lee, C.; Aller, J. Characterization of the proteinaceous matter in marine aerosols. Mar. Chem. 2005, 96, 359-377.

54. Hawkins, L.N.; Russell, L.M. Polysaccharides, proteins, and phytoplankton fragments: Four chemically distinct types of marine primary organic aerosol classified by single particle spectromicroscopy. Adv. Meteorol. 2010, 2010, 1-14.

55. Russell, P.; Bergstrom, R.; Shinozuka, Y.; Clarke, A.; DeCarlo, P.; Jimenez, J.; Livingston, J.; Redemann, J.; Dubovik, O.; Strawa, A. Absorption angstrom exponent in AERONET and related data as an indicator of aerosol composition. Atmos. Chem. Phys. 2010, 10, $1155-1169$.

56. Surratt, J.D.; Kroll, J.H.; Kleindienst, T.E.; Edney, E.O.; Claeys, M.; Sorooshian, A.; $\mathrm{Ng}$, N.L.; Offenberg, J.H.; Lewandowski, M.; Jaoui, M. Evidence for organosulfates in secondary organic aerosol. Environ. Sci. Technol. 2007, 41, 517-527.

57. Noziere, B.; Ekström, S.; Alsberg, T.; Holmström, S. Radical-initiated formation of organosulfates and surfactants in atmospheric aerosols. Geophys. Res. Lett. 2010, 37.

58. McNeill, V.F.; Woo, J.L.; Kim, D.D.; Schwier, A.N.; Wannell, N.J.; Sumner, A.J.; Barakat, J.M. Aqueous-phase secondary organic aerosol and organosulfate formation in atmospheric aerosols: A modeling study. Environ. Sci. Technol. 2012, 46, 8075-8081.

59. Cullis, C.; Hirschler, M. Atmospheric sulphur: Natural and man-made sources. Atmos. Environ. 1980, 14, 1263-1278.

60. Möller, D. Estimation of the global man-made sulphur emission. Atmos. Environ. 1984, 18, 19-27.

61. Andreae, M.O. Dimethylsulfoxide in marine and freshwaters. Limnol. Oceanogr. 1980, 25, 1054-1063.

62. Masiello, C. New directions in black carbon organic geochemistry. Mar. Chem. 2004, 92, 201-213.

63. Decesari, S.; Facchini, M.; Matta, E.; Mircea, M.; Fuzzi, S.; Chughtai, A.; Smith, D. Water soluble organic compounds formed by oxidation of soot. Atmos. Environ. 2002, 36, 1827-1832.

64. Kamegawa, K.; Nishikubo, K.; Kodama, M.; Adachi, Y.; Yoshida, H. Oxidative degradation of carbon blacks with nitric acid II. Formation of water-soluble polynuclear aromatic compounds. Carbon 2002, 40, 1447-1455. 
65. Wagner, S.; Dittmar, T.; Jaffé, R. Molecular characterization of dissolved black nitrogen via electrospray ionization Fourier transform ion cyclotron resonance mass spectrometry. Org. Geochem. 2015, 79, 21-30.

66. Goldberg, E. Black Carbon in the Environment: Properties and Distribution; John Wiley and Sons: New York, NY, USA, 1985.

67. Bateman, A.P.; Nizkorodov, S.A.; Laskin, J.; Laskin, A. High-resolution electrospray ionization mass spectrometry analysis of water-soluble organic aerosols collected with a particle into liquid sampler. Anal. Chem. 2010, 82, 8010-8016.

68. Lee, H.J.; Aiona, P.K.; Laskin, A.; Laskin, J.; Nizkorodov, S.A. Effect of solar radiation on the optical properties and molecular composition of laboratory proxies of atmospheric brown carbon. Environ. Sci. Technol. 2014, 48, 10217-10226.

69. Washenfelder, R.A.; Attwood, A.R.; Brock, C.A.; Guo, H.; Xu, L.; Weber, R.J.; Ng, N.L.; Allen, H.M.; Ayres, B.R.; Baumann, K. Biomass burning dominates brown carbon absorption in the rural southeastern United States. Geophys. Res. Lett. 2015, 42, 1-12.

70. Knicker, H.; Almendros, G.; González-Vila, F.J.; Martín, F.; Lüdemann, H.-D. ${ }^{13}$ C- and ${ }^{15} \mathrm{~N}-\mathrm{NMR}$ spectroscopic examination of the transformation of organic nitrogen in plant biomass during thermal treatment. Soil Biol. Biochem. 1996, 28, 1053-1060.

71. Laskin, A.; Smith, J.; Laskin, J. Molecular characterization of nitrogen-containing organic compounds in biomass burning aerosols using high-resolution mass spectrometry. Environ. Sci. Technol. 2009, 43, 3764-3771.

72. Hertkorn, N.; Benner, R.; Frommberger, M.; Schmitt-Kopplin, P.; Witt, M.; Kaiser, K.; Kettrup, A.; Hedges, J.I. Characterization of a major refractory component of marine dissolved organic matter. Geochim. Cosmochim. Acta 2006, 70, 2990-3010.

73. Ohno, T.; He, Z.; Sleighter, R.L.; Honeycutt, C.W.; Hatcher, P.G. Ultrahigh resolution mass spectrometry and indicator species analysis to identify marker components of soil-and plant biomass-derived organic matter fractions. Environ. Sci. Technol. 2010, 44, 8594-8600.

74. Wozniak, A.S.; Bauer, J.E.; Dickhut, R.M. Characteristics of water-soluble organic carbon associated with aerosol particles in the eastern United States. Atmos. Environ. 2012, 46, 181-188.

75. Altieri, K.E.; Turpin, B.J.; Seitzinger, S.P. Oligomers, organosulfates, and nitrooxy organosulfates in rainwater identified by ultra-high resolution electrospray ionization FT-ICR mass spectrometry. Atmos. Chem. Phys. 2009, 9, 2533-2542.

76. Surratt, J.D.; Gómez-González, Y.; Chan, A.W.H.; Vermeylen, R.; Shahgholi, M.; Kleindienst, T.E.; Edney, E.O.; Offenberg, J.H.; Lewandowski, M.; Jaoui, M. Organosulfate formation in biogenic secondary organic aerosol. J. Phys. Chem. A 2008, 112, 8345-8378.

77. Nishioka, M. Aromatic sulfur compounds other than condensed thiophenes in fossil fuels: Enrichment and identification. Energy Fuels 1988, 2, 214-219.

78. Panda, S.K.; Andersson, J.T.; Schrader, W. Mass-spectrometric analysis of complex volatile and nonvolatile crude oil components: A challenge. Anal. Bioanal. Chem. 2007, 389, 1329-1339. 
79. Anderson, L.; Faul, K.; Paytan, A. Phosphorus associations in aerosols: What can they tell us about P bioavailability? Mar. Chem. 2010, 120, 44-56.

80. Chen, H.; Abdulla, H.A.; Sanders, R.L.; Myneni, S.C.; Mopper, K.; Hatcher, P.G. Production of black carbon-like and aliphatic molecules from terrestrial dissolved organic matter in the presence of sunlight and iron. Environ. Sci. Technol. Lett. 2014, 1, 399-404.

81. Waggoner, D.C.; Chen, H.; Willoughby, A.S.; Hatcher, P.G. Formation of black carbon-like and alicyclic aliphatic compounds by hydroxyl radical initiated degradation of lignin. Org. Geochem. 2015, 82, 69-76.

82. Decesari, S.; Finessi, E.; Rinaldi, M.; Paglione, M.; Fuzzi, S.; Stephanou, E.; Tziaras, T.; Spyros, A.; Ceburnis, D.; O’Dowd, C. Primary and secondary marine organic aerosols over the North Atlantic Ocean during the map experiment. J. Geophys. Res. Atmos. 2011, 116 .

83. Simoneit, B.R.T.; Schauer, J.J.; Nolte, C.; Oros, D.R.; Elias, V.O.; Fraser, M.; Rogge, W.; Cass, G.R. Levoglucosan, a tracer for cellulose in biomass burning and atmospheric particles. Atmos. Environ. 1999, 33, 173-182. 

MDPI AG

St. Alban-Anlage 66

4052 Basel, Switzerland

Tel. +41616837734

Fax +41 613028918

http://www.mdpi.com

Atmosphere Editorial Office

E-mail: atmosphere@mdpi.com

http://www.mdpi.com/journal/atmosphere

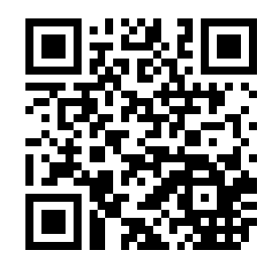



MDPI AG

St. Alban-Anlage 66

4052 Basel

Switzerland

Tel: +41 616837734

Fax: +41 613028918 